\title{
Climatología de tornados en España Peninsular y Baleares
}

\author{
Jesús Riesco Martín \\ Fausto Polvorinos Pascual \\ José Ángel Núñez Mora \\ Juan de Dios Soriano Romero \\ Carlos Jiménez Alonso
}


Aviso Legal: los contenidos de esta publicación podrán ser reutilizados, citando la fuente y la fecha, en su caso, de la última actualización

\section{Edita:}

(c) Ministerio de Agricultura, Alimentación y Medio Ambiente Agencia Estatal de Meteorología

Madrid, 2015

Catálogo de Publicaciones de la Administración General del Estado: https://cpage.mpr.gob.es

NIPO: 281-15-005-8

https://doi.org/10.31978/281-15-005-8

Agencia Estatal de Meteorología (AEMET)

$\mathrm{C} /$ Leonardo Prieto Castro, 8

28040 Madrid

http://www.aemet.es/

@Aemet_Esp 


\section{ÍNDICE}

\section{I.- INTRODUCCIÓN}

I.1.- Objetivo y consideraciones iniciales

I.2.- Fuente de datos

I.3.- Estructura del trabajo

\section{II.- CLIMATOLOGÍA DE TORNADOS OBSERVADOS}

II.1.- Características básicas de los tornados observados

II.2.- Distribución espacial y temporal de tornados observados

II.3.- Mapa de densidad de tornados observados

II.4.- Tornados históricos

II.5.- Estadística de descargas eléctricas

II.6.- Relación entre tornados y descargas eléctricas

\section{III.- CLIMATOLOGÍA MEJORADA DE TORNADOS}

III.1.- Estadísticas de parámetros relevantes de sondeos

III.2.- Sondeos próximos y parámetros relevantes en casos de tornado

III.3.- Densidad mejorada de tornados

\section{IV.- CARACTERIZACIÓN METEOROLÓGICA DE LAS SITUACIONES GENERADORAS DE TORNADOS}

IV.1.- Introducción

IV.2.- Tornados de la vertiente Atlántica

IV.3.- Tornados de primavera-verano

IV.4.- Tornados de la vertiente Mediterránea

\section{V.- CONCLUSIONES}

V.1.- Climatología básica de tornados

V.2.- Climatología básica de descargas eléctricas

V.3.- Parámetros meteorológicos clave

V.4.- Densidad de tornados

V.5.- Caracterización meteorológica de las situaciones de tornado

\section{BIBLIOGRAFÍA}

\section{GLOSARIO}

LISTA DE ACRÓNIMOS

ANEXO: ESCALA FUJITA REALZADA 


\section{I.- INTRODUCCIÓN}

\section{I.1.- Objetivo y consideraciones iniciales}

Los fenómenos usualmente convectivos que son los tornados (tornados terrestres y trombas marinas) tienen una cierta frecuencia de aparición en España, causando en bastantes ocasiones importantes desperfectos asociados a los intensos vientos que generan. Lógicamente los tornados han existido siempre, pero en los últimos decenios se ha producido en España una constatación de que son más frecuentes de lo que se podía pensar.

Es muy compleja la realización de una climatología de estos fenómenos en España sobre todo debido al hecho de que en muchos casos pasan desapercibidos al afectar a zonas despobladas, y a la dificultad que conlleva el registro de los mismos en una base de datos consistente. En España hay pocos trabajos sobre climatología de tornados, siendo del de Gayà (2011) el que puede considerarse como referencia. En cambio en otras zonas del mundo sí que hay numerosos estudios de existencia de tornados basados en observaciones directas (Doswell and Burguess, 1998; Concannon et al., 2000; Brooks and Doswell, 2001; Leitao, 2002; Giaiotti, 2007; Rauhala et al., 2011; etc.).

Los tornados son fenómenos de microescala y por ello es muy complicada su detección si no se dispone de una red de observatorios lo suficientemente densa para este fin. De hecho no hay una base de datos oficial de este tipo de fenómenos en AEMET. No obstante en 2012, se ha generado una herramienta para el registro, a partir de ese año, de fenómenos raros (entre los que figuran los severos). Es la base de datos SINOBAS (http://sinobas.aemet.es). Sin embargo hay varios motivos por los que es complicada o imposible la observación de tornados (Elsom, 1985). Entre ellos destacan la falta de presencia de una persona que detecte y registre el tornado, su ocurrencia a veces en horas nocturnas y la ocultación del mismo por parte de precipitación, edificios y otros obstáculos naturales. No obstante a menudo pueden realizarse estudios de campo que permiten deducir con alto grado de fiabilidad que un tornado fue el responsable de unos destrozos bien identificados.

Es verdad que para poder ofrecer una climatología de garantía en cualquier tipo de variable meteorológica, se ha de disponer de un periodo mínimo en general alrededor de 30 años, aumentándose este periodo recomendable para los fenómenos "raros" como son los tornados. Pero por otra parte, de cara a calcular la densidad de tornados registrados, no es bueno remontarnos más allá de 10 años, debido fundamentalmente a la escasez de datos anteriores a esa fecha, lo cual desvirtuaría los valores, ya de por sí aproximados y seguramente infraestimados, por lo anteriormente comentado, de la última década. Por ello y a pesar de todas las dificultades, se ha intentado realizar una climatología orientativa y básica sobre la frecuencia y representatividad espacial de los tornados y trombas marinas en la zona abarcada por España peninsular y Baleares, a partir de información correspondiente al periodo 2003-2012.

\section{I.2.- Fuente de datos}

En este trabajo se van a considerar tornados en sentido amplio, a los tornados terrestres y a las trombas marinas. Quedan explícitamente excluidos los vórtices de racha ("gustnados").

Denominamos tornado (terrestre) a una columna de aire que gira violentamente, estando en contacto con el suelo y colgando de una nube cumuliforme, y frecuentemente, pero no siempre, visible como una nube-embudo. Además, el tornado hace referencia al vórtice de viento, no a la nube de condensación. Si la rotación no alcanza el suelo, el vórtice se denomina nube de embudo o tuba ("funnel cloud").

Una tromba marina es un tornado sobre el agua. Las trombas marinas consisten en vórtices o torbellinos frecuentemente conectados a nubes cumuliformes. La parte inferior de una tromba puede consistir en agua pulverizada. La columna se suele hacer cada vez más inclinada con el tiempo debido a la cizalladura del viento en la capa baja por debajo de la tormenta o nube madre. Con cierta frecuencia alcanzan el litoral, pudiendo causar destrozos en zonas de playa y puertos. Normalmente se disipan muy pronto tras tocar tierra, aunque determinadas trombas pueden llegar a adentrarse algún kilómetro hasta su disipación.

La escala que emplearemos para la calificación de la intensidad de los tornados y trombas marinas es la Fujita mejorada (Enhanced Fujita Scale). La intensidad de aquéllos se mide en función de los daños generados proponiéndose una clasificación que va desde EF0 hasta EF5 (de menor a mayor intensidad). Los tornados EF0 y EF1 se suelen llamar "débiles", los EF2 y EF3 "fuertes" y los EF4 y EF5 "violentos". Asimismo también en EE.UU. 
se suelen denominar tornados significativos a los de categoría EF2 o superior. En España la gran mayoría de tornados que se producen son de categoría "débil".

La fuente de datos que se ha empleado en este trabajo para la elaboración de la climatología de tornados en la España peninsular y Baleares es una colección de 224 tornados (entre tornados terrestres y trombas marinas) registrados entre 2003-2012. Aunque son sólo 10 años y la muestra pueda parecer insuficiente en tamaño, se ha optado por disponer de una cantidad de años donde claramente se ha incrementado el número de reportes fiables de tornados respecto a épocas anteriores. Con ello trataríamos de disponer de una base de datos con información de "cierta homogeneidad". No quiere esto decir que haya aumentando el número de tornados en los últimos años respecto a épocas pasadas, sino que lo que ha sufrido un incremento es el número de observaciones de ellos debido a una mayor disponibilidad de recursos técnicos por parte de la sociedad (en concreto debido a la proliferación de dispositivos de fotografiado y grabación) y un mayor uso de las tecnologías de comunicación como por ejemplo internet. Es por ello que se dispone hoy en día de mayor capacidad general para captar el fenómeno en tiempo real, o bien para documentar a posteriori los desperfectos provocados. También es cierto que en el pasado algunos tornados han podido más fácilmente ser confundidos por la opinión pública con otros fenómenos de vientos muy intensos. Por otra parte es preferible para la estimación de la probabilidad, el uso de una cantidad reducida de años, que utilizar un periodo muy largo donde se apreciaría una destacadísima tendencia falsa al incremento progresivo del número de tornados y trombas marinas debido a las causas ya citadas.

Las fuentes de información para la generación de la base de datos han sido fundamentalmente las observaciones de aficionados (internet), medios de comunicación, los estudios e informes realizados por AEMET y diversa documentación facilitada por el Consorcio de Compensación de Seguros.

Cada registro de la base de datos contiene la información de un tornado o tromba marina. Se han intentado recopilar principalmente los siguientes campos para cada fenómeno registrado: fecha, localización geográfica, localidad, provincia, tipo de vórtice (tornado/tromba), duración, longitud de la trayectoria, anchura de la trayectoria, intensidad de la escala Fujita Mejorada y dirección del movimiento.

A cada tornado/tromba se le ha asignado una localización espacial coincidente con el punto inicial de observación del mismo, aunque algunos hayan recorrido varios kilómetros. A las trombas marinas avistadas desde la costa, se les ha atribuido la posición del punto litoral más cercano. Hay que hacer constar que el objetivo de este trabajo es la representación de la frecuencia de aparición de este tipo de fenómenos, sin profundizar en las características de anchura del sendero ni de la longitud de la trayectoria por donde discurrió el tornado.

\section{I.3.- Estructura del trabajo}

Los capítulos que recoge este trabajo versan principalmente sobre una climatología básica sobre la frecuencia de tornados observados en la zona de estudio (España Peninsular y Baleares), tanto en general como por meses y por horas, y asimismo haciendo un desglose por tipos de tornados (terrestres y trombas marinas, $y$ por categorías según la escala Fujita). Para ello primero se ha procedido a una depuración de los datos de tornados observados disponibles en la base de datos de partida. Seguidamente, a partir de la base de datos se ha generado, mediante un análisis espacial, un mapa de densidad de tornados observados, complementado con un estudio climatológico de densidad de descargas eléctricas.

Posteriormente se han realizado climatologías a partir de "sondeos próximos" en los casos de tornados observados, tratando de inferir las condiciones meteorológicas ambientales representativas de los tornados, para a partir de aquí generar un mapa más realista de densidad de tornados, que podríamos llamar "mapa mejorado de densidad de tornados".

También muy destacable es el tema que trata de poner de manifiesto la caracterización de las condiciones meteorológicas (sinópticas y mesoescalares) asociadas a cada tipología de tornados en España.

Realzada.

Por último se incluye un capítulo con las conclusiones extraídas y un anexo sobre la escala Fujita 


\section{II.- CLIMATOLOGÍA DE TORNADOS OBSERVADOS}

\section{II.1.- Características básicas de los tornados observados}

El área del estudio realizado comprende dos zonas: España peninsular e Islas Baleares. Por su parte los datos de partida corresponden a una muestra recopilada en AEMET, de tornados y trombas marinas, durante un periodo de 10 años (2003-2012). La frecuencia anual de tornados y trombas marinas durante dicho periodo presenta una cierta tendencia positiva (figura II.1.1), que no debe ser entendida de manera literal, sino mas bien como un aumento paulatino de la disponibilidad de las observaciones de estos fenómenos debido a la proliferación de dispositivos electrónicos que permiten su captación, y a la mejora de los cauces de comunicación y presentación de la información en las redes sociales e internet en general. En cualquier caso, la media anual de tornados se sitúa en unos 22 en el área y periodo de la muestra considerada.

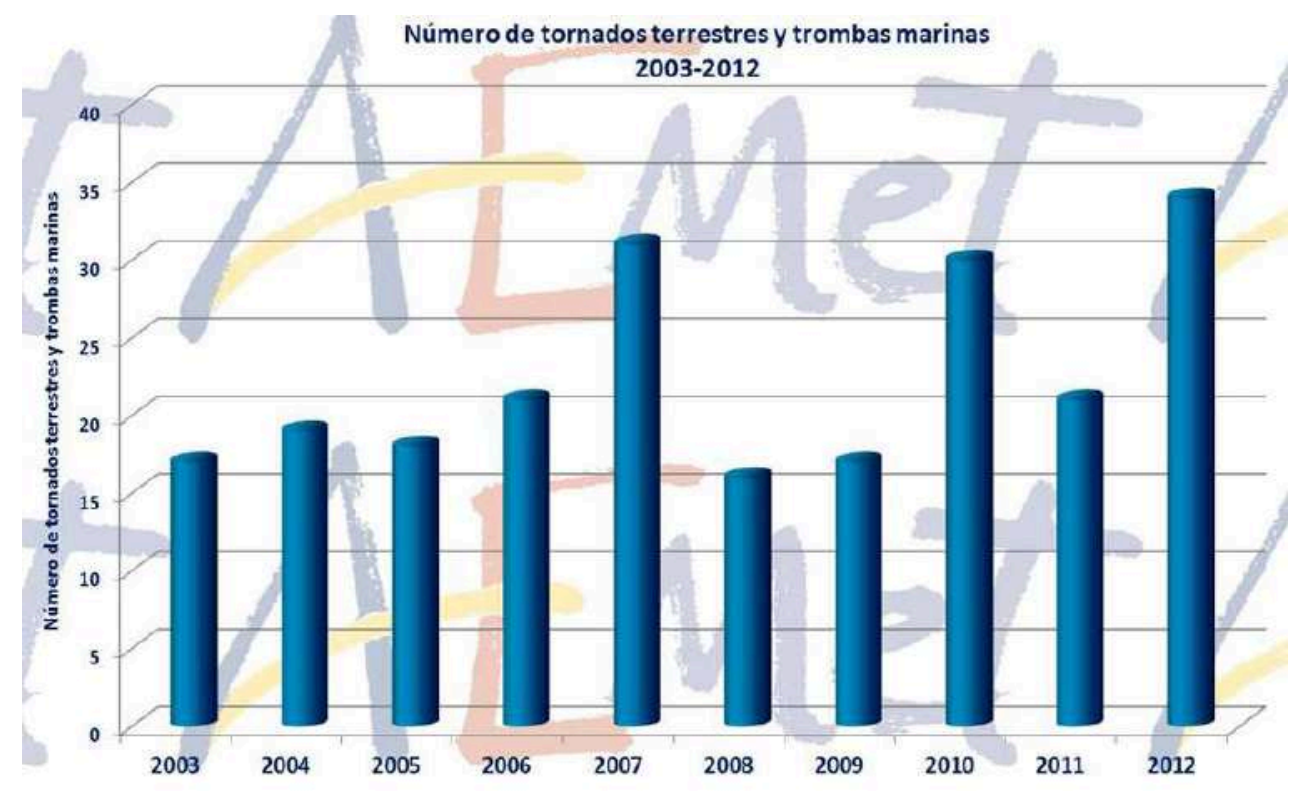

Figura II.1.1: Tornados y trombas marinas en España peninsular y Baleares durante el periodo $2003-2012$

En cuanto a la distribución mensual (figura II.1.2), en general la máxima actividad de tornados en sentido amplio, ocurre a finales de verano y en otoño, algo típico de otros países Mediterráneos del sur de Europa como Italia (Giaiotti et al., 2007) y Portugal (Leitao, 2003), y en clara contraposición a otros como Alemania e Irlanda con un máximo primaveral. Sin embargo en determinadas zonas interiores de la península existen máximos durante la primavera, algo análogo a lo que sucede con la máxima actividad tormentosa en esa zona. 


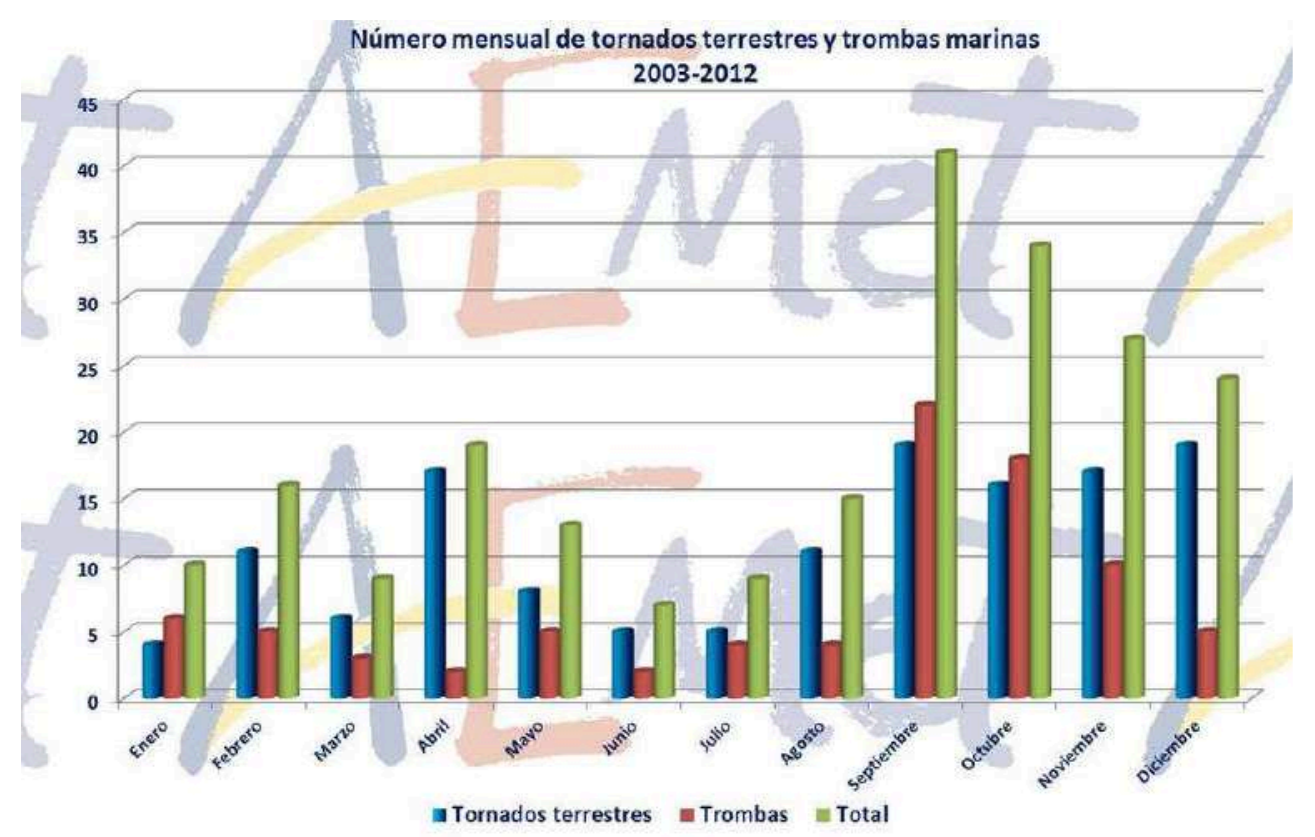

Figura II.1.2: Número de tornados terrestres y trombas marinas por meses en la España Peninsular y Baleares. 2003-2012

No obstante hay que reseñar que los tornados terrestres tienen un máximo relativo a finales de verano y en otoño, y otro de menor intensidad en primavera (abril). En cambio las trombas marinas presentan un máximo destacadísimo a finales de verano y principios del otoño, hecho ligado en general a la mayor temperatura del agua del mar Mediterráneo en esa época y a la importante influencia en los episodios, de días con varias trombas marinas y de la diferencia entre la temperatura del agua del mar y la de la superficie isobárica de $850 \mathrm{hPa}$ (Sioukas et al.).

Durante el día, las horas más favorables para la ocurrencia de tornados y trombas marinas se sitúa durante la tarde (entre 10 y 18 UTC), tal y como se aprecia en la figura II.1.3. Una de las causas es el importante papel que juega el calentamiento diurno en el disparo convectivo. En el caso de las trombas marinas hay que hacer la salvedad de que aparece una destacada frecuencia durante el día debido sobre todo a la dificultad de avistamiento de aquéllas durante la noche.

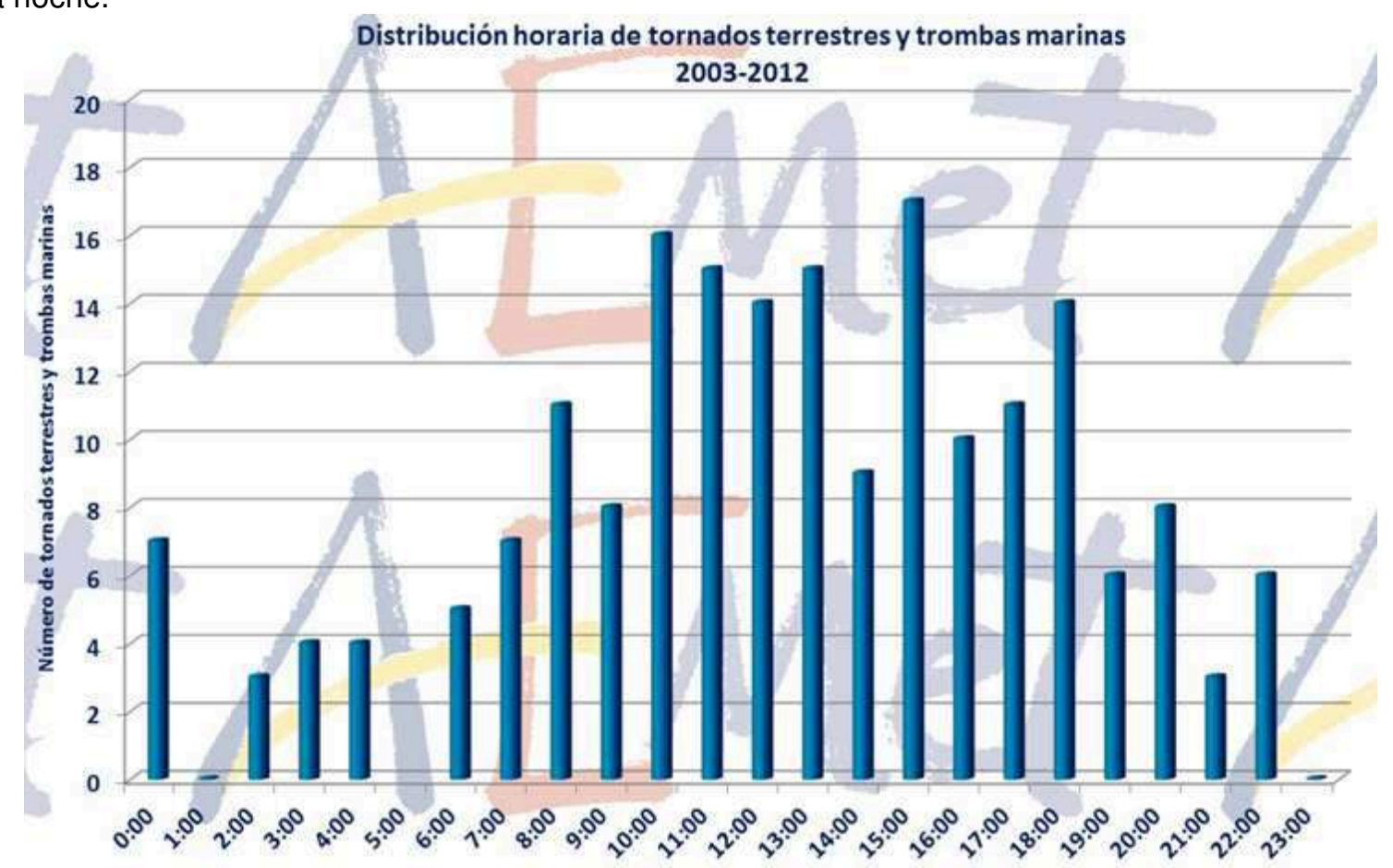

Figura II.1.3: Reparto horario (horas UTC) del número de tornados (tornados terrestres y trombas marinas) en España Peninsular y Baleares. 2003-2012

De los 224 tornados hubo 138 que fueron terrestres (62\%), mientras que 86 fueron trombas marinas (38\%), proporción que refleja la figura II.1.4. Lógicamente esto es fruto de la muestra disponible y no debe corresponderse con el reparto real, ya que es mucho más difícil visualizar trombas marinas (que además normalmente son sólo avistadas cerca de la costa o al penetrar en el litoral), que tornados "terrestres". 


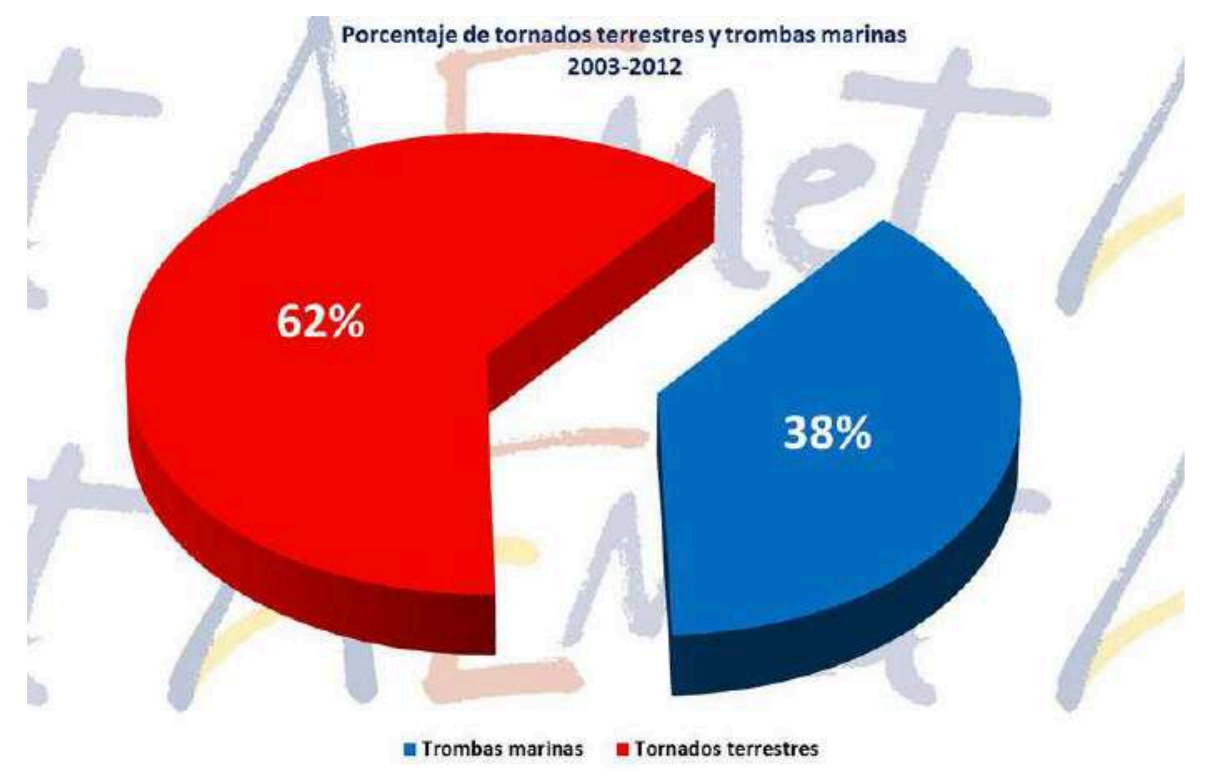

Figura II.1.4: Porcentaje de tornados terrestres y trombas marinas en la España Peninsular y Baleares. 2003-2012

Todos los tornados (terrestres y marinos) fueron de intensidad EF2 o inferior (figura II.1.5), con un predominio claro de la categoría EF0 (70\%), seguida de la EF1 (23\%). Sólo un $7 \%$ fue de intensidad EF2.

Mención especial merecen las trombas marinas, cuya intensidad fue EF0 en un 97\% de los casos, mientras que el $3 \%$ restante fue $\mathrm{EF} 1$.

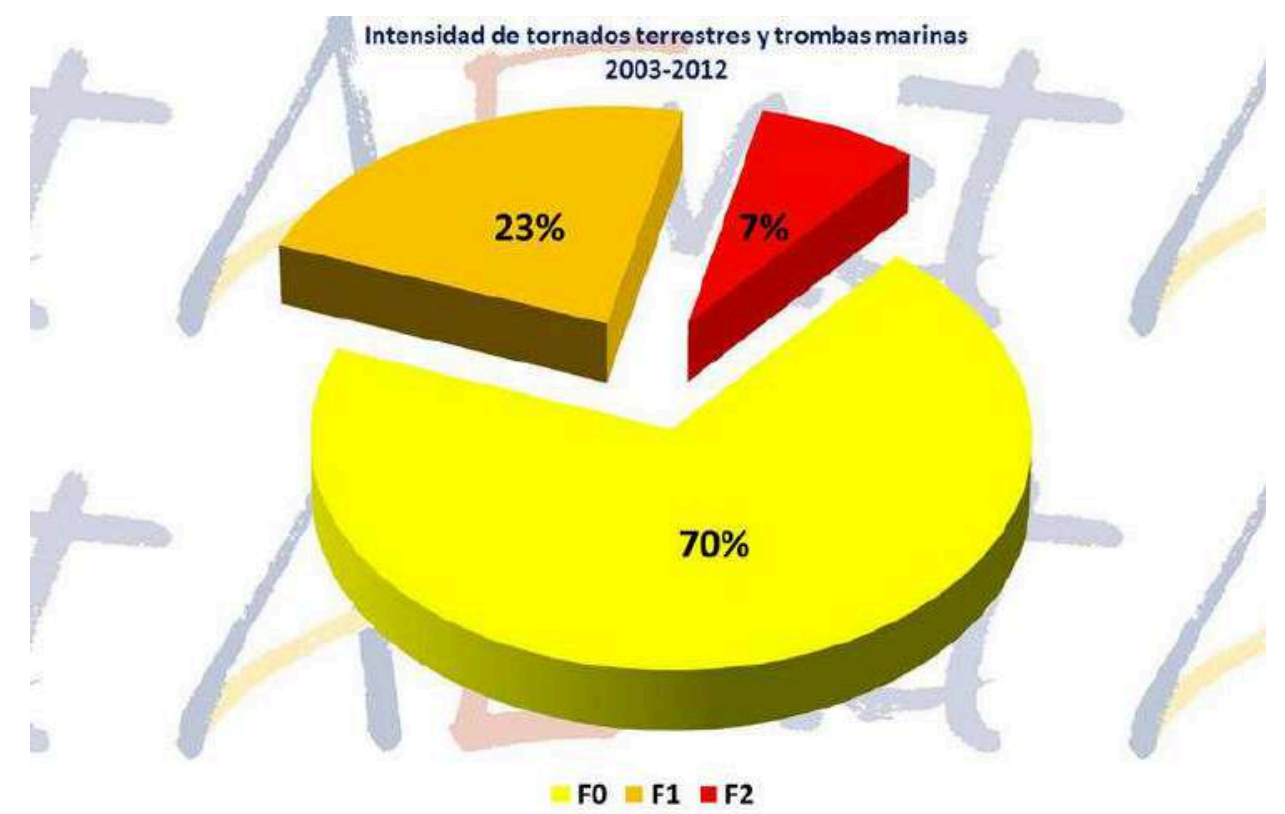

Figura II.1.5: Intensidades (según la escala Fujita mejorada) de tornados terrestres y trombas marinas en España Peninsular y Baleares. 2003-2012

Otras características de los tornados y trombas marinas son las siguientes (Gayà, 2011):

- La longitud de la trayectoria suele oscilar desde unos centenares de metros a unos pocos kilómetros. Aproximadamente tres cuartas partes de los tornados y trombas marinas recorren un camino inferior a $5 \mathrm{~km}$, siendo muy raro encontrar tornados con trayectorias superiores a $10 \mathrm{~km}$. En especial presentan escaso recorrido las trombas marinas, algunas de las cuales discurren cerca de la franja litoral y se disipan poco después de tocar tierra.

- El ancho máximo del tornado normalmente está comprendido entre algunas decenas y unos centenares de metros. 
- La mayoría de tornados tienen trayectorias de sur o suroeste. En la costa este Mediterránea y Baleares en cambio giran y la dirección es del SE. Con flujos débiles las trombas marinas suelen ser desplazadas según el régimen de brisas

Es importante por último, destacar la existencia de una apreciable correlación positiva entre la intensidad de un tornado (según la escala Fujita) con la longitud y también con la anchura del sendero. Este hecho ha sido puesto de manifiesto en muchas zonas del mundo, especialmente en Estados Unidos (Brooks, 2004; Elsner, 2013)

\section{II.2.- Distribución espacial y temporal de tornados observados}

En este apartado se pondrán de relieve algunas de las características espaciales básicas de los tornados y trombas marinas observados según la base de datos disponible en AEMET. La base de datos de tornados se ha construido con datos del periodo de 10 años 2003-2012, en base a tornados y trombas marinas documentados en la España peninsular, Baleares, Ceuta y Melilla a través de las siguientes fuentes primarias

- Informes disponibles en AEMET (internos y remitidos al Consorcio de Compensación de Seguros sobre la existencia de un tornado: fenómeno meteorológico considerado como de "riesgo extraordinario" en el Real Decreto 300/2004, de 20 de febrero).

- Reportes contenidos en SINOBAS, http://sinobas.aemet.es, web de AEMET dedicada a la notificación de observaciones atmosféricas singulares.

- Información proporcionada por el Consorcio de Compensación de Seguros.

- Información obtenida de internet, siempre y cuando esta información contuviera la documentación (videos, fotografías, extensos reportajes, etc) que hiciera indudable la existencia de un tornado o tromba marina en una zona determinada.

Lógicamente la observación de este tipo de fenómenos presenta muchas limitaciones, por lo que la frecuencia de aparición de los mismos en la realidad será posiblemente superior a la frecuencia observada disponible en la base de datos de referencia. Dicho lo anterior, la distribución espacial conjunta de tornados y trombas marinas presenta un máximo en la costa Mediterránea tal y como se observa en la figura II.2.1. Las trombas marinas tienen una mayor incidencia en el mar Mediterráneo, especialmente en las zonas litorales de Baleares y este Peninsular, con un máximo secundario en Gibraltar, noroeste de la Península y Golfo de Vizcaya. En cambio respecto a los tornados terrestres, la franja Mediterránea y el Golfo de Cádiz se erigen en las áreas de mayor actividad en este sentido. El patrón espacial de frecuencia de tornados está condicionado por varios factores, entre ellos la presencia de varios tipos de configuraciones atmosféricas favorables (en general algunas asociadas a precipitaciones intensas en el área Mediterránea 0 al paso de frentes Atlánticos con convección embebida en la parte oeste de la Península, o a situaciones de tormentas fuertes especialmente en primavera-verano en zonas interiores de centro y norte peninsular) y a la interacción del terreno. Por ello la mayor parte de tornados y trombas marinas a finales de verano y otoño ocurren en el área Mediterránea, tendiendo luego durante el invierno y primavera a desplazarse el máximo hacia zonas situadas más al oeste. 


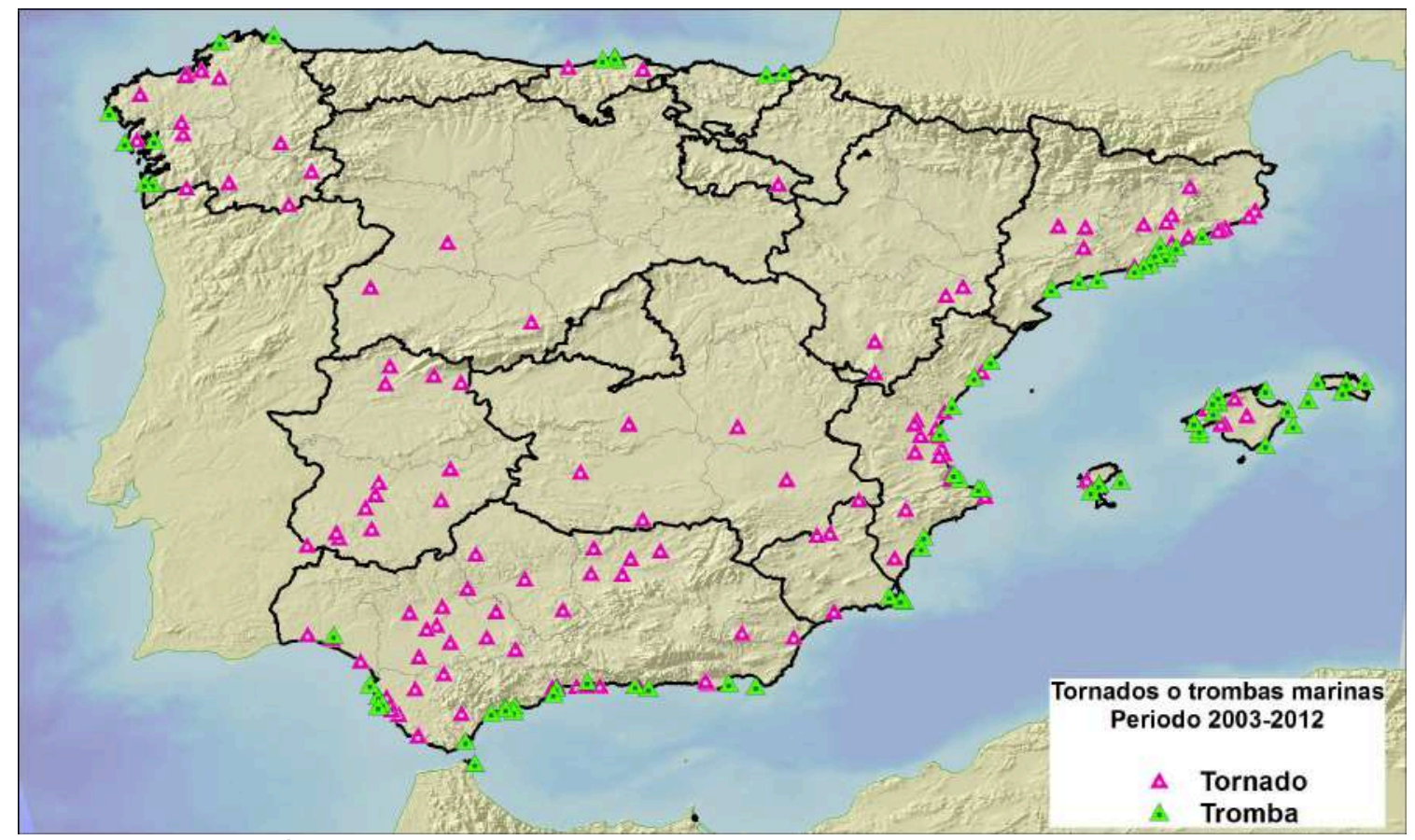

Figura II.2.1: Distribución espacial de tornados y trombas marinas en España peninsular y Baleares (2003-2012).

En cuanto a la distribución estacional de los mismos, surge la figura II.2.2, en la que aparecen marcadas las localizaciones de los tornados y trombas marinas para cada estación del año. Lo primero que destaca es el desplazamiento del área de influencia desde el este peninsular al oeste, al pasar de otoño a invierno. Mientras que en el otoño predominan los tornados y trombas en la franja mediterránea fruto de la inestabilidad termodinámica típica de la época y zona, en invierno el área más afectada es el sur peninsular, y zonas del oeste (Extremadura y Galicia), por lo que parece que en esta estación hay otro tipo de tornados ligado a la dinámica frontal de las borrascas Atlánticas. En primavera y verano existe una mayor repercusión del interior peninsular, fruto de las tormentas típicas de esta zona, produciéndose una deriva a finales de verano hacia la zona Mediterránea.
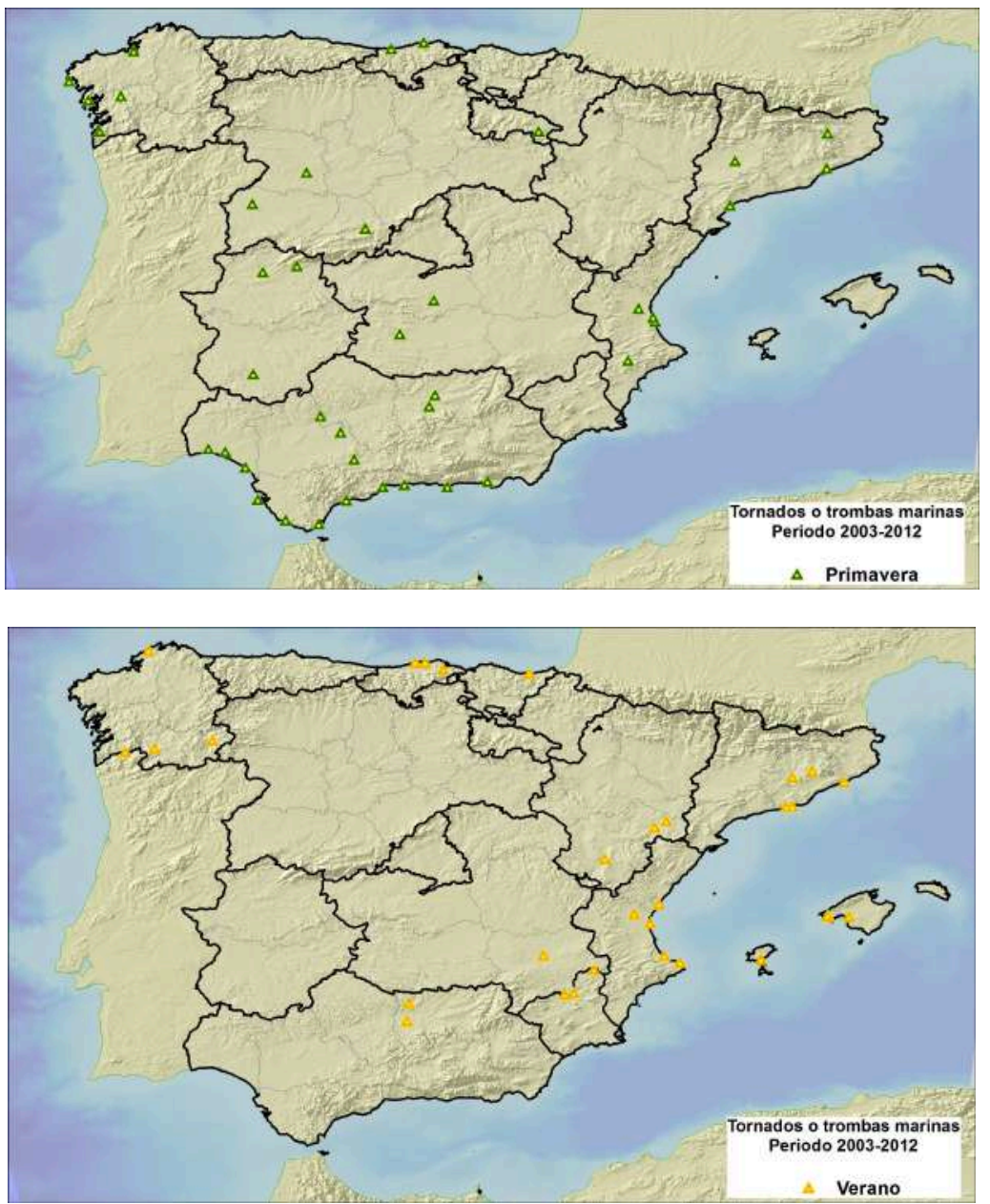

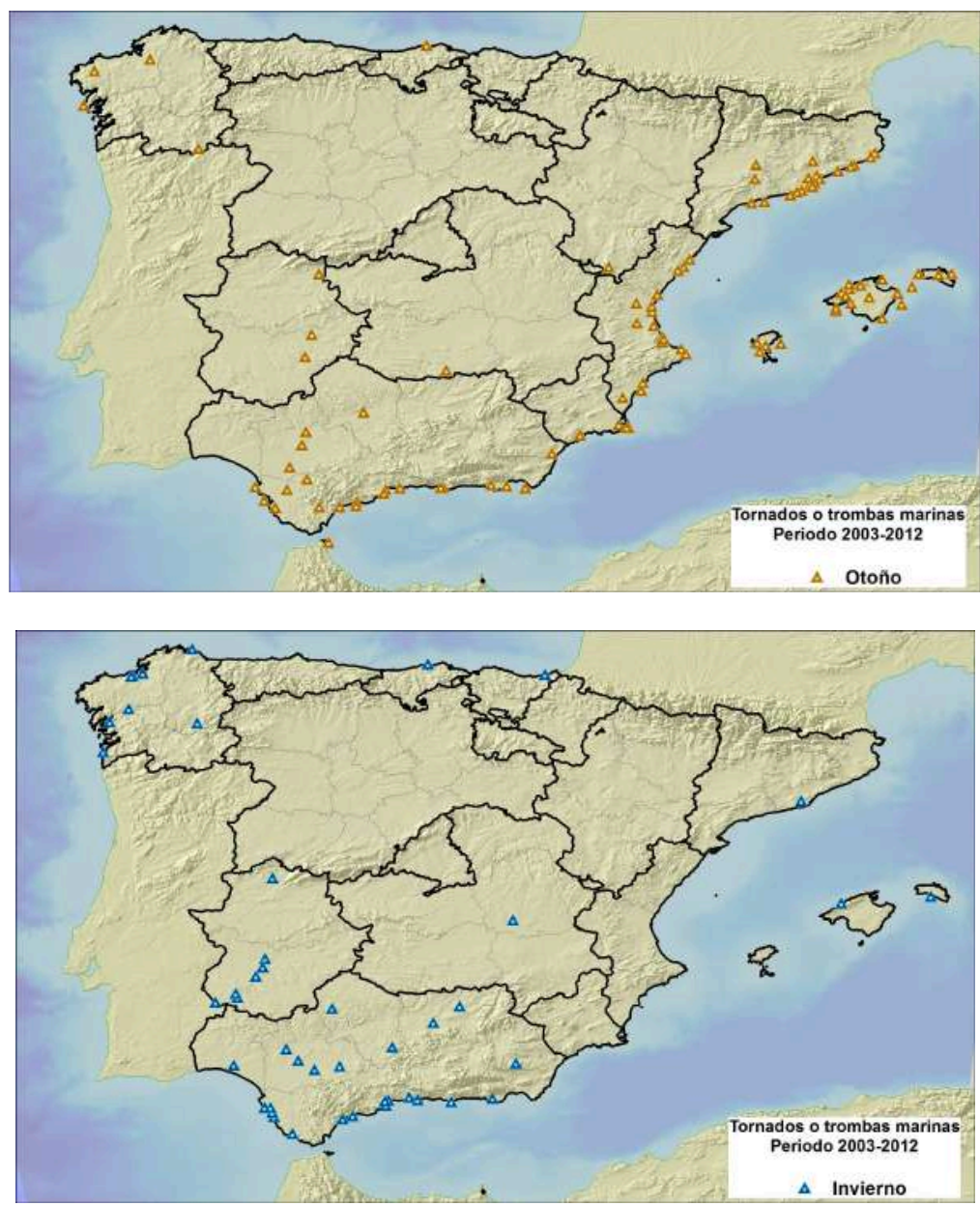

Figura II.2.2: Distribución estacional de tornados y trombas marinas (primavera, verano, otoño, invierno).

A continuación se presentan las localizaciones espaciales de tornados y trombas marinas separados por categorías según la escala Fujita mejorada (figura II.2.3), reflejándose una distribución de gran preferencia por zonas bajas (Valle del Guadalquivir y franjas costeras), algo a lo que ha contribuido lógicamente la buena proporción de trombas marinas existentes (casi todas EF0). Dicha explicación sobre la distribución espacial es por supuesto válida para los tornados y trombas de categoría EF0 (entre 105 y $137 \mathrm{~km} / \mathrm{h}$ ), que son la gran mayoría respecto al total.

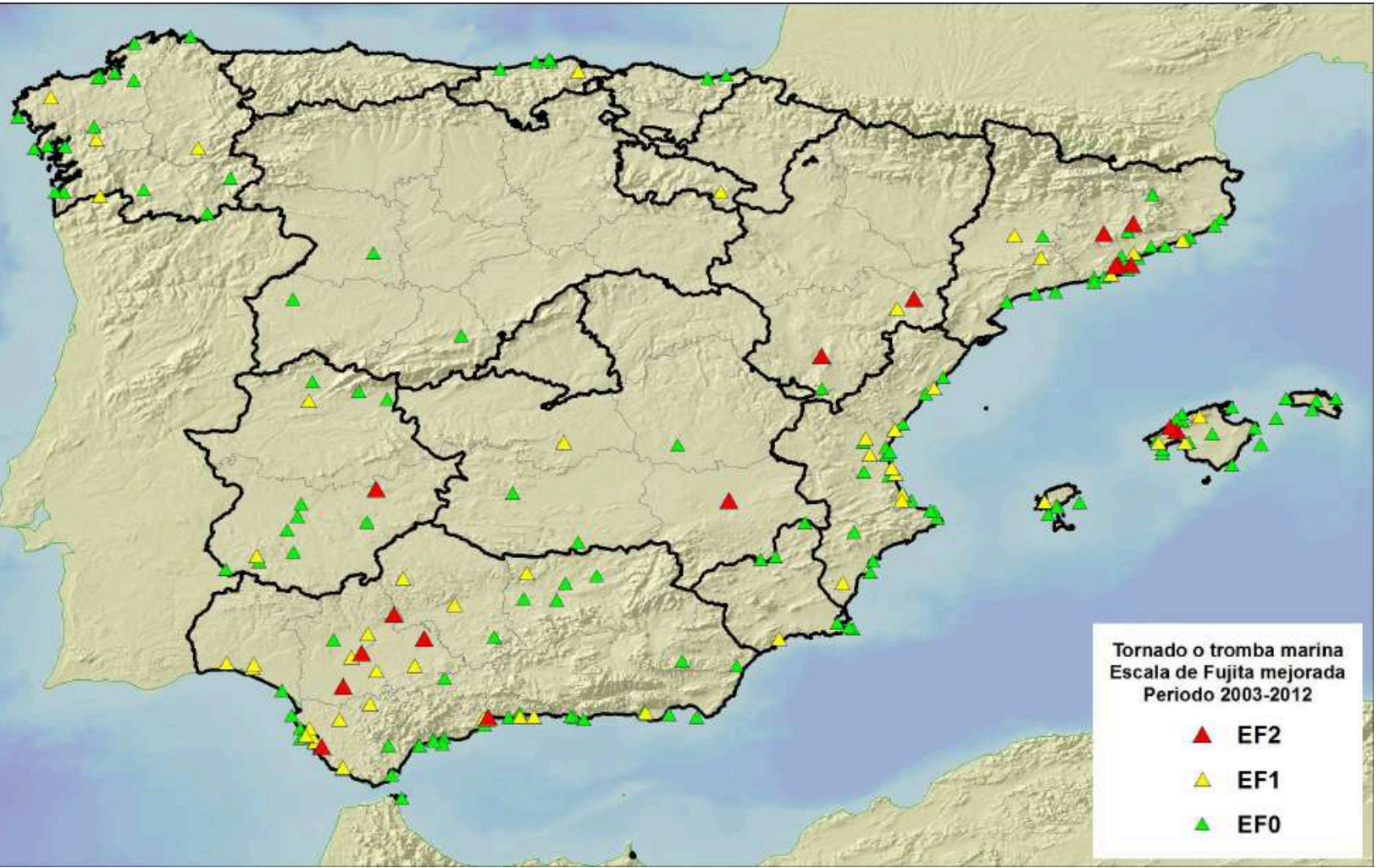

Figura II.2.3: Distribución espacial de los tornados y trombas marinas por categorías según la escala Fujita 
Los de categoría EFO (105 - $137 \mathrm{~km} / \mathrm{h})$ tienen una repercusión general más acusada en la costa Mediterránea, Andalucía, Extremadura y Galicia, con algunos casos en el Cantábrico y en las Mesetas (figura II.2.4)

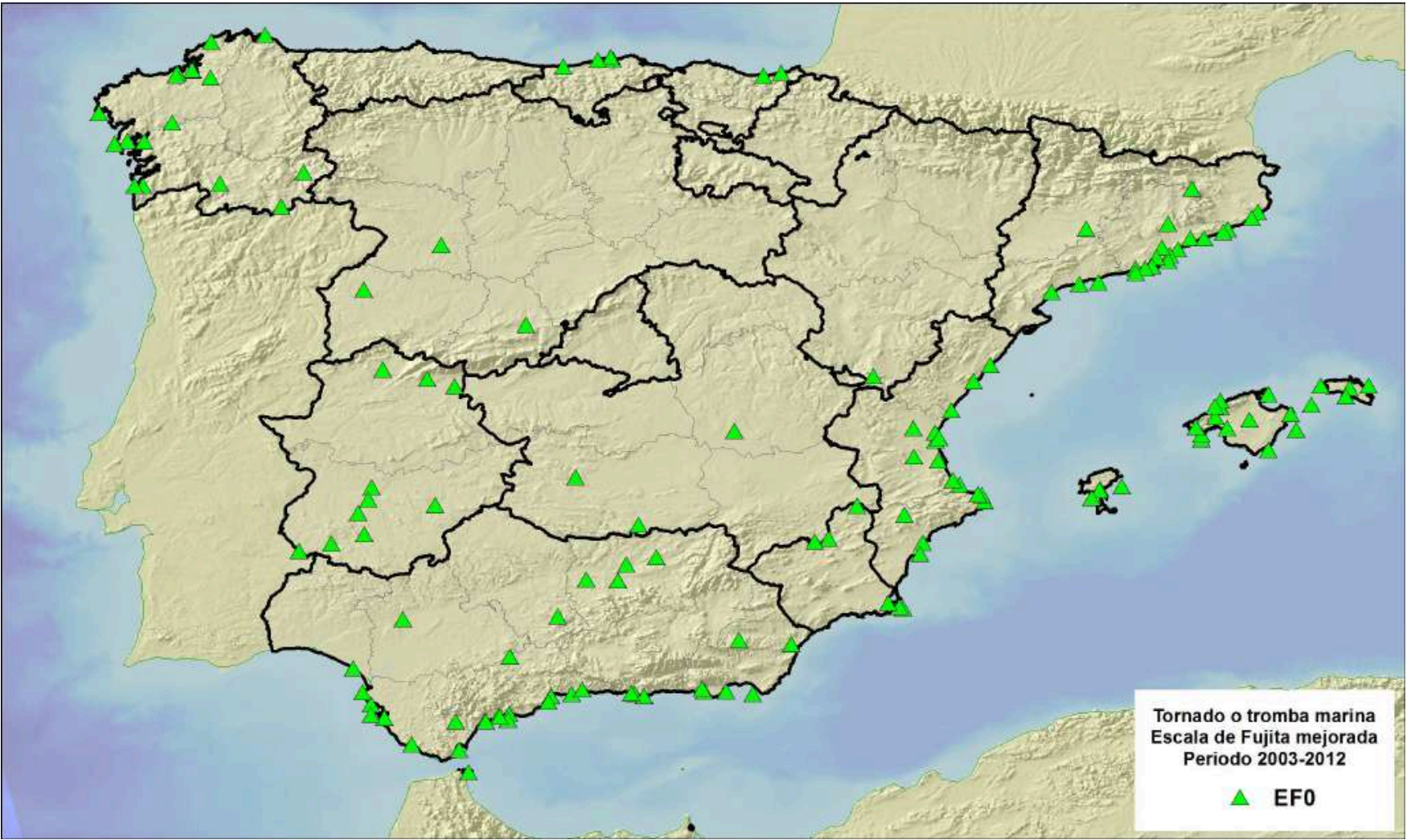

Figura II.2.4: Distribución espacial de los tornados y trombas marinas de categoría EFO según la escala Fujita

En cuanto a los de categoría EF1 $(138-178 \mathrm{~km} / \mathrm{h})$ de nuevo se pone de manifiesto la diferenciación entre la afectación costera y la interior, todavía con predominio de las zonas bajas de la franja litoral. Sin embargo en esta categoría apenas aparecen ya trombas marinas (figura II.2.5).

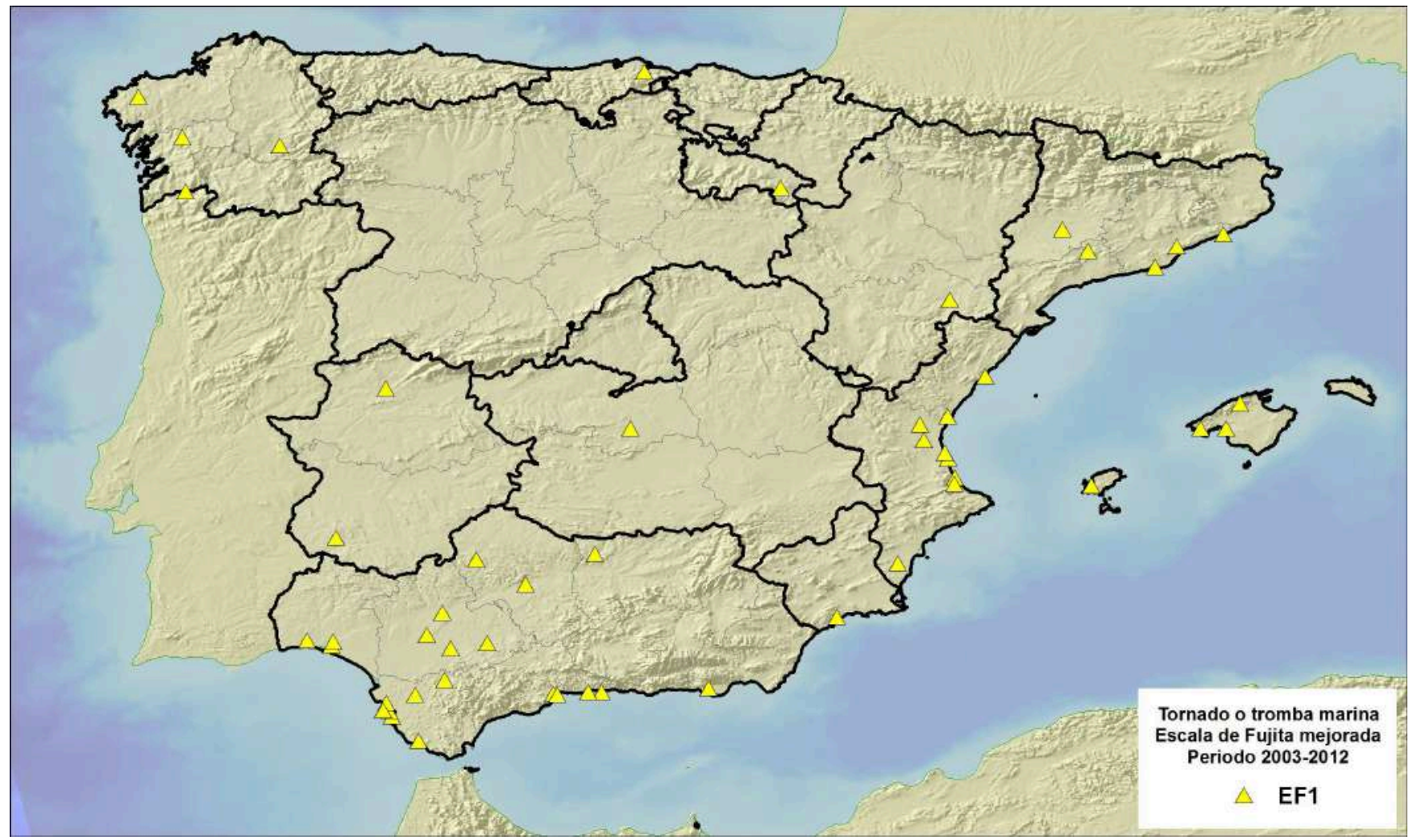

Figura Il.2.5: Distribución espacial de tornados y trombas marinas de categoría EF1

Por último, respecto a la categoría EF2 $(179-218 \mathrm{~km} / \mathrm{h})$, se debe destacar que todos son tornados y hay un reparto casi equitativo entre el interior y la costa, aunque afectando casi exclusivamente a Andalucía y a la vertiente 
Mediterránea. Aproximadamente la mitad de estos tornados tienen lugar en los meses comprendidos entre septiembre y diciembre, ligados a situaciones de inestabilidad de origen marítimo. El resto suelen ser situaciones de primavera-verano.

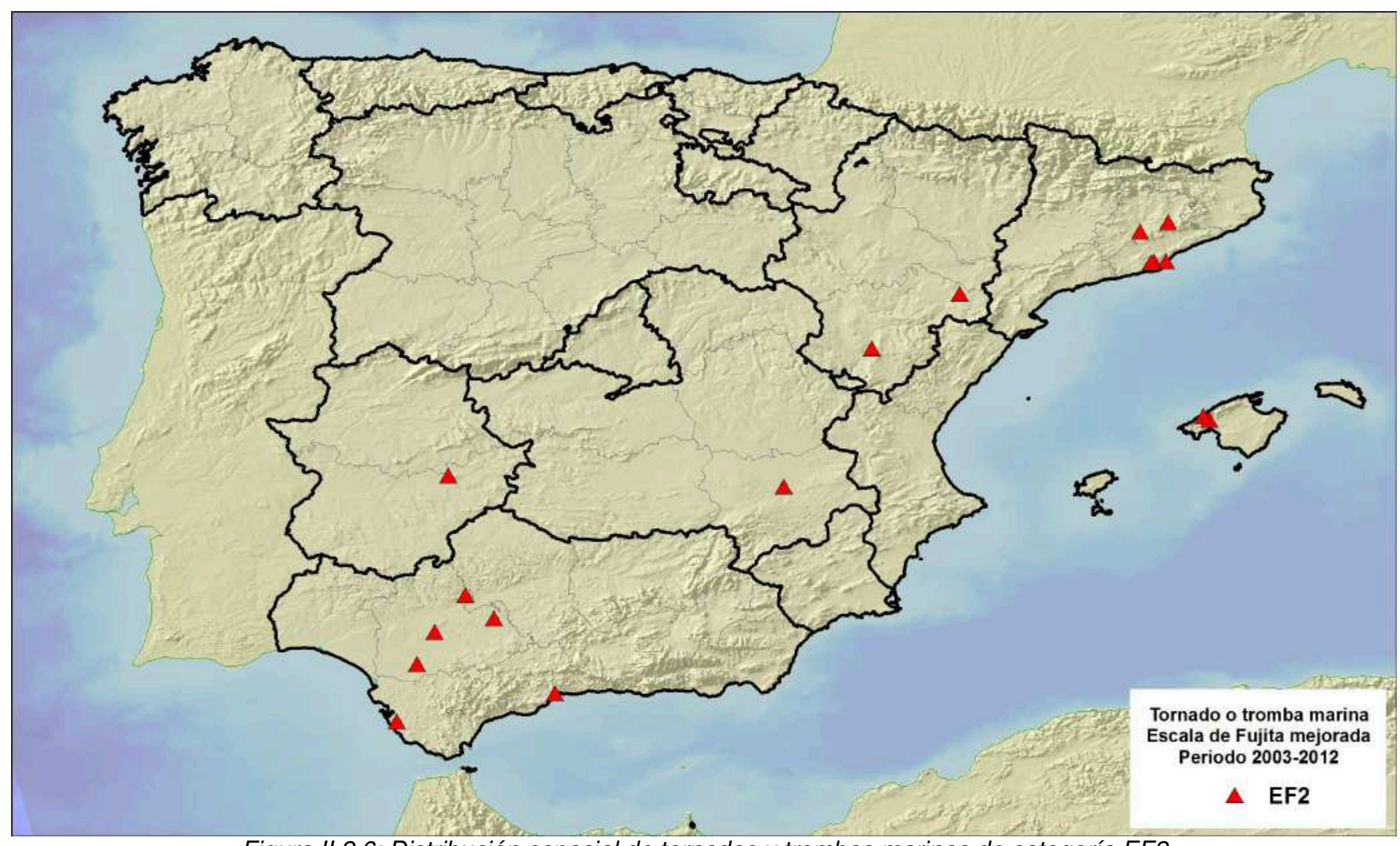

\section{II.3.- Mapa de densidad de tornados observados}

Para el trazado de mapas de densidad de tornados (probabilidad de ocurrencia) se han empleado las herramientas de "densidad" que ofrecen los sistemas de información geográfica. Mediante estas herramientas se ha calculado la densidad de las entidades de entrada dentro de una vecindad alrededor de cada celda de salida.

Debido a la escasa población de la serie de datos analizada (10 años) y la baja probabilidad de ocurrencia del fenómeno, con los cálculos de densidad se ha intentado expandir de alguna manera los valores de entrada (en este caso tornados observados en el periodo 2003-2012) sobre una superficie. Por tanto la probabilidad de ocurrencia de cada tornado de la muestra se distribuye en todo el área de estudio (en este caso la superficie de la España peninsular y las Islas Baleares) y se calcula un valor de densidad para cada celda en la zona de salida. Para los mapas de densidad de tornados, se ha aplicado un área para expandir los valores alrededor de cada ubicación. En este caso el área de expansión empleada para los cálculos ha sido de radios de búsqueda de $0.5^{\circ} \mathrm{x}$ $0.5^{\circ}$ (para el centro de la Península serían radios de búsqueda de $55 \mathrm{~km} \times 55 \mathrm{~km}$ aproximadamente). La resolución final del mapa con los datos de densidad obtenidos ha sido de $0.005^{\circ} \times 0.005^{\circ}$ (para el centro de la Península sería una resolución aproximada de 500 m x 500 m aproximadamente)

Aunque se puede calcular la densidad utilizando cálculos simples de forma que el número de tornados que caen en la misma zona de búsqueda se suman y luego se dividen por el tamaño del área para obtener el valor de densidad de cada celda, se ha optado por emplear cálculos de densidad con función kernel. La función kernel se basa en la función cuadrática que describió Silverman (1986). Las superficies resultantes que rodean a cada punto en la densidad kernel se obtienen mediante una fórmula cuadrada con el valor más alto en el centro de la superficie (la ubicación del punto donde se ha registrado el tornado) y se estrechan hasta cero en la distancia de radio de búsqueda. Para cada celda de salida, se calcula el número total de intersecciones acumuladas de las superficies de expansión individual. De acuerdo con la mayoría de la bibliografía consultada, se ha calculado una magnitud por unidad de área a partir de las entidades de punto que constituyen los tornados observados mediante una función kernel para adaptar una superficie suavemente estrechada a cada punto. Evidentemente el rendimiento de los estimadores de densidad kernel depende fundamentalmente del valor del parámetro de suavizado, comúnmente conocido como radio de búsqueda. En nuestro caso, y como se ha comentado anteriormente, se ha escogido un radio de búsqueda de $0.5^{\circ} \times 0.5^{\circ}$ con una salida de grid de $0.005^{\circ} \times 0.005^{\circ}$.

La primera consideración al hacer los mapas de densidad con los datos observados en el periodo 20032012 es que la base de datos de entrada no es homogénea, ni espacial ni temporalmente. Espacialmente existe una mayor concentración de tornados observados en las zonas más densamente pobladas, especialmente en la costa mediterránea, ya que es evidentemente que estos fenómenos de escala reducida sólo pueden ser 
notificados por testimonios directos o bien a través de la peritación de los daños provocados en superficie y por tanto un tornado de intensidad débil (EF0), cuyos efectos en superficie no son muy importantes sobre todo cuando estamos considerando áreas no urbanizadas, es muy probable que nunca llegue a ser notificado. Temporalmente se ha visto un aumento progresivo del número de tornados incluidos en la base de datos con el paso del tiempo que seguramente no se corresponde con una mayor frecuencia de estos fenómenos (figura II.3.1), sino con la mayor capacidad de observación directa debido a la proliferación de cámaras fotográficas digitales, que han posibilitado la captura de imágenes de tornados y trombas marinas.

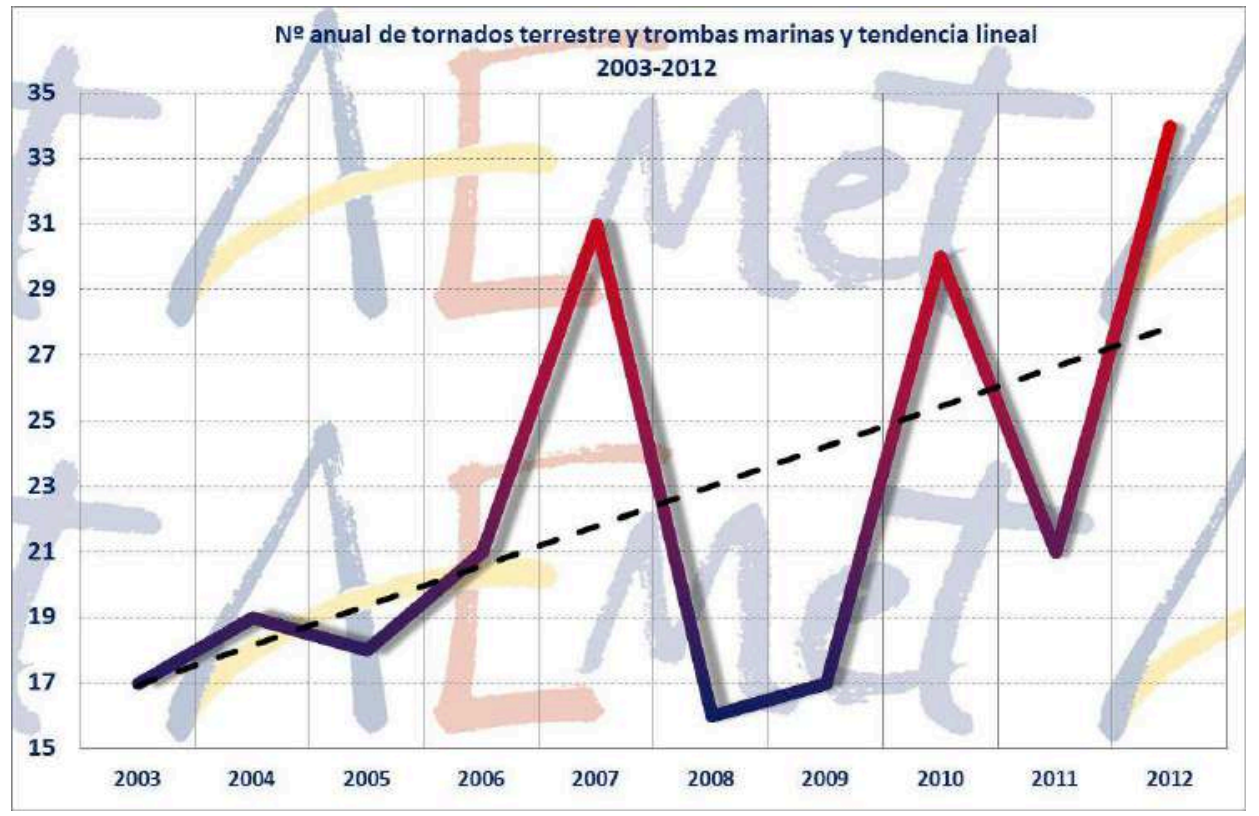

Figura II.3.1: Número y tendencia anual de tornados observados anualmente (2003-2012)

Estas consideraciones previas deben ser tenidas muy en cuenta a la hora de interpretar los mapas de densidad ya que con una probabilidad alta los datos están sesgados por la abundancia de observaciones cerca de las grandes ciudades o áreas de alta densidad de población. El mapa de densidad de tornados que se ofrece a continuación (figura II.3.2) hay que tomarlo por tanto, no como una distribución real de tornados en España, sino como una distribución en base a las observaciones reportadas en los 10 años del periodo analizado. Para su elaboración, y para obtener una mejor representación en los bordes del territorio, también se han empleado tornados o trombas marinas de Portugal, sur de Francia y norte de África. En total 335 tornados o trombas marinas, de los cuales 224 pertenecientes a España y 111 a países limítrofes.

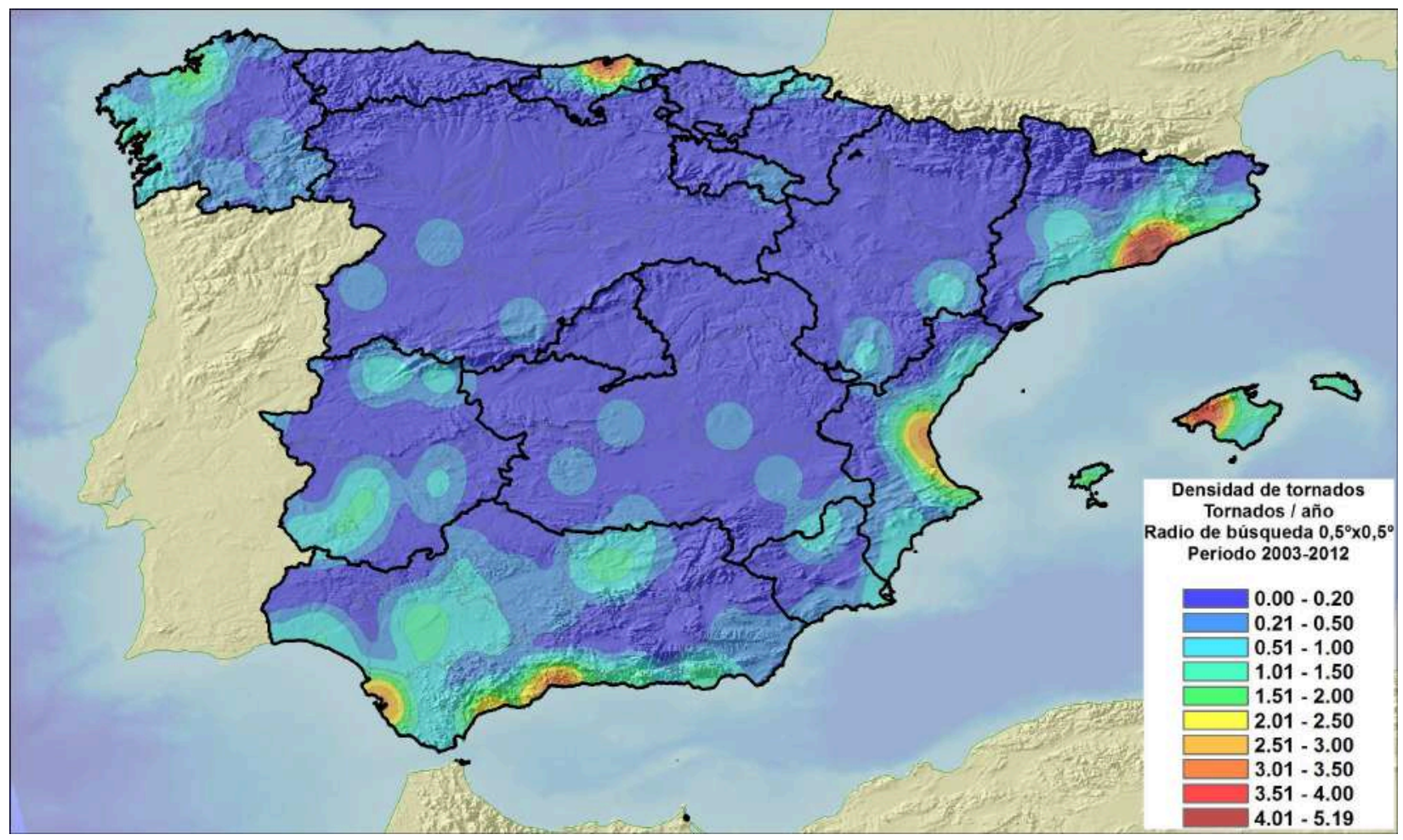



de la muestra de tornados observados disponible en AEMET

El análisis del mapa de densidad de tornados indica una zona de máxima densidad en la vertiente Mediterránea, especialmente en el litoral de Barcelona y en el oeste de Mallorca. En esta zona la densidad de tornados o trombas marinas está entre 4 y 5 al año, en una cuadrícula de $0.5^{\circ} \times 0.5^{\circ}$ alrededor de cada punto, es decir, aproximadamente 5 tornados o trombas marinas al año en una superficie aproximada de $3000 \mathrm{~km}^{2}$. Fuera de la zona de máxima densidad, hay varios máximos secundarios en varios puntos del litoral mediterráneo (Golfo de Valencia y Costa del Sol), así como en el litoral de la provincia de Cádiz y en menor medida Huelva, y en el Cantábrico oriental. Ya por el interior aparecen núcleos mucho más aislados y de menor frecuencia, destacando los del Valle del Guadalquivir, Extremadura, etc.

\section{II.4.- Tornados históricos}

Hay que tener en cuenta que en la base de datos disponible para este trabajo (2003-2012) aparecen 17 casos de tornados significativos (categoría EF2 ó superior). Es reseñable el hecho de que no se dispone de ningún registro superior a EF2 en dicha base de datos. No obstante algunos de ellos fueron bastante destacables como el de Málaga del 1 de Febrero de 2009 (Sánchez-Laulhé, 2010) por ser de los pocos recientes de esta categoría que atravesaron una capital en el periodo reciente.

Sin embargo los tornados de mayor repercusión en el pasado se produjeron ya hace muchos años. Concretamente se pueden citar el de Cádiz de 1671 (Sánchez-Laulhé, 2005) que pudo ser un EF3 y ocasionó más de 60 víctimas mortales, y el de Madrid de 1886 que causó un importante número de muertos (47) y heridos, debido al colapso de las estructuras en las que se refugiaron, además de cuantiosos daños materiales. Pudo haberse tratado de un EF3 originado por una tormenta que se inició en Carabanchel Alto. Sólo en su paso por El Retiro y por el Jardín Botánico arrancó cerca de 400 árboles, derribando muros de casas y volcando carruajes, e incluso volteó un tranvía con 14 personas a bordo.

También en la recta final del siglo XX, merecen especial mención los tornados de Sevilla en 1978, CiutadellaFerreries (Baleares) en 1992, y Navaleno-San Leonardo de Yagüe (Soria) en 1999. En estos casos podrían haberse tratado de tornados de categoría EF3.

\section{II.5.- Estadística de descargas eléctricas}

Debido a las limitaciones de la información disponible de tornados, se pensó inicialmente en la necesidad de disponer de otras variables o fuentes de información adicional para la elaboración final de un mapa de densidad de tornados lo más ajustado posible a la realidad. Es por esto que se utilizaron datos de descargas eléctricas, que en cierto modo se pensaba inicialmente que podían tener cierta relación con la presencia de tornados. Esta es la justificación de que en este apartado se presente una climatología básica de descargas eléctricas.

Para la caracterización de la densidad de descargas eléctricas nube-tierra, se ha seleccionado una zona que aparece delimitada en la figura II.5.1 (latitud de $35^{\circ} \mathrm{N}$ a $44^{\circ} \mathrm{N}$ y longitud desde $10^{\circ} \mathrm{W}$ a $5^{\circ} \mathrm{E}$ ) durante el periodo 20032012. Se ha realizado la integración de las descargas en intervalos anuales, mensuales y horarios considerando el área completa utilizada. La información empleada ha sido extraída de la base de datos del sistema de detección de descargas eléctricas de AEMET que utiliza 29 estaciones de radiodetección con tecnología GPS, que son capaces de registrar el campo electromagnético de cada señal. Hay que tener en cuenta que se contabilizan aquí descargas, no rayos, y por ello el número de rayos será menor ya que cada uno puede tener varias descargas asociadas. En total, en el área y periodo indicados se han obtenido 13.330.231 descargas eléctricas nube-tierra. 


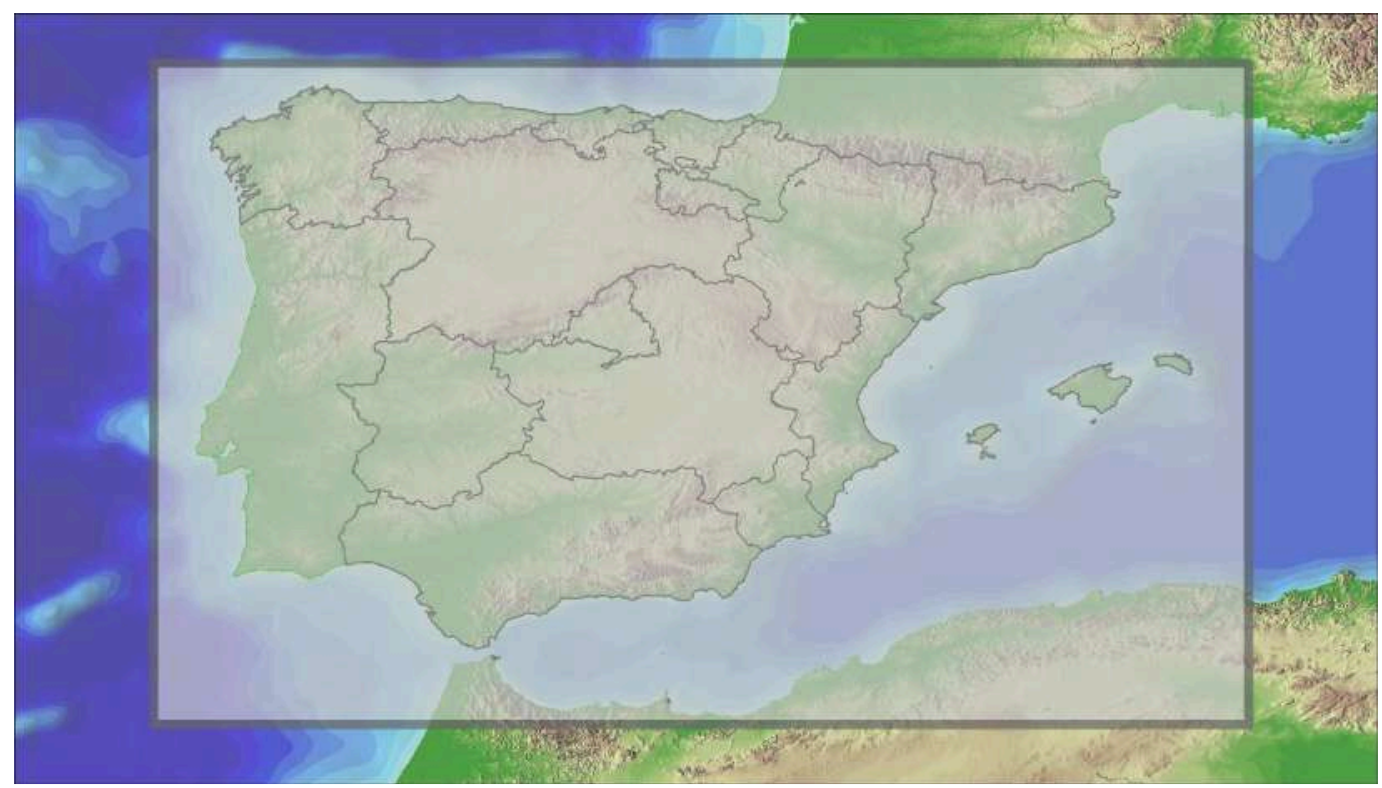

Figura II.5.1: Zona de estudio (resaltada en sombreado) para las descargas eléctricas durante el periodo $2003-2012$

En primer lugar se presenta la evolución anual de descargas detectadas (figura II.5.2), que indica una importante variabilidad interanual, y una cierta tendencia negativa (posiblemente casual) en cuanto a número de descargas anuales en el periodo estudiado.

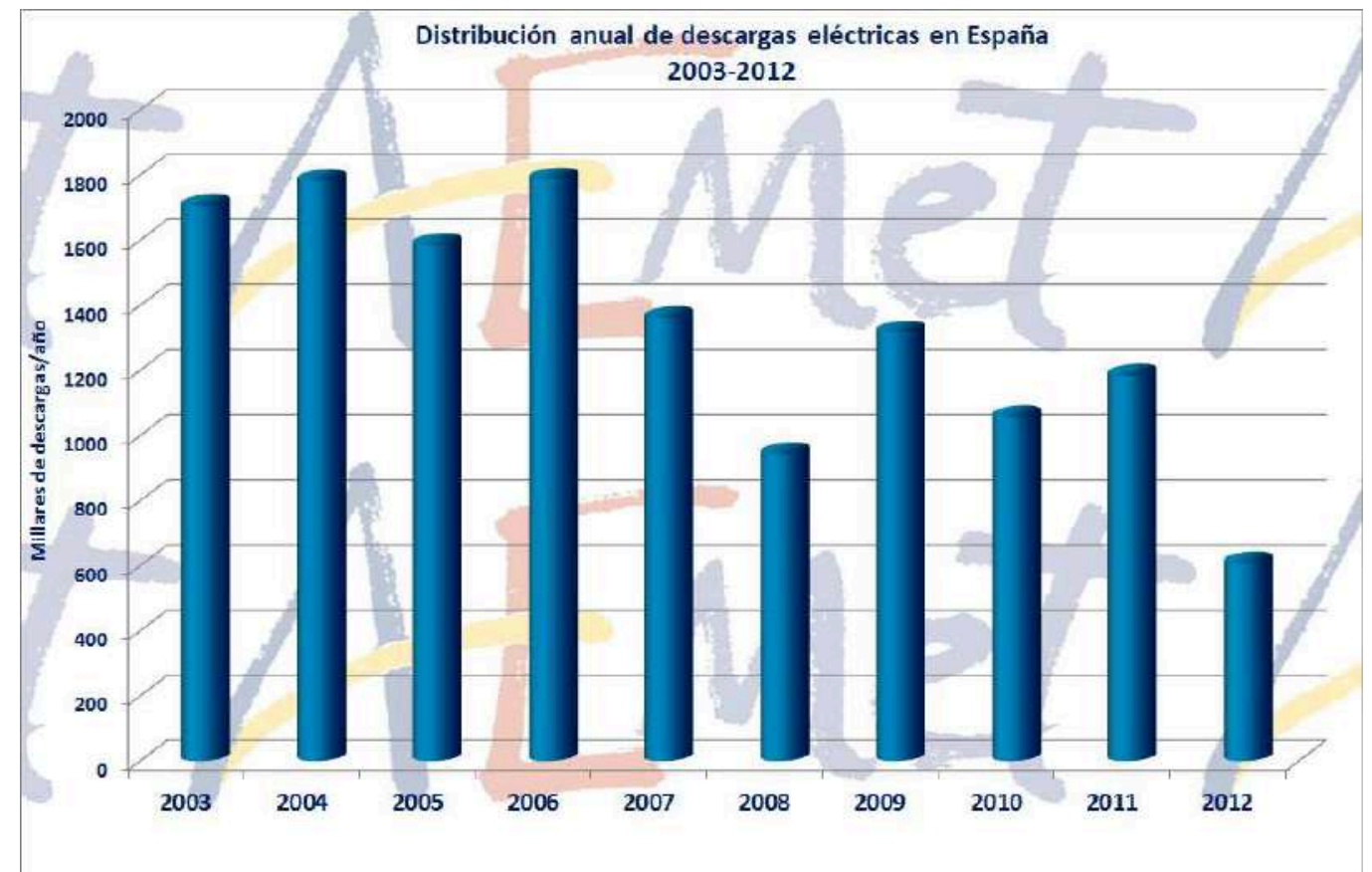

Figura II.5.2: Número anual de descargas en la España Peninsular y Baleares, durante el periodo 2003-2012

En la figura II.5.3 se presenta la media mensual de descargas del periodo seleccionado. Como se puede observar el máximo se registra entre los meses de mayo y septiembre, algo que tiene relación entre otros factores, con el ciclo anual de la temperatura del aire en superficie. 


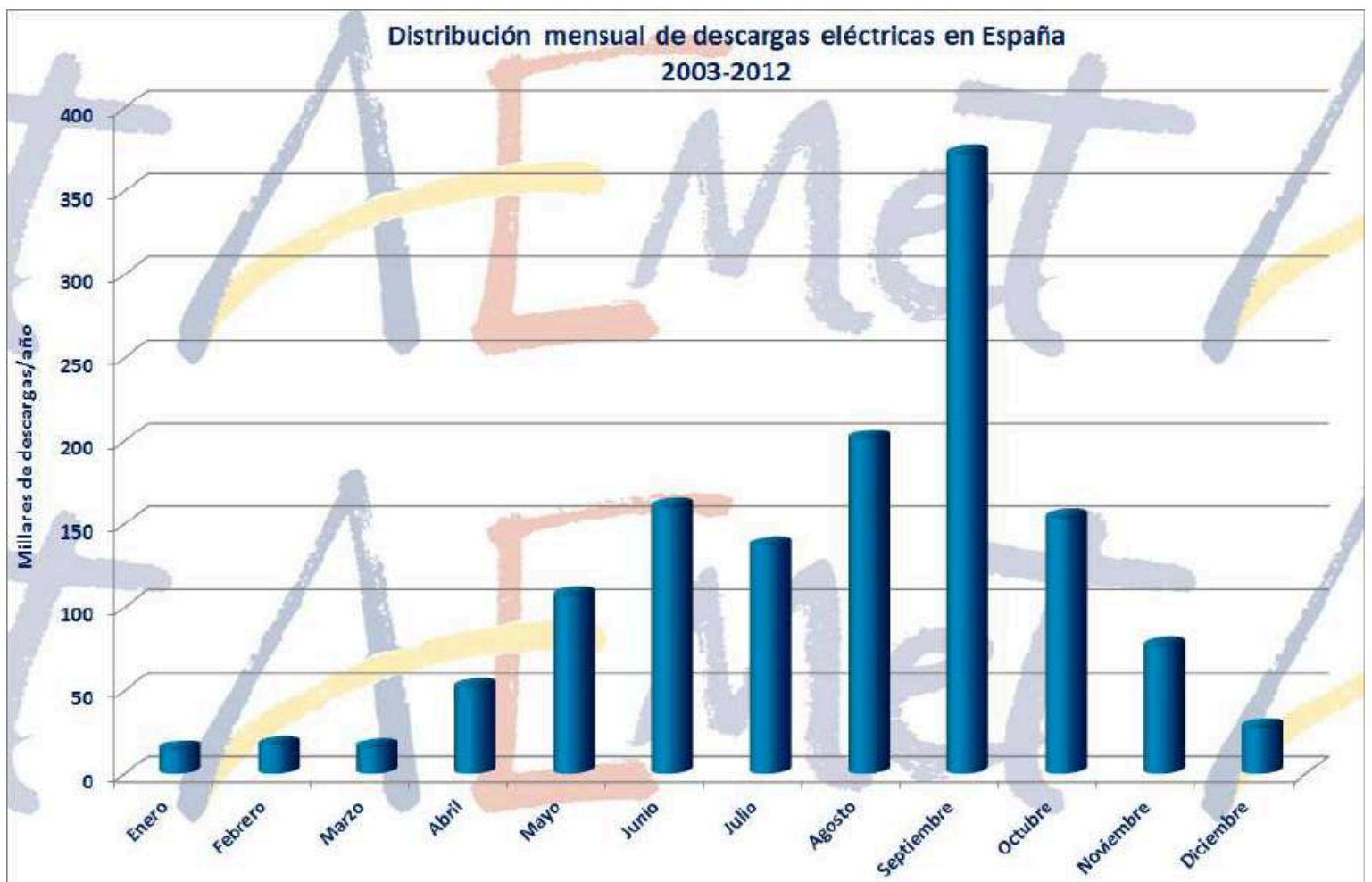

Figura II.5.3: Distribución mensual de descargas en la España Peninsular y Baleares, durante el periodo $2003-2012$

La distribución horaria (figura II.5.4), pone de manifiesto la existencia de un máximo hacia las 16 UTC y un mínimo a las 9 UTC, respondiendo al ciclo diurno de insolación.

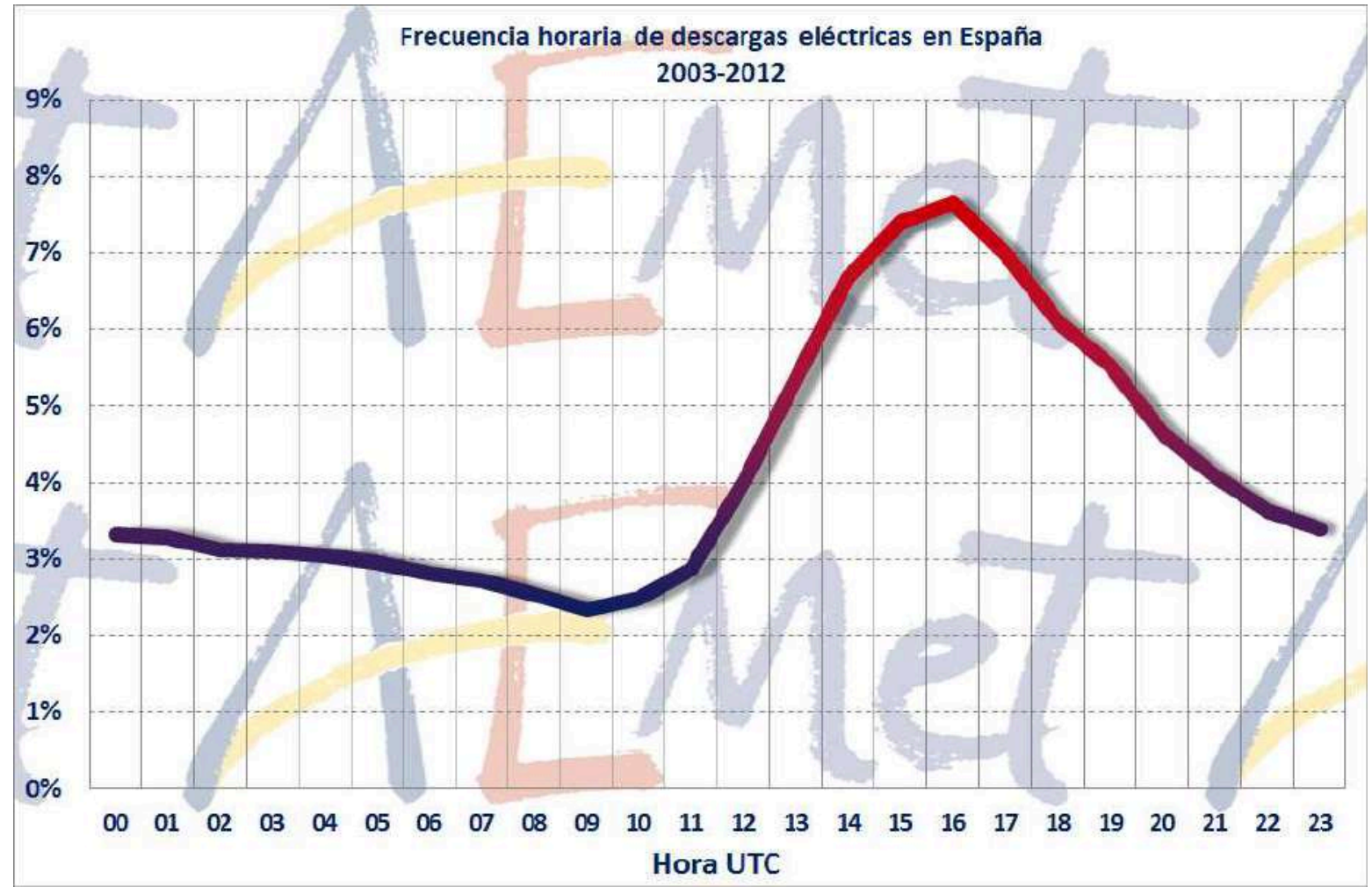

Figura II.5.4: Distribución horaria de descargas en la España Peninsular y Baleares, durante el periodo $2003-2012$

En el gráfico de la figura II.5.5 se presenta la evolución mes a mes durante todo el periodo del número de descargas, destacando en cuanto a mayor actividad eléctrica el mes de septiembre de 2009, con cerca de 700.000 descargas. 


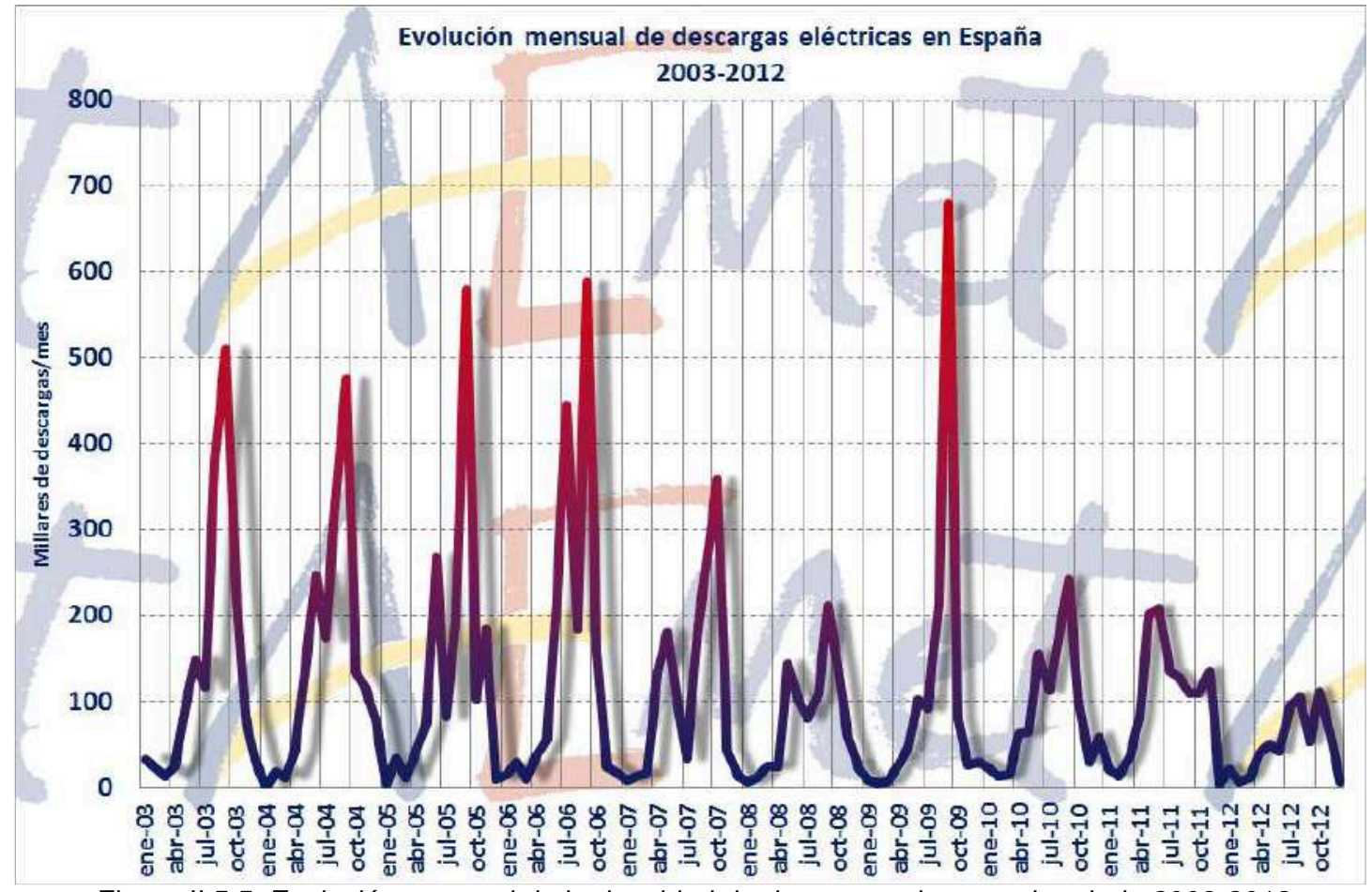

Figura II.5.5: Evolución mensual de la densidad de descargas durante el periodo 2003-2012

El porcentaje de descargas positivas respecto a las totales es del $9 \%$, (figura II.4.6), encontrándose el máximo durante el año en los meses fríos. La media de la intensidad de la corriente de las descargas positivas es de 28,1 kA, mientras que la de las negativas es de -17,6 kA algo que confirma que las descargas positivas suelen ser más intensas, y por tanto más peligrosas, que las negativas.

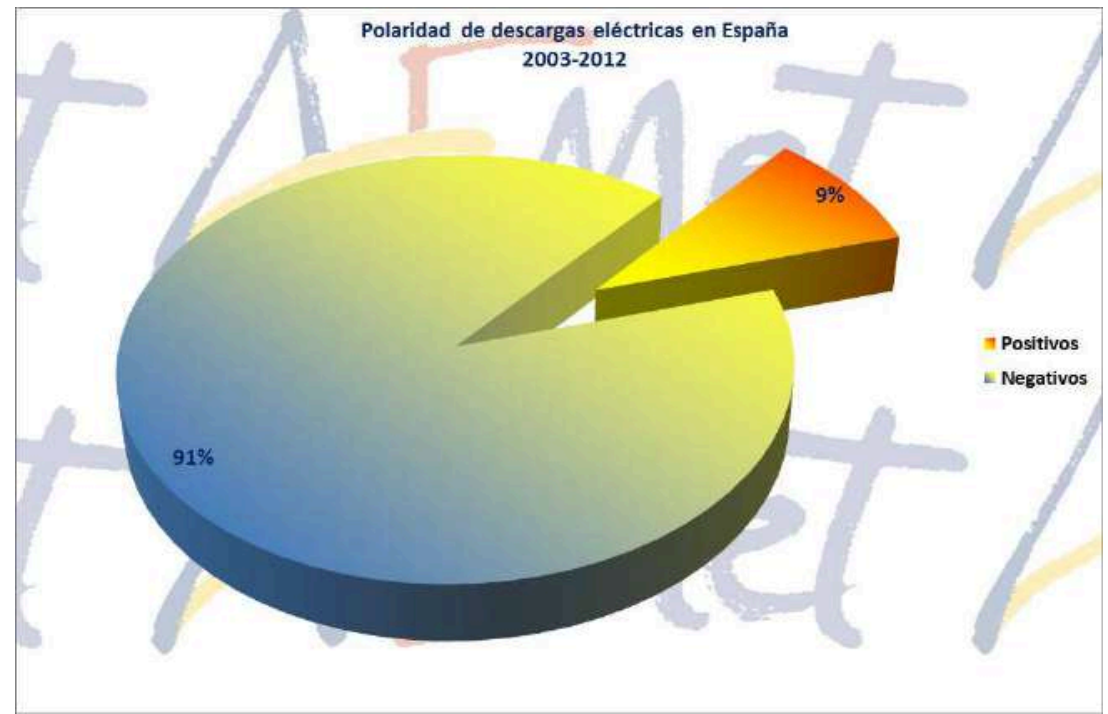

Figura II.5.6: Porcentaje encontrado de cargas negativas y positivas

A continuación se enumeran los días que registraron más de 100.000 descargas en la zona y periodo estudiados: 2006-09-12 (152238), 2005-09-06 (150639), 2005-09-25 (106846), 2009-09-14 (104686), 2006-09-13 (104512) y 2003-08-17 (104686). Como se aprecia los días con mayor actividad eléctrica pertenecen casi en exclusiva al mes de septiembre.

En cuanto a la densidad media anual de descargas, la figura II.5.7 muestra la distribución a lo largo de la zona estudiada durante el periodo 2003-2012. 


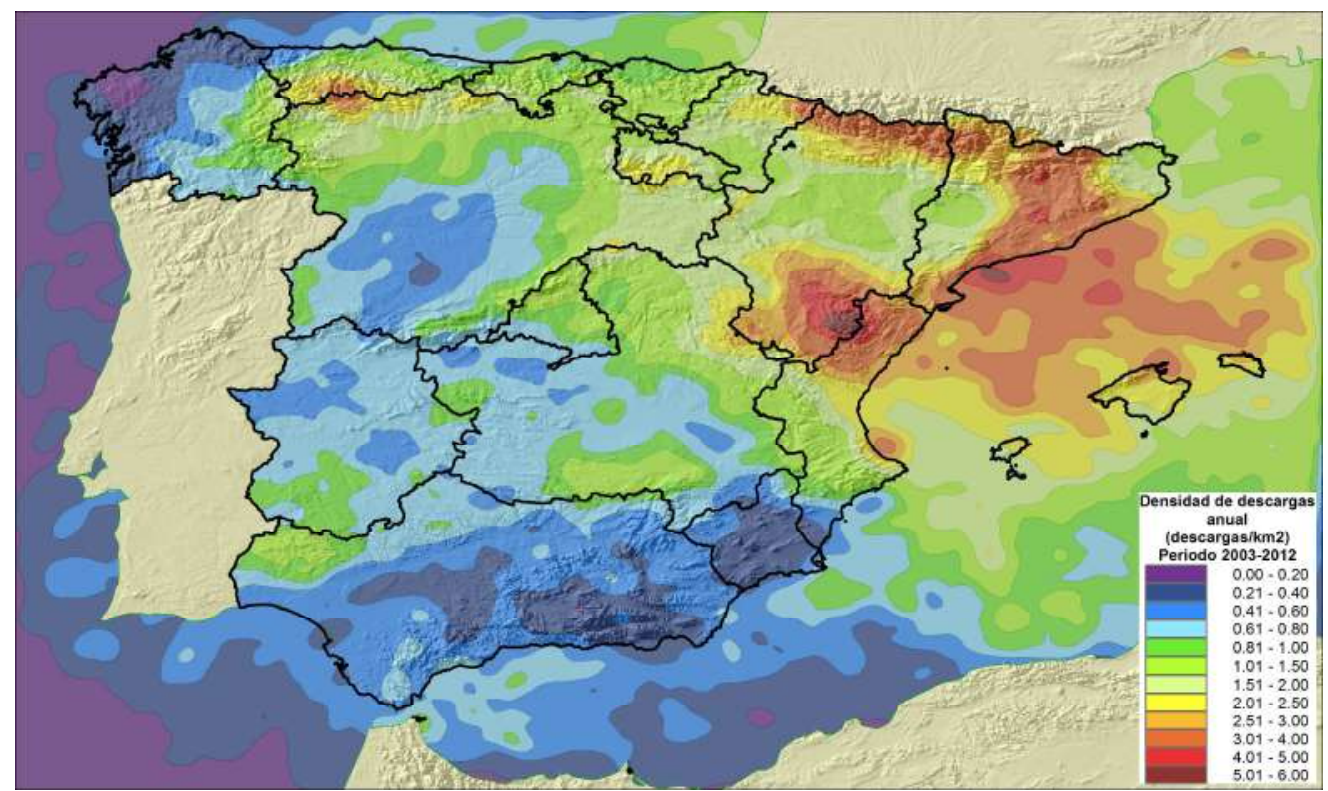

Figura II.5.7: Densidad anual de descargas eléctricas (Número de descargas $/ \mathrm{km}^{2}$ ).

Si consideramos la frecuencia de descargas en el área de terrestre de España peninsular y Baleares, claramente aparece el factor orográfico como uno de los más influyentes en la distribución espacial. Las áreas de mayor actividad eléctrica son las de los Pirineos, el Sistema Ibérico, los Sistemas Costeros y Precosteros Catalanes y zonas de la Cordillera Cantábrica, resultados análogos a los obtenidos por Rivas et al. (2005). El valor más alto de densidad anual de descargas sobre tierra se encuentra en el Maestrazgo turolense y castellonense, con el máximo absoluto en la Sierra del Rayo (Teruel), entre Mosqueruela, Fortanete y Valdelinares, y en Vilafranca del Cid (Castellón), donde la densidad media anual es de 6,1 descargas $/ \mathrm{km}^{2}$. También aparecen máximos secundarios aunque inferiores en la costa mediterránea de Cataluña y Comunidad Valencia, y en menor medida, Baleares. En toda esa zona se genera importante actividad convectiva, especialmente en otoño, debido al aporte de calor y humedad que transfiere a la masa de aire principalmente en esa época, lo que genera importante inestabilidad. El mínimo de densidad de rayos se observa en la provincia de la Coruña y en el sur Peninsular. Un hecho llamativo es que no se aprecia un máximo destacable en las montañas del Sistema Penibético. El valor mínimo puntual de densidad anual de descargas toma el valor de 0,2 descargas $/ \mathrm{km}^{2}$ y se encuentra en la comarca de Bergantiños (Coruña).

En lo que se refiere al número de descargas nube-tierra sobre el área marítima circundante, aparece un zona que destaca de manera muy significativa en cuanto a sus valores elevados, que es el mar Balear, con un máximo muy acusado junto al litoral tarraconense, disminuyendo abruptamente en la costa de Gerona y también hacia el sur del Cabo de La Nao. Por otra parte el mínimo costero se presenta en el litoral coruñés.

En cuanto al reparto provincial anual de densidad de descargas por provincias subsiste la tabla II.5.1, en la que las provincias del nordeste peninsular son las más activas en cuanto a descargas eléctricas (encabezadas por Barcelona, Castellón y Teruel), en contraposición a zonas del sur y noroeste Peninsular (destacando Granada y Coruña). La actividad eléctrica provincial, dividida en varios intervalos, puede apreciarse en la figura II.5.8.

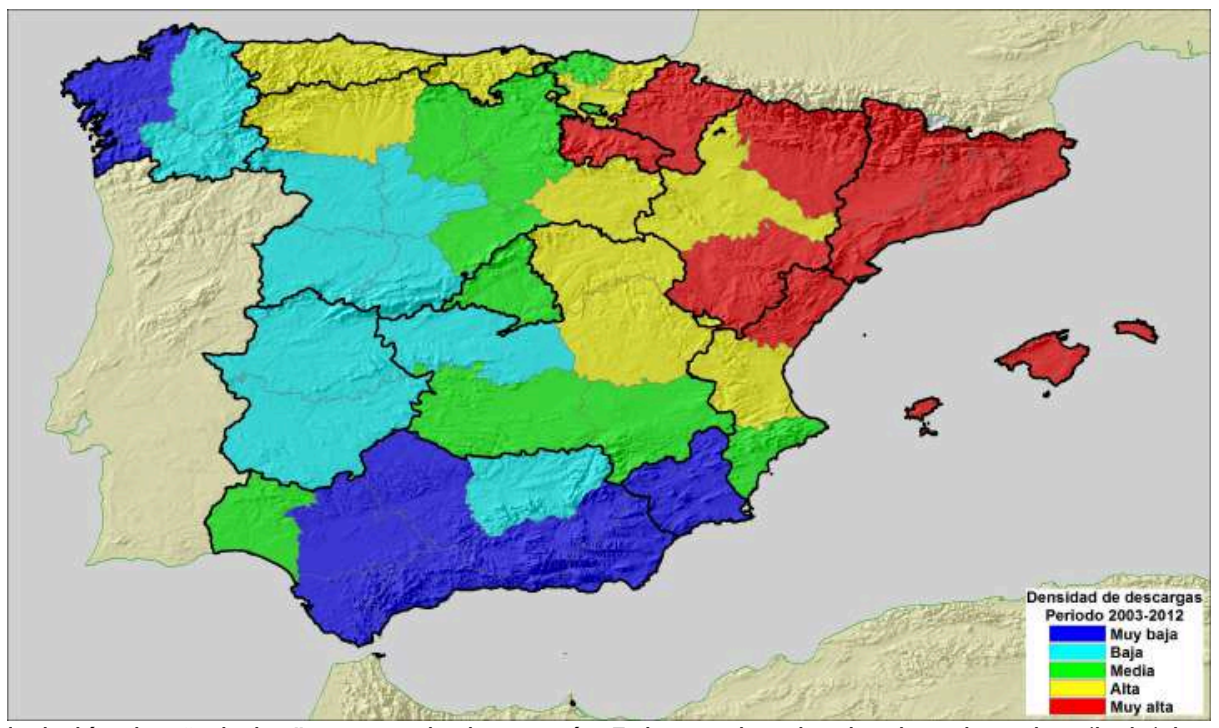

Figura II.5.8: Actividad eléctrica "relativa" por provincias según 5 intervalos desde el azul marino (baja) hasta el rojo (muy alta) 


\begin{tabular}{|c|c|c|c|c|c|c|}
\hline Provincia & $\begin{array}{c}\text { Descargas } \\
\text { totales }\end{array}$ & $\begin{array}{l}\text { Densidad } \\
\text { media } \\
\text { provincial }\end{array}$ & $\begin{array}{l}\text { Densidad } \\
\text { mínima } \\
\text { provincial }\end{array}$ & $\begin{array}{l}\text { Densidad } \\
\text { máxima } \\
\text { provincial }\end{array}$ & Amplitud & $\begin{array}{l}\text { Desviación } \\
\text { típica }\end{array}$ \\
\hline Barcelona & 273561 & 3.5 & 2.2 & 4.2 & 2.0 & 0.4 \\
\hline Castellón/Castelló & 225344 & 3.4 & 2.3 & 5.6 & 3.2 & 0.6 \\
\hline Teruel & 478036 & 3.2 & 1.4 & 6.1 & 4.7 & 0.9 \\
\hline Tarragona & 181395 & 2.9 & 1.5 & 5.0 & 3.5 & 0.8 \\
\hline Girona & 136755 & 2.3 & 1.2 & 3.9 & 2.7 & 0.7 \\
\hline Lleida & 271107 & 2.3 & 1.0 & 4.1 & 3.1 & 0.7 \\
\hline Illes Balears & 113761 & 2.2 & 1.5 & 3.4 & 1.9 & 0.3 \\
\hline Huesca & 353871 & 2.2 & 1.0 & 3.8 & 2.8 & 0.8 \\
\hline La Rioja & 90453 & 1.8 & 1.1 & 2.3 & 1.2 & 0.3 \\
\hline Navarra & 184569 & 1.8 & 1.1 & 3.6 & 2.5 & 0.5 \\
\hline Soria & 181725 & 1.7 & 1.1 & 2.3 & 1.2 & 0.2 \\
\hline Zaragoza & 284512 & 1.7 & 1.1 & 3.1 & 2.0 & 0.3 \\
\hline León & 257992 & 1.6 & 0.8 & 3.5 & 2.7 & 0.5 \\
\hline Valencia/Valéncia & 171359 & 1.6 & 1.0 & 2.9 & 1.8 & 0.4 \\
\hline Guadalajara & 179038 & 1.5 & 0.9 & 2.7 & 1.8 & 0.4 \\
\hline Asturias & 150555 & 1.4 & 0.4 & 3.5 & 3.1 & 0.7 \\
\hline Araba/Álava & 39929 & 1.3 & 1.0 & 1.6 & 0.6 & 0.1 \\
\hline Cuenca & 216085 & 1.3 & 0.6 & 2.8 & 2.2 & 0.5 \\
\hline Cantabria & 62157 & 1.2 & 0.8 & 2.3 & 1.6 & 0.3 \\
\hline Gipuzkoa & 22078 & 1.1 & 0.9 & 1.3 & 0.4 & 0.1 \\
\hline Burgos & 163044 & 1.1 & 0.6 & 2.1 & 1.4 & 0.3 \\
\hline Palencia & 85949 & 1.1 & 0.6 & 2.4 & 1.8 & 0.4 \\
\hline Bizkaia & 21378 & 1.0 & 0.8 & 1.4 & 0.6 & 0.1 \\
\hline Madrid & 78797 & 1.0 & 0.6 & 1.5 & 0.9 & 0.2 \\
\hline Alicante/Alacant & 56327 & 1.0 & 0.3 & 2.7 & 2.5 & 0.5 \\
\hline Segovia & 61990 & 0.9 & 0.5 & 2.0 & 1.5 & 0.2 \\
\hline Ceuta & 221 & 0.9 & 0.9 & 0.9 & 0.0 & 0.0 \\
\hline Huelva & 83430 & 0.8 & 0.3 & 1.4 & 1.0 & 0.3 \\
\hline Ciudad Real & 159739 & 0.8 & 0.5 & 1.2 & 0.6 & 0.2 \\
\hline Albacete & 117274 & 0.8 & 0.4 & 1.3 & 0.9 & 0.2 \\
\hline Ourense & 56828 & 0.8 & 0.5 & 1.3 & 0.7 & 0.1 \\
\hline Lugo & 75403 & 0.8 & 0.3 & 2.1 & 1.9 & 0.4 \\
\hline Badajoz & 161573 & 0.7 & 0.5 & 1.1 & 0.7 & 0.1 \\
\hline Zamora & 76134 & 0.7 & 0.4 & 1.2 & 0.8 & 0.2 \\
\hline Ávila & 58183 & 0.7 & 0.4 & 1.1 & 0.7 & 0.1 \\
\hline Toledo & 103861 & 0.7 & 0.5 & 1.0 & 0.4 & 0.1 \\
\hline Cáceres & 128556 & 0.6 & 0.5 & 0.9 & 0.5 & 0.1 \\
\hline Salamanca & 76328 & 0.6 & 0.4 & 0.9 & 0.6 & 0.1 \\
\hline Valladolid & 49780 & 0.6 & 0.4 & 1.1 & 0.7 & 0.1 \\
\hline Jaén & 74978 & 0.6 & 0.4 & 1.1 & 0.7 & 0.1 \\
\hline Córdoba & 77338 & 0.6 & 0.3 & 0.8 & 0.5 & 0.1 \\
\hline Cádiz & 39387 & 0.5 & 0.4 & 0.7 & 0.4 & 0.1 \\
\hline Sevilla & 70968 & 0.5 & 0.3 & 1.0 & 0.8 & 0.2 \\
\hline Málaga & 34025 & 0.5 & 0.3 & 0.7 & 0.5 & 0.1 \\
\hline Almería & 35290 & 0.4 & 0.3 & 0.6 & 0.4 & 0.1 \\
\hline Pontevedra & 17169 & 0.4 & 0.2 & 0.7 & 0.4 & 0.1 \\
\hline Murcia & 44468 & 0.4 & 0.2 & 0.9 & 0.7 & 0.1 \\
\hline Melilla & 48 & 0.4 & 0.4 & 0.4 & 0.0 & 0.0 \\
\hline Granada & 48104 & 0.4 & 0.2 & 0.6 & 0.4 & 0.1 \\
\hline A Coruña & 20620 & 0.3 & 0.1 & 0.7 & 0.6 & 0.1 \\
\hline
\end{tabular}

Tabla Il.5.1: Densidad media anual de descargas por provincias ordenadas según la densidad media 
II.5.9.

Es importante por último plasmar la variación espacial estacional de las descargas, surgiendo así la figura

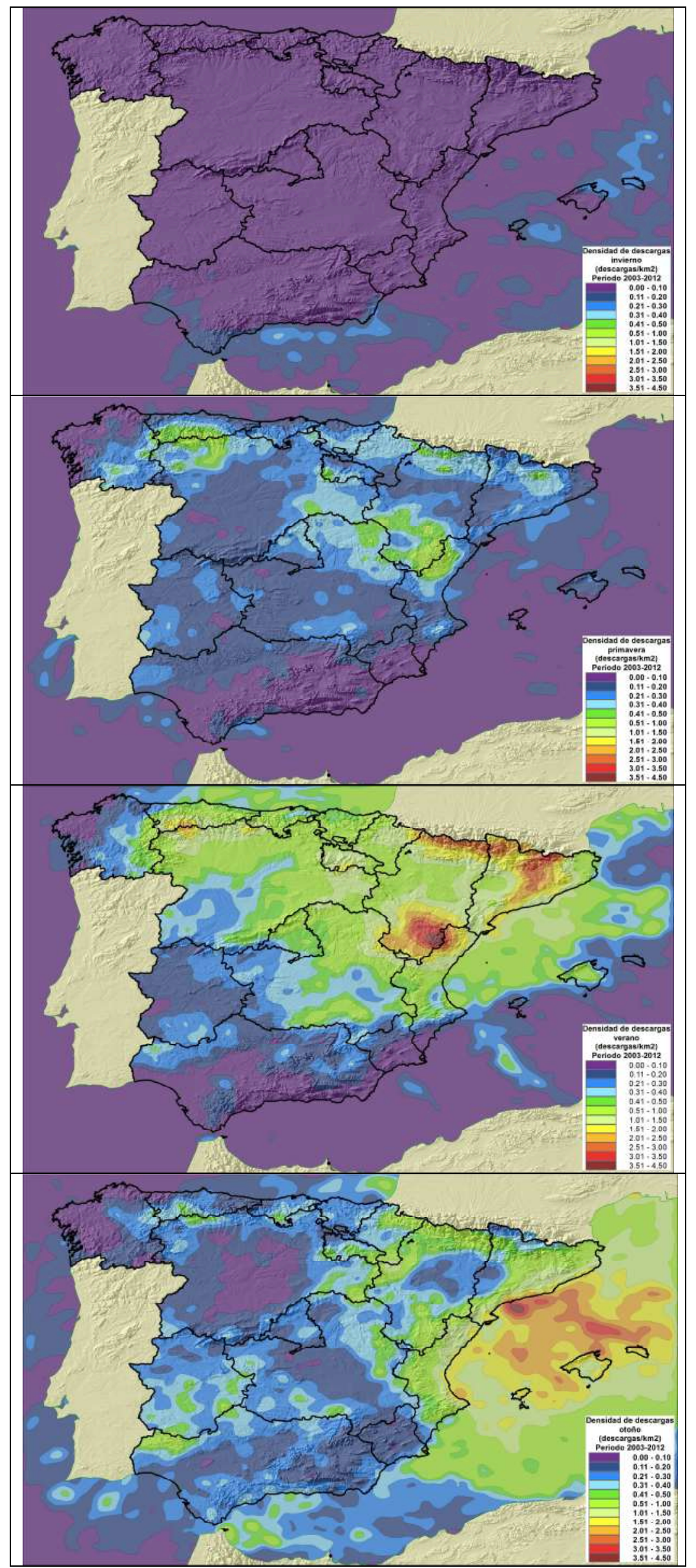

Figura II.5.9: Mapas de distribución estacional de descargas eléctricas (invierno, primavera, verano y otoño). 
En cuanto a la variabilidad estacional, hay una clara dependencia del contraste térmico tierra-mar durante el ciclo anual.

Mientras que en grandes áreas del interior peninsular la actividad eléctrica comienza con la primavera con un máximo prácticamente a finales de ésta o durante el verano, en el otoño (o exactamente a finales de agosto), las zonas de mayor número de descargas se desplaza hacia el este debido a la influencia de mar Mediterráneo.

\section{II.6.- Relación entre tornados y descargas eléctricas}

No existe demasiada relación entre las distribuciones espaciales de tornados y descargas eléctricas, pues aunque en algunas zonas coinciden los máximos de ambas distribuciones (como en el litoral de la Comunidad Valenciana, Baleares y Cataluña), y también los mínimos (Galicia y algunos lugares del interior peninsular), en otras áreas no existe esa coincidencia (por ejemplo en el litoral andaluz y Valle del Guadalquivir) en el que no habiendo demasiadas descargas, sí existe un importante número de tornados.

Aunque los tornados tienen un carácter predominantemente convectivo, para que éstos se produzcan debe existir un entorno meteorológico en el que estén presentes unos determinados ingredientes. Además la observación de tornados depende mucho de la densidad de población de la zona desde donde se reporta la información, mientras que la detección de rayos es un hecho objetivo.

En cualquier caso es un hecho indudable que el mapa de densidad de tornados presenta unos patrones espaciales diferentes a los del mapa de densidad de descargas eléctricas. 


\section{III.- CLIMATOLOGÍA MEJORADA DE TORNADOS}

\section{III.1.- Estadísticas de parámetros relevantes de sondeos}

Una constante a nivel mundial es tratar de encontrar valores favorables de determinados parámetros dinámicos y termodinámicos atmosféricos relacionados con entornos propicios para la ocurrencia de tornados en las proximidades. No obstante casi todas las referencias están basadas en tornados significativos, o sea tornados de categoría EF2 ó superior según la escala Fujita mejorada. En nuestro caso hemos tratado en primer lugar de realizar una climatología de diversos parámetros procedentes de sondeos representativos del entorno de referencia (tabla III.1) considerados de interés en la generación de tornados, tal y como establece la bibliografía general. El periodo de estudio es el comprendido entre el año 1999 y el 2012, utilizándose datos de 0 y 12 UTC. Los datos, con diversos parámetros ya calculados (tabla III.2) han sido tomados de la Universidad de Plymouth (http://vortex.plymouth.edu/uacalplt-u.html)

\begin{tabular}{|c|c|c|c|}
\hline Indicativo & Nombre & Latitud () & Longitud () \\
\hline 08001 & A Coruña & 43,36 & $-8,41$ \\
\hline 08495 & Gibraltar & 36,15 & $-5,35$ \\
\hline 08221 & Madrid & 40,50 & $-3,58$ \\
\hline 08023 & Santander & 43,48 & $-3,80$ \\
\hline 08160 & Zaragoza & 41,66 & $-1,01$ \\
\hline 08302 & Palma & 39,61 & 2,71 \\
\hline 08430 & Murcia & 38,00 & $-1,16$ \\
\hline 07645 & Nimes & 43,86 & 4,40 \\
\hline 60018 & Tenerife & 28,47 & $-16,38$ \\
\hline 07761 & Ajaccio & 41,91 & 8,80 \\
\hline 07510 & Burdeos & 44,83 & $-0,68$ \\
\hline 60155 & Casablanca & 33,53 & $-7,58$ \\
\hline 08579 & Lisboa & 38,76 & $-9,13$ \\
\hline 08190 & Barcelona & 41,62 & 2,20 \\
\hline 60390 & Dar el Beida & 36,68 & 3,21 \\
\hline \multicolumn{3}{|c|}{ Tabla III.1: Sondeos utilizados } \\
\hline
\end{tabular}

\begin{tabular}{|c|c|}
\hline Acrónimo & Nombre y unidades \\
\hline PW & Agua precipitable (mm) \\
\hline LCL & Nivel de condensación por ascenso (m) \\
\hline $\mathrm{CCL}$ & Nivel de condensación convectivo (m) \\
\hline LFC & Nivel de convección libre $(\mathrm{m})$ \\
\hline EL & Nivel de equilibrio \\
\hline 700_500LR & gradiente térmico vertical entre 700 y $500 \mathrm{mb}$. ( $\left.{ }^{\circ} \mathrm{C} / \mathrm{km}\right)$ \\
\hline MMR & proporción de mezcla en capas bajas ( $\mathrm{g} / \mathrm{kg}$ ) \\
\hline $\mathrm{LI}$ & Lifted Index en 500 mb (ㅇ C) \\
\hline LI7 & Lifted Index en 700 mb (ㅇ C) \\
\hline CAPE & Energía potencial convectiva disponible (J/kg) \\
\hline SM_DDD & Dirección de movimiento de la tormenta $(\stackrel{\circ}{)})$ \\
\hline SM_FF & Intensidad de movimiento de la tormenta (kt) \\
\hline CIZ_0_3000 & Cizalladura en los 3 primeros kilómetros $\left(10^{-3} \mathrm{~s}^{-1}\right)$ \\
\hline SRH_0_3000 & Valor absoluto de la Helicidad relativa a la tormenta en los tres primeros kilómetros $\left(\mathrm{m}^{2} / \mathrm{s}^{2}\right)$. \\
\hline $\mathrm{EHI}$ & Índice de Helicidad Energía (adimensional) \\
\hline BRN & Número de Richardson global (adimensional) \\
\hline ISOC & Isocero $(\mathrm{m})$ \\
\hline $\mathrm{TI}$ & Indice ThetaE (o C) \\
\hline SI & Índice de Showalter ( $(0$ C) \\
\hline TT & Índice total de totales ( $\left.{ }^{\circ} \mathrm{C}\right)$ \\
\hline $\mathrm{K}$ & Índice K (adimensional) \\
\hline Z925 & geopotencial en $925(\mathrm{~m})$ \\
\hline
\end{tabular}

Tabla III.2: Parámetros de sondeos utilizados en la estadística 
A todo lo anterior hay que hacer una puntualización importante. El parámetro cizalladura (CIZ_0_3000) en este caso es calculado tomando los vectores de viento con incrementos verticales de $500 \mathrm{~m}$ desde la superficie hasta $3000 \mathrm{~m}$ por encima de la superficie. Las diferencias en las componentes de viento ( $u, v)$ de cada capa se van añadiendo sucesivamente hasta llegar hasta arriba. Se tienen en cuenta los valores positivos y negativos (para sumar y restar). Finalmente se obtiene un valor acumulado de $u$ y de $v$, que se transforma $a\left(u^{\wedge} 2+v^{\wedge} 2\right)^{1 / 2}$ y este valor resultante se divide por la altura vertical que en este caso es de $3000 \mathrm{~m}$. Este método es distinto al usado operativamente en otras instancias, y como consecuencia los valores que aquí se presentan serán comparativamente en general bastante inferiores a los usuales obtenidos en otros ámbitos. No obstante las comparaciones relativas entre unos días y otros del valor aquí calculado para la cizalladura, tienen plena vigencia interna.

Con los datos de cada sondeo se han elaborado estadísticas básicas de cada parámetro, como mínimo, máximo, medias (figura III.1.1), percentiles y desviación típica, tanto para cada mes como para el periodo completo, tanto a 0 como a 12 UTC y a ambas horas.

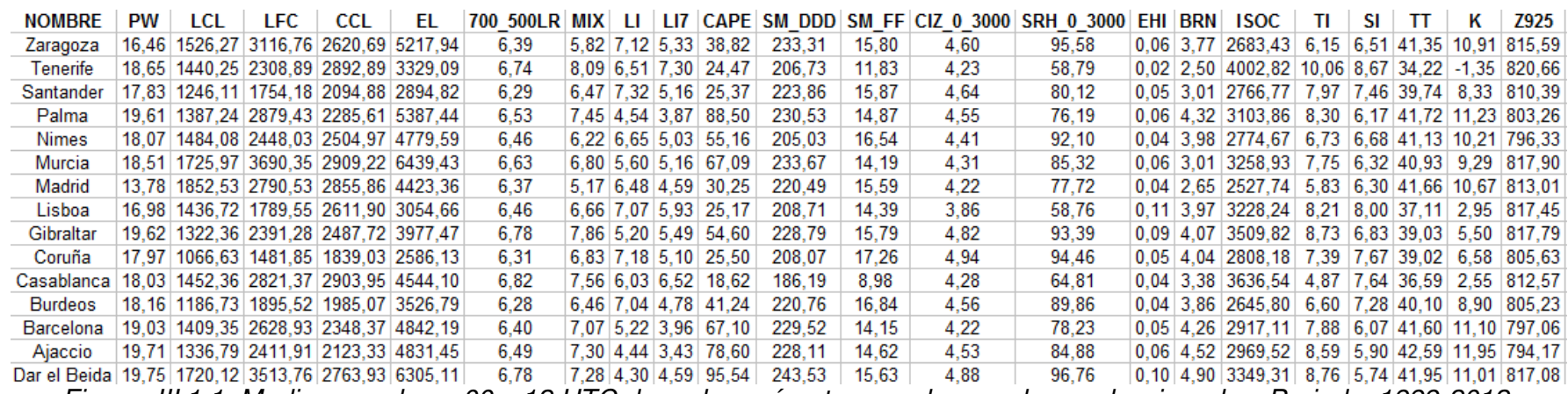

Figura III.1.1: Medias anuales a 00 y 12 UTC de cada parámetro para los sondeos seleccionados. Periodo: 1999-2012.

También se han generado gráficos de dispersión Box-Plot para cada variable (figura III.1.2).

\section{Estadisticas LI 1999-2012}

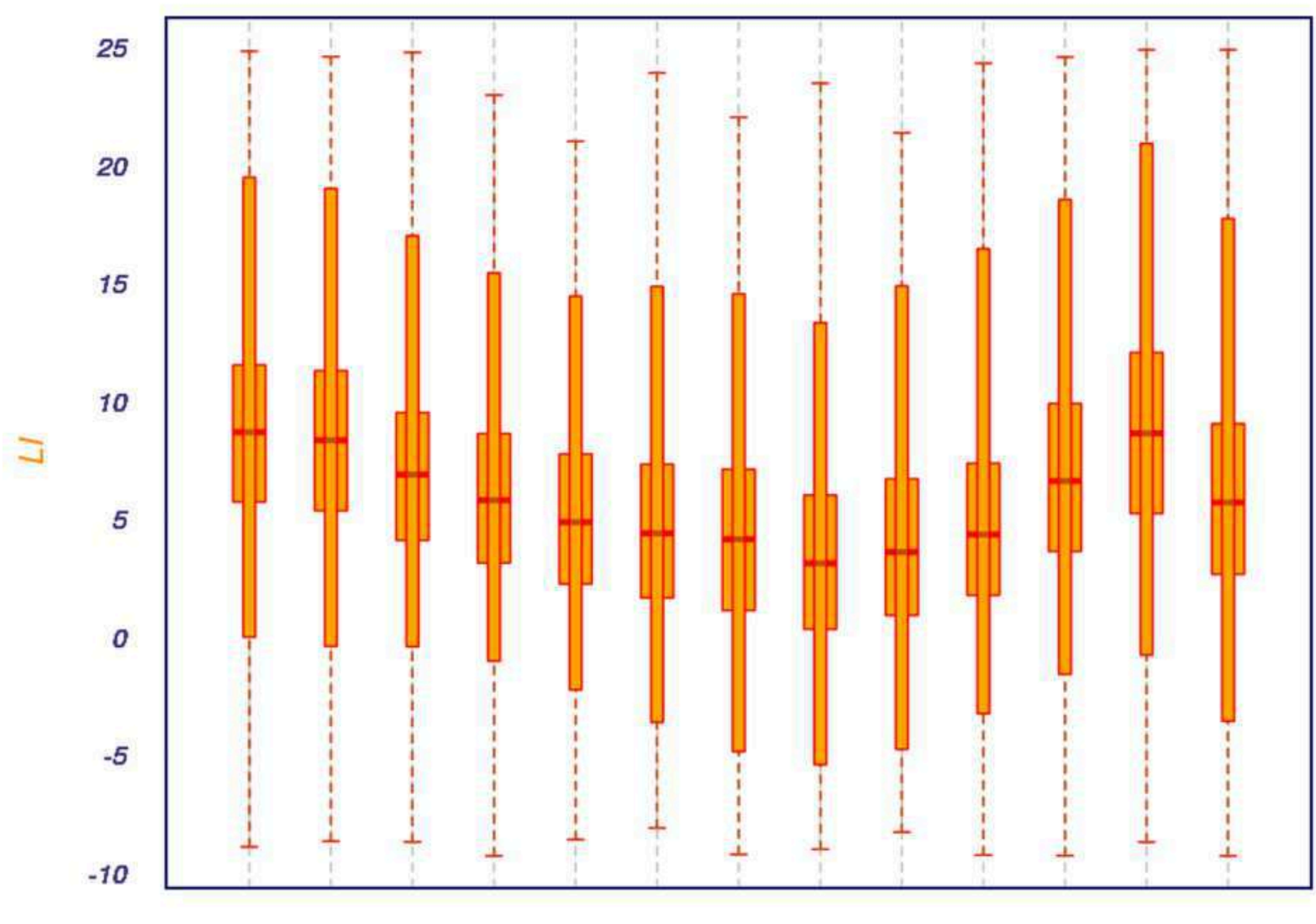

$\begin{array}{llllllllllll}1 & 2 & 3 & 4 & 5 & 6 & 7 & 8 & 9 & 10 & 11 & 12\end{array}$

Figura III.1.2: Medias mensuales y anuales a 00 y 12 UTC del índice LI, usando los sondeos disponibles. Periodo: $1999-2012$ 
Y aparte se dispone de mapas de distribución espacial de valores medios (anuales y mensuales, a 0 y 12 UTC) de los parámetros calculados en los puntos de sondeo (figura III.1.3)

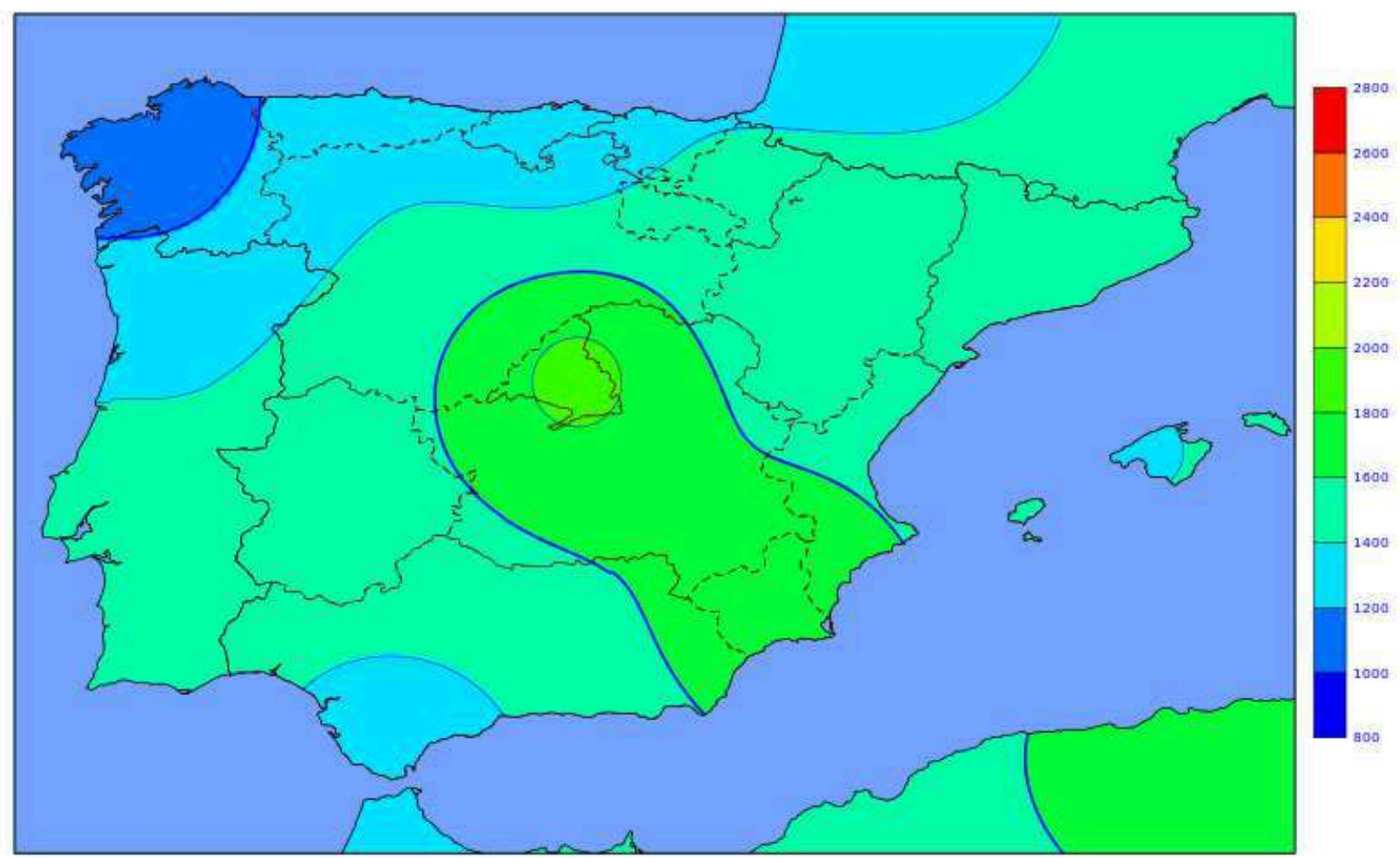

Figura III.1.3: Mapa medio anual a 00 y 12 UTC del parámetro LCL, usando los sondeos disponibles. Periodo: $1999-2012$

\section{III.2.- Sondeos próximos y parámetros relevantes en casos de tornado}

Tanto a nivel global como europeo, para el uso de campos o parámetros de interés en situaciones de tornado se han empleado reanálisis de modelos globales y datos procedentes de sondeos "próximos". Referencias destacables pueden considerarse las de Romero et al. (2007) y Brooks et al. (2003).

En cuanto a trabajos relacionados con los parámetros clave en relación con la presencia de tornados se pueden citar el de Rasmussen et al. (1998), Craven et al. (2002) y Thomson et al. (2002). No obstante el problema recurrente es que en casi todos los estudios americanos se tratan exclusivamente los tornados significativos (iguales o de superior intensidad a EF2), los cuales son poco frecuentes en España.

Para considerar suficientemente representativo (o próximo) un sondeo del entorno meteorológico donde se ha desarrollado un tornado, se considerará aquí un criterio intermedio entre algunos de los que se recogen en Craven and Brooks (2004). Se ha usado un filtro que permite recoger datos de parámetros del sondeo más próximo siempre que su emplazamiento esté localizado a menos de $200 \mathrm{~km}$ y en las 3 horas anteriores o posteriores a la ocurrencia del tornado cuya hora registrada haya tenido una precisión adecuada en la base de datos (nunca superior a 120 minutos). La muestra bajo esta restricción adicional impuesta queda finalmente relegada a un total de $\mathbf{8 6}$ tornados con sus respectivos "sondeos próximos" asociados. 


\section{III.2.1.- Parámetros relevantes: percentiles}

En primer lugar debemos asociar a cada tornado de la muestra final disponible (86 casos), los parámetros asociados a su sondeo próximo.

Posteriormente podemos comparar la distribución estadística de cada uno de los parámetros del sondeo "próximo" de cada tornado disponible, calculada anteriormente (figura III.1.1), con la distribución estadística de los parámetros de los sondeos en todo el periodo (1999-2012) de datos diarios de observaciones (a 0 y 12 UTC).

Una posibilidad es ver qué valor percentil toma cada parámetro del sondeo próximo de cada tornado respecto a la distribución de ese parámetro en el periodo global de referencia de los sondeos. De esta manera para cada tornado y parámetro obtendremos un percentil respecto a la distribución estadística de ese parámetro en el periodo de referencia.

O sea de cada parámetro considerado tendremos un percentil para cada tornado respecto al periodo de referencia (1999-2012), indicando de esta manera el comportamiento de este parámetro en cada día de tornado. Si el percentil de un parámetro en día de tornado es alto o bajo, significará que este parámetro está comportándose de manera anómala.

Finalmente dispondremos de 86 valores percentiles para cada parámetro en día de tornado que nos indicarán la mayor o menor anomalía en el comportamiento respecto al periodo de referencia (1999-2012). Para poder comparar unos parámetros con otros se define el "percentil representativo" de cada parámetro en día de tornado como la mediana del conjunto de los 86 percentiles de ese parámetro en los respectivos casos de tornado.

Precisamente de esta manera habremos conseguido identificar los parámetros de mayor interés, que serán aquéllos cuyos "percentiles representativos" sean muy altos o muy bajos en la muestra de días de tornado respecto al periodo total de días del periodo de años de la estadística de los sondeos. Estos parámetros de interés serán por tanto los que se comporten de una manera rara en días de tornado, respecto a lo habitual en el periodo considerado. Éste es un método análogo al seguido por Romero et al. (2007) para tornados significativos en Europa.

\section{a) Muestra de todos los "tornados próximos"}

En la figura III.2.1 se muestran los "percentiles representativos" de cada uno de los parámetros de los sondeos próximos en los casos de días de tornado (86), respecto a los valores del periodo de referencia climatológica disponible (1999 a 2012).

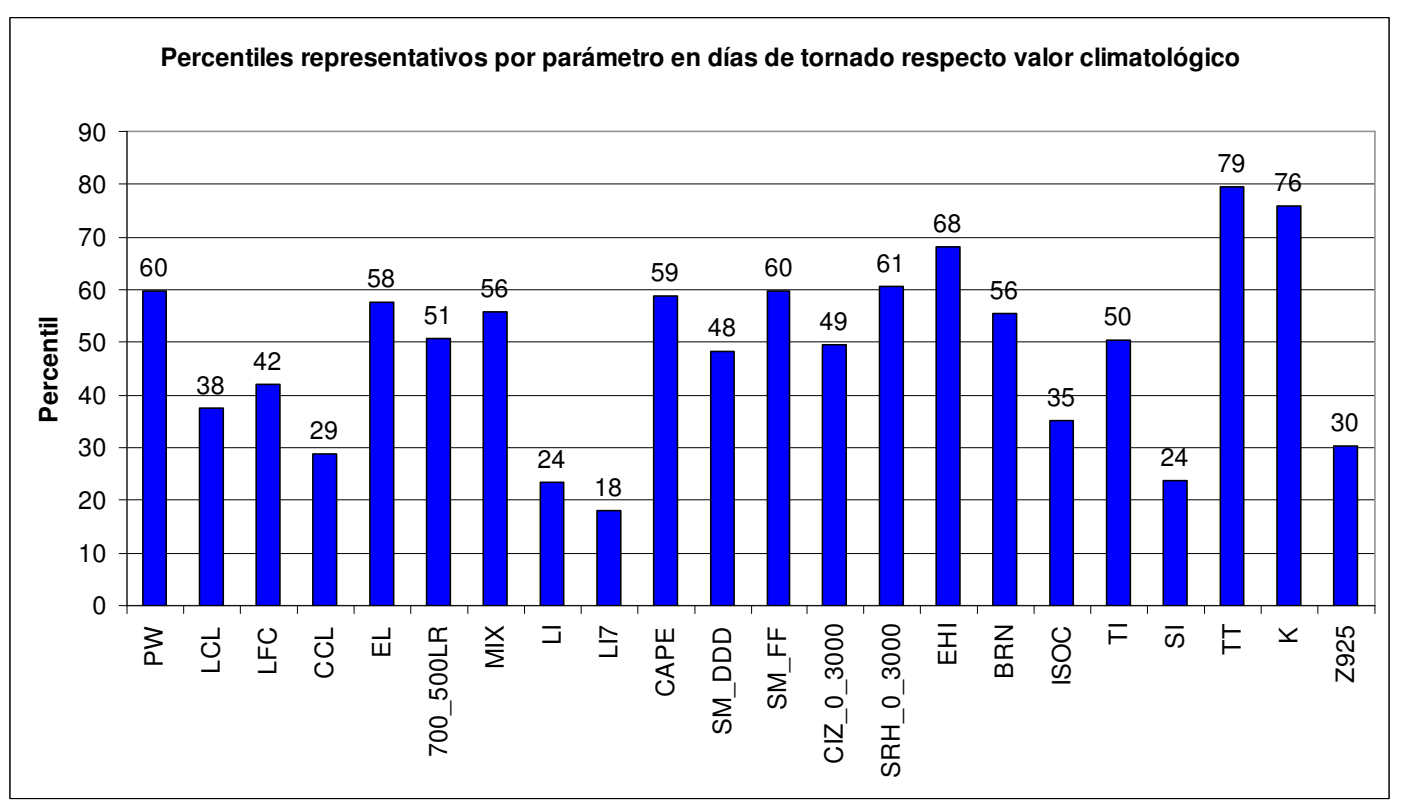

Figura III.2.1: Percentiles representativos de los parámetros de sondeos "próximos" durante los días de tornado, para la muestra seleccionada de 86 tornados. 
Debemos pues considerar los parámetros cuyo comportamiento es "raro" en los días de tornado, o sea los que tengan más altos o más bajos valores de los percentiles representativos, de forma nos permitan discriminar mejor la posible ocurrencia de tornados. Tomando en consideración la figura II.2.1, podemos seleccionar los siguientes índices:

- Parámetros con percentiles altos: EHI, TT, K

- Parámetros con percentiles bajos: LI, LI7, SI, CCL, Z925

Por tanto entre las situaciones de tornado, en general mayoritariamente nos encontramos con destacables valores de índices de inestabilidad clásicos (TT, K, LI, LI7, SI), con un elevado valor del índice de HelicidadEnergia (EHI), con baja altitud del nivel de condensación convectivo y con entornos de bajas presiones en niveles bajos (relativamente pequeños valores del geopotencial en 925 mb, Z925).

\section{b) Muestra de los "tornados próximos de categoría EF2"}

Si hacemos lo mismo que lo realizado anteriormente, pero sólo con los 3 tornados EF2 con "sondeos próximos", y obtenemos los percentiles representativos (figura III.2.2), comprobamos ahora que estos valores para algunos índices toman valores más extremos (altos o bajos) que en el caso de todos los "tornados próximos". Lógicamente por tanto su caracterización es más fácil pero por el contrario los tornados de categoría EF2 suponen una parte muy reducida del total de tornados en España.

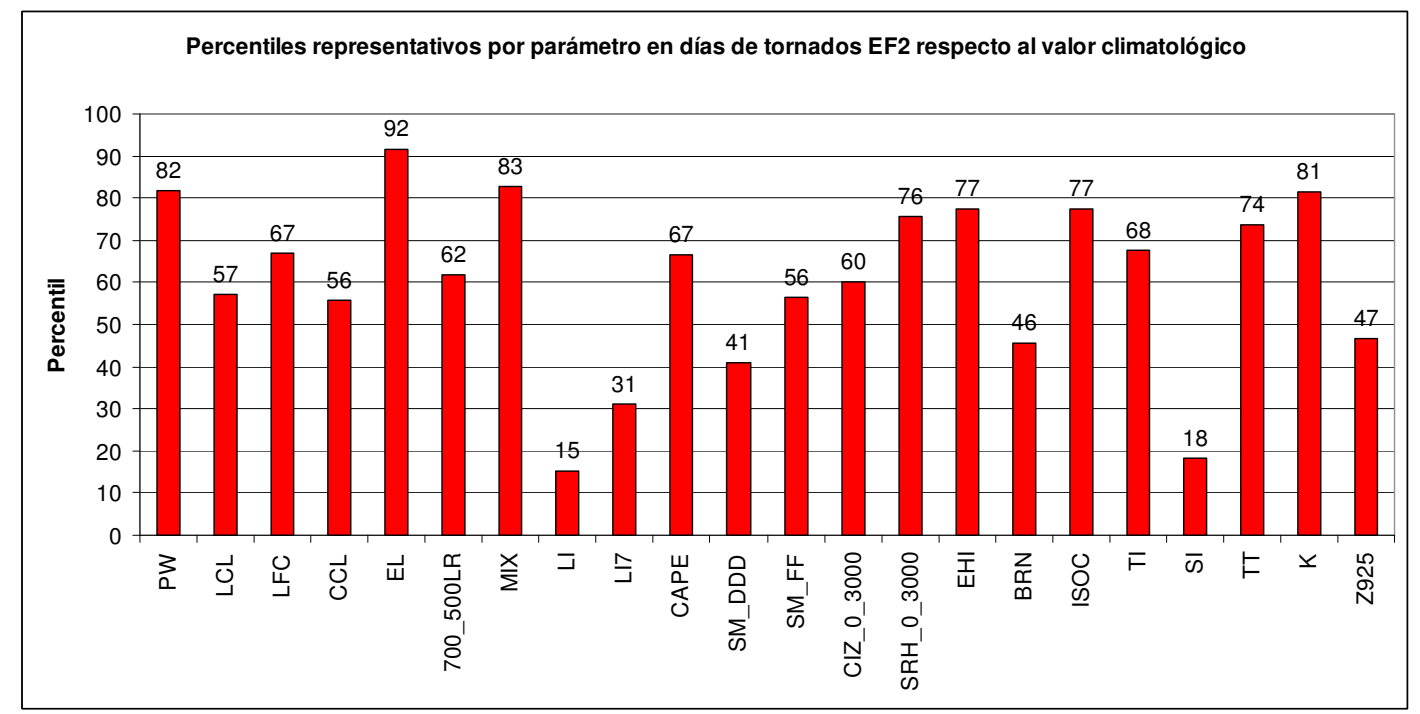

Figura III.2.2: Percentiles representativos de los parámetros de sondeos "próximos" durante los días de tornado, para los 3 tornados de categoría EF2 de la muestra seleccionada.

En estos casos también aparecen y de manera más acusada, elevados valores de los percentiles de los índices de inestabilidad y Helicidad-Energía. Pero además tienen valores significativamente altos de "percentiles representativos" otros parámetros como el PW, MIX, SRH_0_3000, CIZ_0_3000 y EL.

O sea que los tornados EF2 presentarían en general (aun con la salvedad de lo pequeña que es la muestra) convección profunda, con elevados valores de cantidad de agua precipitable y proporción de mezcla en niveles bajos y entornos ricos en cizalladura vertical y helicidad relativa a la tormenta en los primeros tres kilómetros. Precisamente muchos trabajos a nivel mundial (en Estados Unidos, Europa, etc), ponen de relieve estos valores elevados para estos parámetros citados en entornos meteorológicos de tornados significativos (EF2 o superiores).

\section{III.2.2.- Dispersión de los parámetros: periodo total vs días de tornado.}

A continuación se presentan los gráficos comparados de dispersión de algunas variables (formato "Box Plot") para los datos de la muestra de los 86 tornados y toda la climatología con datos diarios en el periodo 1999-2012.

Lógicamente nos interesan los parámetros que presentan en días de tornado distinto comportamiento de la climatología, y por tanto con gráficos de dispersión diferentes (desplazados), de forma que discriminen los tornados según su clasificación de la escala de Fujita. A continuación se presentan los tres de los más significativos en este sentido: LI, LI7 y EHI (figura III.2.3). 


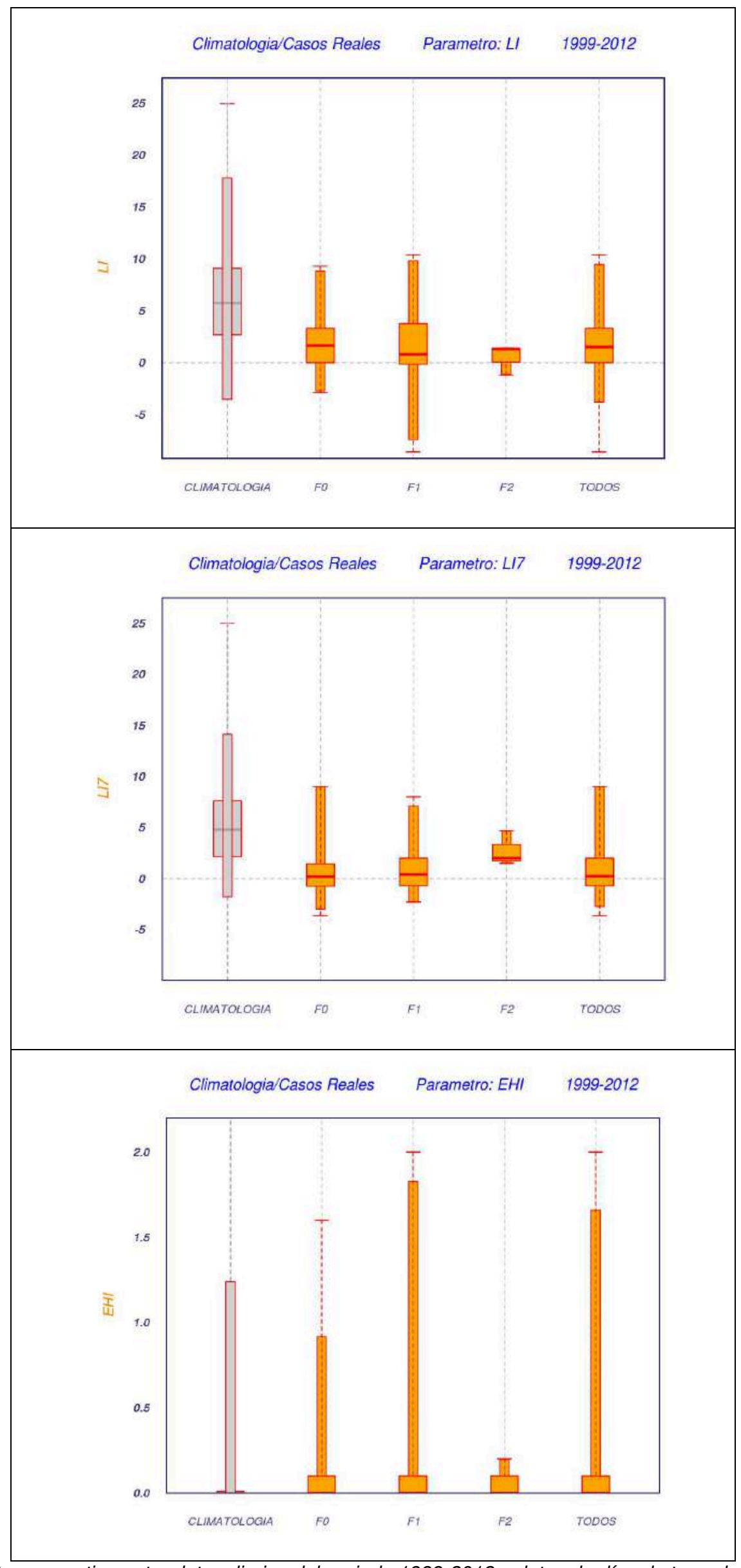

Figura III.2.3: Boxplot comparativo entre datos diarios del periodo 1999-2012 y datos de días de tornados con sondeo próximo, para las variables $\mathrm{LI}, \mathrm{LI}$ y $\mathrm{EHI}$ 


\section{III.2.3.- Gráficos significativos de distribución bivariante de parámetros clave}

En este apartado se presentan algunos gráficos bivariantes representativos de los días de tornado, mostrando dos variables significativas en cada caso, a partir de los datos de cada sondeo "próximo".

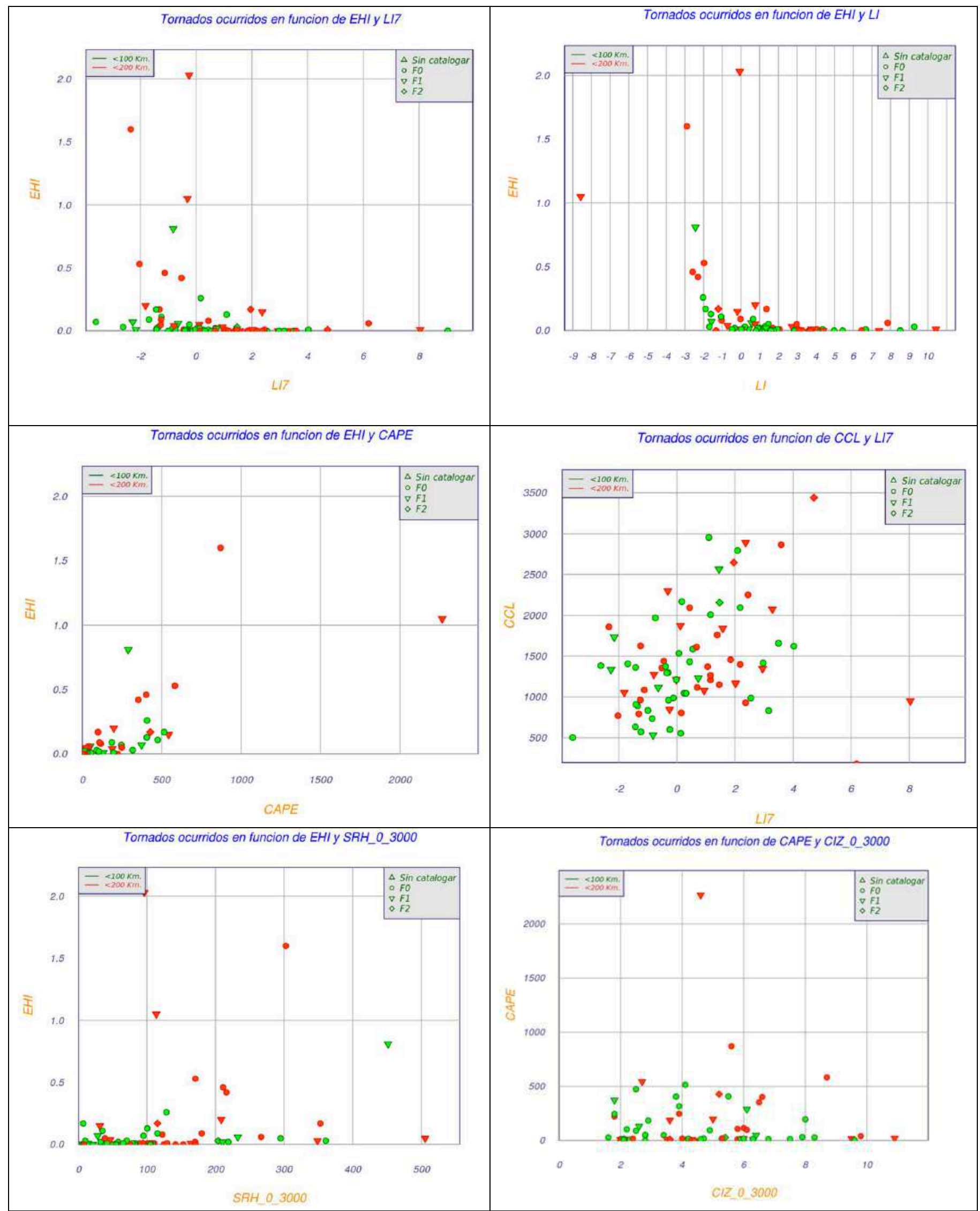

Figura III.2.4: Varios gráficos bivariantes de interés en los días de tornados. Datos obtenidos de "sondeos próximos". Se han obtenido representaciones para distintas combinaciones entre dos parámetros de los de interés. 
En la figura III.2.5. se muestran las combinaciones en general de mayor interés. Por una parte LI frente a LI7 muestra que en general que la mayoría de tornados se producen con inestabilidad acusada o ligera (con LI ó LI7 inferiores a 2). También se muestra que en general hay una parte de tornados significativa que presentan valores de CIZ_0_3000 superiores a 4 y valores de SRH_0_3000 mayores de 100.

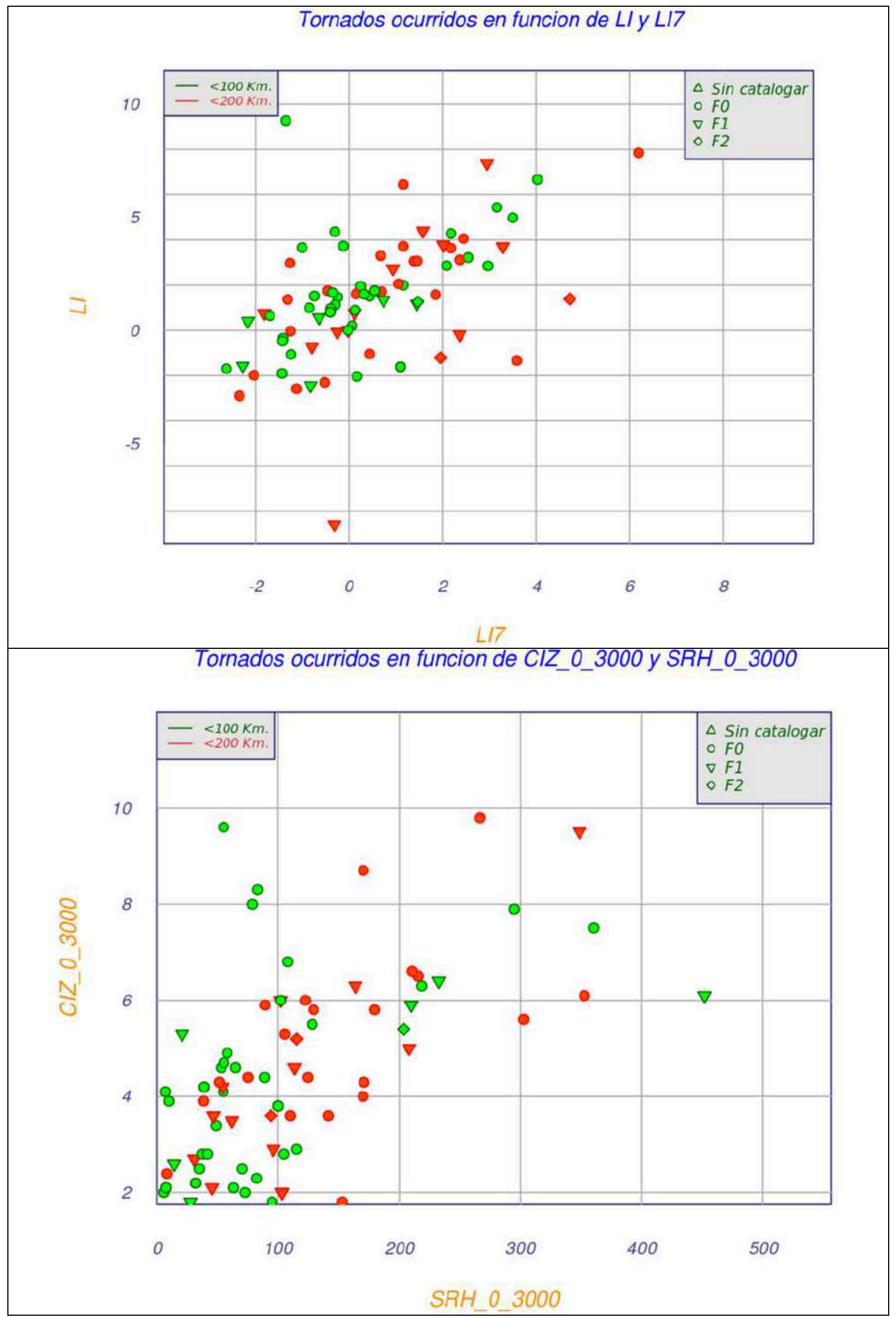

Figura II.2.5: Gráficos bivariantes en días de tornado (a partir de sondeos "próximos"). Arriba: LI vs LI7. Abajo: CIZ_0_3000 vs SRH_0_3000. 


\section{III.3.- Densidad mejorada de tornados}

\section{III.3.1.- Objetivo}

La generación de tornados implica la existencia de entornos atmosféricos ricos en inestabilidad (al menos ligera), cizalladura y helicidad relativa a la tormenta en los primeros tres kilómetros desde superficie, aparte de humedad destacable en niveles bajos.

Como hemos visto previamente, cuanto más intensos son los tornados, más señal ofrecen determinados parámetros meteorológicos. De ahí que la caracterización de los tornados "significativos" (de categoría EF2 ó superior) sea más sencilla que los de categoría "débil" (EF0 y EF1).

El problema es que en España hay muy pocos tornados "significativos", y por tanto su caracterización y predicción resulta más difícil que en países como Estados Unidos donde hay gran cantidad de tornados intensos.

A continuación se intentará ajustar y calibrar mejor el mapa de densidad de tornados observados (a partir de la base de datos de tornados del periodo 2003-2012), mediante información indirecta, de modo que aquél presente una información más coherente y realista.

\section{III.3.2.- Mapa mejorado de densidad de tornados}

En la generación del mapa mejorado de tornados se han realizado una serie de ajustes al mapa de tornados observados mostrado en el capítulo anterior, a partir de un sistema de información geográfica, de modo que se reduzcan las limitaciones presentes en aquél. A continuación se describe brevemente la metodología utilizada.

Como el número de variables empleado para elaborar el mapa de densidad es bajo (224 tornados o trombas en 10 años y en una superficie de algo menos de $500.000 \mathrm{~km}^{2}$ ), el resultado del mapa de densidad ofrece una idea de las zonas de mayor concentración de estos fenómenos, pero no es totalmente satisfactorio, por lo que es necesario para obtener un mapa mejorado, emplear técnicas geoestadísticas de interpolación Kriging con un modelo de tendencia o deriva externa

Las variables auxiliares que se han empleado para construir la rejilla que se va a aplicar al fichero de densidad observada están extraídas fundamentalmente de los datos de los radiosondeos de España, Portugal, sur de Francia y norte de África. En total 15 puntos de observación: Zaragoza, Tenerife, Santander, Palma, Nimes, Murcia, Madrid, Lisboa, Gibraltar, La Coruña, Casablanca, Burdeos Barcelona, Ajaccio y Dar el Beida.

Con los datos de estos radiosondeos se ha identificado para cada punto cuales eran las condiciones medias bajo las cuales se producía un tornado o tromba marina en los alrededores. Así, se han obtenido valores de distintos índices en cada punto de sondeo favorable para la génesis de un tornado: PW, LCL, LFC, CCL, EL, 700_500LR, MIX, LI, LI7, CAPE, CIZ_0_3000, SRH_0_3000, EHI, ISOC, TT y K.

Este conjunto de índices finalmente ha sido reducido a 2, que son los que mejor correlación estadística ofrecían. Estos 2 índices son, ClZ_0_3000, que es la cizalladura del viento medio en los primeros $3000 \mathrm{~m}$, y que guarda una relación logarítmica con la densidad de tornados observada, lo que resulta coherente con el modelo conceptual de la convección severa, que indica que valores muy altos de cizalladura vertical del viento puede ser un factor limitador tanto de la intensidad como de la organización de la convección, y la helicidad relativa a la tormenta SRH_0_3000, que es una medida de la componente horizontal de vorticidad paralela al flujo que alimenta la tormenta calculada para los 3 primeros kilómetros del sondeo. Tampoco la helicidad presenta una correlación lineal con la densidad de tornados observada y el mejor ajuste se obtiene con la raíz cuadrada del índice.

La distribución de los tornados observados también presenta una buena correlación con índices relacionados con la continentalidad, como la distancia al mar o la altitud y también de forma logarítmica, de forma que el mejor ajuste se ha obtenido con el logaritmo natural del producto de la altitud por la distancia al mar de cada punto.

Con todos estos índices se han construido dos rejillas, una la de la densidad real de tornados observados y otra construida con los índices de inestabilidad y continentalidad que ha servido como variable auxiliar de deriva externa. Al aplicar la función Kriging, la deriva externa nos está sirviendo para hacer una suavización del campo densidad de tornados, aunque al final este campo original es el que más peso tiene a la hora de hacer la representación espacial. 
Surge así finalmente la figura III.3.1, que contiene el mapa de densidad mejorada de tornados (tornados terrestres y trombas marinas), en una rejilla de $0,5^{\circ} \times 0.5^{\circ}$ (o sea con celdillas de unos $55 \mathrm{~km}$ de lado, aproximadamente). Por mucho que se haya intentado realizar una mejora de la densidad estrictamente observada, los valores que aparecen en el mapa mejorado también deben ser entendidos como una aproximación a la realidad. En ningún caso pueden interpretarse de forma estrictamente cuantitativa, pues la fuente inicial de datos de tornados observados (muestra disponible en AEMET para el periodo 2003-2012) es incompleta y aproximada como ya se ha comentado con antelación, debido a las características inherentes a la dificultosa disponibilidad de datos procedentes del avistamiento y detección de tornados.

No obstante, uno de los principales usos del mapa es el de la discriminación entre distintas zonas con diferentes impactos en cuanto a la frecuencia estimada de tornados.

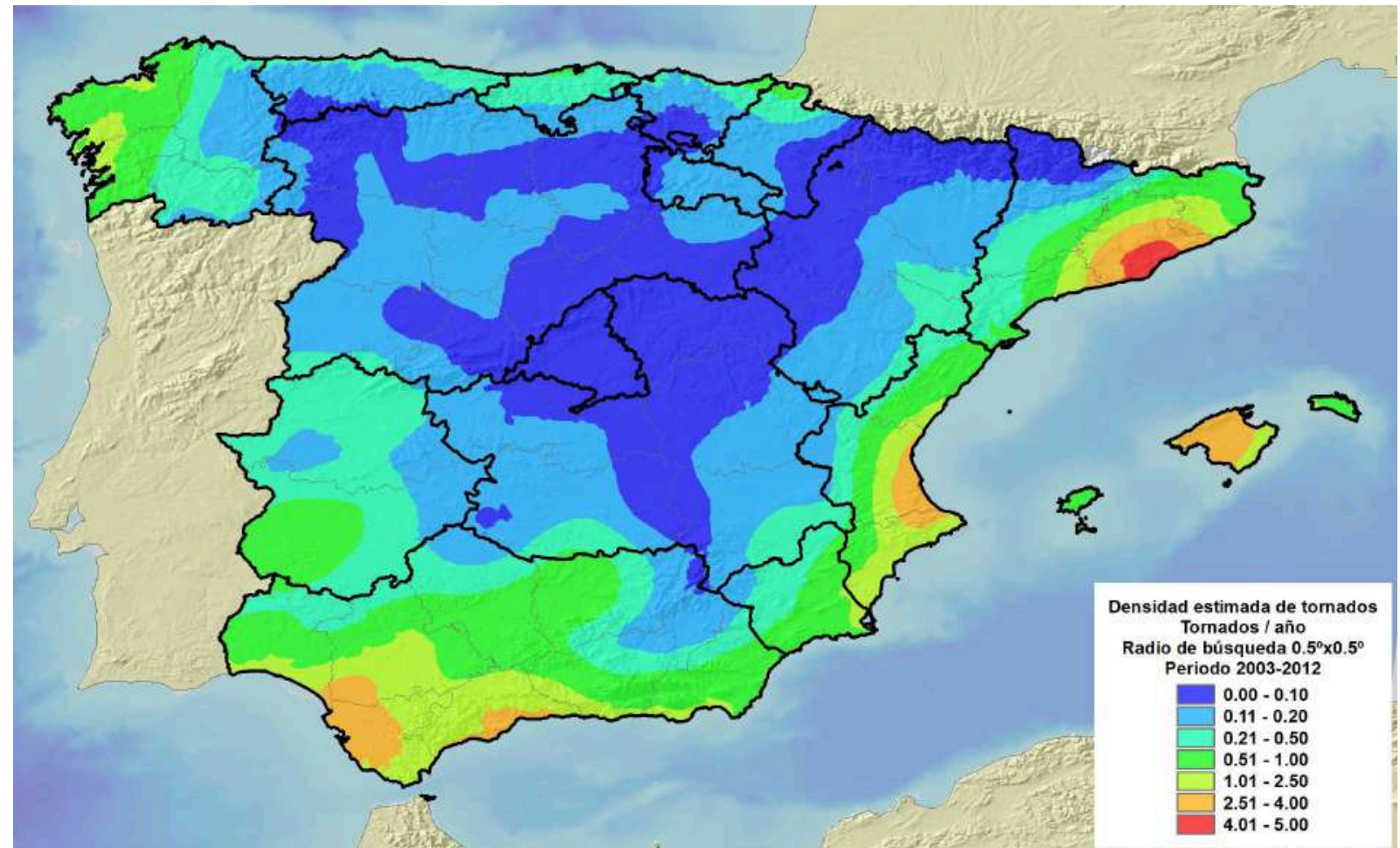

Figura III.3.1: Mapa mejorado de densidad anual de tornados en España (Península y Baleares), en una rejilla de 0,5ํ de lado.

El mapa evidencia la gran variabilidad que presenta la frecuencia de tornados entre unas zonas y otras, aunque prácticamente todas las Comunidades Autónomas han sufrido algún tornado durante el periodo de estudio (2003-2012). Sin embargo parece que la representación espacial todavía presenta limitaciones en cuanto a la posible sobrevaloración de la densidad de tornados en zonas altamente pobladas, y por el contrario una infravaloración en áreas inhóspitas, todo ello debido a la mayor y menor cantidad de fuentes de información disponible de reportes de tornados. En cualquier caso, y a pesar de algunas carencias, el mapa debe responder en gran medida a la existencia de una conjunción de valores adecuados de inestabilidad, cizalladura y helicidad, junto con una orografía apropiada que maximice los valores de dichas variables.

Grosso modo, la densidad anual de tornados en la mencionada rejilla de $0.5^{\circ} \times 0.5^{\circ}$ posee los valores más elevados en la costa Mediterránea y los mínimos en áreas del centro Peninsular.

Destaca el máximo anual de la costa de Barcelona (entre 4 y 5 tornados al año en la rejilla considerada), seguido de Mallorca y las costas de las provincias de Valencia, Málaga y Cádiz (entre 2,5 y 4 tornados al año). Se trata de provincias marítimas a cuya frecuencia han contribuido tanto los tornados terrestres como las trombas marinas. Además el mar Mediterráneo juega un importante papel inestabilizador de la atmósfera, que es uno de los factores tornadogenéticos, aunque obviamente acompañado de otros.

Por el contrario los valores mínimos se centran en puntos de las dos Castillas, Madrid, y algunas áreas de Aragón y País Vasco (entre 0 y 0,1 tornados al año).

Frecuencias intermedias se encuentran en el interior de Andalucía, zona costera de la Región de Murcia, interior de la Comunidad Valenciana y de Cataluña, áreas de Badajoz y Rías Gallegas.

Un hecho importante a tener en cuenta, a partir del mapa anterior, es que si dividimos el número anual de tornados en cada rejilla entre el número de días del año, dispondremos de la probabilidad básica estimada de que en un día aparezca un tornado en cada celda considerada. 


\section{III.3.3.- Zonificación del riesgo}

Como se ha indicado, los tornados en España son fenómenos no demasiado frecuentes y como se deduce de la estadística por categoría de tornados según la escala de Fujita realzada, en general su intensidad es "baja", ya que una gran mayoría son EF0 ó EF1.

En función del mapa mejorado de densidad de tornados, también se ha trazado una zona de riesgo con 5 categorías diferentes, aunque hay que hacer la precisión que no significa que la zona de riesgo muy alto tenga unas probabilidades muy altas de verse afectada por un tornado o tromba, sino que se refiere a que es una zona de alto riesgo relativo, en comparación con otras zonas a partir de la información directa e indirecta disponibles.

Surge así el mapa de riesgo "relativo" o zonificación categórica de la densidad de tornados (figura III.3.2), que pretende diferenciar zonas de diferente frecuencia o riesgo de tornados. Se han establecido finalmente 5 categorías de riesgo "relativo" en función de la frecuencia estimada de tornados: muy bajo, bajo a muy bajo, bajo, bajo a moderado y moderado.

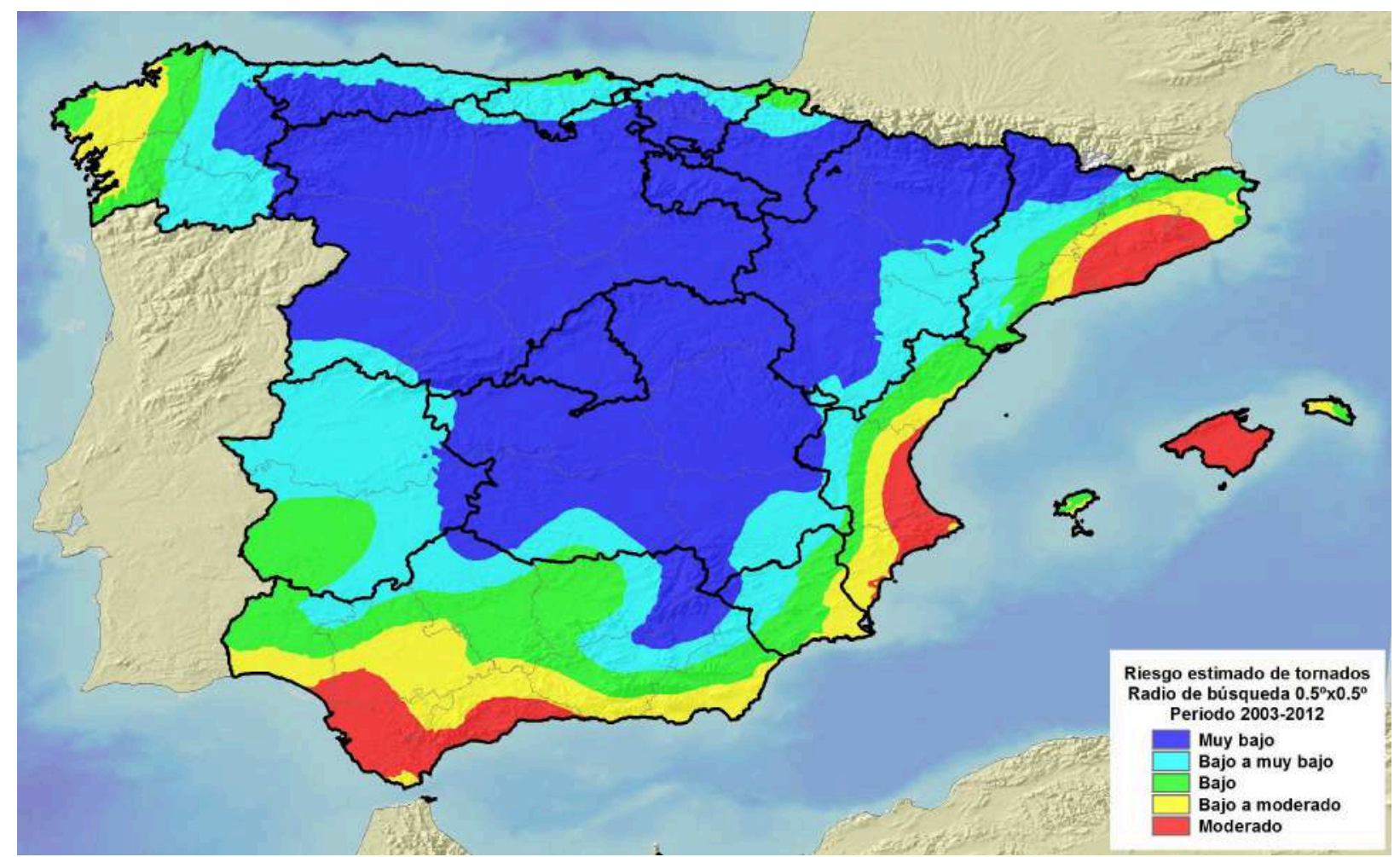

Figura III.3.2: Mapa de riesgo "relativo" de tornados según 5 categorías. Explicación en el texto. 


\section{IV.- CARACTERIZACIÓN METEOROLÓGICA DE LAS SITUACIONES GENERADORAS DE TORNADOS}

\section{IV.1.- Introducción}

En la España Peninsular y Baleares, la convección presenta una variabilidad regional y estacional muy acusadas. Existe un máximo de actividad convectiva general en primavera y verano, más notable en el interior. En las costas Mediterráneas el máximo se desplaza al otoño. Por otro lado existe un máximo secundario en invierno, que llega a ser máximo absoluto en los litorales Atlántico y Cantábrico, y relativo en el Valle del Guadalquivir. Las tormentas de verano suelen producirse en entornos de baja cizalladura y relativamente elevada inestabilidad, siguiendo el ciclo diurno de temperaturas. En otoño la convección Mediterránea suele ir asociada a depresiones aisladas de niveles altos que producen ambientes de moderada cizalladura vertical y una inestabilidad apoyada en gran medida en una elevada temperatura de la superficie del agua del mar.

Los tornados en la Península y Baleares son mayoritariamente de categorías EF0 y EF1 según la escala Fujita Realzada, siendo por tanto no significativos según la terminología norteamericana. Una importante parte de los tornados son realmente trombas marinas ("waterspouts"), casi todas de categoría EF0 que tienen su ciclo de vida sobre el mar aunque en algunos casos pueden afectar al litoral. Aunque hay distintas formas de generación de tornados, todos tienen en común que se desarrollan en un entorno meteorológico de al menos cierta inestabilidad y además rico en helicidad y cizalladura del viento. También es importante especificar que se excluyen explícitamente de la categoría de tornados en este trabajo, los vórtices de racha ("gustnados").

Dicho lo anterior, y sin entrar en detalles, nos encontramos en general en el mundo con dos tipos de tornados según su genealogía:

- Tornados no mesociclónicos. Parecen los más frecuentes a nivel mundial. Incluyen los tornados no supercelulares y aquellos supercelulares no mesociclónicos.

- Tornados mesociclónicos. Se producen en la fase de colapso del mesociclón de una supercélula (o minisupercélula).

Respecto a su distribución espacial y estacional, los tornados se pueden encuadrar mayoritariamente en alguno de estos tipos.

- Invernales (vertiente Atlántica y Mar de Alborán),

- De primavera-verano (interior de la Península) y

- De otoño o finales de verano (Mar Mediterráneo y Mar de Alborán).

Para la caracterización de las situaciones meteorológicas que dan a lugar a tornados en la Península y Baleares, se han estudiado los marcos meteorológicos sinóptico y mesoescalar de un número suficientemente significativo de casos disponibles en la base de datos de tornados, llegándose a la conclusión de que se pueden agrupar en tres clases.

- Tornados de la vertiente Atlántica (en situaciones preferentemente de invierno y otoño)

- Borrascas centradas al sur del paralelo $45^{\circ} \mathrm{N}$ con fuerte flujo del suroeste.

- Otras situaciones Atlánticas.

- Tornados de primavera-verano (fundamentalmente en el interior Peninsular)

Caracterizados por la presencia de una depresión térmica en superficie y paso de un embolsamiento frío en altura, o la rama delantera de una vaguada, o un vórtice mesoescalar, o la existencia de una línea de deformación en las proximidades. Combinación de forzamiento térmico, orográfico y dinámico.

- Tornados de la vertiente Mediterránea (frecuentemente a finales de verano y durante el otoño).

Asociados a vaguadas en altura, o depresiones aisladas o la transición de las primeras a las segundas. Son situaciones sinópticas con chorro de cierta amplitud (meandros) y con flujo de levante en capas bajas, que provocan gran inestabilidad en el Mediterráneo Occidental y Mar de Alborán.

El espectro de situaciones es continuo. Algunas situaciones Atlánticas enlazan con episodios de verano en lo que se refiere a la inestabilidad, auque la cizalladura en capas bajas siempre es mayor. Hay situaciones de verano que también lo son de la vertiente Mediterránea, pudiéndose observar tornados simultáneamente en el interior de la Península y en el área Mediterránea. 


\section{IV.2 Tornados de la vertiente Atlántica}

En España son relativamente frecuentes los tornados invernales, particularmente en la vertiente Atlántica, y sobre todo cerca del litoral del Golfo de Cádiz, Estrecho y, en menor medida, Galicia. En otras zonas del mundo con características climáticas similares, como California o el sur de Australia, se da la misma circunstancia.

Las situaciones sinópticas en que se producen tornados suelen estar asociadas a profundas borrascas Atlánticas que pueden tener reflejo en todos los niveles de la troposfera. Estas estructuras sinópticas proporcionan condiciones favorables para la ocurrencia de tornados. En ocasiones producen condiciones de inestabilidad débil y valores destacables de cizalladura, condiciones similares, por ejemplo, a las que provocan tornados en bandas exteriores de ciclones tropicales. A veces las condiciones de cizalladura y flotabilidad conducen a la aparición de sistemas convectivos cuasilineales capaces también de generar tornados. Otras veces, el aire frío en altura produce grandes diferencias térmicas entre la superficie (particularmente la marina) y niveles medios de la troposfera, lo que unido a la presencia de líneas de convergencia o simplemente la existencia de una fuerte vorticidad cerca del centro de la baja en superficie, favorece la formación de trombas marinas y tornados terrestres (en este caso similares a los landspouts de EEUU).

Entre los meses de noviembre y febrero, el chorro polar desciende de latitud, siendo frecuente que discurra por el sur de la Península lbérica, acompañado en niveles bajos por borrascas más o menos profundas y en niveles medios por bolsas de aire relativamente frío. Este aire frío de niveles medios de la troposfera se superpone a un mar relativamente cálido durante todo el invierno, sobre todo en el Golfo de Cádiz. Es relativamente frecuente además que estas borrascas Atlánticas induzcan la formación de un chorro del suroeste en niveles bajos, cálido y húmedo, procedente en ocasiones de latitudes tropicales o subtropicales, y que en todo caso advecta una capa de aire marítimo, más cálida, hacia el interior del suroeste de la Península, aumentando la inestabilidad en niveles bajos. Con estas situaciones es frecuente que la convección esté presente en el oeste peninsular aún en la estación fría, y que incluso el máximo mensual de días de tormenta en capitales como Cádiz o Huelva se localice en los meses de diciembre y enero. Esta convección suele producirse además en entornos de muy elevada cizalladura, debido a la presencia del chorro en niveles altos. Incluso en niveles bajos, la advección cálida de procedencia marítima en la parte delantera de las vaguadas favorece el giro de los vientos ("veering"), a componente sur e incluso en ocasiones sureste, aumentando de ese modo la cizalladura en niveles bajos y alcanzándose muy destacables valores de helicidad.

Este fenómeno no es exclusivo de la Península Ibérica. Algo similar ocurre en otras zonas del mundo con similares características climáticas, como California (EEUU) o zonas del sur de Australia. Hanstrum et al. (2002) encuentran que una mayoría de los tornados de esas regiones se produce en la estación fría. Los mismos autores muestran que las situaciones sinópticas responsables de dichos episodios suelen presentar una profunda borrasca de latitudes medias, el entorno más favorable revela inestabilidad débil y fuerte cizalladura vertical concentrada en niveles bajos, así como convergencia también en bajos niveles, indicando como significativos valores totales de CAPE de 200-400 J/kg, LI7 (hasta $700 \mathrm{hPa}$ ) ligeramente negativo y cizalladura entre $0-1 \mathrm{~km}$ mayor de $10^{-2} \mathrm{~s}^{-2}$.

Este tipo de ambientes se encuentra también asociado a situaciones sinópticas tan distintas como las de ciclones tropicales, en sus bandas exteriores, cuando tocan tierra. Estudios de McCaul (1991) y McCaul y Weismann (1994), entre otros, muestran la formación de supercélulas tornádicas de poco desarrollo en dichos entornos, caracterizados también por inestabilidad débil y fuerte cizalladura vertical concentrada en niveles bajos. Wicker y Cantrell (1996), entre otros, demuestran que una fuerte cizalladura vertical con hodógrafa anticiclónica en una capa con suficiente inestabilidad aumenta significativamente la intensidad de corriente ascendente, lo que hace posible que en entornos con CAPE total pequeño pero significativo en niveles bajos y fuerte cizalladura y helicidad, se puedan generar células convectivas muy similares a las supercélulas de las Grandes Llanuras americanas, aunque mucho más reducidas de tamaño, como indican McCaul y Weismann (2001) en sus simulaciones de entornos convectivos con inestabilidad débil. Con frecuencia, estas a veces llamadas minisupercélulas (Burgess et al. 1995), provocan como único efecto severo en superficie precisamente tornados, no registrándose granizo ni incluso en muchas ocasiones descargas eléctricas. Por último, Markowsky y Straka (2005) han identificado tornados asociados a mesociclones en células convectivas con topes tan bajos como 5 ó 6 $\mathrm{km}$.

En definitiva, las situaciones Atlánticas son responsables de gran parte de los tornados de estación fría en España, cuya máxima ocurrencia se da en Galicia, Extremadura y Andalucía (sobre todo en el litoral y Valle del Guadalquivir). 
La experiencia y el estudio de situaciones de la muestra disponible de tornados, permiten esbozar la siguiente subclasificación de las situaciones “Atlánticas” generadoras de tornados.

- Borrascas Atlánticas centradas al sur del paralelo 45 $\mathrm{N}$, con fuerte flujo del suroeste

- Tornados litorales de otoño/invierno.

- Tornados litorales y de interior en otoño/invierno. Oleadas de tornados.

- Otras situaciones Atlánticas con flujo del oeste

- Bajas profundas y extensas centradas por encima del paralelo $45^{\circ} \mathrm{N}$ que no cruzan por la Península, pero que la abarcan dentro de su radio de acción.

- Situaciones de flujo rápido con una corriente en chorro de pequeña amplitud, en las que la circulación general del oeste es intensa y persistente, pudiendo afectar a toda la vertiente Atlántica o solamente a la parte septentrional.

Seguidamente se intentan poner de manifiesto las condiciones generales asociadas a cada uno de los subtipos de situaciones Atlánticas generadoras de tornados.

\section{IV.2.1 Borrascas Atlánticas centradas al sur del paralelo $45^{\circ} \mathrm{N}$, con fuerte flujo del suroeste}

Los tornados se producen en zonas de la vertiente Atlántica y del Mar de Alborán, bajo la influencia de una profunda borrasca Atlántica, en muchos casos de muy pequeñas dimensiones, centrada al sur del paralelo $450 \mathrm{~N}$ y que se deslaza rápidamente cruzando la Península lbérica o pasando cerca de ella. Son ambientes típicos del invierno y del otoño, pero también se observan en primavera.

El mapa sinóptico que mejor identifica estas situaciones es el de superficie. Esta baja puede observarse también en los análisis de $500 \mathrm{hPa}$ (tornados de Málaga y Estepona, 1 de febrero de 2009) o no (tornado de Huelva, 19 de enero de 2014).

En capas medias y altas puede identificarse además de una baja cerrada, una vaguada profunda o una onda corta (en las imágenes del satélite Meteosat del canal de vapor de agua de $6.3 \mu \mathrm{m}$, casi siempre se observa un máximo de vorticidad o varios encadenados por líneas de deformación). Está además presente una corriente en chorro de gran amplitud (meandros).

En este sentido los tornados serían fenómenos de capas bajas, ya que bastaría un mapa de superficie y parámetros deducidos de las capas bajas de los sondeos para identificar las posibles situaciones que pueden provocar tornados. La presión mínima media a nivel del mar de los episodios estudiados (19 y 33 días) fue de 991 $\mathrm{hPa}$. En la mitad de los casos la presión fue inferior a $990 \mathrm{hPa}$, y en tres cuartas partes de los días la presión fue inferior a $997,5 \mathrm{hPa}$.

El día 2 de mayo de 2004 se observaron dos tornados EF0 en el litoral norte del Mar de Alborán, uno en San Pedro de Alcántara (Málaga) y otro en Carchuna (Granada). En la Figura IV.2.1 se pueden apreciar las pequeñas dimensiones de la baja y su profundidad a las 18 UTC.

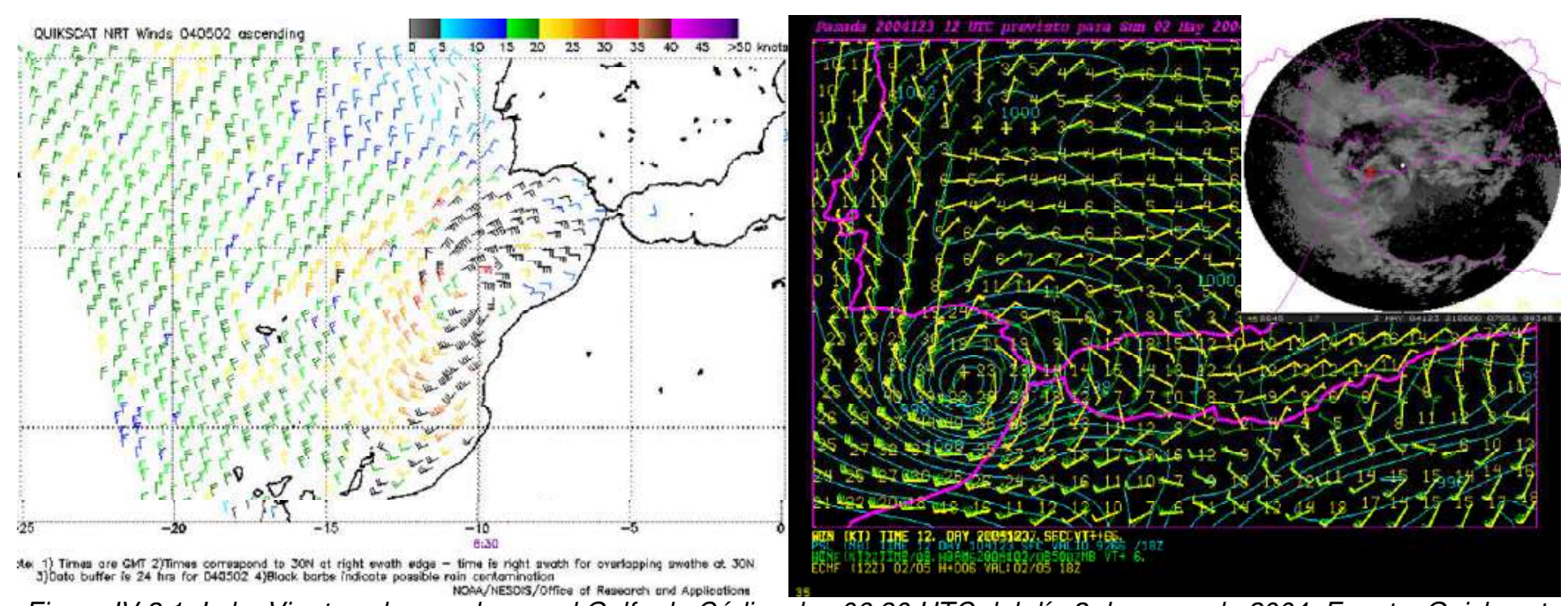

Figura IV.2.1. Izda: Vientos observados en el Golfo de Cádiz a las 06:30 UTC del día 2 de mayo de 2004. Fuente: Quickscat.

Dcha: mapa de superficie (viento y PSL) previsto por el modelo del ECMWF para las 18 UTC (H+6) y vientos en verde en 850 hPa; en la parte superior derecha: imagen del radar de Málaga detectando la situación de la baja a las 21 UTC. 
Las condiciones de superficie suelen ser las siguientes:

- Baja centrada al sur del paralelo 45N

- Presión mínima a nivel del mar menor de $1000 \mathrm{hPa}$

- Preferiblemente baja de pequeñas dimensiones (mayores vorticidad y cizalladura horizontal y vertical)

A menudo los tornados no se observan en el momento del paso de la baja o del mínimo de presión, sino en la zona convectiva delantera (Figura IV.2.2), como ocurrió el día 2 de mayo de 2004 en San Pedro de Alcántara y en Carchuna, o allí donde existan fronteras o límites bruscos con vorticidad ciclónica en niveles bajos, o a lo largo o cerca de los frentes asociados.

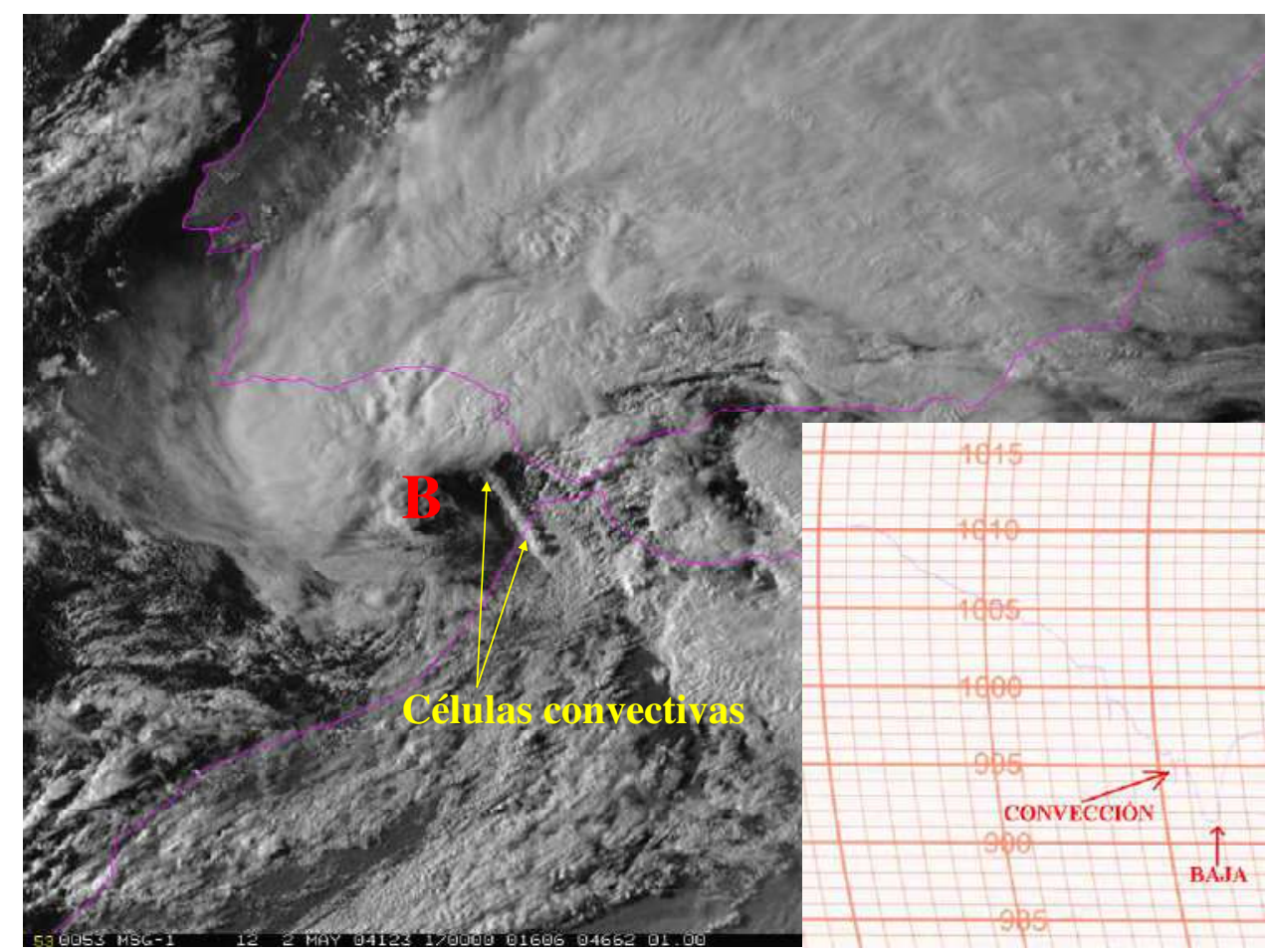

Figura IV.2.2. Imagen visible (HRV) del satélite Meteosat de las 17 UTC del 2 de mayo de 2004 y banda del barógrafo del observatorio de Puerto Banús donde se aprecia la caída brusca de la presión (Málaga).

Los tornados suelen observarse en la zona asociada a vientos fuertes del sur, aunque si la orografía es favorable a veces se forman en la zona de vientos del norte la zona descendente de la baja en superficie, bien al bajar de la tierra al mar o al entrar del mar a tierra. Podemos ver en la imagen del día 7 de diciembre de 2010 la procedencia subtropical de la masa de aire de la zona delantera de la baja (Figura IV.2.3).

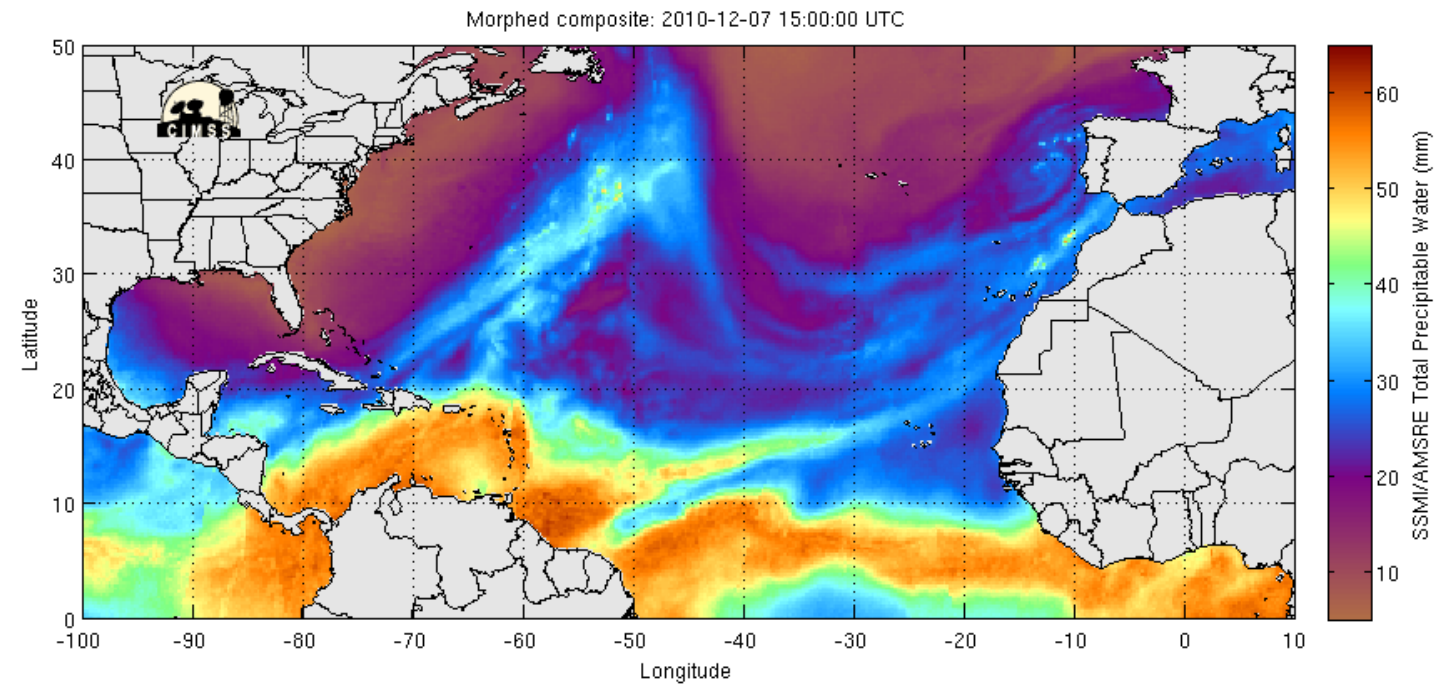

Figura IV.2.3. Imagen del agua precipitable total en la columna, a las 15 UTC del 7 de diciembre de 2010. Fuente: CIMSS

En estas situaciones encontramos humedad, inestabilidad, mecanismos de ascenso (forzamiento) y vientos fuertes del sur o suroeste por debajo de $700 \mathrm{hPa}$, lo que implica fuerte cizalladura vertical del viento, pudiendo existir además, fronteras baroclinas y cinemáticas. 
Los tornados se observan con mayor frecuencia en aquellas zonas en las que se yuxtaponen estas condiciones de inestabilidad y vientos fuertes, y muy cerca del mar si la inestabilidad se confina en capas medias bajas (índice LI7 negativo y LI -hasta 500 hPa- positivo o nulo), y van apareciendo tierra adentro y a la derecha del avance de la baja a medida que la inestabilidad afecta a capas más profundas de la atmósfera.

Como se apunta en el apartado II-6, los días en que se han observado tornados, la actividad eléctrica puede ser pequeña (LI positivos) o grande (LI negativos). Cuanto mayores sean la inestabilidad y el forzamiento, más actividad eléctrica habrá y más tierra adentro penetrarán las tormentas. En la Figura IV.2.4 se presentan ambos casos extremos: las descargas observadas a la hora del tornado de Huelva del día 19 de enero de 2014 y de la oleada de tornados del día 7 de diciembre de 2010.

Debido a una mayor cizalladura, menor dimensión vertical de la capa cálida de la nube, convección menos profunda y, en ocasiones, pequeña altitud de la tropopausa, es común observar un porcentaje de descargas positivas respecto a las totales bastante mayor que en otras situaciones de inestabilidad ( 1 de cada 4 el día 7 de diciembre de 2010).

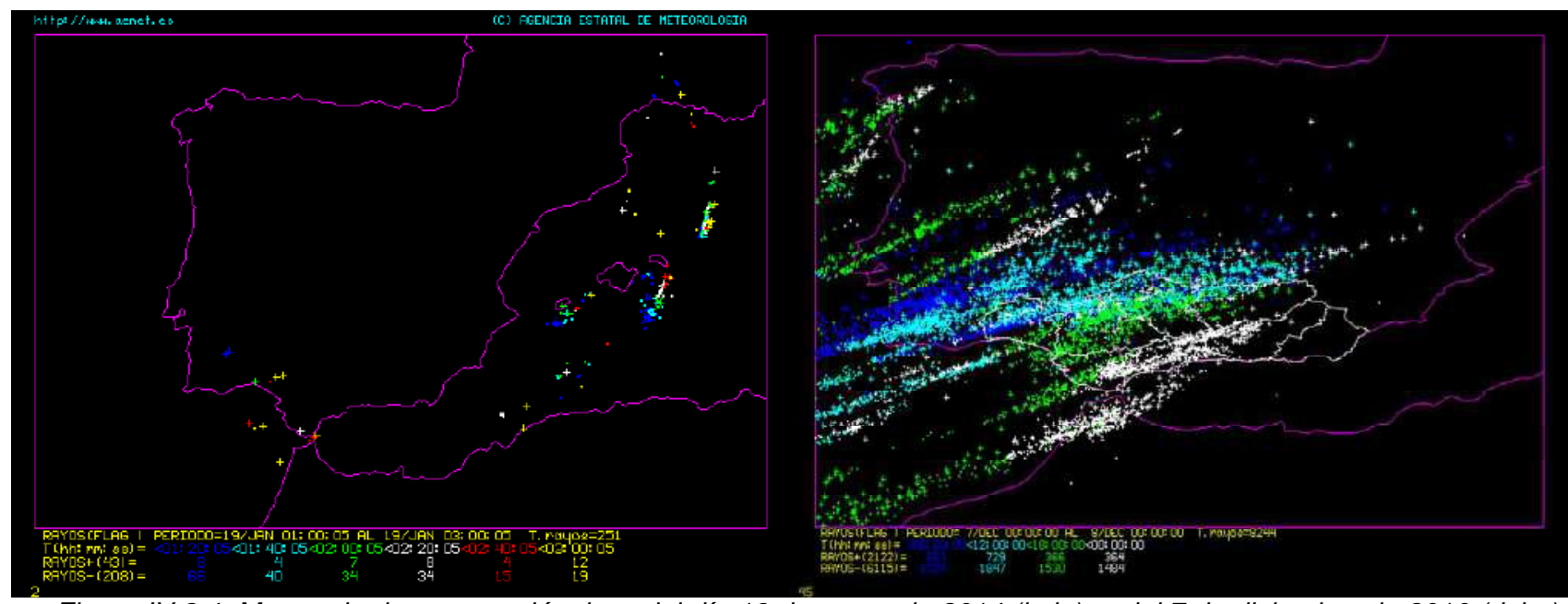

Figura IV.2.4. Mapas de descargas eléctricas del día 19 de enero de 2014 (izda) y del 7 de diciembre de 2010 (dcha).

Dentro de este tipo de situaciones, nos encontramos dos subtipos que a continuación se describen.

\section{IV.2.1.a Tornados litorales de otoño/invierno}

Suelen observarse tanto en la vertiente Atlántica Peninsular como en el litoral del Mar de Alborán. Es suficiente con una estratificación del aire inestable en capas bajas (LI7 < 0), y no es necesario un gran CAPE (la estratificación puede ser débilmente inestable), siendo suficiente con que exista CAPE3 (CAPE hasta 3 km). En estos ambientes de pequeño CAPE, la magnitud de la cizalladura vertical en capas bajas puede ser el parámetro más importante a la hora de la predicción.

Una situación representativa de este subtipo es la situación del día 1 de febrero de 2009. En la Figura IV.2.5 se aprecia la distribución del LI7. Durante esa jornada se observó un tornado de categoría EF2 en Málaga y varios de menor categoría en otros puntos de Andalucía (El Coronil y Antequera).

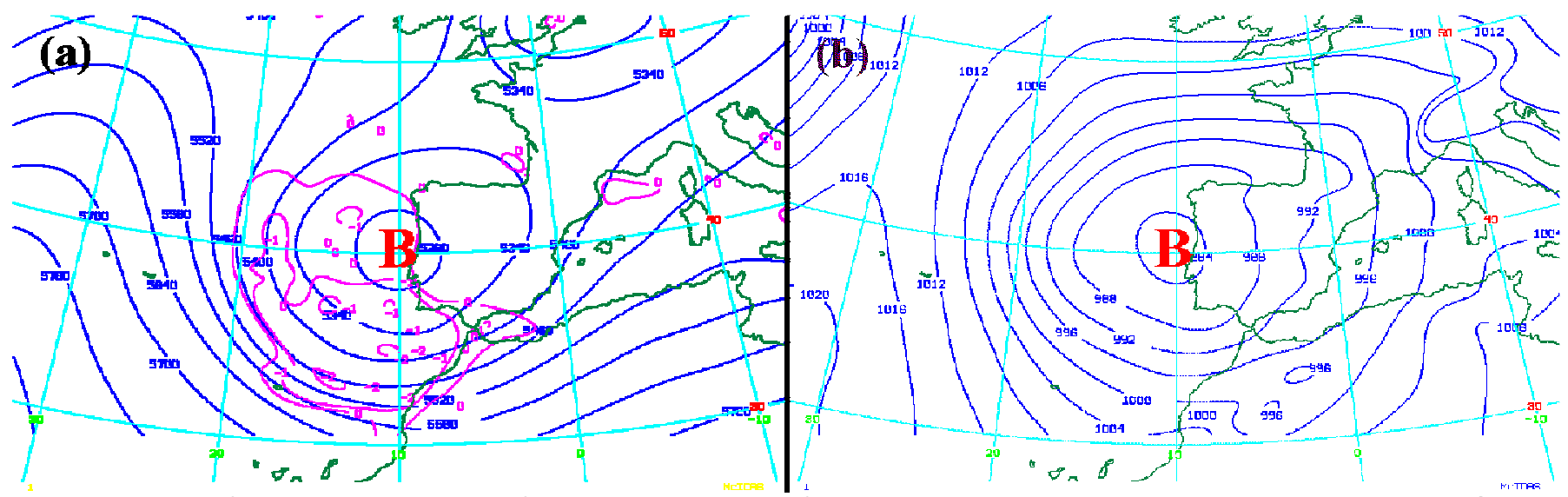

Figura IV.2.5. Campos del modelo del CEPPM para las 18 UTC del 1 de febrero de 2009. (a) Altura del geopotencial (línea azul) en 500 hPa e índice LI7 (línea magenta), (b) Presión a nivel del mar. 
Generalmente se observan tornados EF0 cercanos a la línea de costa, decreciendo rápidamente la frecuencia de su observación tierra adentro especialmente en aquéllos lugares de fuertes pendientes (Figura IV.2.6). Cuando la baja es de muy pequeñas dimensiones y solamente LI $<0$, se pueden producir a cualquier hora del día aunque parece darse un máximo secundario al amanecer (con el foco caliente en el mar).

A medida que las dimensiones de la baja aumentan y la inestabilidad afecta a capas más profundas de la atmósfera se observan tornados tierra adentro y con mayor frecuencia en las horas de mayor calentamiento. Los tornados suelen formarse debido a $\mathrm{Cu}$ o $\mathrm{Cb}$ de desarrollo rápido en fronteras o límites bruscos con vorticidad ciclónica en niveles bajos. Aunque no suelen observarse, no se pueden descartar las tormentas multicelulares organizadas, como la del día 2 de noviembre de 2002, en el que un eco en arco recorrió todo el litoral norte del mar de Alborán, reportándose un tornado en el Rincón de la Victoria.

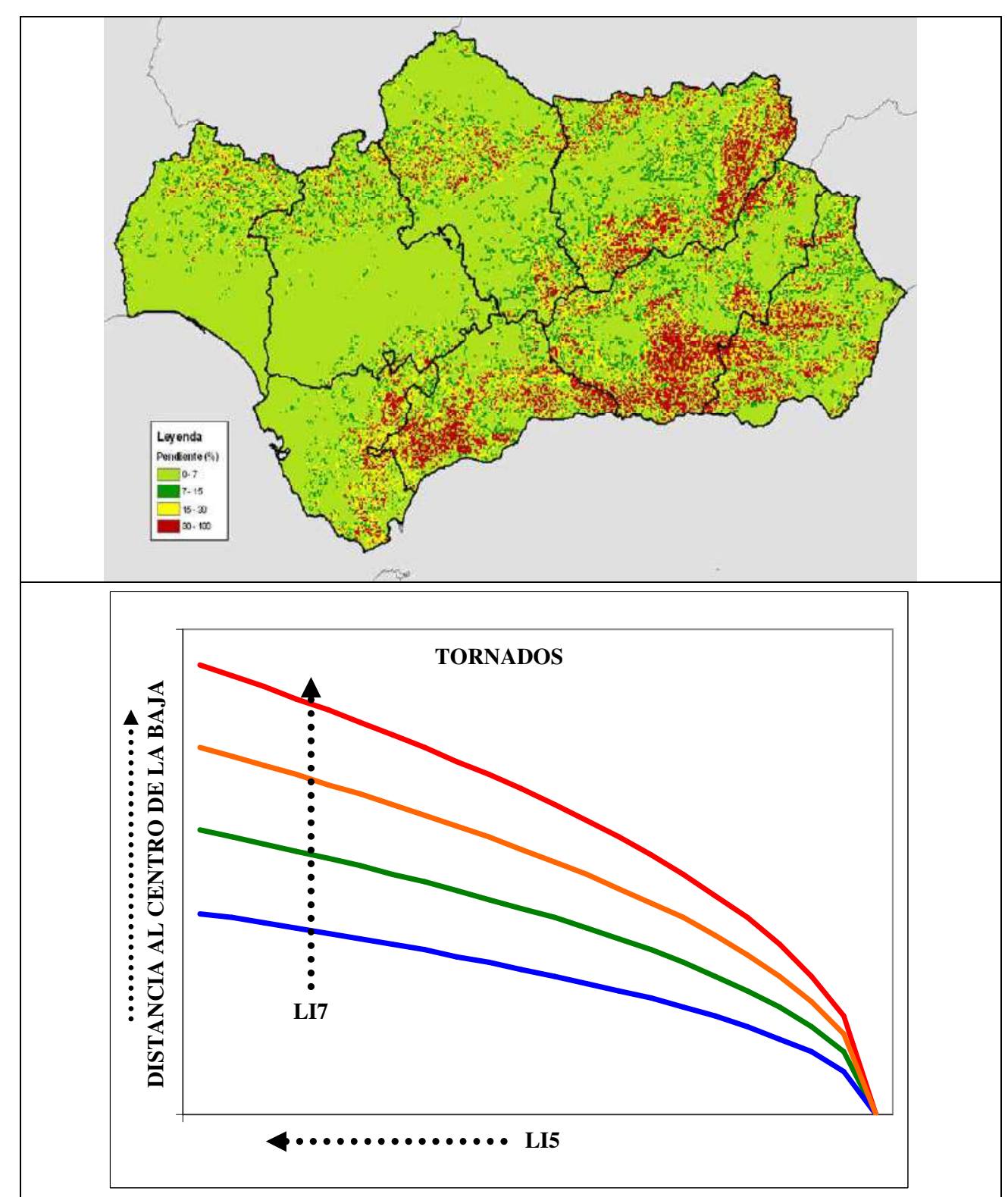

Figura IV.2.6. Niveles de pendiente en Andalucía (arriba) y distancia de los tornados al centro de la baja en función de la inestabilidad (abajo).

Otra situación de interés dentro de este subtipo es la del tornado de Huelva del 19 de enero de 2014. En la Figura IV.2.7 podemos ver algunos valores de estos índices en dicha situación, encontrándose cantidades favorables de cizalladura, LI7 y CAPE3 sólo en las cercanías del litoral. 


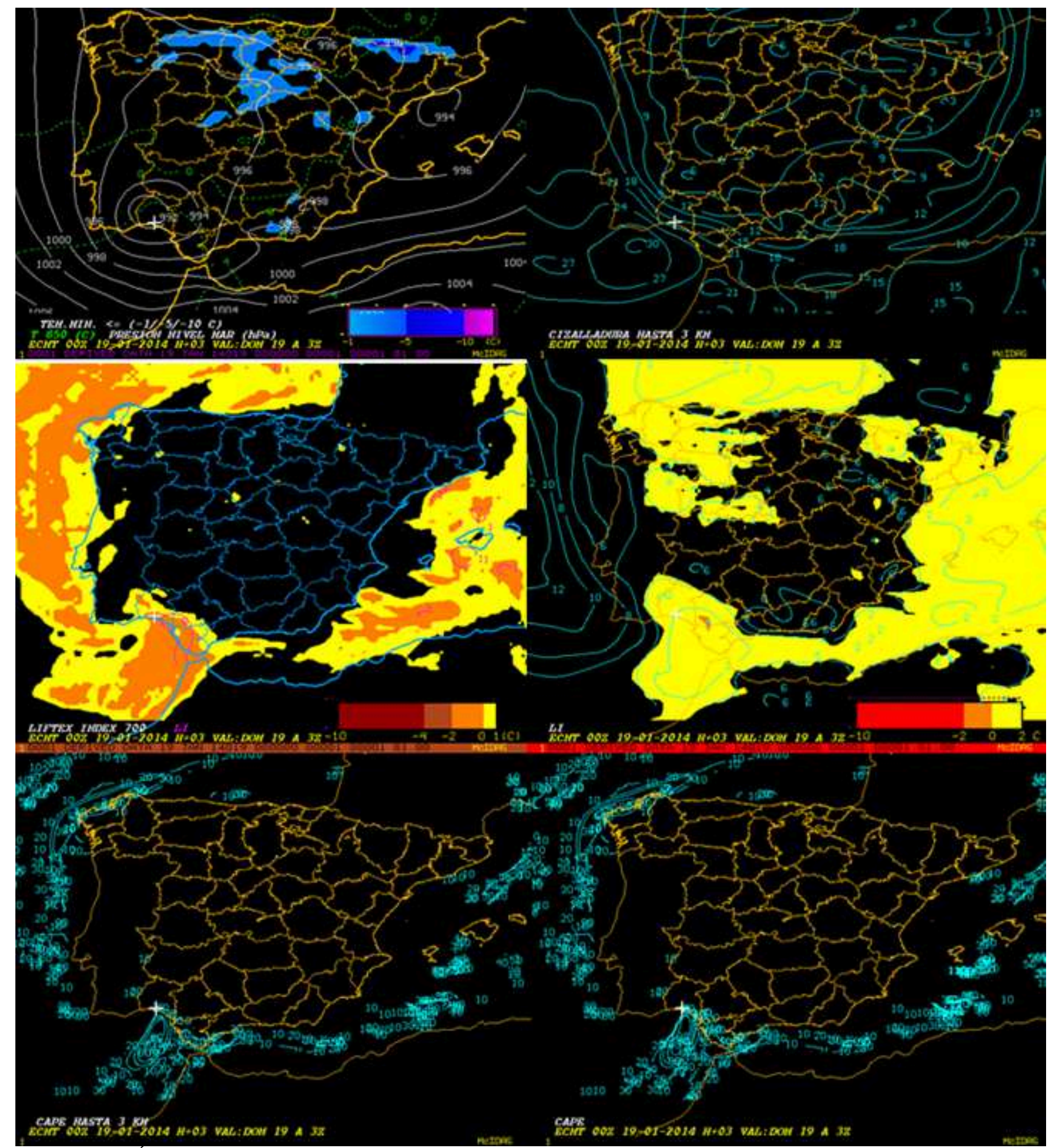

Figura IV.2.7. Indice y parámetro, el día 19 de enero de 2014 a 3 UTC. De izquierda a derecha y de arriba a abajo: a) T850 y Tmin sfc, b) CIZ_0_3000, c) LI700, d) LI, e)CAPE3, f) CAPE

Un resumen de los ingredientes clave, condiciones favorables y algunas características de este tipo de tornados (como el tornado de Málaga del 1 de febrero de 2009), sería el siguiente:

Ingredientes clave:

$\checkmark$ Baja centrada en superficie al sur del paralelo $45^{\circ} \mathrm{N}$.

$\checkmark$ Baja profunda (PSL $<1000 \mathrm{hPa})$.

$\checkmark \quad$ Inestabilidad (LI-700 < 0). Flotabilidad, CAPE3, aunque no es necesario mucho CAPE.

$\checkmark$ Vientos muy fuertes por debajo de $700 \mathrm{hPa}$ lo que implica cizalladura vertical del viento.

$\checkmark$ Señales superiores al $80 \%$ de los índices de predicción extrema de los vientos.

Condiciones favorables:

$\checkmark$ Pequeñas dimensiones de la baja: más vorticidad y más cizalladura horizontal y vertical.

$\checkmark$ Lugares que marquen aquellos índices que combinan la cizalladura y la inestabilidad en capas bajas.

$\checkmark$ Distribución horaria con dos máximos, uno por la mañana y otro por la tarde. 


\section{IV.2.1.b Tornados litorales y de interior en otoño/invierno. Oleada de tornados}

Cuanto más grande y profunda es la borrasca Atlántica, mayor será su alcance e irá afectando a zonas más amplias del interior de la vertiente Atlántica Peninsular y del Mar de Alborán. En estos casos se observa en altura una profunda vaguada con eje orientado de suroeste a nordeste, que puede durar varios días con lo que los vientos fuertes de componente sur y la cizalladura se observan en zonas más extensas de la Península lbérica.

Cuando la inestabilidad afecta a capas más profundas de la atmósfera (con valores de LI5 más negativos), pueden producirse oleadas de tornados ("tornado outbreak") que afectan tierra adentro, alcanzando a zonas más altas de la vertiente Atlántica peninsular. El máximo diurno se va desplazando hacia las horas de mayor calentamiento, observándose en las imágenes de radar además de las células ordinarias como los cúmulos o cumulonimbos de desarrollo rápido, otros tipos de convección como los sistemas multicelulares que pueden ser desorganizados (agrupaciones caóticas) u organizados (sistemas convectivos cuasilineales).

\section{$\begin{aligned} & \text { Un ejemplo de estas situacior } \\ & \text { los días } 5 \text { y } 8 \text { de diciembre } 2010 .\end{aligned}$}

Se observaron 12 tornados en la vertiente Atlántica de la Península lbérica. El día 6, en Doña Mencía (Córdoba) y en Osuna (Sevilla), el día 7, ocurrieron 6 en Badajoz (Jerez de los Caballeros, Mérida, Torremejía, Aceuchal, Valencia de Mombuey, Santibéñez el Bajos) y 2 en Portugal (Tomar y Carvalhal Formoso) y el día 8, uno en Fuenteovejuna y otro en Moguer (Huelva).

Durante el episodio, en las imágenes de vapor de agua se observaron varios centros de vorticidad (circulación ascendente y forzamiento atmosférico), aunque en los análisis del ECWMF de $500 \mathrm{hPa}$ y de $300 \mathrm{hPa}$ no siempre queda clara la existencia de una baja cerrada en altura (Figura IV.2.8).

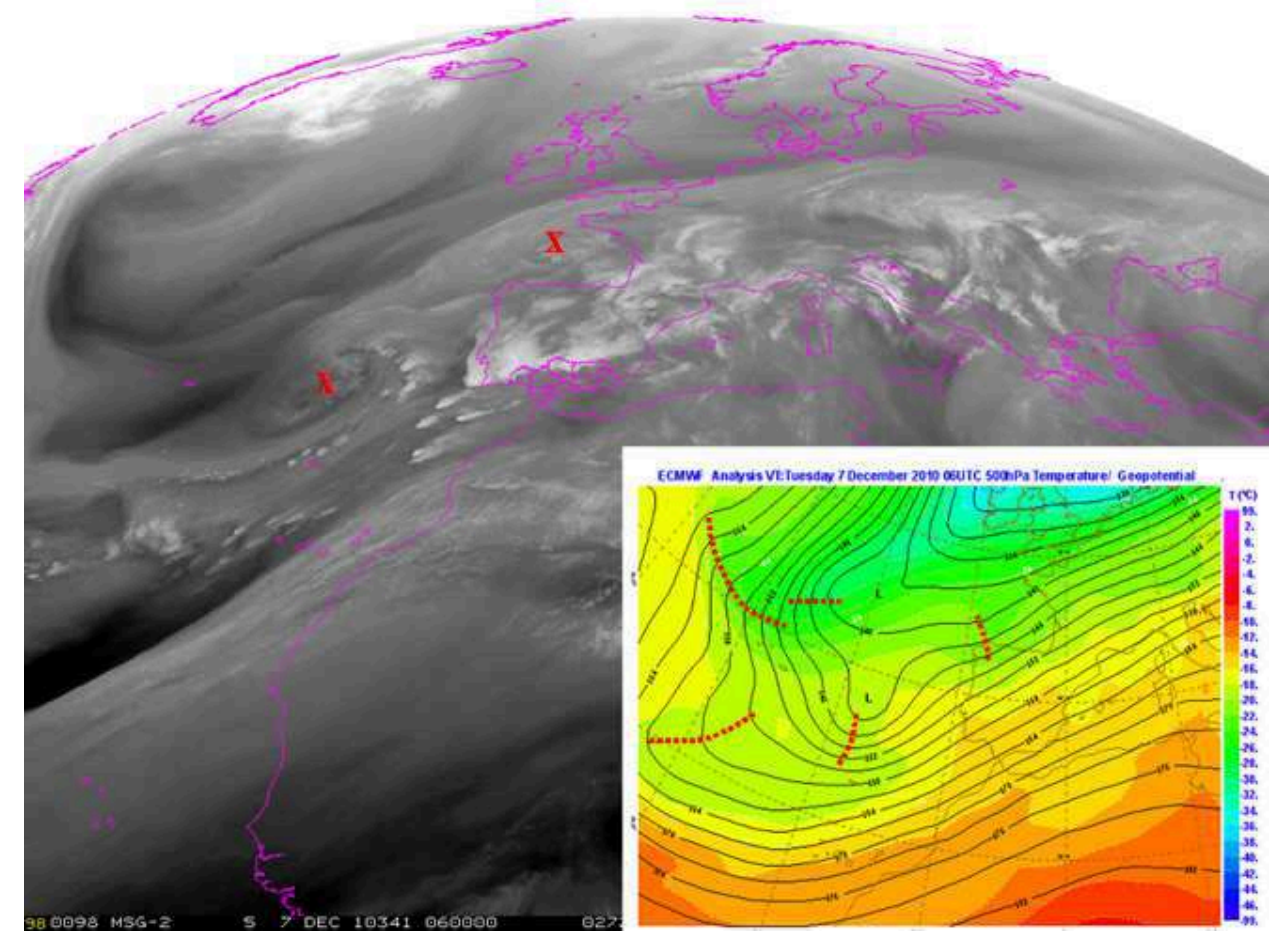

Figura IV.2.8. Imagen WV $06.2 \mu \mathrm{m}$ del Meteosat y campos de geopotencial y temperatura en 500 hPa del modelo del CEPPM correspondientes a las 06 UTC del día 7 de diciembre de 2010. Sobre la imagen se marcan los centros de vorticidad y sobre el mapa los ejes de las vaguadas.

Durante el día 7 una baja Atlántica muy profunda, con una presión mínima de $987 \mathrm{hPa}$ centrada a las 0 UTC en $37^{\circ} \mathrm{N} 20^{\circ} \mathrm{W}$ se desplaza hacia el nordeste, de forma que a las 24 UTC estaba centrada sobre las Rías Bajas con un mínimo de presión de $991 \mathrm{hPa}$. Ya a primeras horas de la mañana se detectan en la costa del sur de Portugal vientos del suroeste superiores a 40 kt (Figura IV.2.9). 


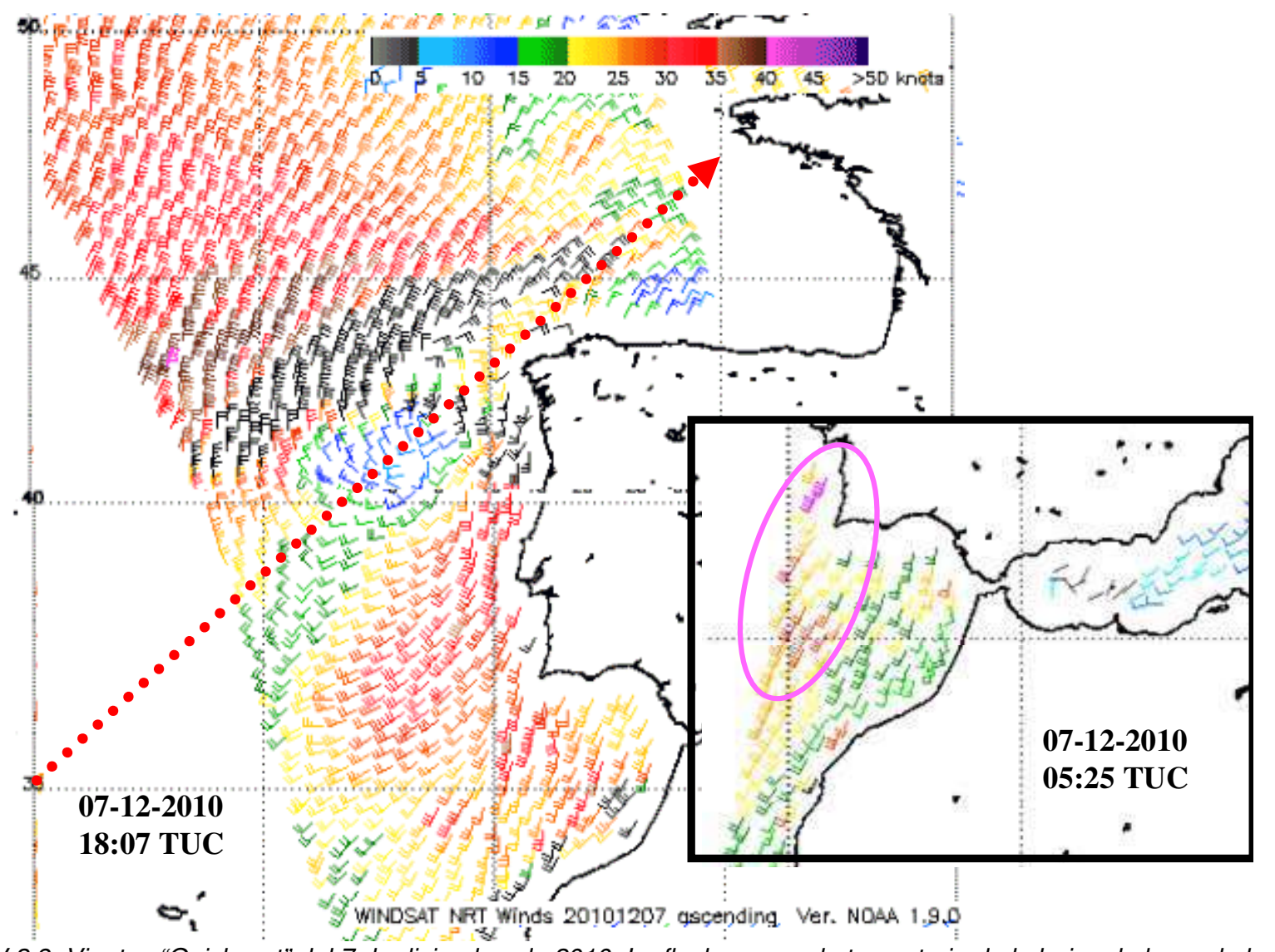

Figura IV.2.9. Vientos "Quickscat" del 7 de diciembre de 2010. La flecha marca la trayectoria de la baja a lo largo de la jornada.

Como muestran las imágenes de agua precipitable total en la columna (Figura IV.2.3), los datos de vientos por satélite (Figura IV.2.9) y los mapas de isobaras a nivel del mar y de líneas de corriente en $300 \mathrm{hPa}$ del modelo del CEPPM (Figura IV.2.10), sobre la mayor parte de la Península Ibérica había una circulación del suroeste en todos los niveles de la atmósfera, con vientos de componente sur asociados a una circulación ciclónica con centro en el Atlántico y que se movía con rapidez de suroeste a nordeste.
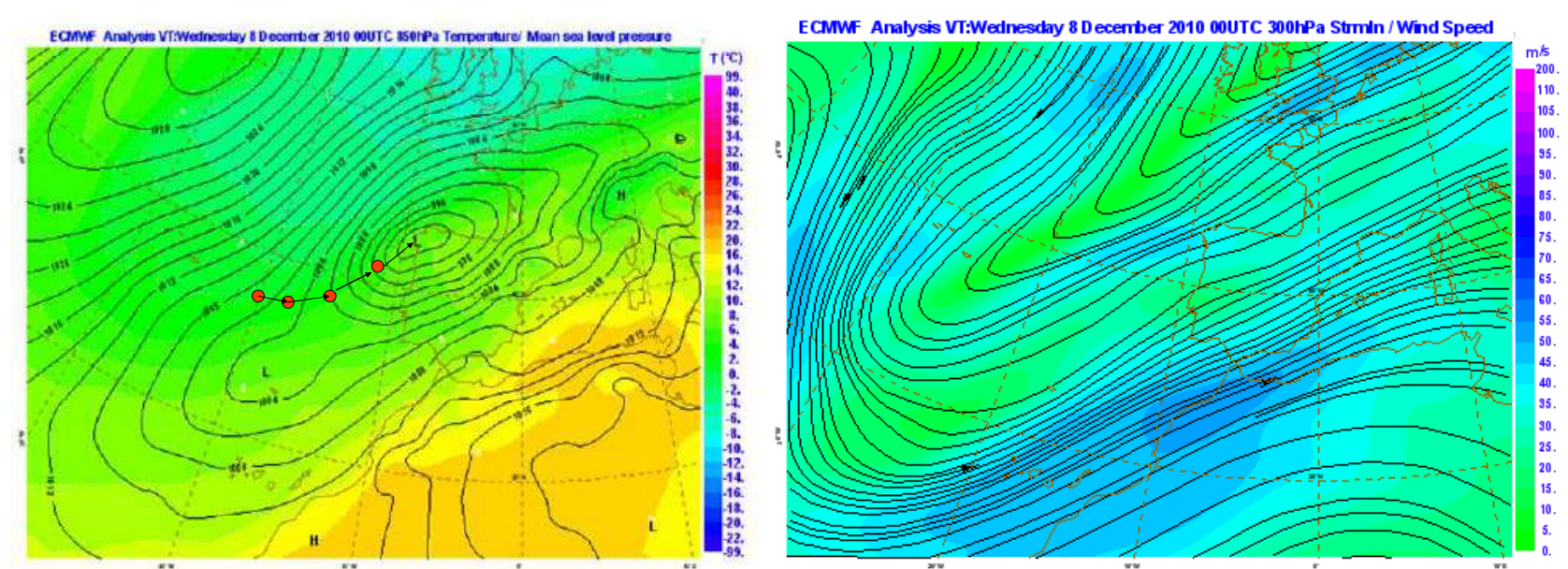

Figura IV.2.10. Campos de modelos del ECMWF para las 00 UTC del 8 de diciembre de 2010. Presión a nivel del mar y temperatura en $850 \mathrm{hPa}$ (izq) y líneas de corriente y velocidad del viento en $300 \mathrm{hPa}$ (dcha). Sobre el mapa de superficie se marca la posición del centro de la baja a las 0, 6, 12 y 18 UTC del día 7 de diciembre de 2010.

Las condiciones de inestabilidad, como se aprecia en los datos de rayos (Figura IV.2.4), duraron todo el día 7. En la distribución horaria se distinguen dos máximos: uno entre las 4 y las 9 (con un porcentaje de positivos del $30 \%$ ) y otro entre las 16 y las 21 (con un porcentaje del 20\%). Los tornados se produjeron tanto a primeras horas de la mañana como por la tarde, coincidiendo con el paso de sendas líneas nubosas (Figuras IV.2.8 y 11). 


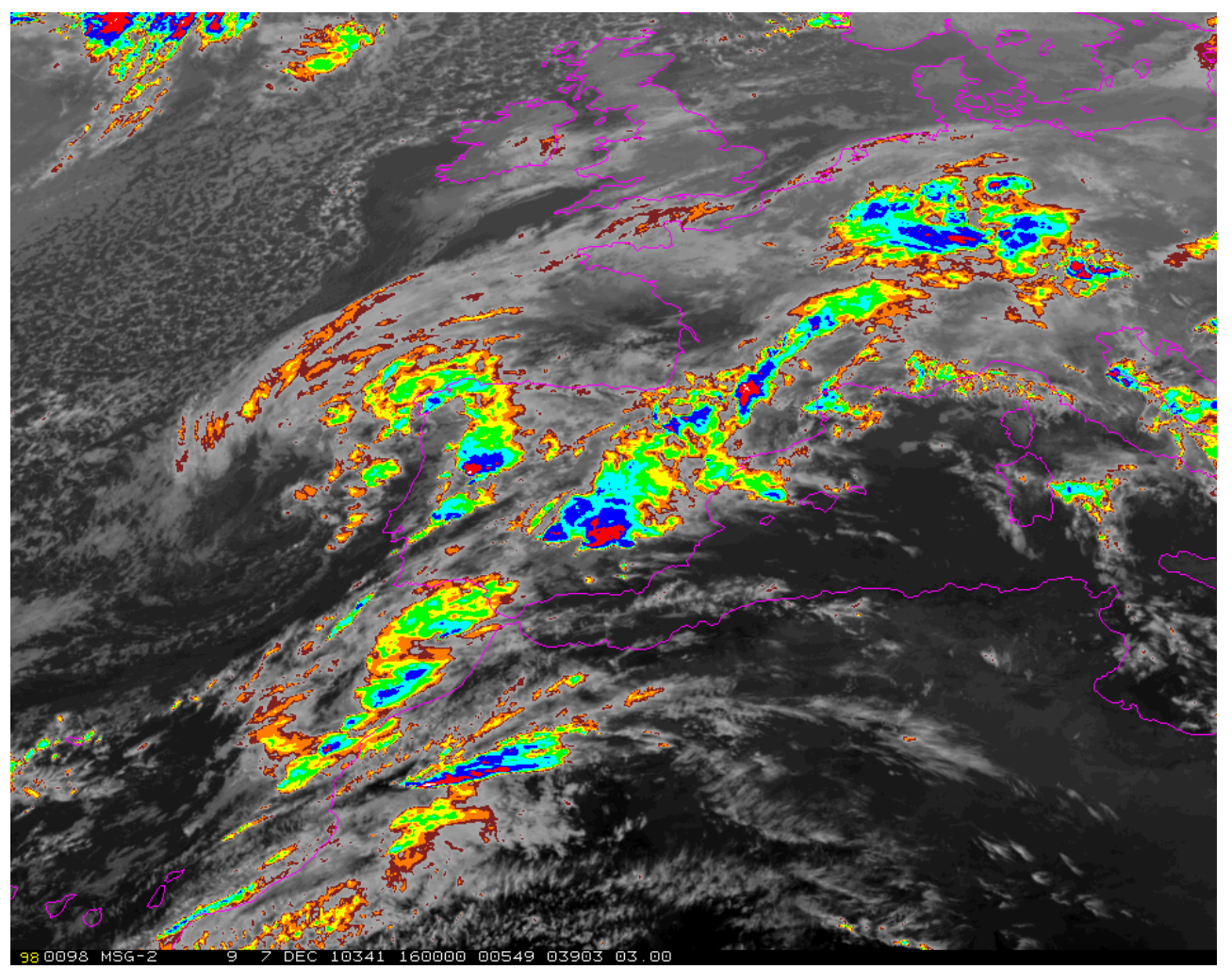

Figura IV.2.11. Imagen IR $10.8 \mu \mathrm{m}$ del Meteosat correspondientes a las 16 UTC del día 7 de diciembre de 2010. A las 16:15 UTC se observó un tornado en Carvalhal Formoso (Portugal).

A las 6:20 (Figura IV.2.12), se aprecia en las imágenes del radar de Extremadura, un sistema cuasilineal con arcos en forma de onda que recuerda a las LWEP ("Line Echo Wave Patterns").

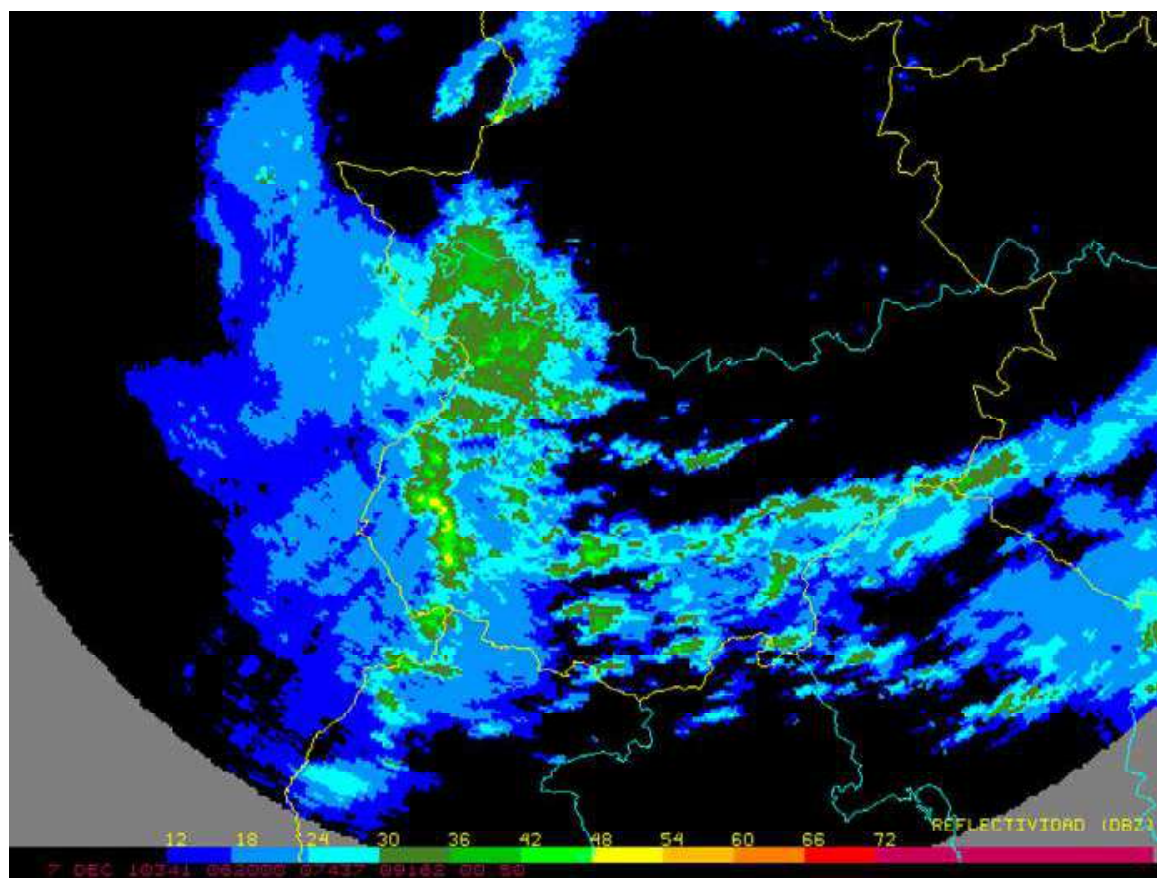

Figura IV.2.12. Imagen PPI de las 6:20 UTC del día 7 de diciembre del radar de Extremadura

En la Figura IV.2.13 podemos ver los valores para las 15 UTC de los mismos índices utilizados para la situación del tornado de Huelva del día 19 de enero de 2014. Se aprecia que los mayores valores de cizalladura son del mismo orden, pero los valores más altos (por encima de 21), afectaban a todo el cuadrante suroeste de la Península Ibérica. Los valores negativos del LI7 indican la existencia de inestabilidad en todo el litoral Atlántico así como las tierras bajas cercanas. El LI delimita las zonas con mayor inestabilidad, como el Golfo de Cádiz, y nos da una idea de las zonas altas del interior a las que pueden llegar las tormentas, que en este caso alcanzaron las cabeceras del Guadiana, Tajo y Guadalquivir. 
La principal diferencia entre el CAPE y el CAPE3 no sólo estriba en la diferente distribución espacial de CAPE significativos, sino también y principalmente a los superiores valores de la variable CAPE (Figura IV.3.13).

Los CAPE observados en sondeos hechos desde aviones que partían de Faro, Lisboa y Oporto se encuentran entre unos 700 y $1000 \mathrm{~J} / \mathrm{kg}$ (sondeo de Faro de las 14:40), valores del orden de los observados en algunos tornados de verano. Los valores de LI7 y LI obtenidos fueron los siguientes: Faro -2,4 y -4,6; Lisboa -4,4 y $-4,6$; Oporto $-2,8$ y -1,9 para evoluciones desde unos 200 metros de altitud con temperaturas de $17^{\circ} \mathrm{C}$ y puntos de rocío de $15^{\circ} \mathrm{C}$. En la Figura IV.2.13 se incluye el sondeo de Oporto de las 12:26.

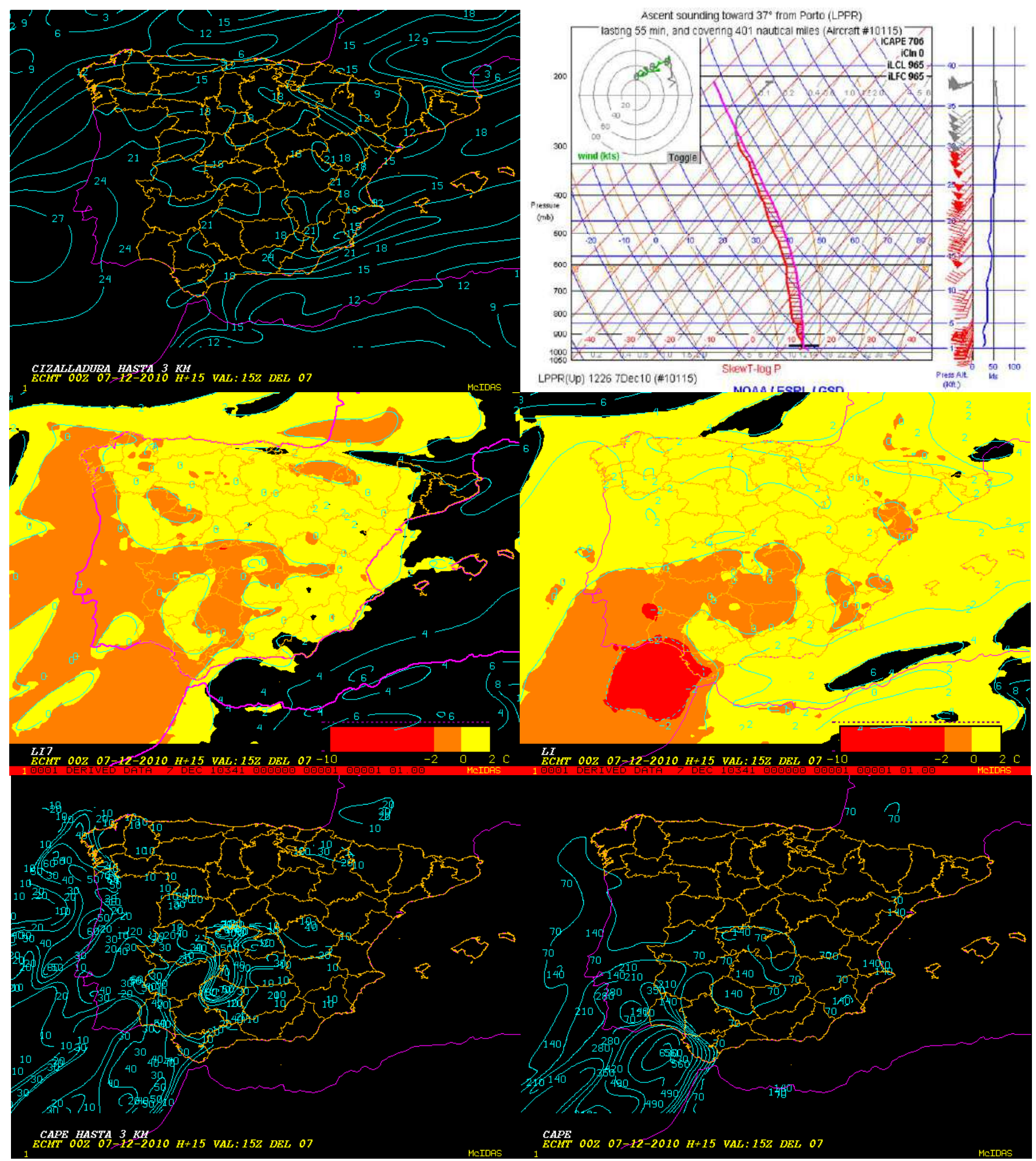

Figura IV.2.13. Valores de algunos índices y parámetros el día 7 de diciembre de 2010 a 15 UTC. De izquierda a derecha y de arriba a abajo: a) CIZ_0_3000, b) Sondeo de avión en Oporto, c) LI700, d) LI, e) CAPE3, f) CAPE 
A continuación se presenta un resumen de los ingredientes clave y algunas condiciones favorables a este tipo de oleadas de tornados Atlánticos, cuyo prototipo sería la situación del 7 de diciembre de 2010.

Ingredientes clave:

$\checkmark$ Baja centrada en superficie al sur del paralelo $45^{\circ} \mathrm{N}$

$\checkmark$ Baja profunda (PSL $<1000 \mathrm{hPa})$

$\checkmark$ Inestabilidad (LI < 0). Flotabilidad, CAPE3 (cuanto mayor CAPE más probabilidad de oleadas de tornados).

$\checkmark$ Vientos muy fuertes por debajo de $700 \mathrm{hPa}$ lo que implica cizalladura vertical del viento

Condiciones favorables:

$\checkmark$ Que la baja sea extensa, o se produzca una sucesión de bajas, lo que favorecerá la invasión de aire marítimo subtropical.

$\checkmark$ Lugares señalados por aquellos índices que combinen la cizalladura y la inestabilidad en capas bajas (helicidad energía, helicidad relativa a la tormenta en la capa efectiva,...).

\section{IV.2.2 Otras situaciones Atlánticas invernales con flujo del oeste}

Además de las situaciones Atlánticas anteriormente vistas, también provocan tornados ciertas configuraciones en las que el flujo en superficie es del oeste sobre la fachada Atlántica.

- Bajas profundas y extensas centradas por encima del paralelo 45 $\mathrm{N}$ que no cruzan por la Península, pero que la abarcan dentro de su radio de acción en el momento de máxima intensidad de la baja en superficie. También se observa en estos casos la presencia de un chorro de gran amplitud.

- Situaciones de flujo rápido con una corriente en chorro de pequeña amplitud, en las que la circulación general del oeste es intensa y persistente, pudiendo afectar a toda la vertiente Atlántica o únicamente a la parte septentrional. En el primer caso la zona de vientos máximos pasa por la Península (al sur del paralelo $45^{\circ} \mathrm{N}$ ) y en el segundo, más al norte.

oestes.

Entre estas situaciones estudiamos el caso de profunda borrasca en el seno de la circulación de los

Entre el 15 y el 16 de febrero de 2011 se tiene constancia de la ocurrencia de 5 tornados en España, 2 de ellos en Galicia y 3 en Andalucía, estos últimos en la provincia de Sevilla y en puntos muy próximos, aunque separados en el tiempo. El día 15 tuvo lugar el de Alcalá de Guadaira (Sevilla) y el día siguiente, 16, acaecieron los de Arousa (Pontevedra) y Castrosante (Lugo), Alcalá de Guadaira (Sevilla) y Arahal (Sevilla). Hay que destacar que dentro de esta situación, más o menos homogénea, los tornados registrados presentan características diversas.

\section{IV.2.2.1. Situación invernal del tornado del 15 de febrero de 2011 en Alcalá de Guadaira (Sevilla)}

Como ejemplo de un tipo de situaciones invernales se presentan las características de la que generó el tornado del 15 de febrero de 2011 en Alcalá de Guadaira, que seguidamente se revisa.

La situación sinóptica es una de las más representativas en cuanto a la ocurrencia de tornados en invierno en la Península; a grandes rasgos borrasca profunda con frentes asociados barriendo la Península de oeste a este con circulación zonal en altura y chorro al sur de la misma. El análisis de $300 \mathrm{hPa}$ del ECMWF del día 15 a las 12 UTC muestra claramente definida una circulación zonal, con un eje de vaguada justo delante de las costas portuguesas y ligera difluencia sobre el oeste de la Península. Un chorro de $65 \mathrm{~m} / \mathrm{s}$ (más de $120 \mathrm{kt}$ ) tiene salida al suroeste de aquélla (Figura IV.2.14 y IV.2.15). 
ECMWF Analysis VT:Tuesday 15 February 2011 12UTC 300hPa Strmin / Wind Speed

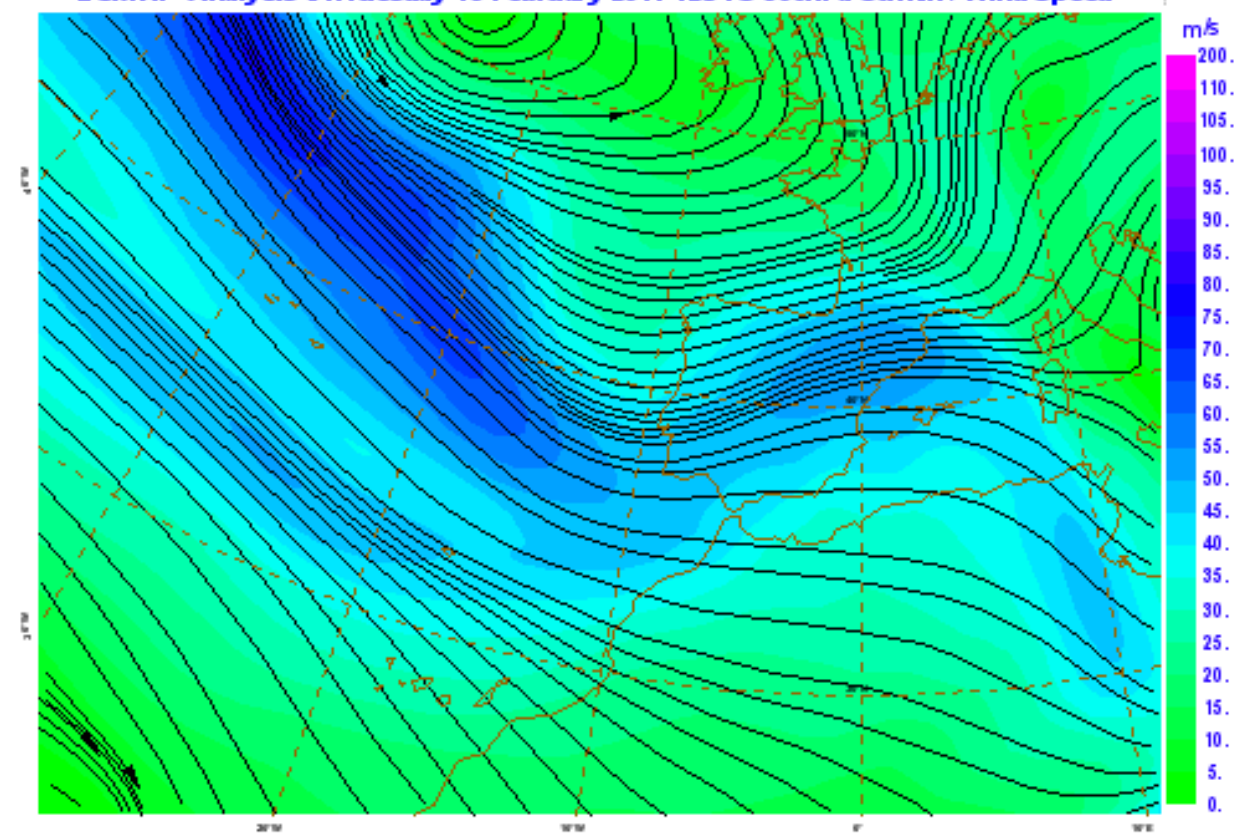

Figura IV.2.14: Líneas de corriente e isotacas al nivel de 300 hPa. Análisis de ECMWF. Día 15 a las 12 UTC

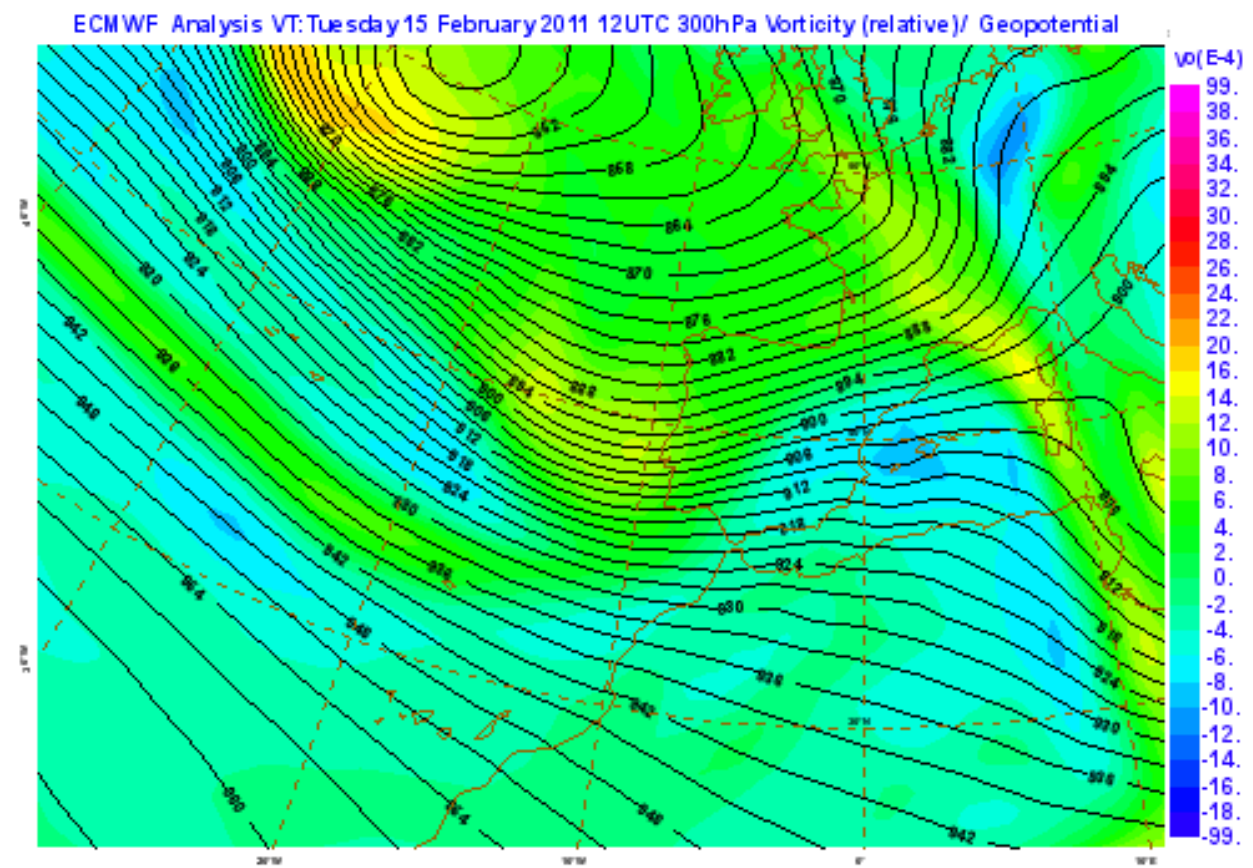

Figura IV.2.15: Geopotencial y vorticidad relativa en 300 hPa. Análisis de ECMWF. Día 15 a las 12 UTC

En $500 \mathrm{hPa}$ la vaguada aparece menos acusada, aunque se observa también sobre las costas portuguesas. Se identifica una masa fría desacoplada de la vaguada dinámica, con advección fría sobre el oeste peninsular (Figura IV.2.16). En superficie, a las 12 UTC, una profunda baja abarca en su radio de acción gran parte del Atlántico norte, con su centro sobre Islandia. Un frente frío está terminando de cruzar la Península y se observan indicios de formación de una baja secundaria en el Golfo de León. Sobre la Península, tras el frente, hay circulación de vientos del oeste, con ligeras ondulaciones. En general se aprecia advección fría, con la isoterma de $2^{\circ} \mathrm{C}$ en $850 \mathrm{hPa}$ desde las costas del suroeste hasta el interior nordeste (Figura IV.2.17). 


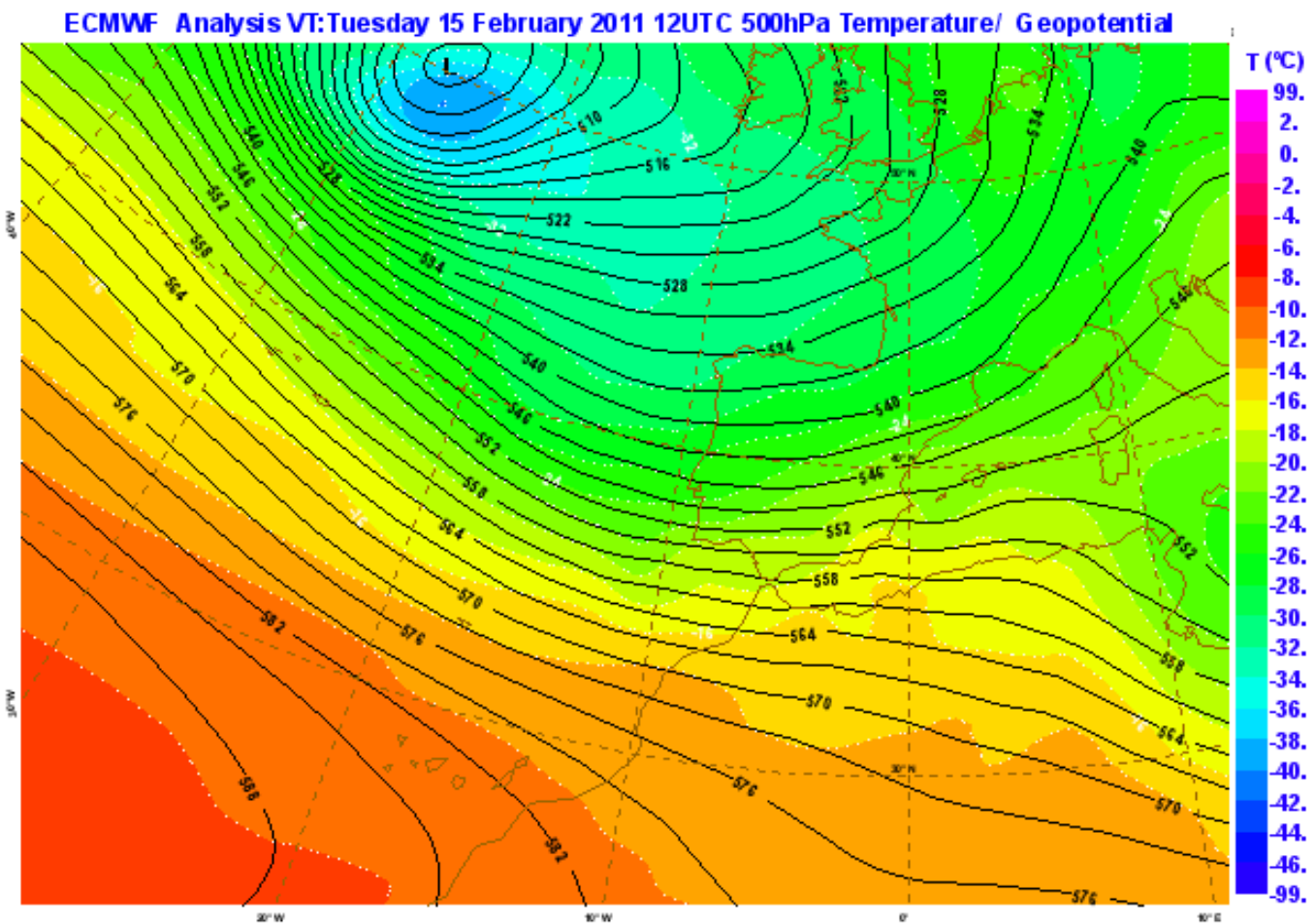

Figura IV.2.16: Geopotencial y temperatura al nivel de 500 hPa. Análisis de ECMWF. Día 15 a las 12 UTC

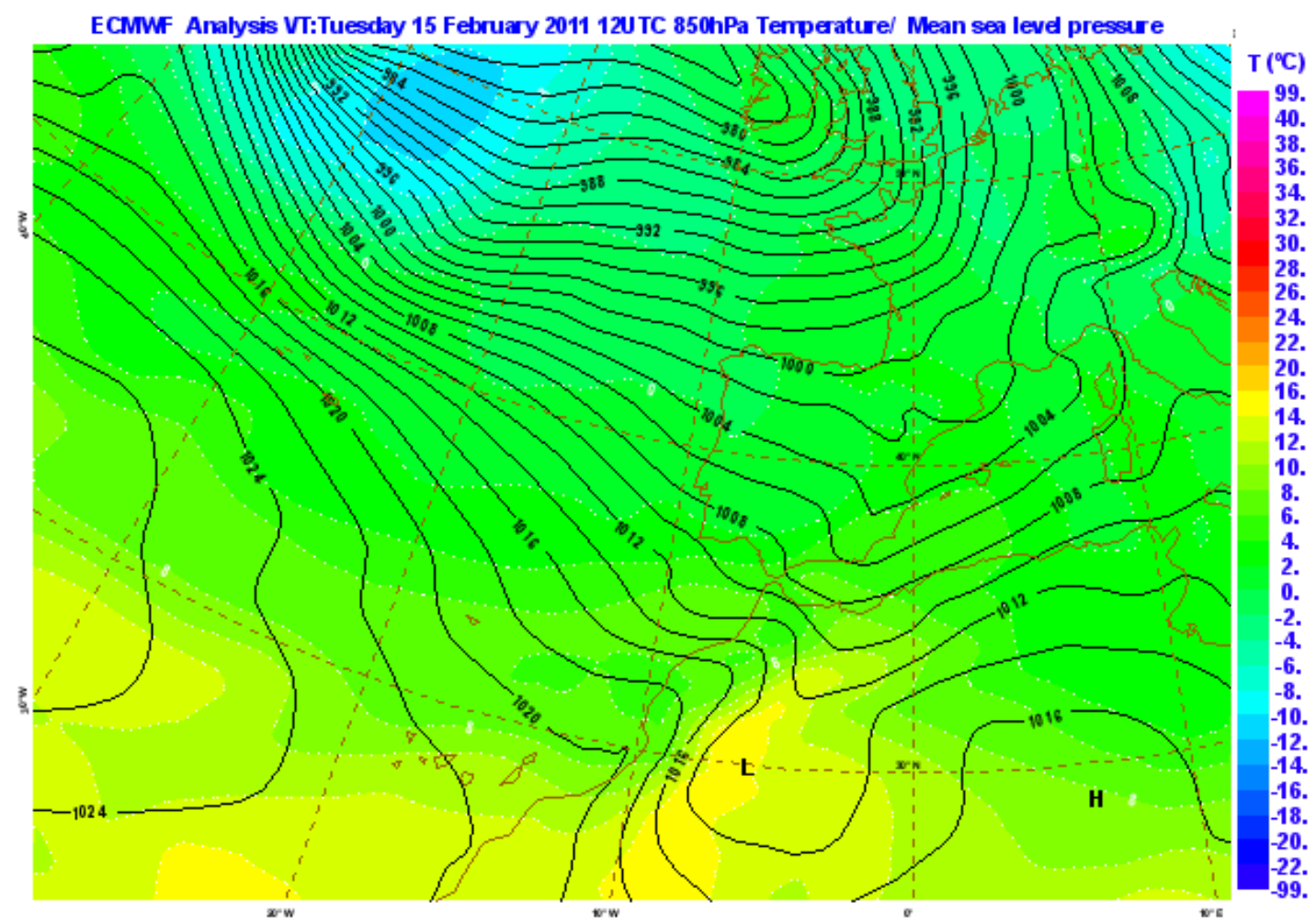

Figura IV.2.17: Presión reducida al nivel del mar y temperatura en 850 hPa. Análisis de ECMWF. Día 15 a las 12 UTC

La vaguada en la circulación de los oestes siguió avanzando y atravesó la Península durante el día 15. A las 18 UTC puede apreciarse el eje de vaguada atravesando el centro de la Península. Continúa apareciendo un máximo de viento con salida hacia el Golfo de Cádiz y Estrecho (Figuras IV.2.18 y IV.2.19). 


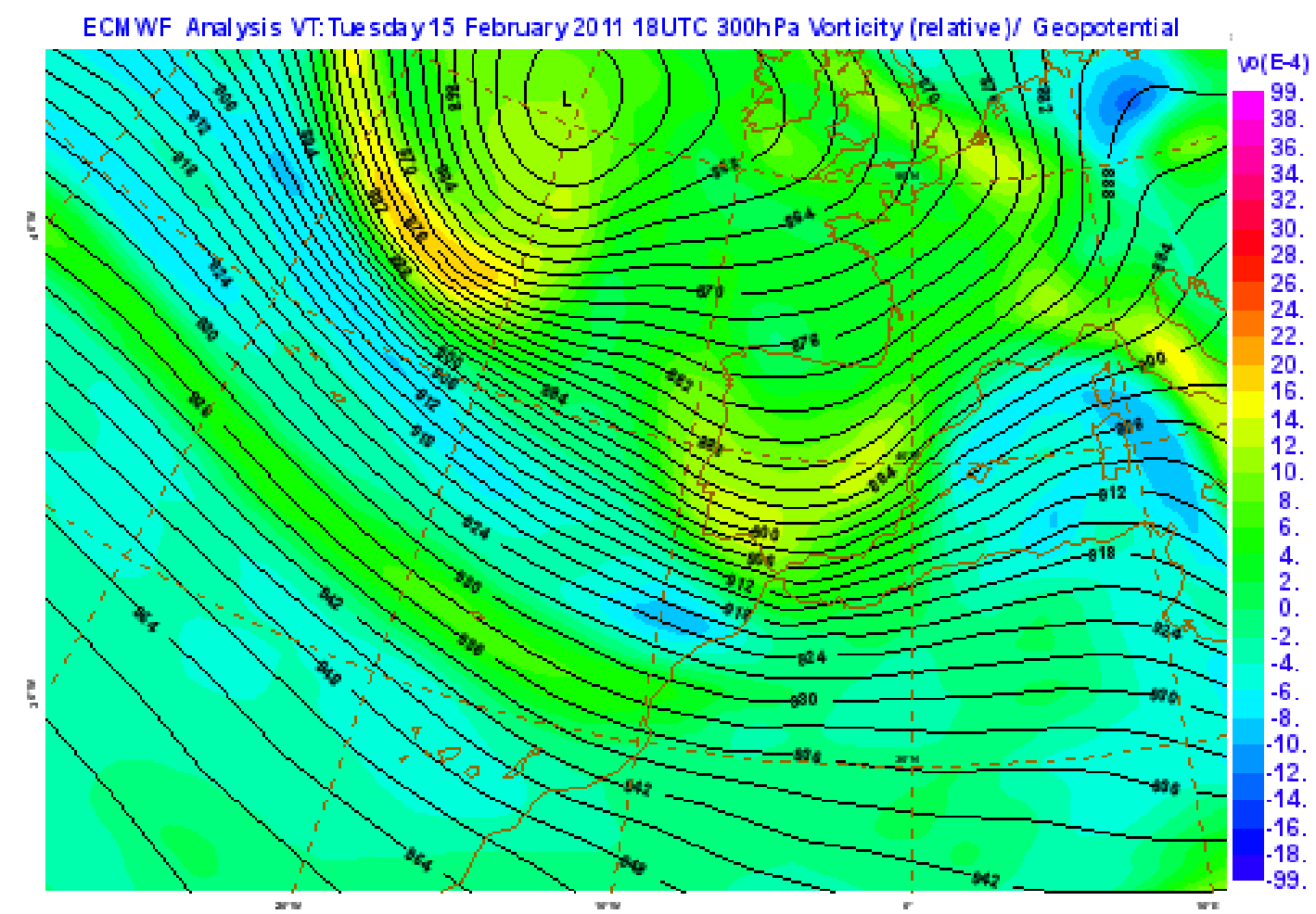

Figura IV.2.18: Geopotencial y vorticidad relativa de 300 hPa. Análisis de ECMWF. Día 15 a las 18 UTC

ECMWF Analysis VT:Tuesday 15 February 2011 180 TC 300hPa Strmin / Wind Speed

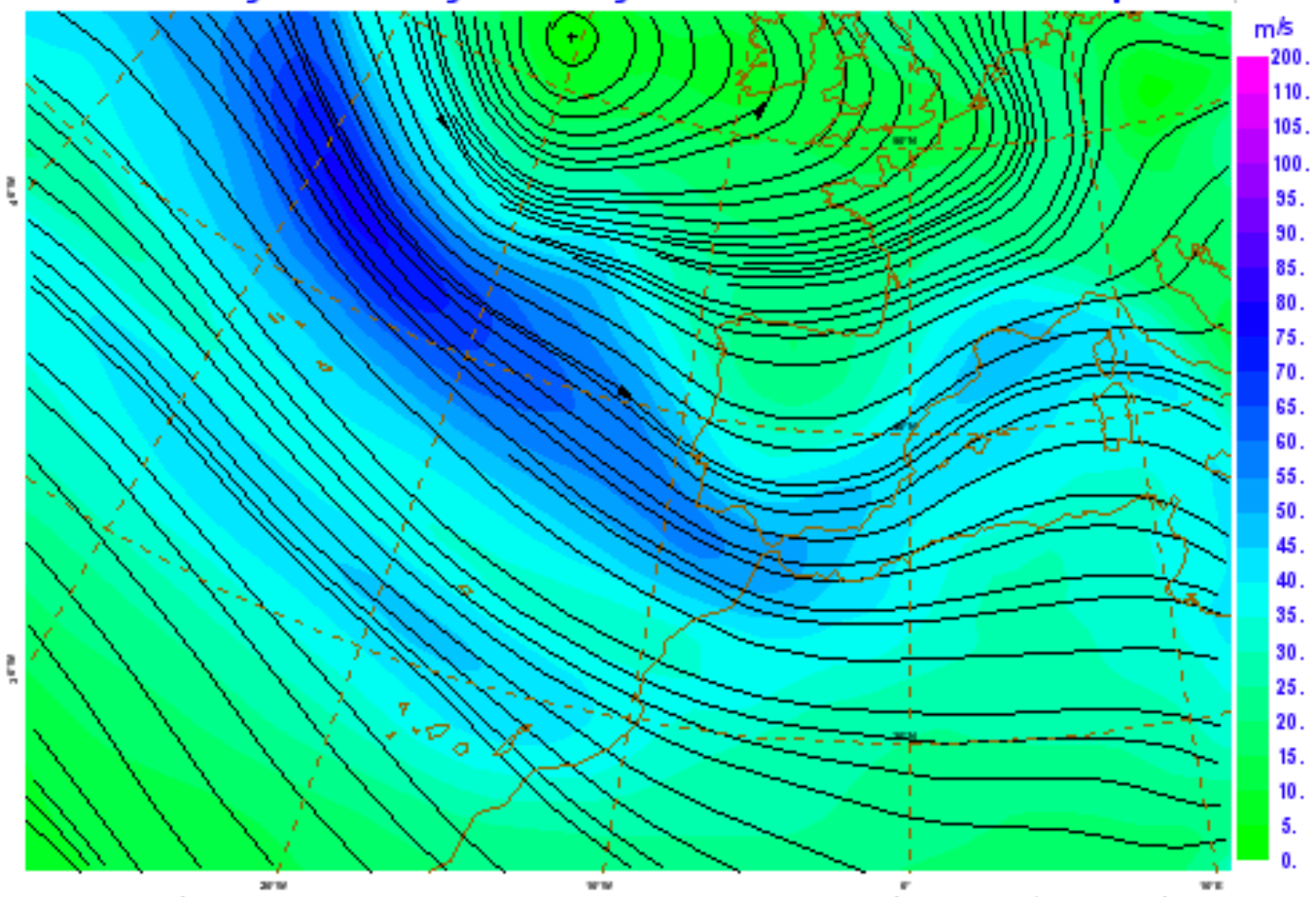

Figura IV.2.19: Líneas de corriente e isotacas al nivel de 300 hPa. Análisis de ECMWF. Día 15 a las 18 UTC

En $500 \mathrm{hPa}$, igual que en el análisis de las 12 UTC, la vaguada es menos marcada que en niveles altos. Se observa que el núcleo frío ha penetrado totalmente en la Península, con temperaturas entre $-20^{\circ}$ y $-24^{\circ} \mathrm{C}$ en la zona donde se produjo el primer tornado, en la provincia de Sevilla (Figura IV.2.20). Mientras tanto, en superficie, el flujo del oeste se curva a grandes rasgos de forma anticiclónica por el suroeste, aunque dentro de la cuña se aprecia una pequeña ondulación ciclónica desde Huelva hasta el centro de la Península. (Figura IV.2.21). 
ECMWF Analysis VT:Tuesday 15 February 2011 18UTC 500hPa Temperature/ Geopotential

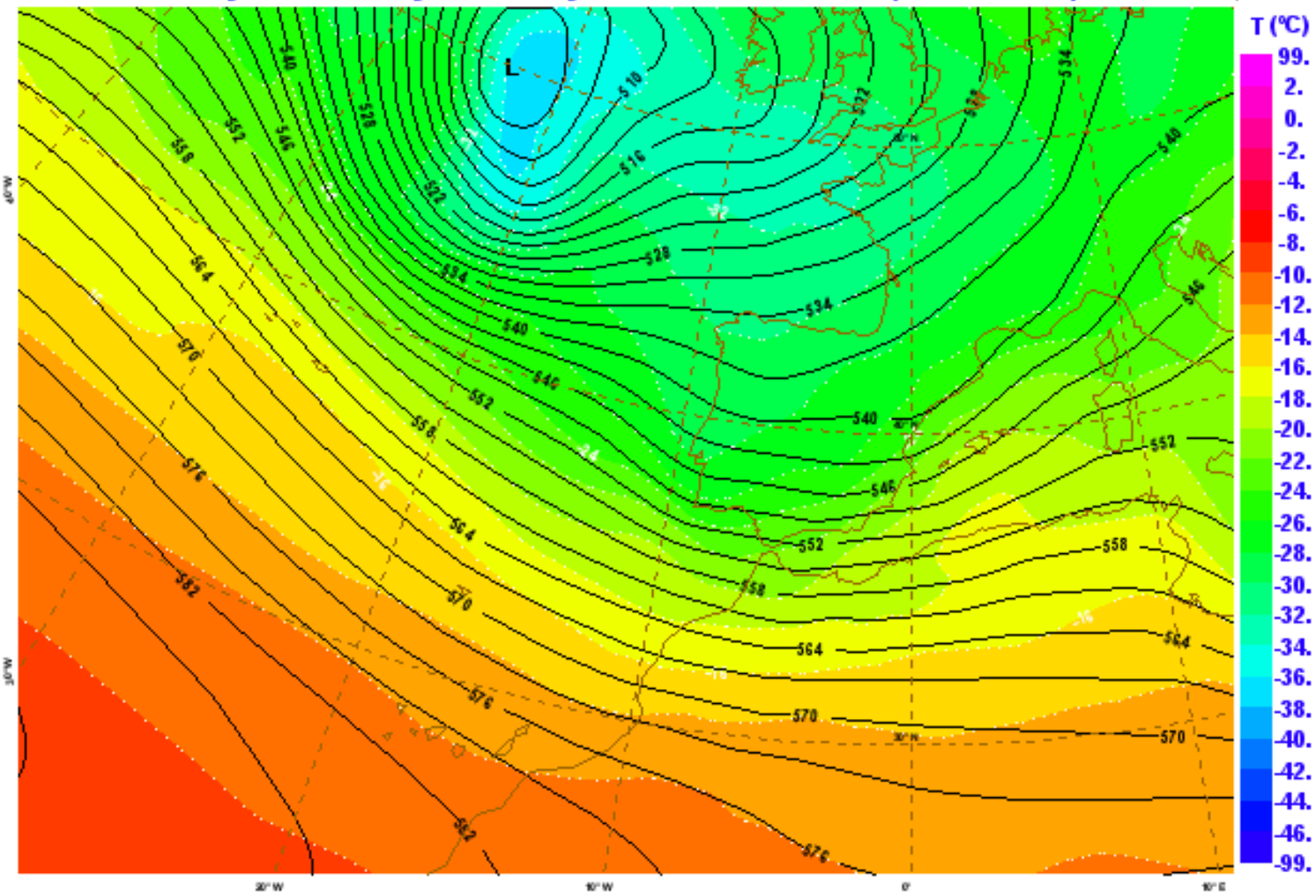

Figura IV.2.20: Geopotencial y temperatura al nivel de 500 hPa. Análisis de ECMWF. Día 15 a las 18 UTC

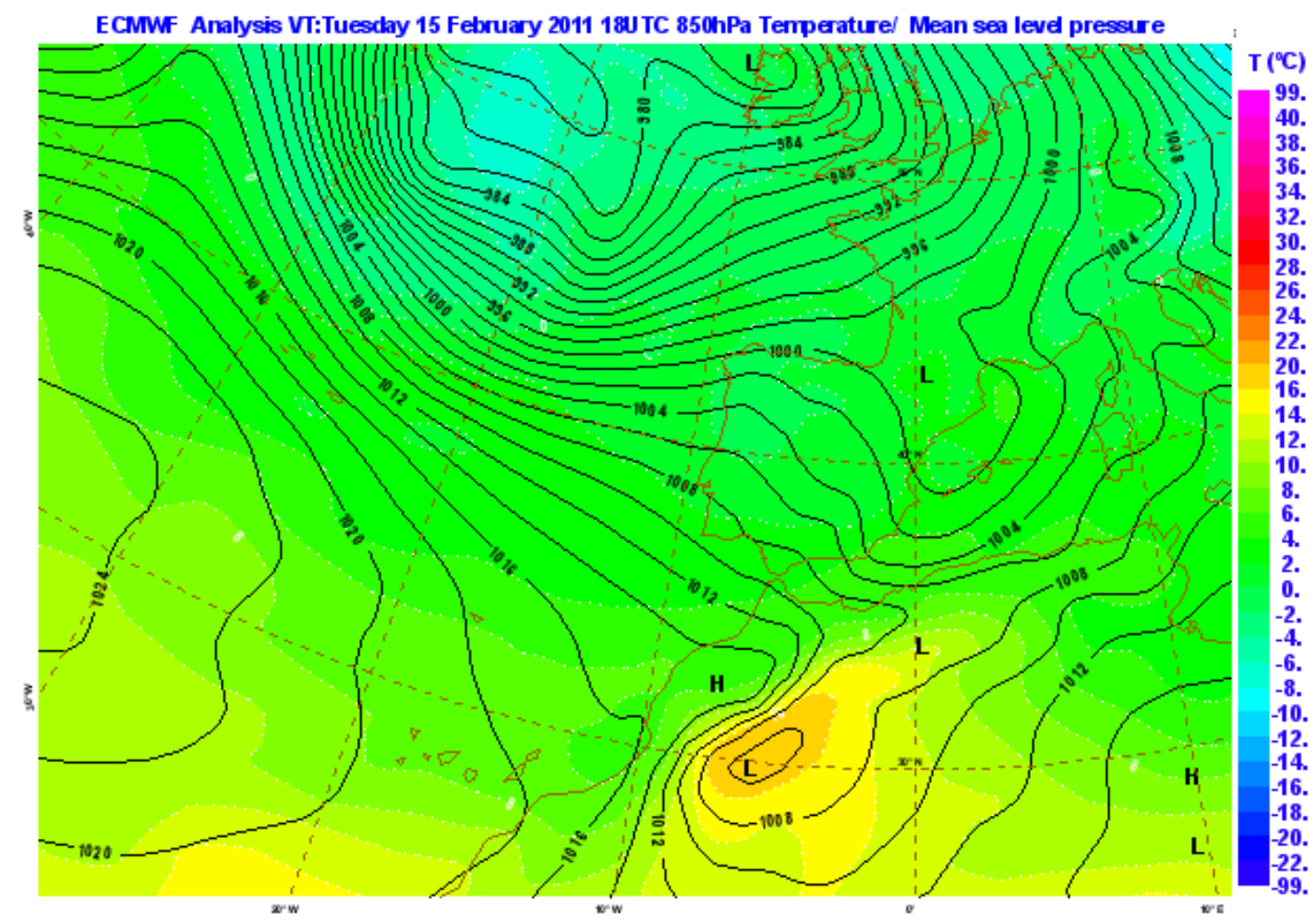

Figura IV.2.21: Presión reducida al nivel del mar y temperatura en 850 hPa. Análisis de ECMWF. Día 15 a las 18 UTC

El tornado ocurre alrededor de las 16 UTC, en el seno de la descarga fría. La identificación de los daños causados mostraba la existencia de una trayectoria de unos $200 \mathrm{~m}$ de largo y unos $10 \mathrm{~m}$ de ancho y algunos testimonios eran también compatibles con la ocurrencia de un pequeño tornado. En la imagen del canal visible de Meteosat (Figura IV.2.22) se observa un cúmulo en desarrollo, en el límite oeste de una zona con abundante nubosidad baja. Destaca la sombra al norte de dicho cúmulo, así como la extensión de la nubosidad en forma de cola hacia el sureste, posiblemente indicativa de la cizalladura vertical existente en el entorno. No hay eco radar en ese momento, y tampoco se detectan rayos en la zona, ni antes ni inmediatamente después del evento. 


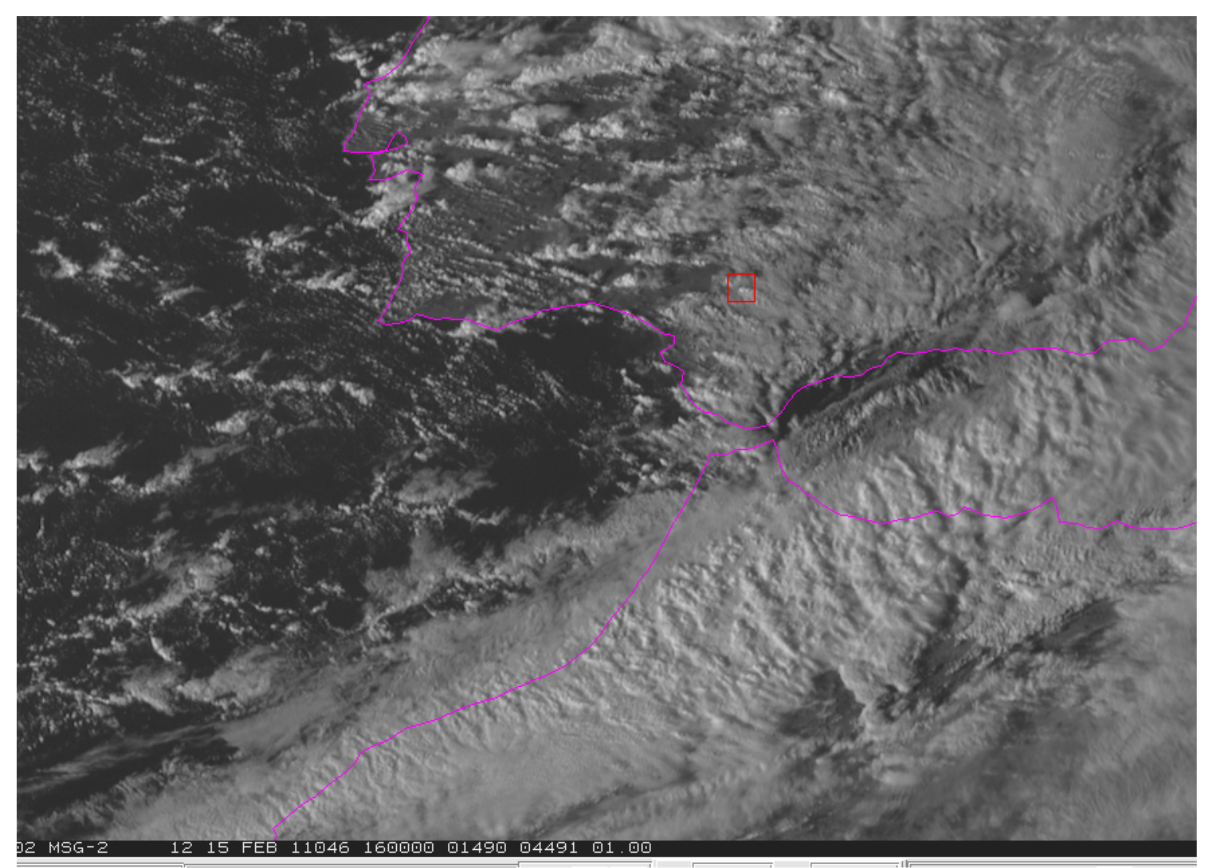

Figura IV.2.22: Imagen del canal HRV de MSG del día 15 a las 16 UTC. Se señala el cúmulo al que probablemente estuvo asociado el tornado de Alcalá de Guadaíra (Sevilla).

En la zona de la descarga fría, a partir del análisis del ECMWF se observa cierta inestabilidad y moderada cizalladura vertical, más importante en niveles bajos. (Figura IV.2.23 y IV.2.24).

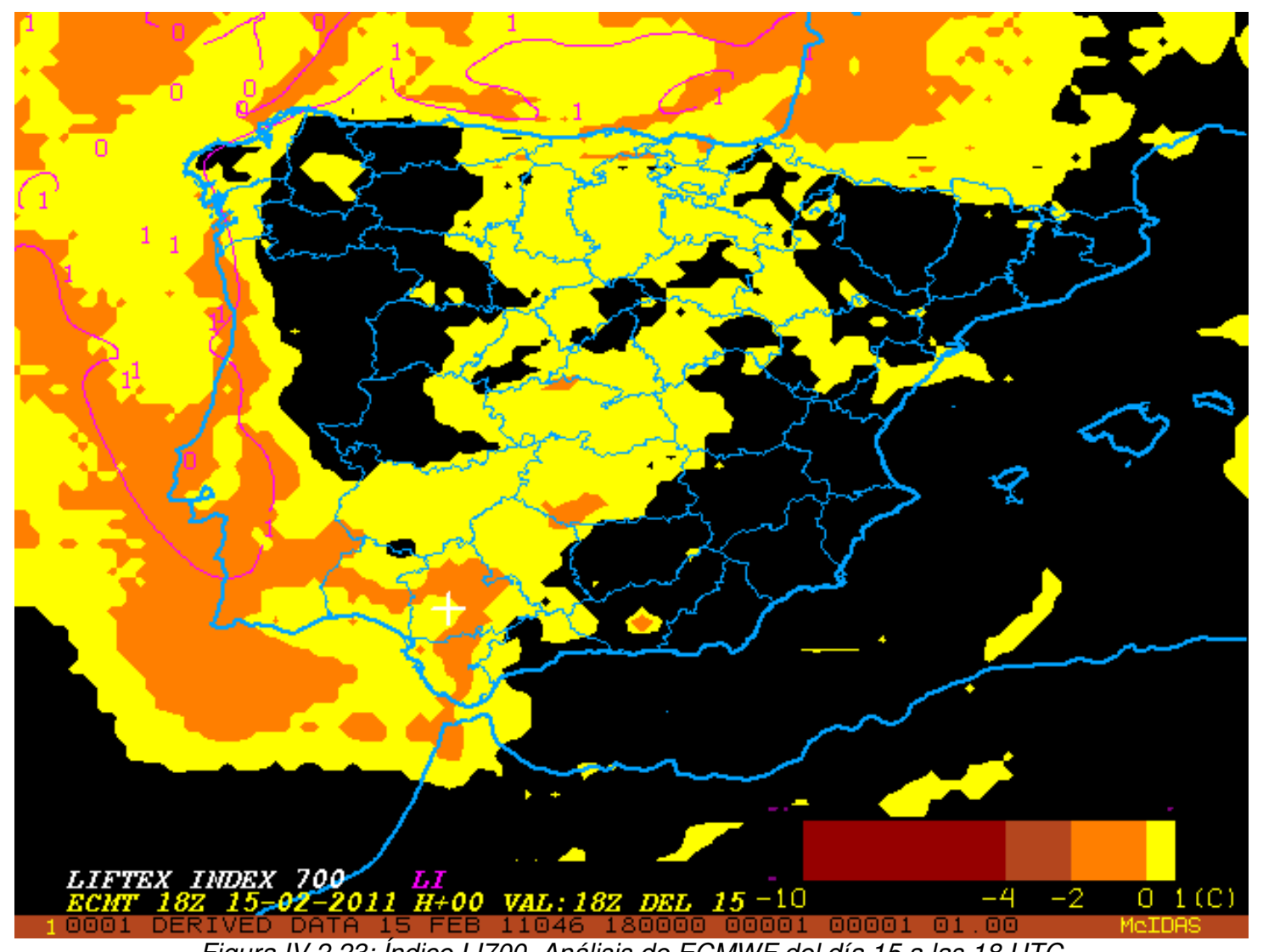

Figura IV.2.23: Índice LI700. Análisis de ECMWF del día 15 a las 18 UTC 


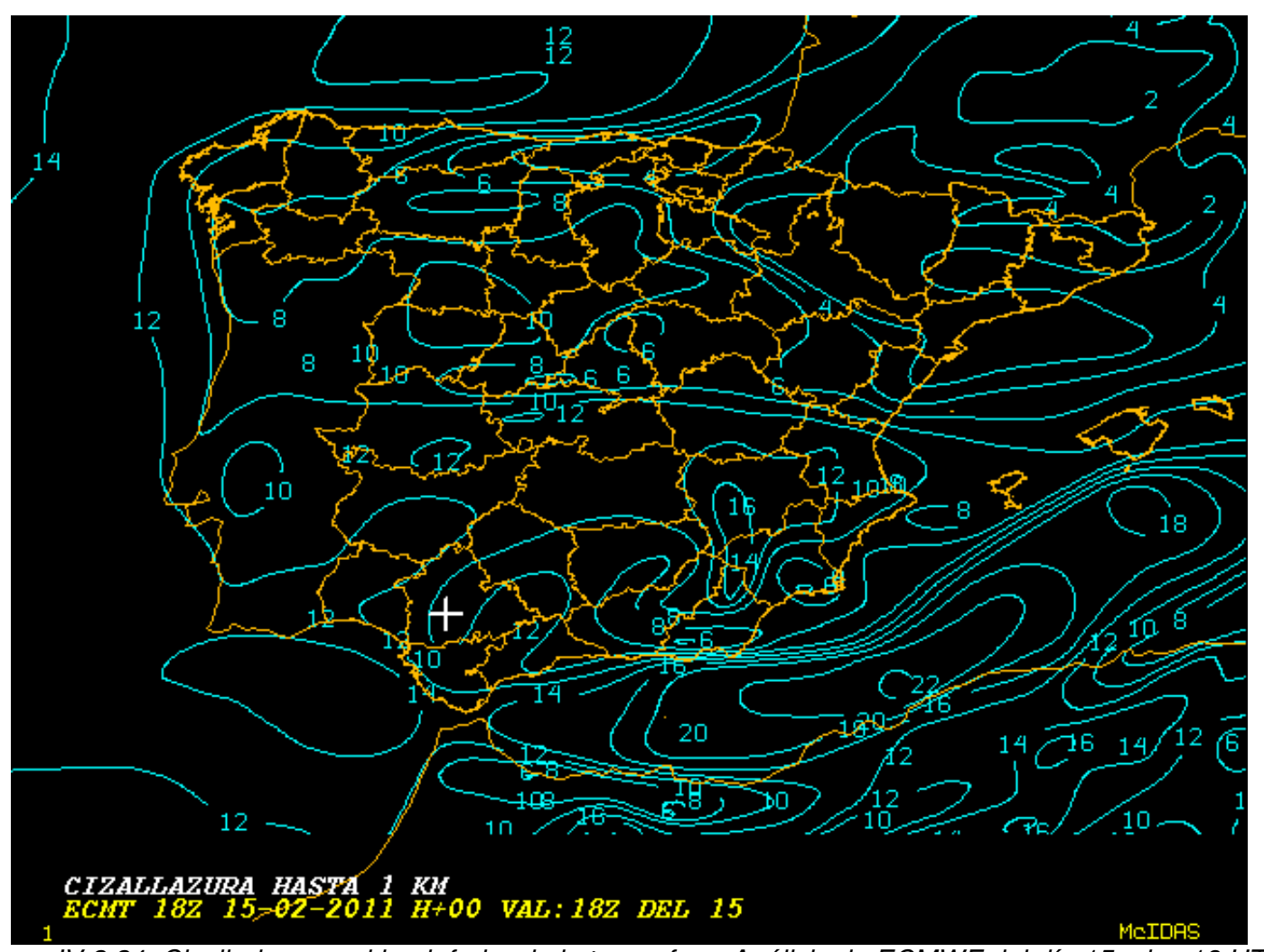

Figura IV.2.24: Cizalladura en el km inferior de la troposfera. Análisis de ECMWF del día 15 a las 18 UTC.

En esa zona frontera existía una marcada discontinuidad de viento, del suroeste por delante y del oeste por detrás, tal y como se observa en los datos de estaciones automáticas cercanas (Figura IV.2.25)

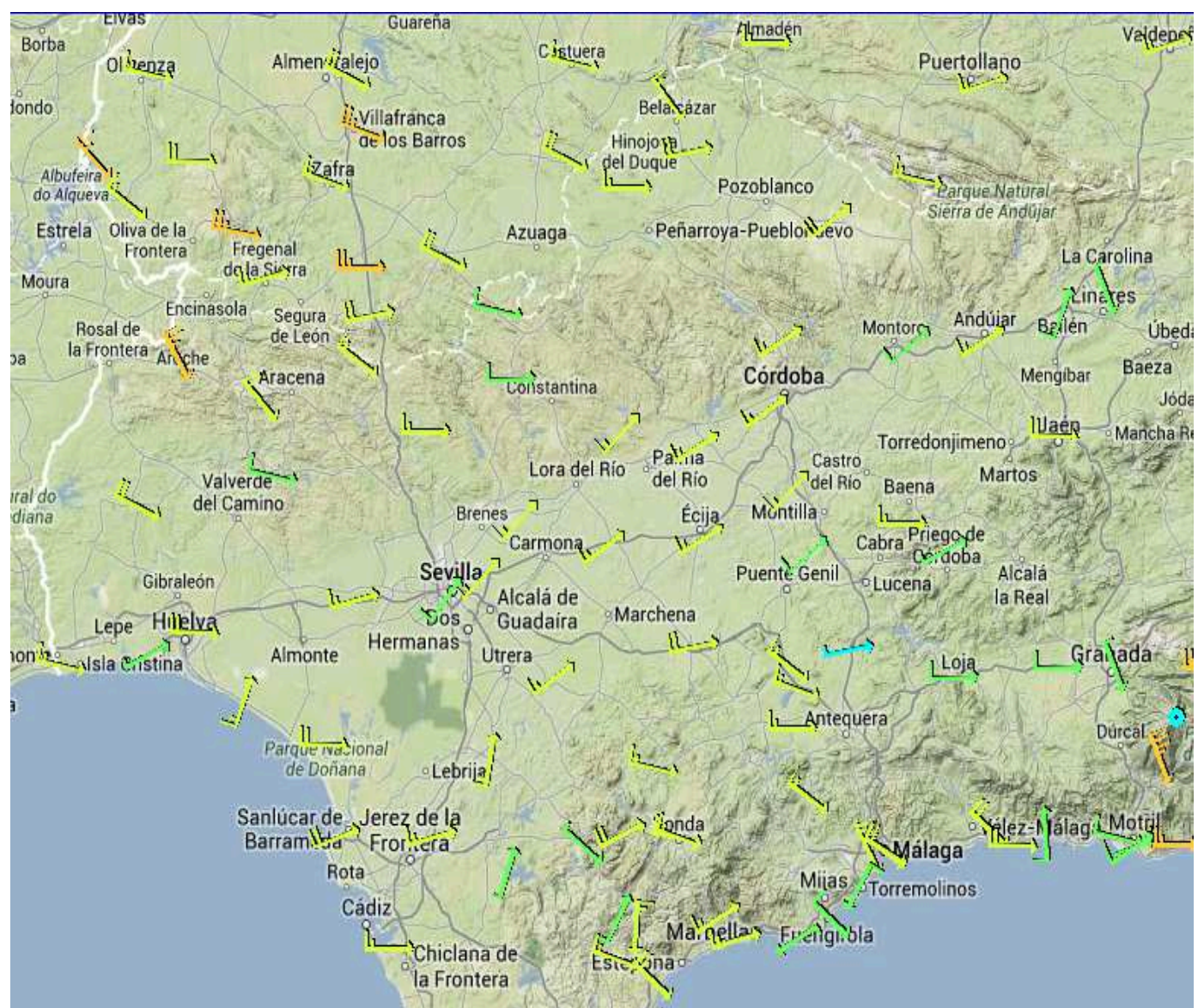

Figura IV.2.25: Rachas máximas registradas en EMAS de AEMET la hora anterior a las 16 UTC del día 15. 
Posiblemente, el rápido desarrollo de la convección sobre dicha frontera causó un tornado tipo landspout por estiramiento de la vorticidad vertical preexistente en superficie. Este episodio sería similar a otros de formación de trombas marinas en el litoral del golfo de Cádiz, también en el seno de una descarga fría postfrontal. (Figura IV.2.26 a, b y c, tornado en San Fernando - Cádiz, el 22-12-2010).

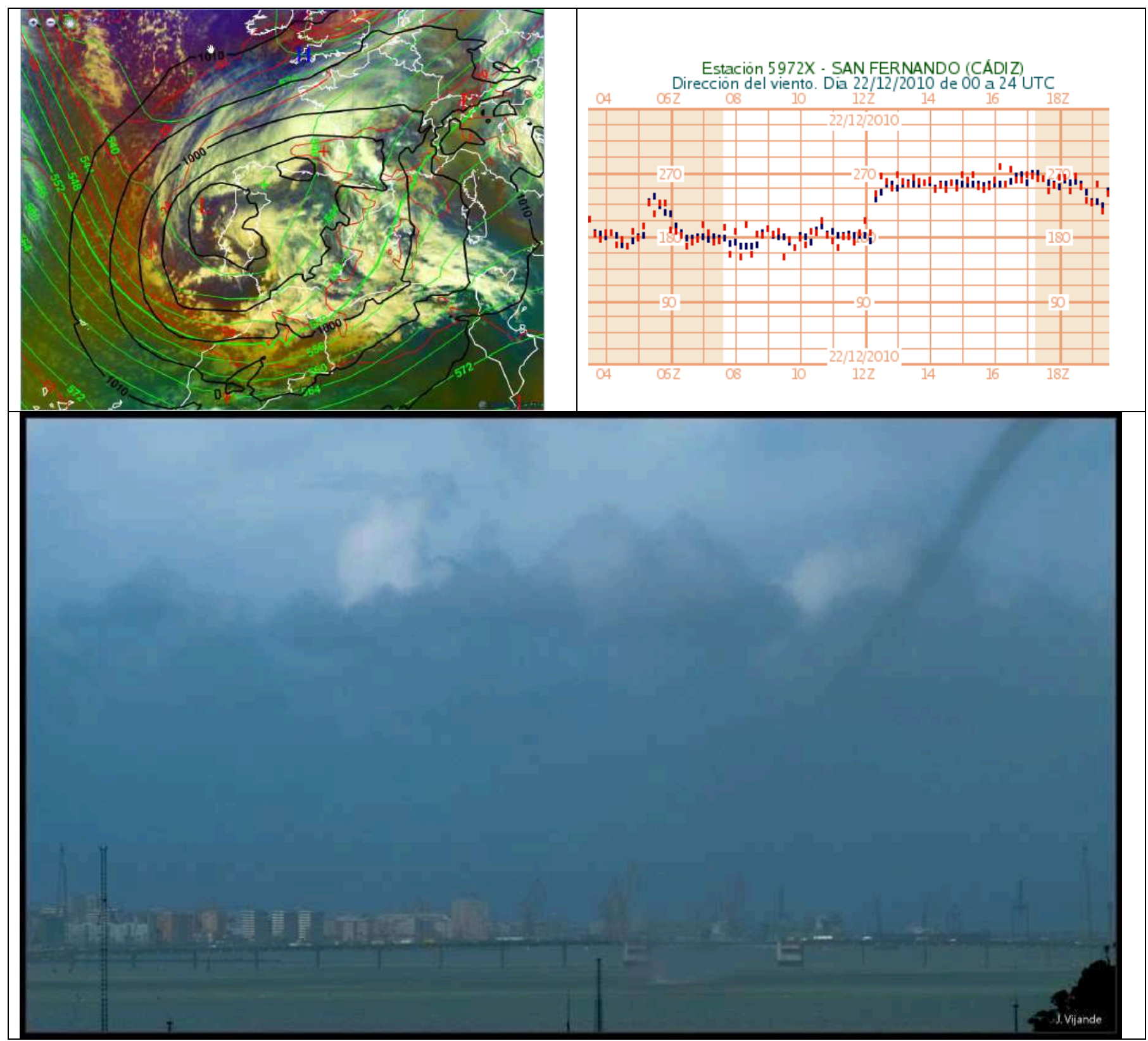

Figura IV.2.26. a: Presión al nivel del mar, Z500 y T500 de ECMWF a las 12 UTC, sobre imagen airmass RGB de MSG

b: Análisis de y registro de dirección de viento en la EMA de San Fernando. Se deduce de la misma el paso de una línea de marcada cizalladura horizontal por la zona donde se desarrolla la célula que origina el tornado

c: Imagen de una de las trombas marinas que se formaron en San Fernando (Cádiz), el 22 de Diciembre de 2010 a las 12 UTC. Esta u otra tromba entró en la ciudad causando destrozos asimilables a EFO o EF1. 


\section{IV.2.2.2. Situación invernal del tornado de 16 de febrero de 2011 en el Arahal (Sevilla)}

A las 18 UTC del 16 de febrero, un eje de vaguada se situó sobre el oeste de la Península, observándose una marcada advección de vorticidad por cizalladura y empujada por un potente máximo de chorro de más de 70 $\mathrm{m} / \mathrm{s}$ con salida hacia el cabo San Vicente. (Figura IV.2.27 a y b).

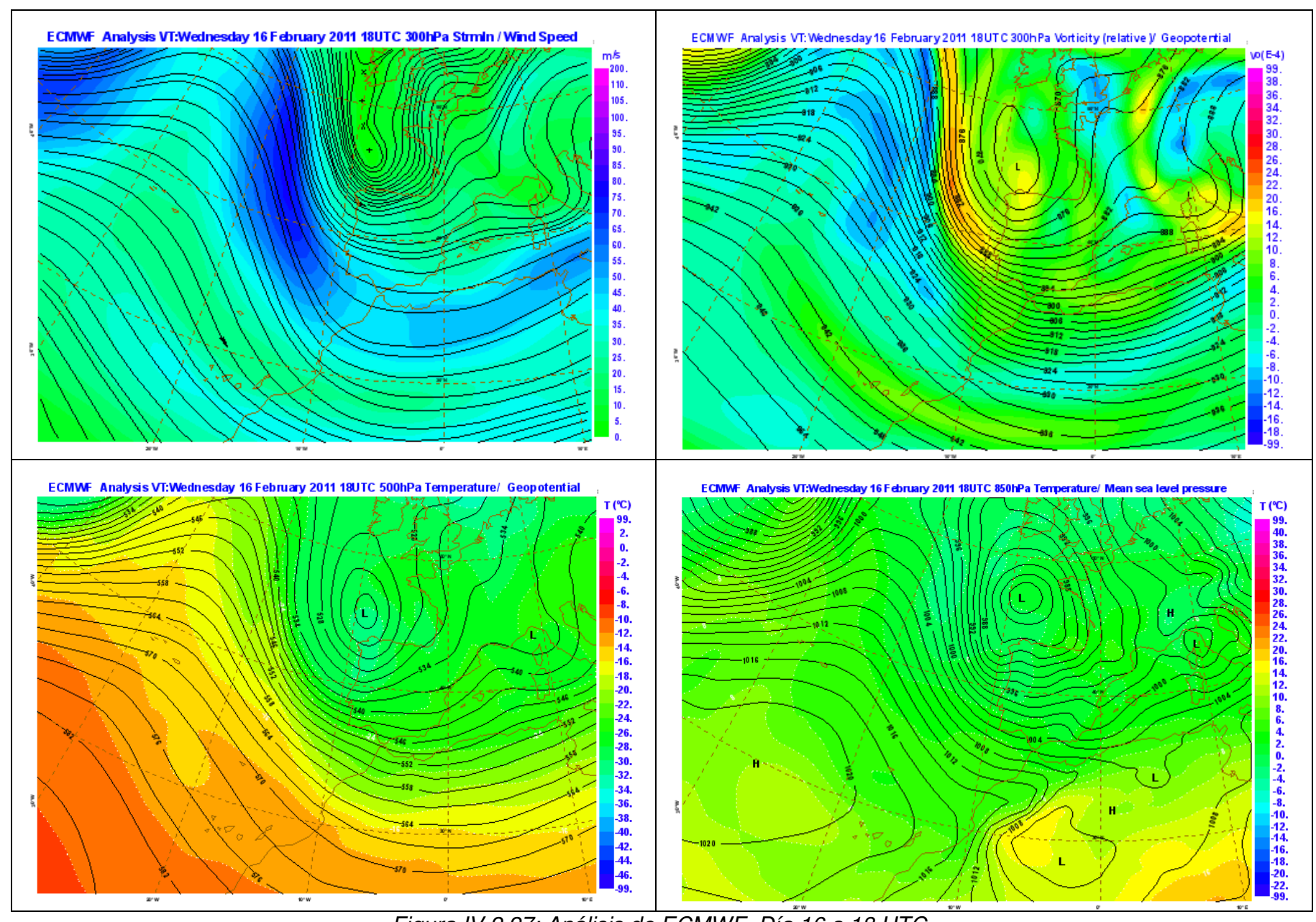

Figura IV.2.27: Análisis de ECMWF. Día 16 a 18 UTC.

a) Líneas de corriente e isotacas al nivel de $300 \mathrm{hPa}$. b) Geopotencial y vorticidad relativa de $300 \mathrm{hPa}$. c) Geopotencial y temperatura al nivel de $500 \mathrm{hPa}$. d) Presión reducida al nivel del mar y temperatura en $850 \mathrm{hPa}$.

En $500 \mathrm{hPa}$ se observa la vaguada muy marcada sobre Portugal, con aire bastante frío (isoterma de -30ํㅡㄴ C) sobre el noroeste peninsular y difluencia sobre el suroeste. (Figura IV.2.27, c).

En superficie el flujo es más de oeste que de suroeste, intensificándose con relación a las horas anteriores. Sobre el sur de la Península se aprecia un pequeño dedo cálido en $850 \mathrm{hPa}$, coincidente en el tiempo y el espacio con la zona de formación del tornado de Arahal (Figura IV.2.27, d).

La intensidad de los vientos queda patente a partir de los datos servidos por el sensor "ASCAT" (Figura IV.2.28), mostrando en el mar vientos entre 30 y $35 \mathrm{KT}$ en la zona del Golfo de Cádiz, cuya intensidad se mantiene durante todo el día.

La advección cálida en niveles bajos junto a la extensión de la bolsa de aire frío en niveles medios hacia el oeste, unida a una muy importante cizalladura, sobre todo en niveles bajos, proporciona un ambiente propicio para la formación de células convectivas organizadas por delante del frente frío, en el sector cálido. En la zona de ocurrencia del tornado, a las 18 UTC, coincide un máximo relativo de inestabilidad con otro de helicidad relativa a la tormenta en niveles bajos. Los niveles de condensación son muy bajos y el perfil es muy húmedo en toda la columna (Figura IV.2.29). 


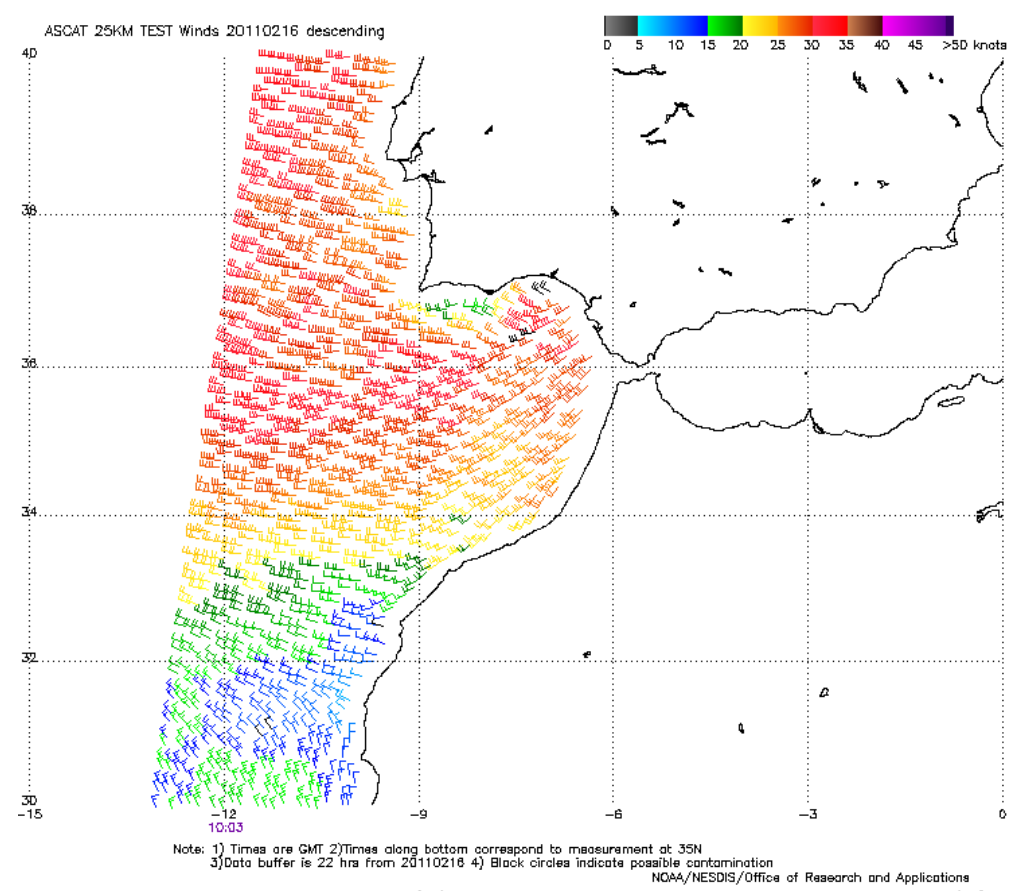

Figura IV.2.28: Vientos detectados por el sensor ASCAT cerca de las costas del golfo de Cádiz. Se observan valores superiores a $35 \mathrm{KT}$ en algunas zonas.
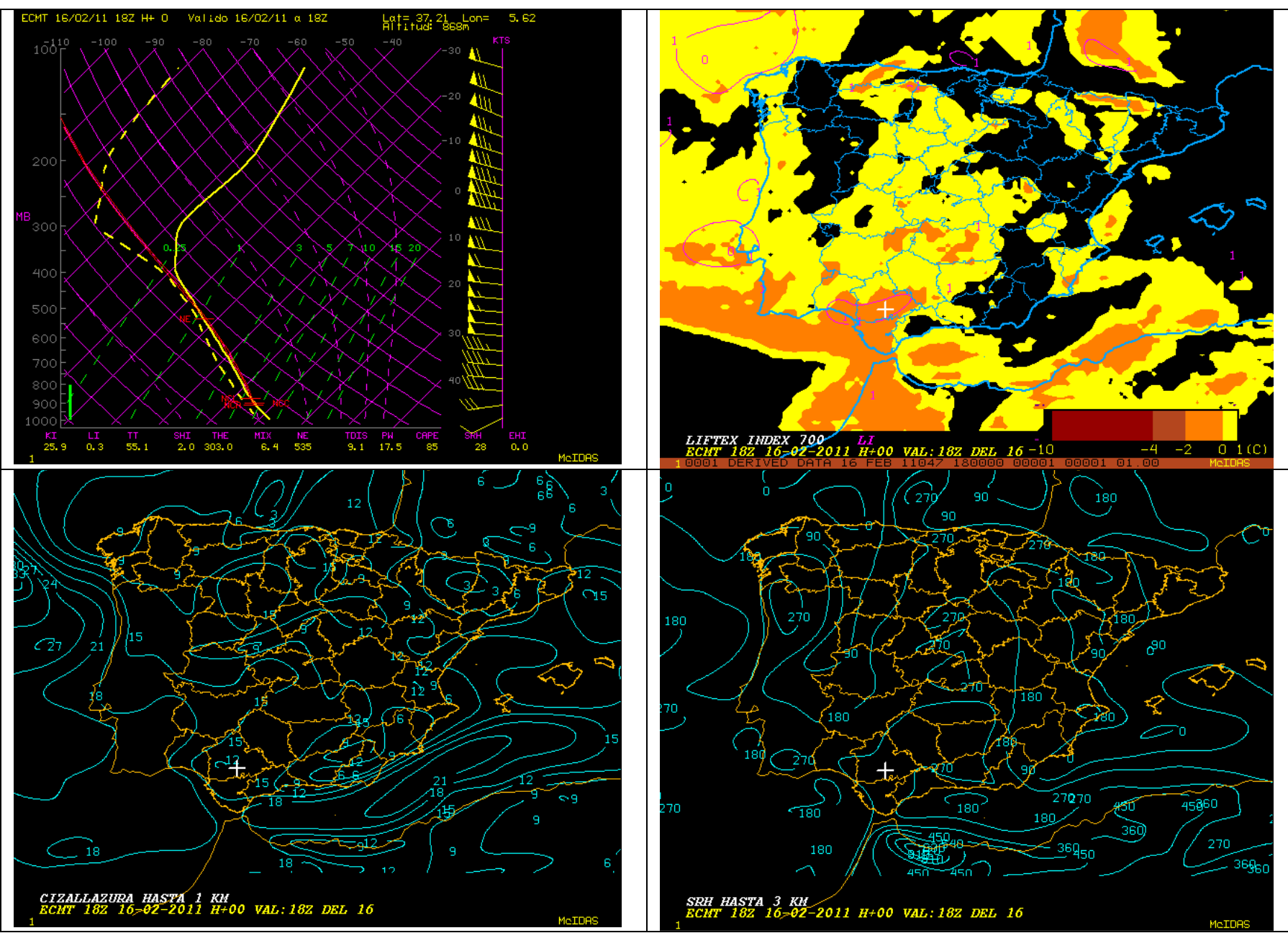

Figura IV.2.29: Análisis de ECMWF de las 18UTC. a) Perfil vertical en la zona del tornado de Arahal. Se observa un perfil muy húmedo, con moderada inestabilidad e importante cizalladura en la capa inestable, sobre todo en niveles bajos, donde se aprecia además un giro de viento ("veering") de suroeste a oeste. El nivel de equilibrio se sitúa ligeramente por debajo de 500 hPa, como es frecuente en invierno en la zona de interés. b) LI700. Se observan valores negativos en el golfo de Cádiz que se extienden por el sur del valle del Guadalquivir y la provincia de Cádiz. c) Cizalladura en el km inferior de la troposfera. Se observan valores significativos, de entre 12 y $15 \mathrm{~s}^{-1}$ en el interior de la provincia de Sevilla, en la zona de ocurrencia del tornado d) Helicidad relativa a la tormenta hasta $3 \mathrm{~km}$. Se observan valores muy importantes, superiores a $270 \mathrm{~m}^{2} \mathrm{~s}^{-2}$ en una amplia zona del S de la Península 
Una de esas células se observa formada a las 18 UTC en el Valle del Guadalquivir, por delante del frente. No se dispone de imágenes del radar de Sevilla, por fortuna sí del de Málaga, aunque los bloqueos orográficos no permiten una cobertura óptima de dicha célula. No obstante se puede intuir una estructura organizada que se mantiene en el tiempo durante varios ciclos de radar. Se identifica en el PPI de reflectividad la existencia de una estructura en gancho. En el PPI de viento radial se observa la persistencia en dicha célula de un patrón compatible con una estructura rotatoria, perceptible incluso en un corte vertical (Figura IV.2.30)

Pero lo más útil para la caracterización de dicha célula es un vídeo tomado desde la Base Aérea de Morón. En él se observa cómo se forma el tornado en la base de lo que parece claramente una nube pared ("wall cloud"). El tornado toca tierra rápidamente y se va ensanchando, recorriendo en unos 5 minutos todo el horizonte visible hacia el norte desde la Base Aérea. (Figura IV.2.31). Esta secuencia de imágenes refuerza la idea del carácter mesociclónico del tornado. Clave en su formación habría sido por tanto la transformación de vorticidad horizontal en vertical. Factores favorecedores de la formación del tornado serían también los bajos niveles de condensación y la convergencia de viento en superficie por delante del frente frío, realzada por la configuración orográfica del bajo Valle del Guadalquivir.

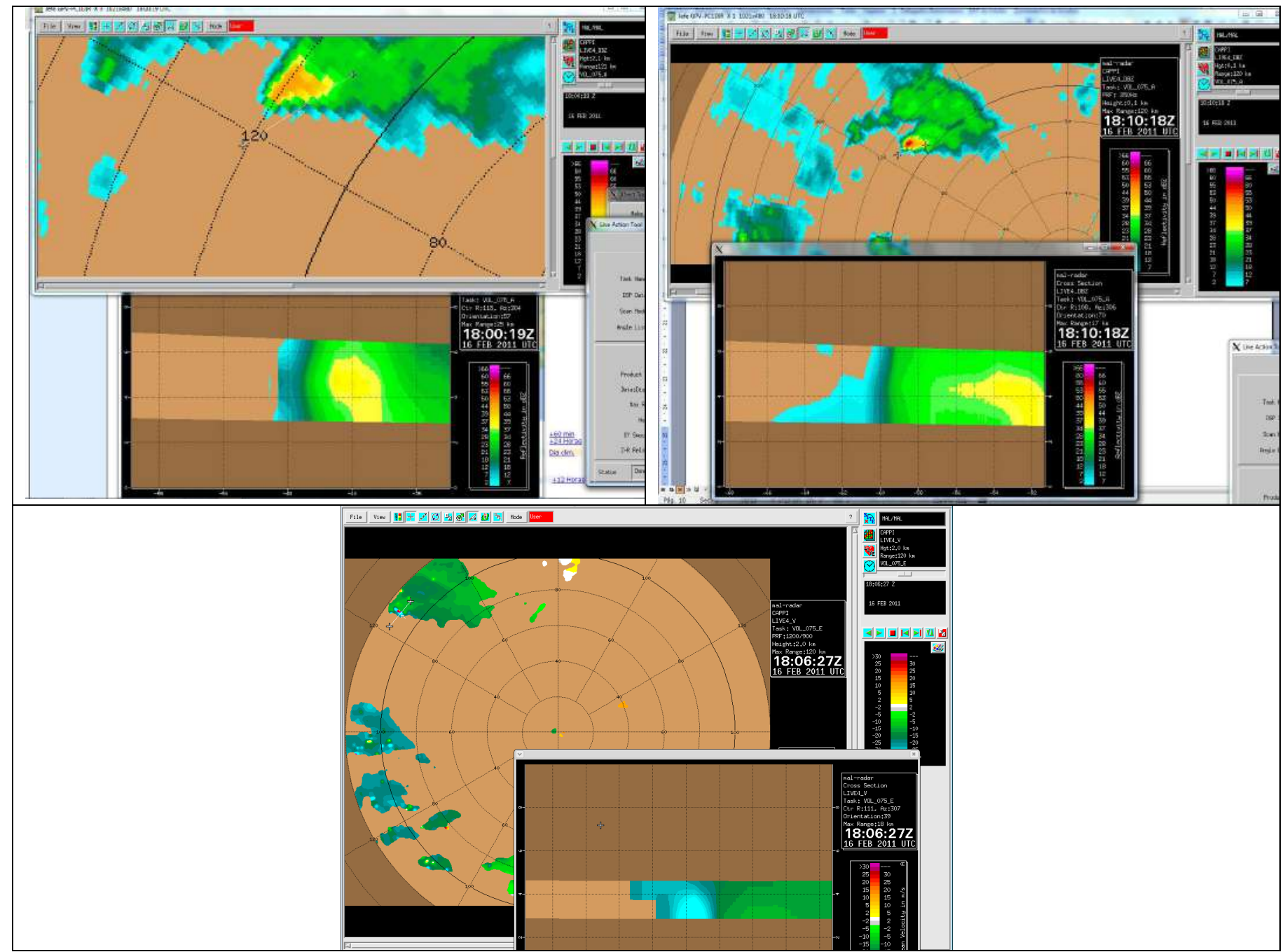

Figura IV.2.30: Radar de Málaga. CAPPI más bajo y corte vertical de reflectividad durante el intervalo aproximado de ocurrencia del tornado: a) a las 18 UTC b) a las 18:10 UTC. A pesar de la lejanía del radar se observa la existencia de estructuras típicamente supercelulares, aunque poco marcadas: gancho en la horizontal y en la vertical, "V-notch", "inflow notch", que se mantienen visibles en sucesivas exploraciones radar. c) imagen de viento radial y corte vertical a las 18:06 UTC.

Se aprecia levemente una estructura rotatoria con reflejo en toda la estructura vertical del eco observable en el radar. Las velocidades de salida aparecen ligeramente negativas (tonos verdes) debido a la velocidad de traslación de la célula, con una componente importante en dirección al radar. 

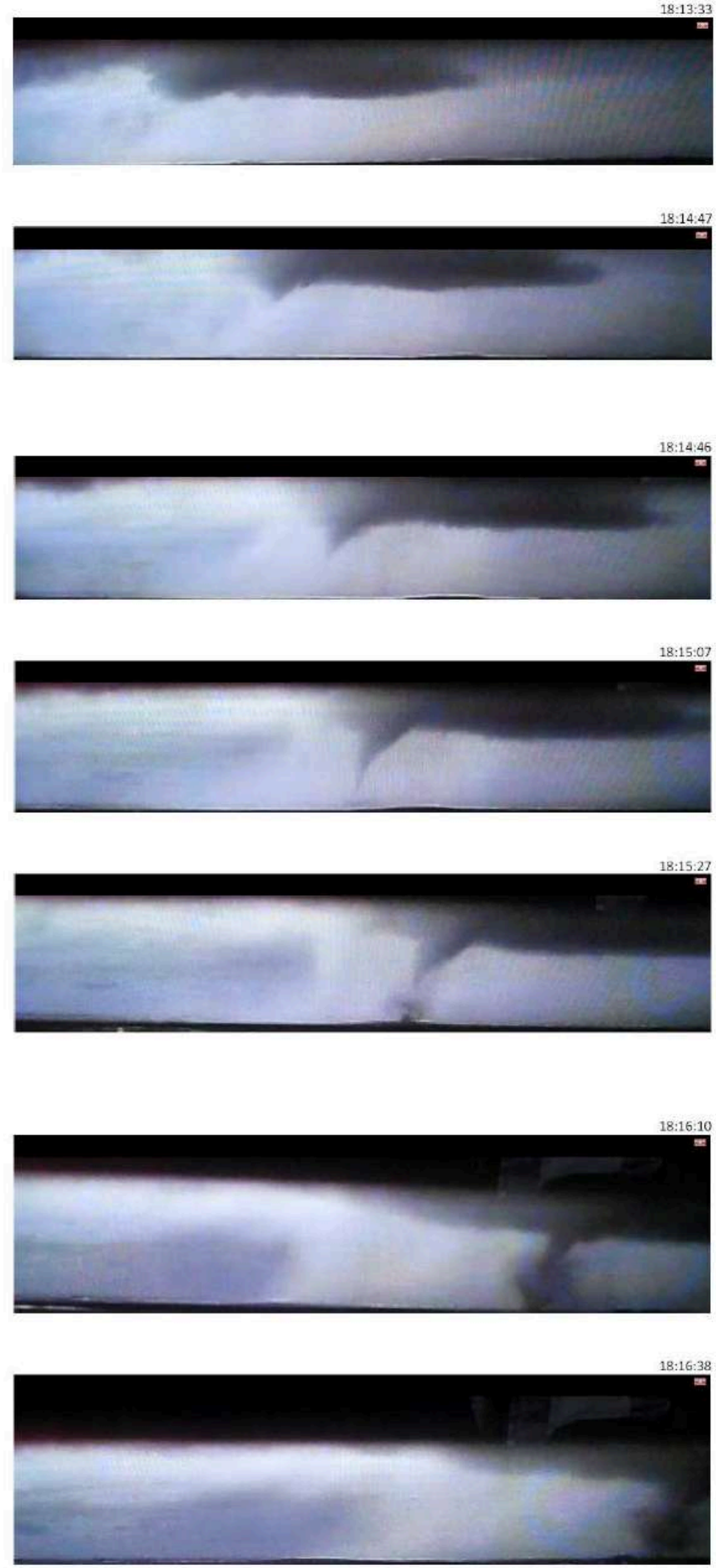

Figura IV.2.31: Secuencia de fotogramas de un vídeo del tornado de Arahal, tomado desde la torre de control de la Base Aérea de Morón. Las horas son UTC. El tornado se forma cerca del extremo oeste del "wall cloud" y se desplaza poco a poco hacia el centro de la misma. Cortesía de Benito Fuentes (AEMET). 


\section{IV.3 Tornados de primavera-verano}

En España se registran tornados en todas las estaciones del año. En la costa Mediterránea son más frecuentes en otoño o a finales del verano. En el litoral Atlántico y zonas llanas adyacentes, la época de mayor frecuencia de tornados coincide con los meses más fríos. En las zonas interiores los tornados son menos frecuentes, pero en ocasiones resultan más intensos. Se presentan al final de la primavera y sobre todo en verano, en situaciones de fuerte inestabilidad térmica e importante cizalladura.

A continuación se expondrán las características de las situaciones en las que se originan estos tornados y se estudiará con más detalle el episodio del 23 de julio de 2003, cuando un tornado de categoría EF2/EF3 asoló zonas rurales de los municipios de Alcañiz, Valdealgorfa y Mazaleón, en la provincia de Teruel.

\section{IV.3.1- Características de los tornados de interior en la península lbérica durante los meses cálidos.}

En el interior de España a finales de la primavera y durante el verano, el perfil vertical atmosférico tipo es muy seco en los niveles bajos. Esto hace que el calentamiento sea muy eficiente, y que en el caso de producirse un enfriamiento significativo en capas medias (basta muchas veces la presencia de aire a $-12^{\circ} \mathrm{C}$ en $500 \mathrm{hPa}$ ), se desarrollen grandes cantidades de CAPE provocándose fuertes tormentas en zonas favorables para que se generen convergencias (Sistema Ibérico, Pirineos, etc.). Es relativamente frecuente la ocurrencia de efectos severos en superficie asociados a estas tormentas, como granizo grande o fuertes rachas de viento. No obstante y aunque a veces la cizalladura sea elevada, estas tormentas suelen tener bases relativamente altas en muchas ocasiones, lo que limita la probabilidad de ocurrencia de tornados. No obstante, cuando el tornado se produce, puede llegar a alcanzar gran intensidad. Así parece que un tornado EF3 fue el responsable de la gran destrucción que asoló zonas de Madrid el 12 de mayo de 1886. Por tanto con cierta frecuencia se observan, en una situación geográfica muy diferente, ambientes que recuerdan a los de las supercélulas de las grandes llanuras americanas: cizalladura profunda y CAPE, pero en los que faltan otros ingredientes que acompañan a las supercélulas tornádicas, como la fuerte cizalladura y humedad relativa grande en la capa límite.

Tornados de importante intensidad ocurren de cuando en cuando en puntos de la provincia de Teruel, en el Sistema Ibérico. De hecho se tienen registros de tornados en los últimos años en Corbalán, Valdealgorfa y Sierra del Rayo. El Sistema Ibérico es una cadena montañosa muy erosionada y por tanto se caracteriza por ser una zona elevada con pendientes relativamente suaves. Muchas zonas son en realidad penillanuras elevadas (por encima de los $1000 \mathrm{~m}$ de altitud), donde la importante insolación diurna produce un gradiente térmico muy elevado entre la superficie y la atmósfera media. En esa área se produce además una convergencia a gran escala realzada por la presencia de la baja térmica Peninsular, muy frecuente en verano. Dicha baja favorece la entrada de vientos del oeste y suroeste procedentes del Atlántico, convergentes en las montañas interiores del este peninsular con las brisas del este procedentes del Mediterráneo (Capel, 1999). Seguramente esta es la principal causa del máximo de frecuencia de tormentas terrestres situado sobre dicha zona en verano (Figura II.5.9), así como de que las tormentas del interior peninsular se formen en sus estribaciones antes que en ningún otro lugar en los meses más cálidos.

Se han registrado tornados de estas características en los últimos años en otras zonas del interior (Guadalajara, Orense, Murcia), aunque dada la menor frecuencia de ocurrencia de tormentas, también el registro de tornados es menor.

El 23 de julio de 2003, un tornado arrasó campos de los términos municipales de Alcañiz, Valdealgorfa y Mazaleón, en la provincia de Teruel. Este tornado presenta las características básicas de los tornados de interior de primavera-verano. A continuación, y basándonos en buena medida en el estudio de Conesa (2004), repasamos de forma somera los principales ingredientes del entorno atmosférico y de la célula convectiva responsable del tornado.

\section{IV.3.2- Situación del día 23 de julio de 2003. Tornado de Valdealgorfa.}

Una onda corta atravesó la Península Ibérica, de oeste a este, a lo largo del día 23 de julio. A las 12 UTC se observa en niveles altos una vaguada muy apuntada, con un máximo de vorticidad orientado de NNE a SSW. Acompañando a la misma, un máximo de viento a la derecha del eje de vaguada se sitúa sobre el nordeste de la Península (Figuras IV.3.1 y IV.3.2). 


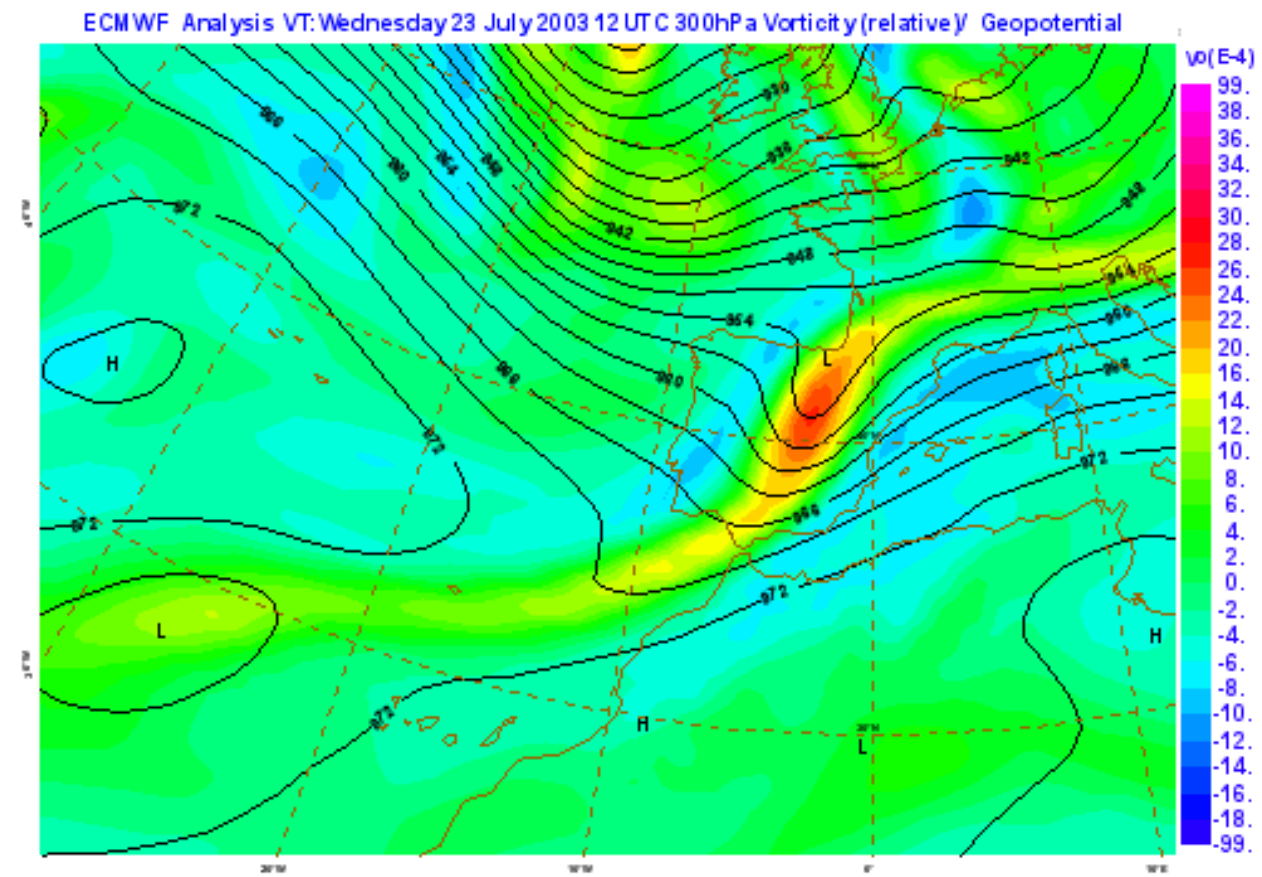

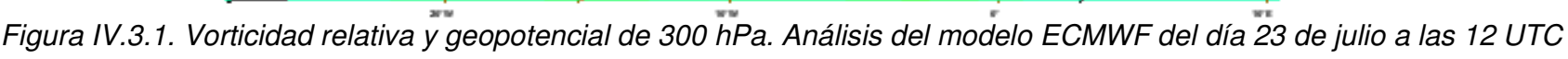

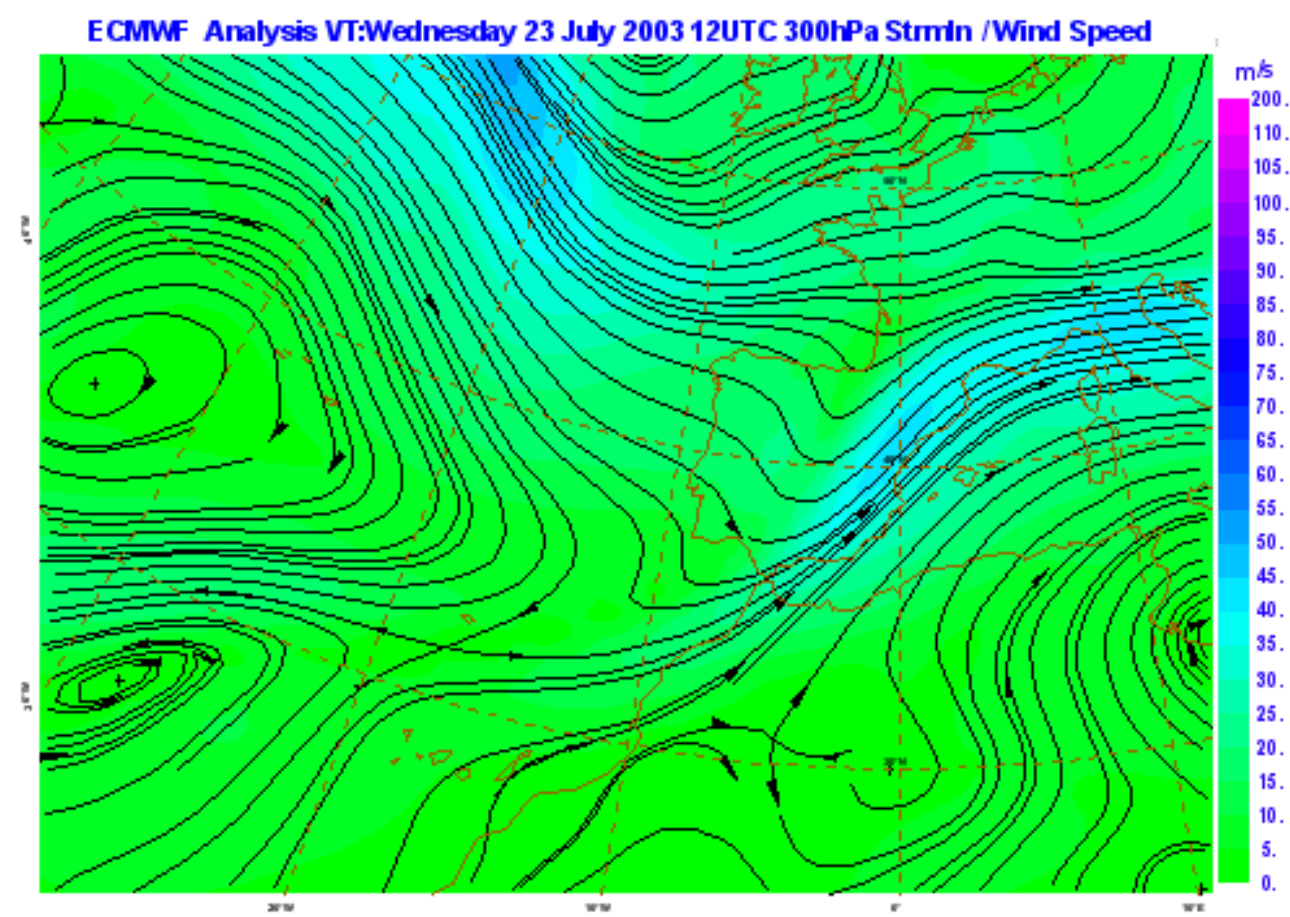

Figura IV.3.2. Líneas de corriente e isotacas en $300 \mathrm{hPa}$. Análisis del modelo ECMWF del día 23 de julio a las 12 UTC

En niveles medios $(500 \mathrm{hPa})$ una bolsa de aire frío a -12을 $\mathrm{C}$ precedía al eje de vaguada, haciendo coincidir la zona de mayor inestabilidad térmica con los vientos máximos en altura (Figura IV.3.3). 


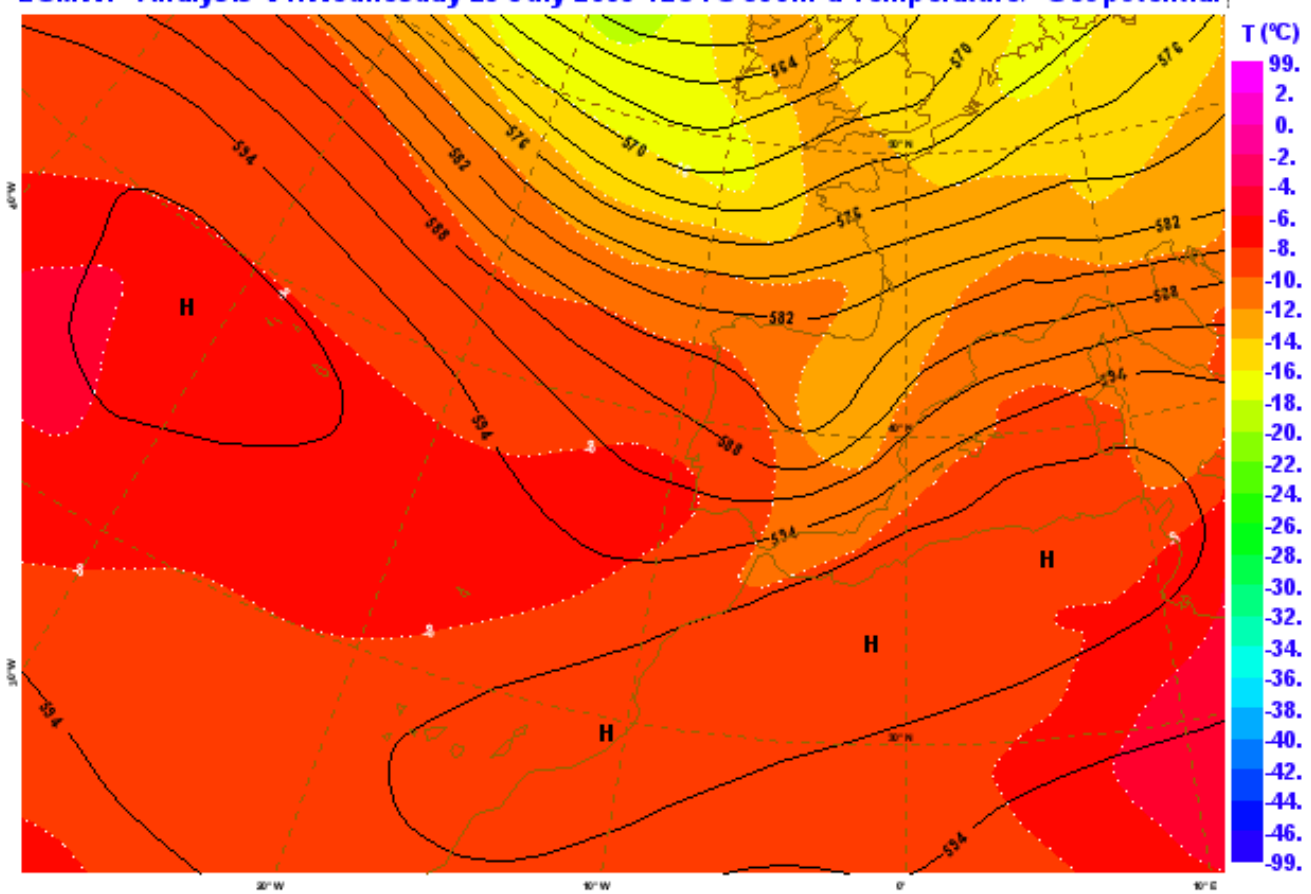

Figura IV.3.3. Geopotencial y temperatura de 500 hPa. Análisis del modelo ECMWF del día 23 de julio a las 12 UTC

En niveles bajos la situación era típicamente veraniega, con el anticiclón Atlántico centrado al oeste de la Península y bajas presiones relativas sobre el Mediterráneo Occidental. Una dorsal térmica ascendía desde el norte de África hacia Baleares y Cerdeña, manteniendo sobre el este de la Península temperaturas superiores a $20^{\circ} \mathrm{C}$ en $850 \mathrm{hPa}$ (Figura IV.3.4). Esta situación en superficie inducía un flujo de vientos del oeste sobre la mayor parte de la Península, aunque permitía el establecimiento de brisas del este sobre la costa Mediterránea. Como es frecuente en verano, aunque en este caso la baja térmica del interior peninsular no está presente como tal, el flujo general de vientos converge a gran escala sobre las montañas del nordeste peninsular, por tanto sobre la zona de estudio situada en el entorno del Sistema Ibérico.

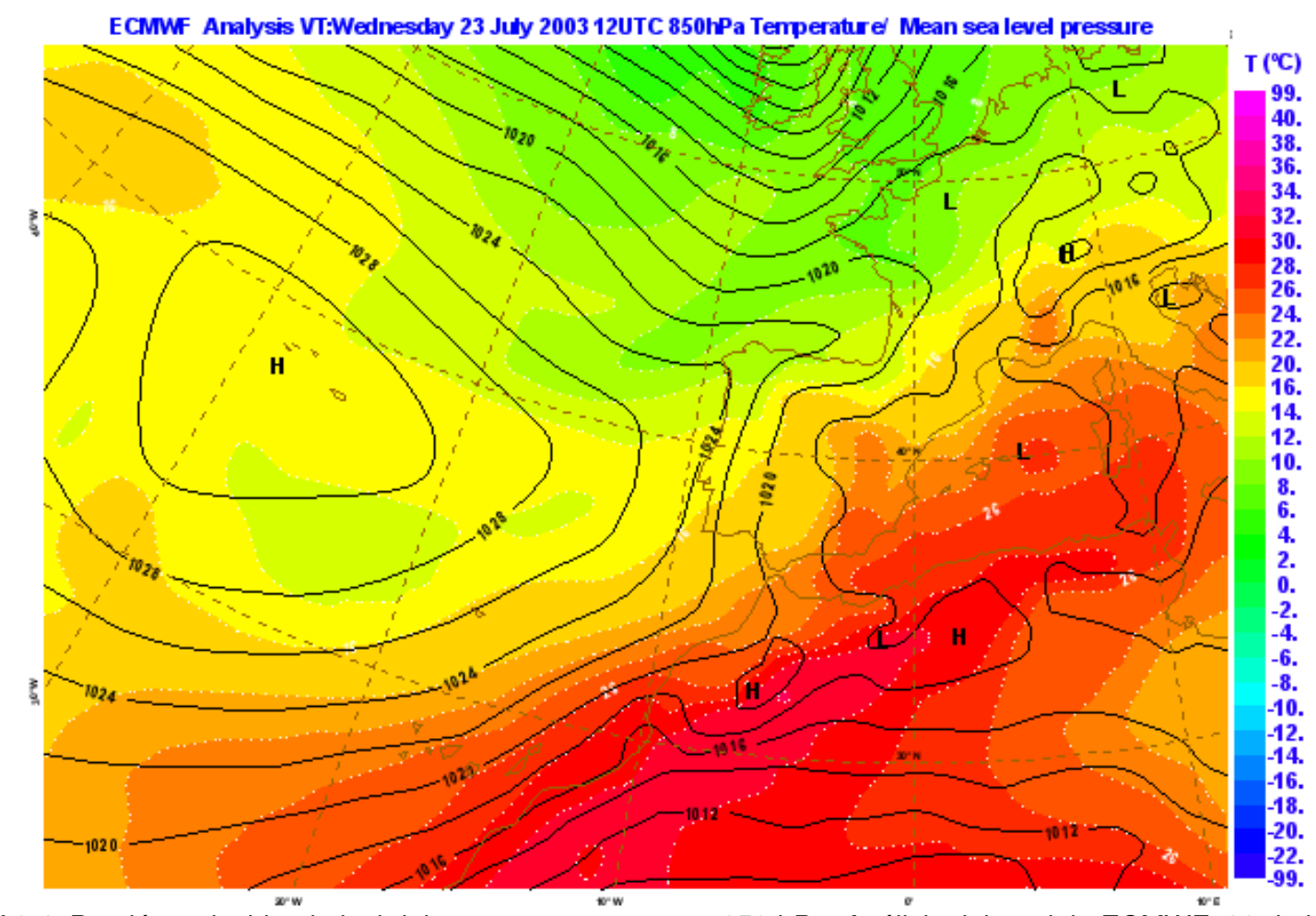

Figura IV.3.4. Presión reducida al nivel del mar y temperatura en 850 hPa. Análisis del modelo ECMWF. 23 de julio a 12 UTC 
A su vez coinciden sobre la provincia de Teruel una zona de convergencia en niveles bajos con temperaturas relativamente cálidas, un embolsamiento de aire frío en niveles medios y vientos fuertes en capas altas de la troposfera. Existe pues, flotabilidad, cizalladura y un mecanismo de disparo eficiente. Estos factores se confirman en las salidas derivadas a $\mathrm{H}+3$ del modelo del ECMWF válidas para las 15 UTC (Figura IV.3.5 a 8)

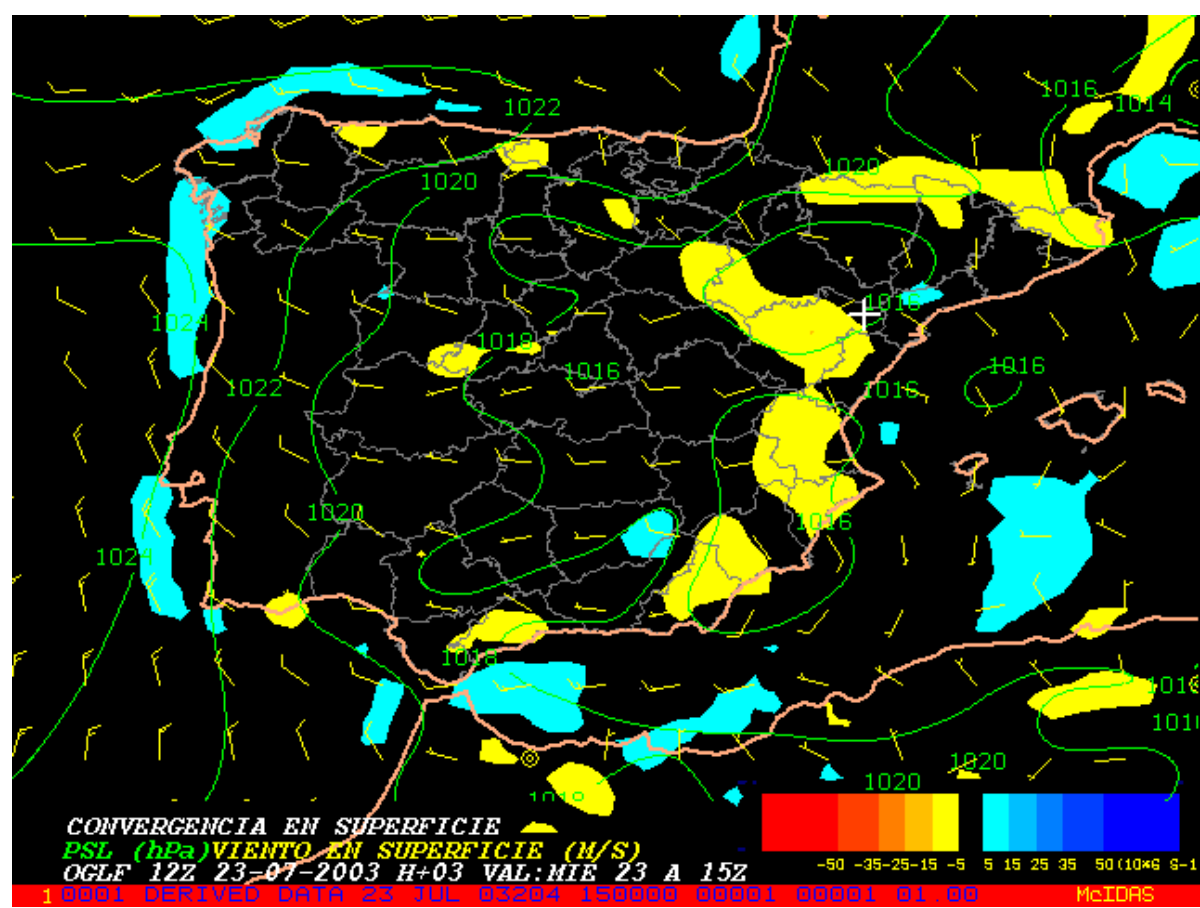

Figura IV.3.5. Modelo ECMWF del día 23 de julio a las 12 UTC. Predicción H+3. Se observa una zona de convergencia en niveles bajos sobre el Sistema lbérico, debida al flujo del este procedente del Mediterráneo y el del oeste procedente de la vertiente Atlántica. La convergencia se acentúa con el débil flujo del noroeste a través del valle del Ebro

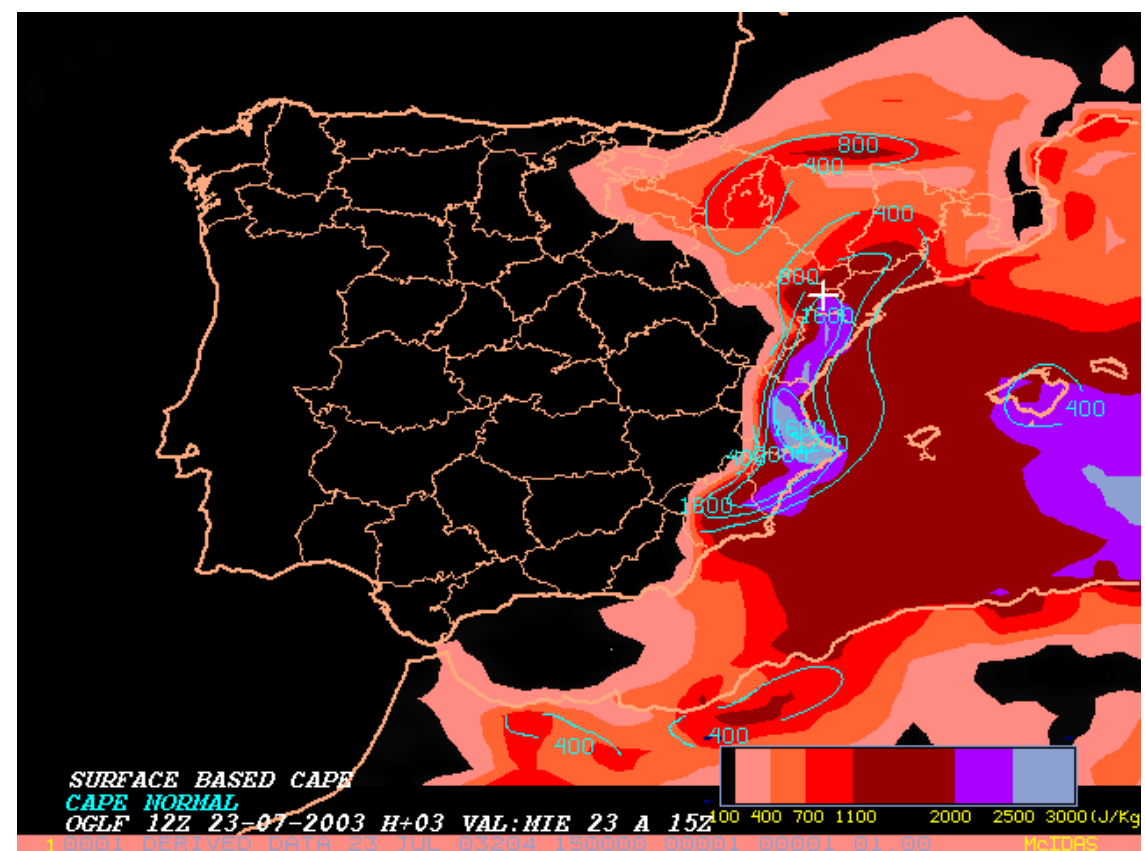

Figura IV.3.6. Modelo ECMWF del día 23 de julio a las 12 UTC. Predicción H+3. Durante las horas centrales del día, la fuerte insolación y las altas temperaturas alcanzadas generan una cantidad de CAPE importante, sobre todo el basado en superficie, cercano a $2000 \mathrm{~J} / \mathrm{Kg}$ en la zona de interés. 


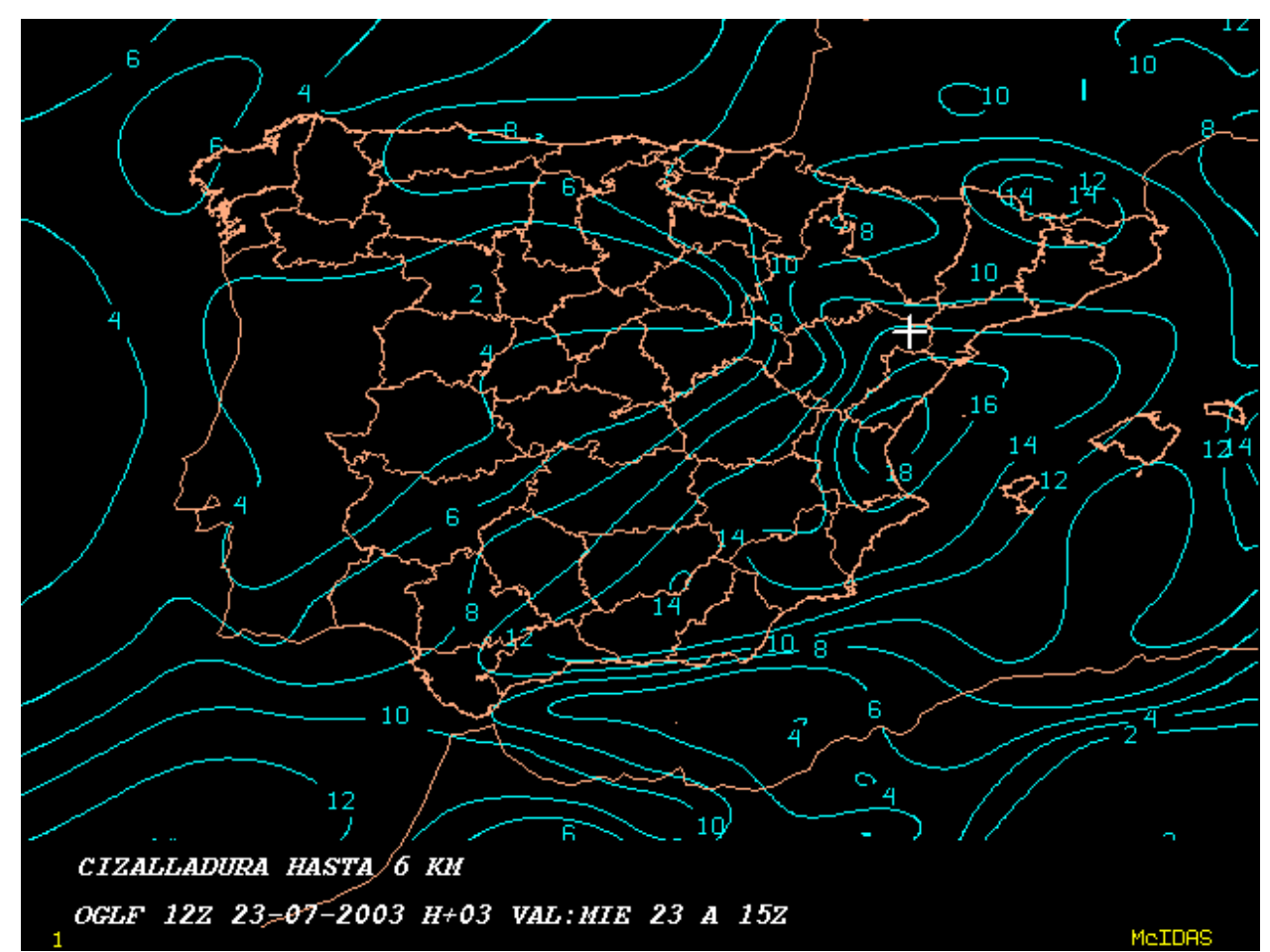

Figura IV.3.7. Modelo ECMWF del día 23 de julio a las 12 UTC. Predicción H+3. La cizalladura en capa profunda (6 km) prevista por el modelo es de unos $14 \mathrm{~m} \mathrm{~s}^{-1}$. Se observa un máximo más importante algo más al sureste, en la costa de Valencia.

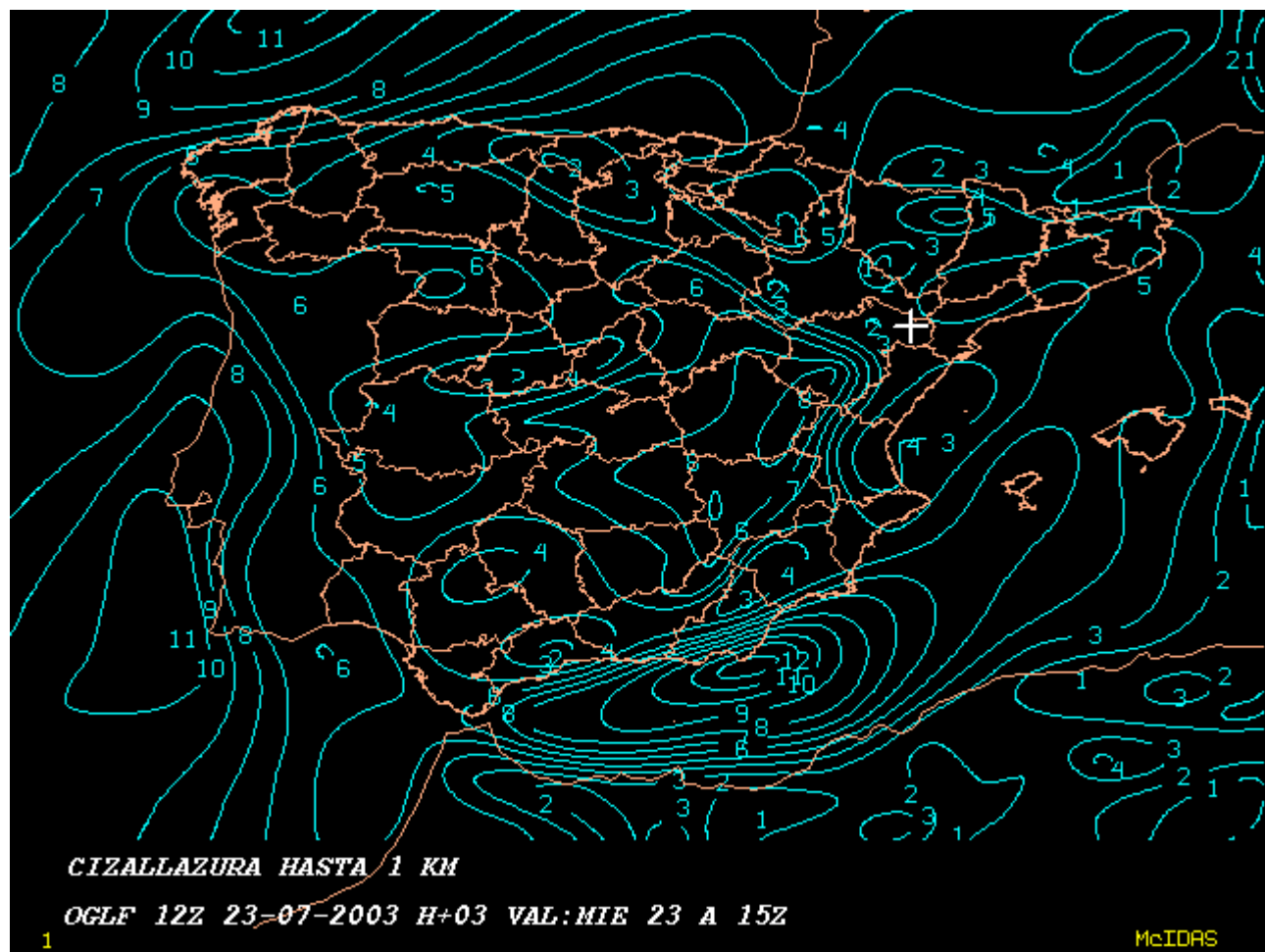

Figura IV.3.8. Modelo ECMWF del día 23 de julio a las 12 UTC. Predicción H+3. La cizalladura prevista por el modelo hasta 1 $\mathrm{km}$ es muy débil. No debe dársele sin embargo gran peso a este parámetro derivado, dada la escasa resolución del modelo para la complicada orografía de la zona. La cizalladura en el km más bajo es muy sensible a la mesoescala: flujos de salida de tormentas, vientos locales, etc.

Con estos ingredientes, la convección se inicia en el Sistema lbérico, a unos $1000 \mathrm{~m}$ de altitud, entre las 13 y las 14 UTC. (Figura IV.3.9). 


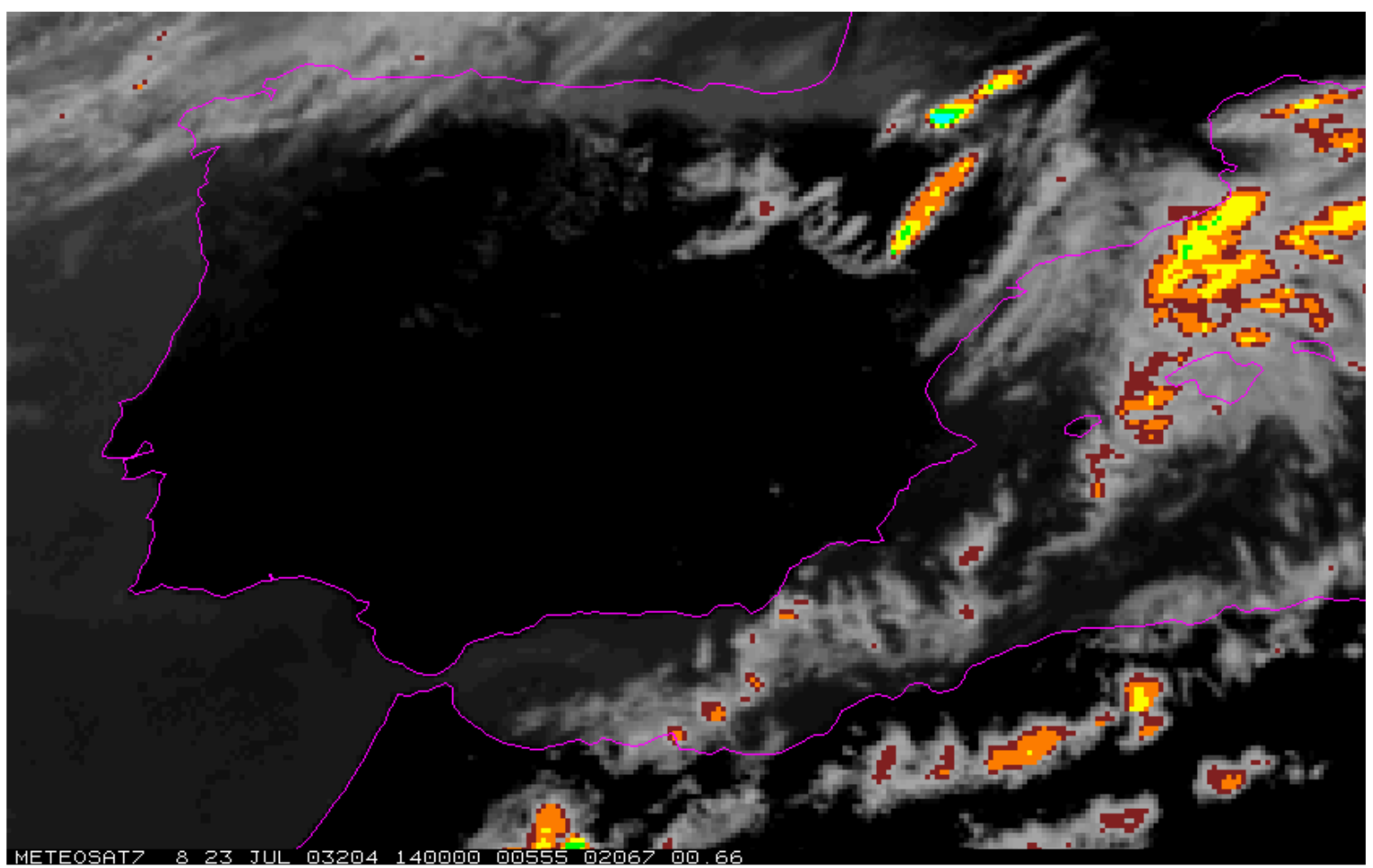

Figura IV.3.9. Imagen IR realzada del satélite Meteosat a las 14 UTC. Se observan algunas células convectivas iniciales en el nordeste de la Península lbérica. No se aprecian signos de organización, si bien la existencia de fuerte cizalladura se hace evidente en una célula muy alongada hacia el NNE, célula que terminará organizándose y generando el tornado de Valdealgorfa.

La convección al principio no aparece organizada, hasta que una de las células empieza a desarrollarse rápidamente, absorbiendo a otras cercanas y exhibiendo algunos signos de organización en las imágenes de satélite: "overshooting", gran yunque con bordes muy definidos, "flanking line", desplazamiento un poco hacia la derecha de la trayectoria inicial, etc. (Figura IV.3.10).

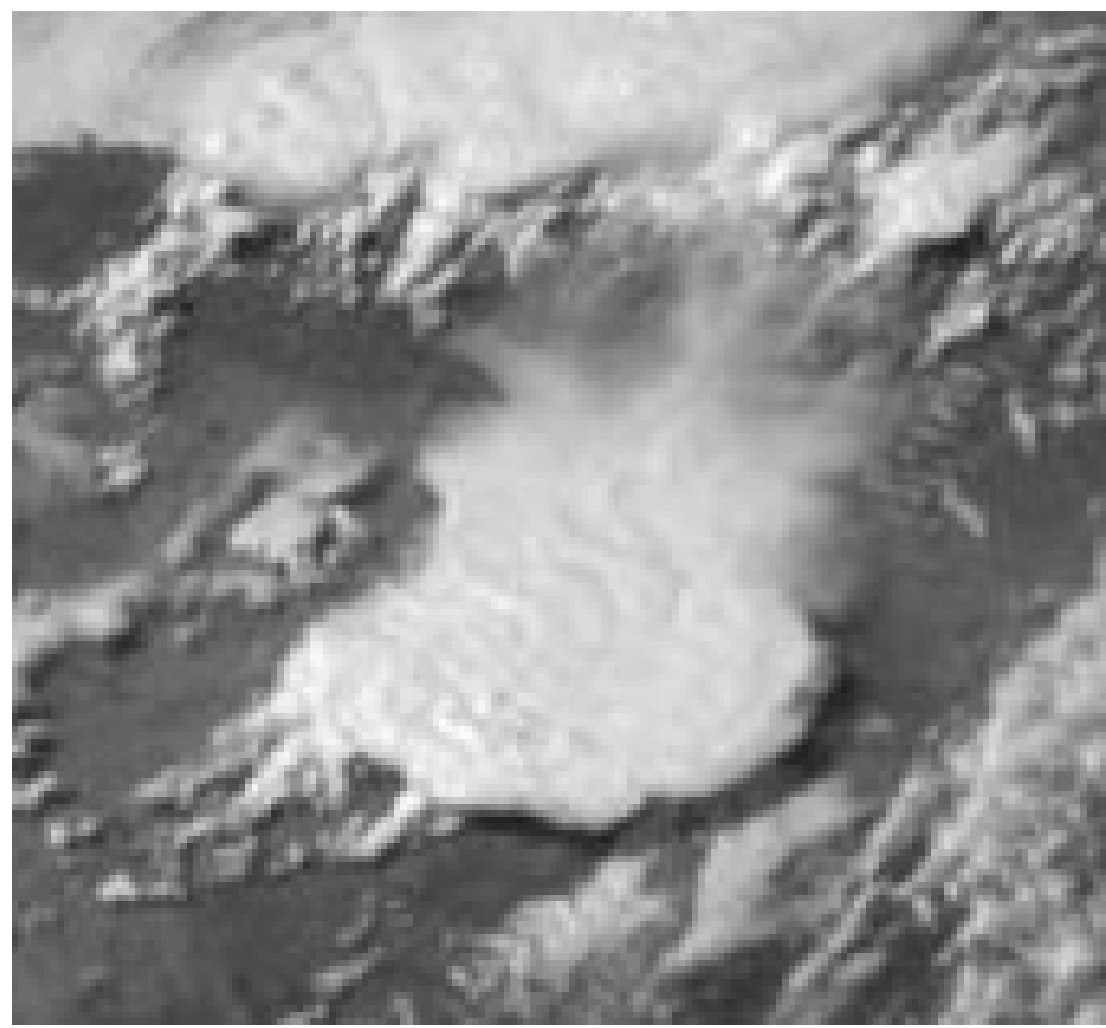

Figura IV.3.10. Imagen del canal visible de Meteosat a las 15 UTC, en la que aparece la célula generadora del tornado. Se observa claramente el yunque de la tormenta con bordes muy definidos y sombra marcada hacia el sureste, así como el

"flanking line" indicativo del flujo de entrada de la célula, hacia el sur - suroeste de la misma. Se observa también el "overshooting" muy cerca, un poco hacia el noroeste. 
A las 15 UTC la tormenta aparece plenamente desarrollada. La imagen radar de reflectividad muestra un gancho en la horizontal y una región de eco débil. El producto de reflectividad máxima en la columna detecta zonas abalconadas (Figura IV.4.11).

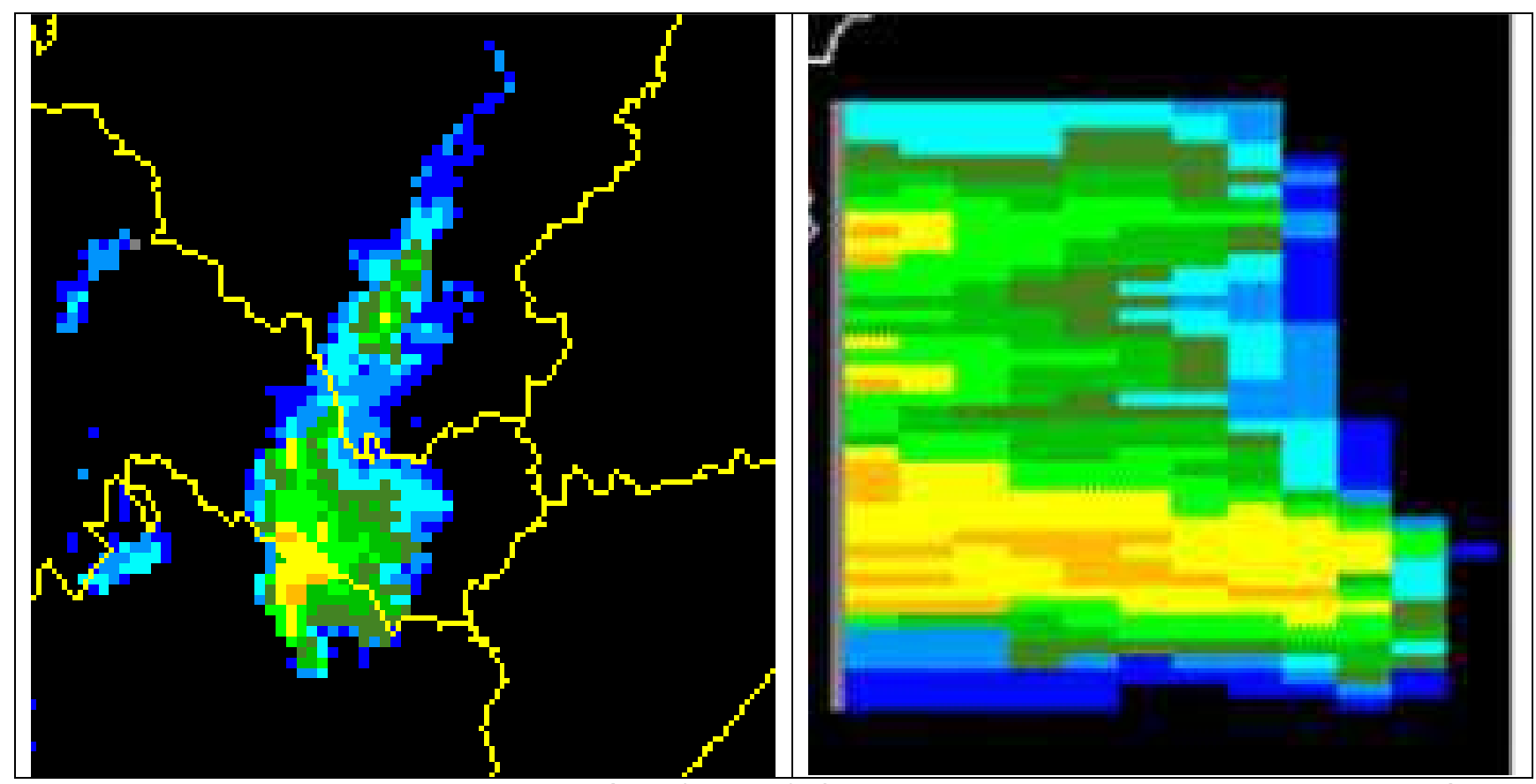

Figura IV.3.11. Izda: PPI de reflectividad. Elevación 0,5‥ 15 UTC. Se observa una estructura de gancho al sur de la célula, así como un zona de eco débil al este del gancho. Se aprecian también estructuras en "V" tanto en la zona de entrada del flujo, al SSE ("inflow notch") como a la salida ("V notch"), al norte. Dcha: proyección del ZMAX a las 14:44 UTC, que muestra la presencia de una estructura abalconada en la vertical (extraído de Conesa, 2004)

Se identificaron trazas de rotación en el producto PPI de viento radial (no mostrado aquí). El producto VIL (contenido líquido integrado en la vertical) muestra valores de $15 \mathrm{~kg} / \mathrm{m}^{2}$. El Echotop de $12 \mathrm{dBz}$ llega a los $16 \mathrm{~km}$ (Figura IV.3.12). En definitiva se aprecian claros signos de organización y fuerte desarrollo de la tormenta, muy probablemente supercelular.

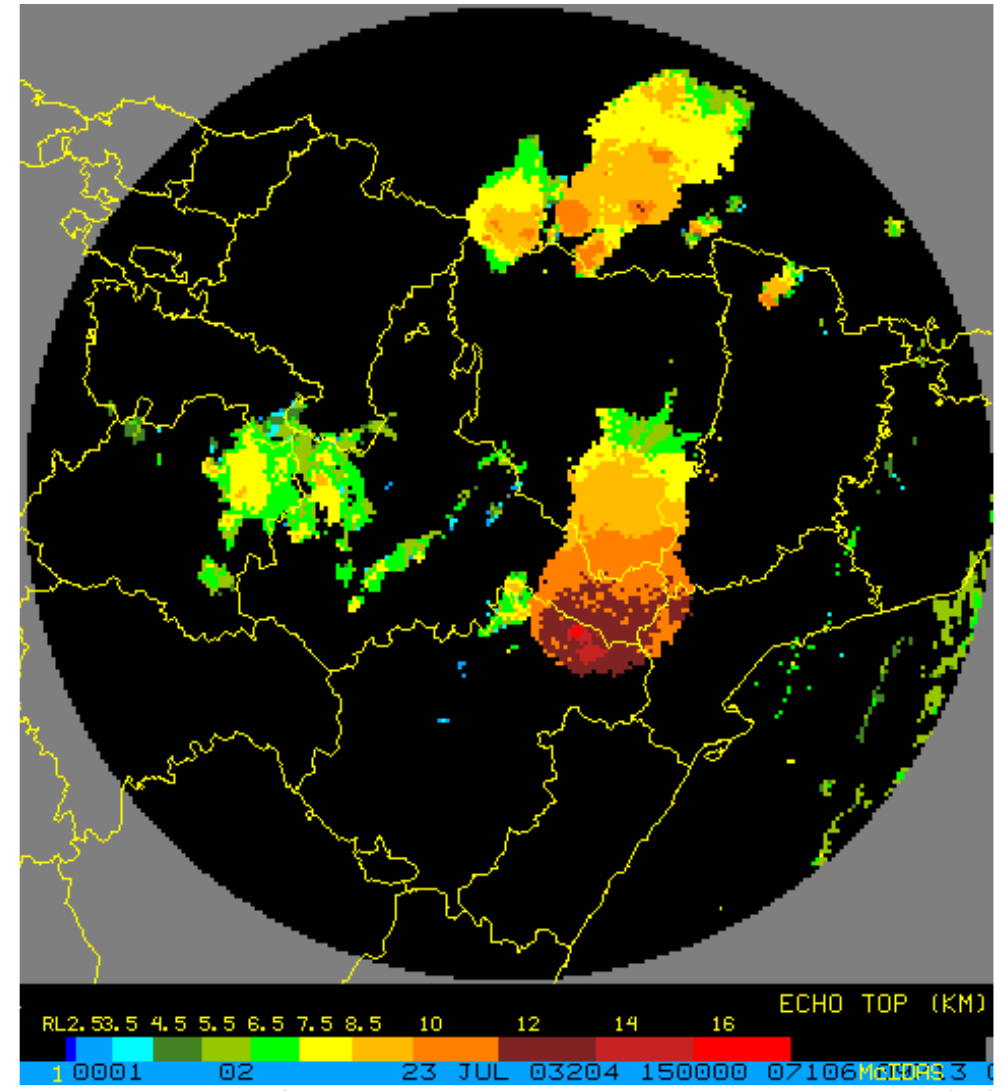

Figura IV.3.12. Imagen de Echotop (altura máxima de ecos de al menos $12 \mathrm{dBz}$ ) a las 15 UTC. Se observa que la célula de estudio tiene topes superiores a $16 \mathrm{~km}$ ) 
Como efectos en superficie, se registraron granizo de $5 \mathrm{~cm}$ de diámetro y un potente tornado EF2/EF3 según la escala Fujita Realzada, que abatió un gran número de árboles en su trayectoria.

En su estudio, Conesa (2004) atribuye, citando a Markowski et al (1998), a la frontera baroclina formada en el entorno de la sombra del yunque, la generación de vorticidad horizontal que pudo ser ingestada en la corriente ascendente de la tormenta (fig IV.3.13), aumentando así el efecto de la relativamente débil cizalladura vertical ambiental en niveles bajos que indicaban los modelos, aunque hay que tener en cuenta que la complicada orografía de la zona está lejos de ser resuelta eficazmente por los modelos numéricos.

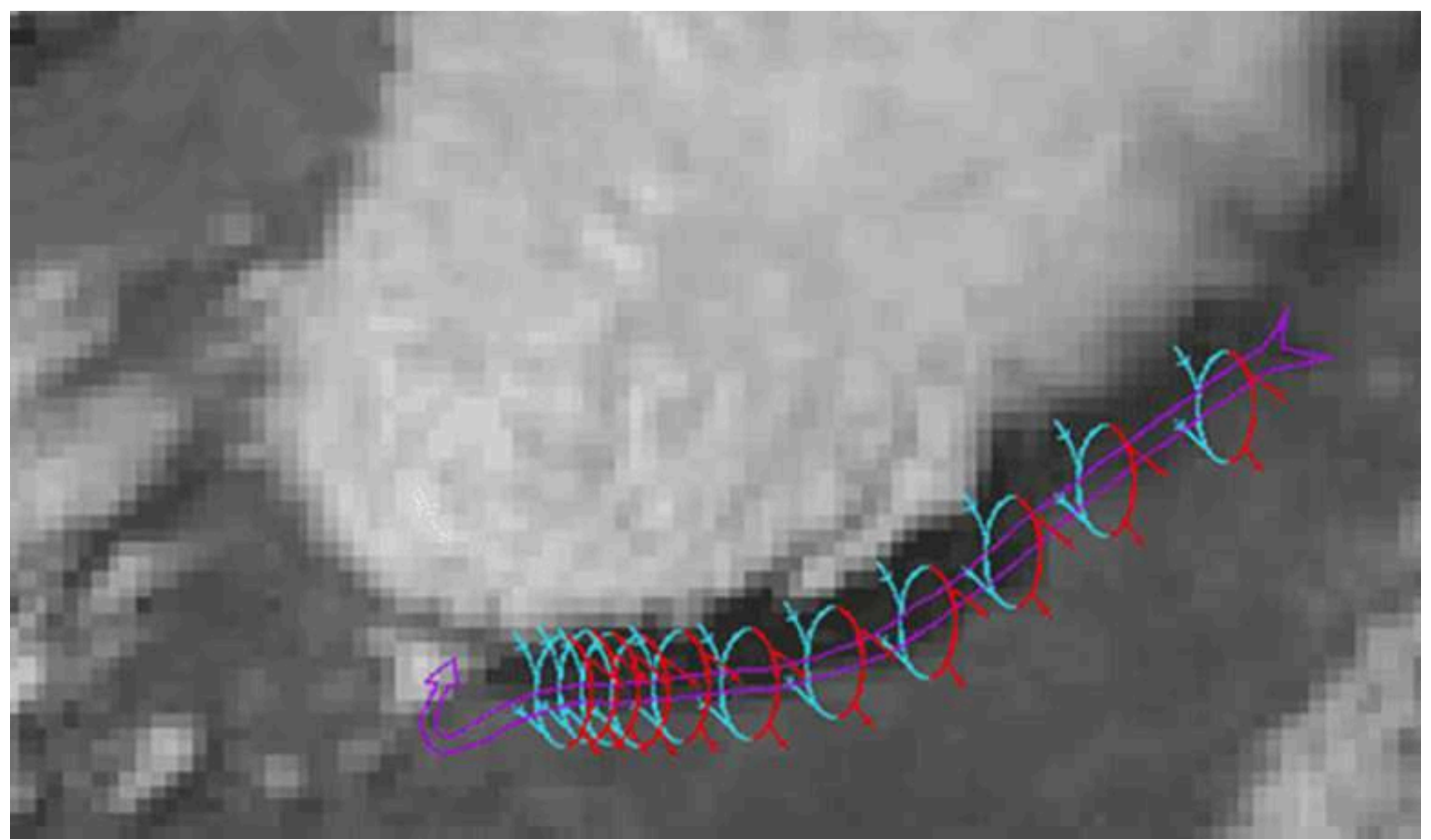

Figura IV.3.13. Posible generación de vorticidad horizontal sobre la frontera baroclina generada por la sombra del yunque, en la imagen visible de las 14:30 UTC. La tormenta se desplaza hacia el este, pudiendo por tanto ingestar esa vorticidad en la corriente ascendente, aumentando el efecto de la cizalladura vertical ambiente de bajos niveles (extraído de Conesa, 2004). 


\section{IV.4 Tornados de la vertiente Mediterránea}

Por último se revisan las características principales de los tornados que tienen lugar en la vertiente Mediterránea, en cuya franja litoral y prelitoral el máximo de actividad convectiva se produce a finales de verano y durante el otoño. Los tornados suelen ocurrir en episodios de acusada inestabilidad en el Mediterráneo Occidental y Mar de Alborán, normalmente en situaciones de precipitaciones intensas ligadas a la presencia de una perturbación en capas medias-altas y a un flujo inestable de origen marítimo en los niveles inferiores.

Se trata de situaciones sinópticas con chorro de cierta amplitud (formando meandros) en capas altas. En niveles medios y altos de la troposfera hay una vaguada o una depresión aislada o la transición de una situación a otra, induciendo un flujo del suroeste con curvatura ciclónica sobre la vertiente Mediterránea, observándose en estos niveles embolsamientos de aire frío en relación a lo normal para la temporada.

En capas bajas suele distinguirse una marcada advección de aire cálido con flujo del sur o del este en superficie, y vientos del suroeste en $500 \mathrm{hPa}$, existiendo una cizalladura vertical de viento con una hodógrafa que muestra un giro en el sentido de movimiento de las agujas del reloj. En estos tipos de entornos, para la formación de tornados es suficiente con que exista inestabilidad en capas bajas (marcada por el índice LI7), pero cuanto mayor sea la inestabilidad en capas medias-altas (índice LI5), más probables serán los tornados.

Además pueden darse otros factores, como una vaguada de onda corta o vórtice dentro de la vaguada principal o depresión aislada, aportando aire frío en altura, ciclogénesis y vorticidad, un centro ciclónico en superficie cercano al litoral, mucho menos profundo que en el caso Atlántico, sondeos con gran inestabilidad (bajos valores de LI5 y gran CAPE) y en ocasiones muy húmedos, aumento de la velocidad con la altura (cizalladura), convergencias en superficie, etc.

Pueden existir también factores agravantes como una interacción con una llamarada de la zona de convergencia intertropical o del Atlas, una troposfera elevada, forzamientos sinópticos, un chorro en $300 \mathrm{hPa}$, etc. En la Figura IV.4.1 se resaltan algunos de los factores que pueden aparecer.

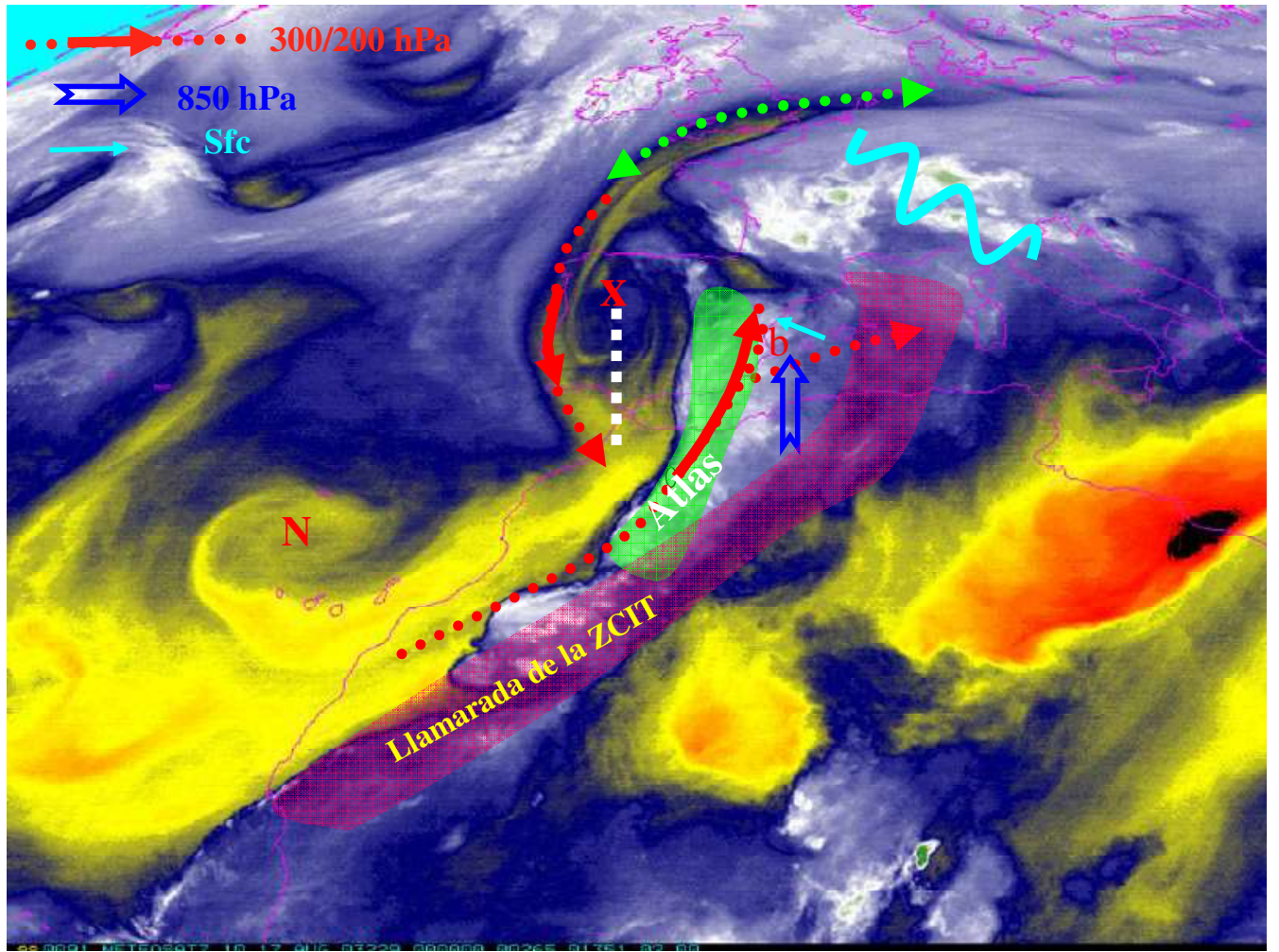

Figura IV.4.1: Ejemplo de imagen realzada de vapor de agua del MSG. En este tipo de imágenes se suelen observar algunos de los factores asociados a las situaciones convectivas del Mediterráneo Occidental. En este caso las flechas marcan los flujos en diferentes niveles de la atmósfera, la doble flecha la zona de deformación, y la línea a trazos el eje de vaguada.

En numerosas ocasiones los tornados son generados por sistemas convectivos en los que se forman fuertes corrientes ascendentes al alcanzar la costa y que se mueven atrapados en ella precedidos por vientos provenientes del mar y paralelos al litoral.

Si el mejor mapa meteorológico para caracterizar sinópticamente las situaciones del Atlántico es el mapa de superficie, en este caso "mandan" los mapas de capas medias y altas. 


\section{IV.4.1. Situación del 17 de agosto de 2003}

Como situación representativa de este tipo de situaciones, se estudia la del día 17 de agosto de 2003, en la que se observaron dos tornados en la provincia de Barcelona, y uno en las de Castellón, Albacete y Murcia.

Los tres primeros serían tornados como los de otoño de la vertiente mediterránea; los de Albacete y Murcia serían típicos tornados de verano. En las imágenes del canal visible de primeras horas de la mañana (Figura IV.4.2) se aprecia un "overshooting" sobre el delta del Ebro y las sombras que proyectan los topes nubosos del sistema convectivo sobre la capa nubosa inferior. En el canal de vapor de agua se aprecia un anillo seco a barlovento que suele acompañar a la convección severa.

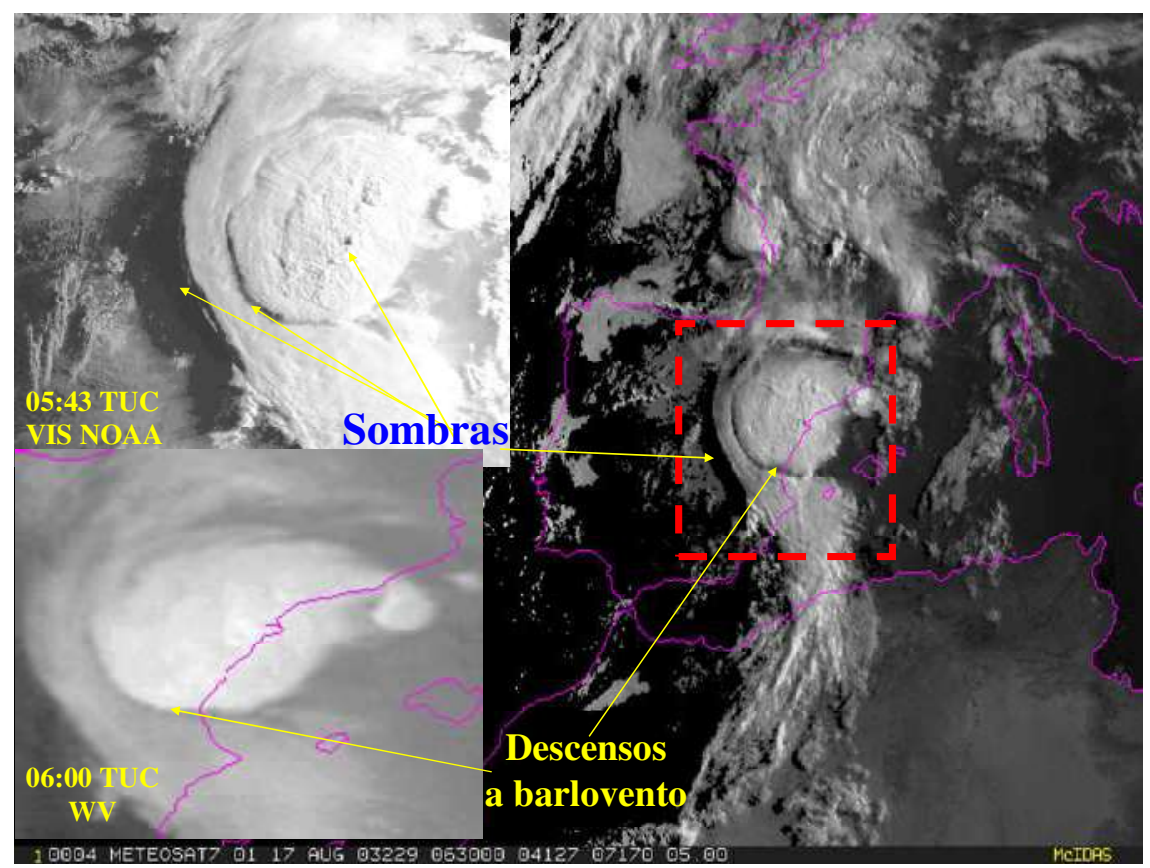

Figura IV.4.2: Imágenes de satélite correspondientes a las 6:30 UTC del día 17 de agosto de 2003. Arriba a la izquierda: detalle del canal visible del satélite NOAA. Abajo a la izquierda, canal de vapor de agua del MSG. A la derecha, Canal visible del MSG.

Entre los días 16 y 17 se identifica en niveles altos y medios de la troposfera, el desplazamiento de oeste a este de una vaguada de orientación norte sur, en la que se forma una depresión sobre la península lbérica. A las 00 UTC del día 17 el flujo sobre la mitad oriental de la Península era del suroeste. Se aprecia un centro de vorticidad positivo sobre Castilla y León y uno negativo entre Madeira y Canarias. El viento máximo del norte de la rama descendente de la vaguada, $75 \mathrm{kt}$, se advierte en $300 \mathrm{hPa}$ y el máximo del sur, $75 \mathrm{kt}$, de la rama ascendente en el estrato 200-250 hPa (Figura IV.4.3). En la zona de salida de este máximo de la corriente en chorro situado en las capas altas de la troposfera, se formó un sistema convectivo que recorrió el litoral Mediterráneo al norte del Cabo de la Nao.

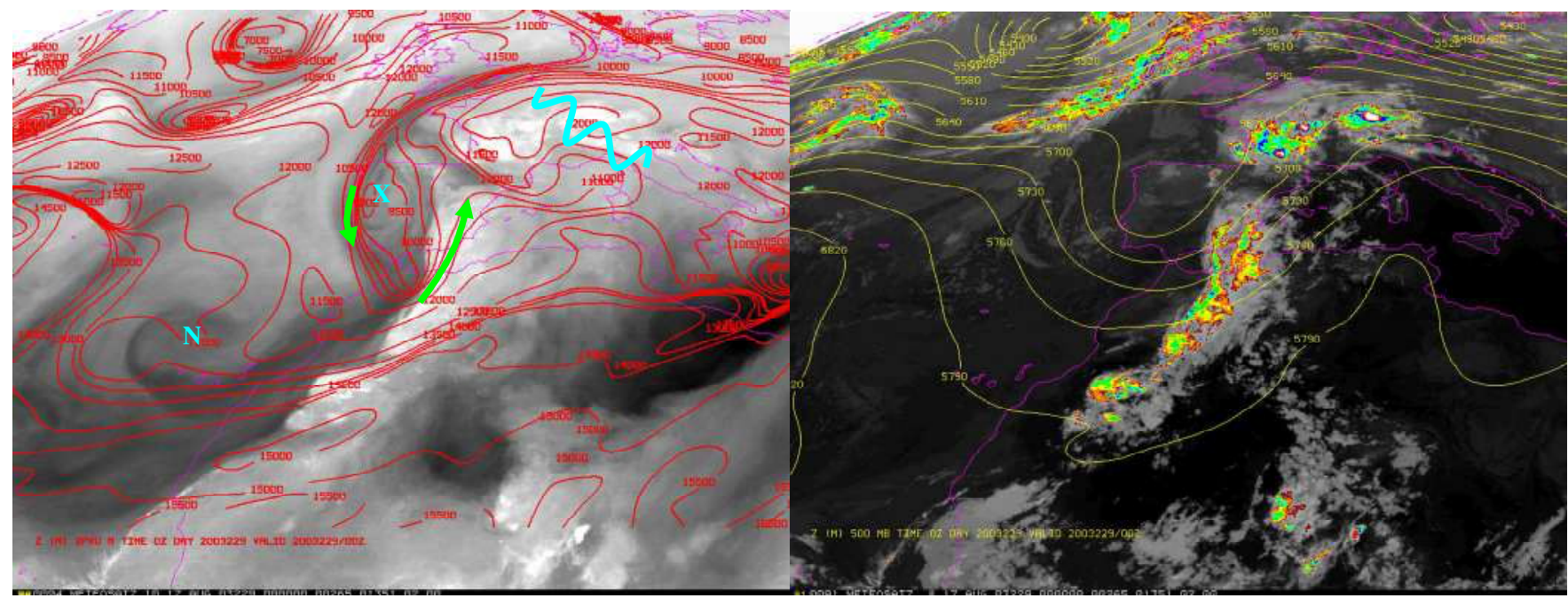

Figura IV.4.3: Imágenes de WV (izda) e IR (dcha) del Meteosat de las 00 UTC del día 17 de agosto de 2003. Sobre ellas se muestran respectivamente los análisis del modelo del ECMWF de la altitud de la superficie 2 PVU y el geopotencial de 500 hPa. A la izquierda en azul se resaltan los centros de vorticidad positiva y negativa y el eje de la dorsal; y en verde el máximo descendente del norte en $300 \mathrm{hPa}$ y el máximo ascendente del sur en $250 \mathrm{hPa}$. 
La situación meteorológica en capas bajas es típica del verano en lo que se refiere a la posición del anticiclón de las Azores, pero no se percibe la depresión térmica peninsular. Las temperaturas más altas en 850 hPa y la dorsal térmica que las acompaña se desplazan al Mediterráneo Occidental, aunque durante los días 16 y 17 se aprecia en este nivel una advección cálida sobre el este de península lbérica. Se distingue una amplia zona de bajas presiones en el Mediterráneo Occidental sin apenas gradiente de presión en superficie. A las 00 UTC hay un mínimo relativo de $1011 \mathrm{hPa}$ en el Golfo de Valencia (Figura IV.4.4). El flujo en superficie fue débil de dirección sur-sureste. En los mapas de temperatura y de punto de rocío se observa una frontera que nos indica el contraste de masas de aire con una mediterránea más cálida y húmeda.
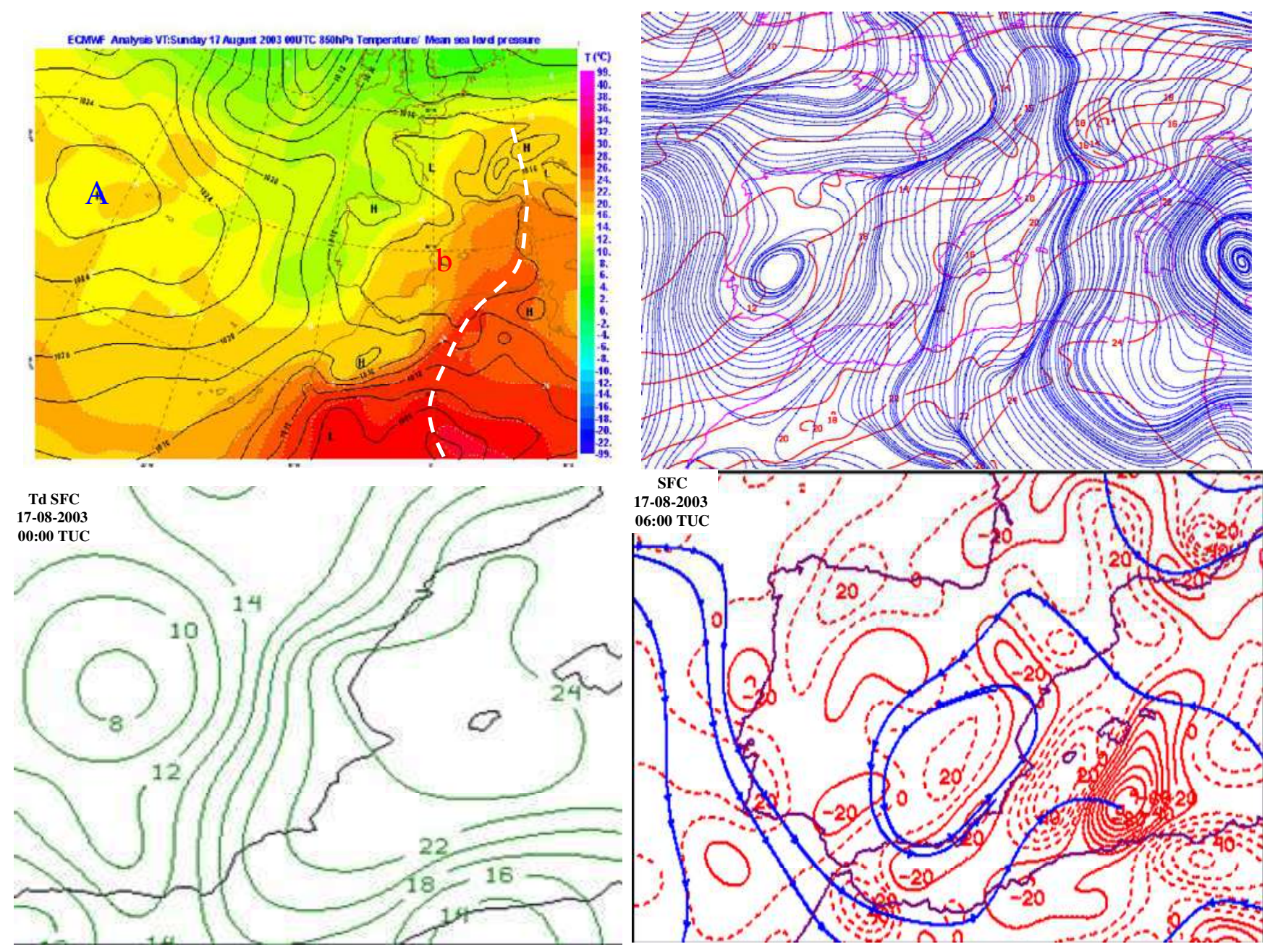

Figura IV.4.4: Análisis del modelo del ECMWF a las 00 UTC del 17 de agosto de 2003: (a) Presión a nivel del mar y temperatura en $850 \mathrm{hPa}$ (b). Líneas de corriente y temperatura en $850 \mathrm{hPa}$. (c) Análisis de los puntos de rocío observados en superficie a 06 UTC y $(d)$ análisis de líneas de corriente y convergencia en superficie del modelo HIRLAM de alta resolución de las 06 UTC.

\section{Interacción tropical-extratropical e interacción con el Atlas}

En las imágenes de satélite de la Figura IV.4.5 destaca una llamarada de la zona de convergencia intertropical (Weldom y Holmes, 1991), que es una expansión rápida de nubes medias y altas por delante de una vaguada. Las Ilamaradas de la ZCIT también se conocen en el este del Océano Pacífico como cinta transportadora húmeda del Pacífico (Pacific moisture conveyor belt). Estas llamaradas o plumas tropicales reflejan la interacción tropical-extratropical asociada con el transporte de humedad desde los trópicos a latitudes extratropicales. Vemos también una cinta transportadora húmeda en la rama delantera de la vaguada. 24 horas después se aprecian dos conveyors húmedos, el procedente de la ZCIT y otro enriquecido con los restos de convección del Atlas (cinta transportadora húmeda del Atlas). Es relativamente frecuente en nuestras latitudes, la llegada de nubosidad proveniente de latitudes tan meridionales, incluso con restos de la convección del norte de África, sin que se produzca tiempo severo. Pero cuando se produce una interacción con la rama ascendente de una vaguada que se amplifica o con una ciclogénesis de latitudes medias, como ocurrió en este caso, se pueden producir episodios de tiempo severo. El humedecimiento provocado por los restos de convección del Atlas contribuyó probablemente a la desestabilización del ambiente (Polvorinos y Sánchez-Laulhé, 1999). 


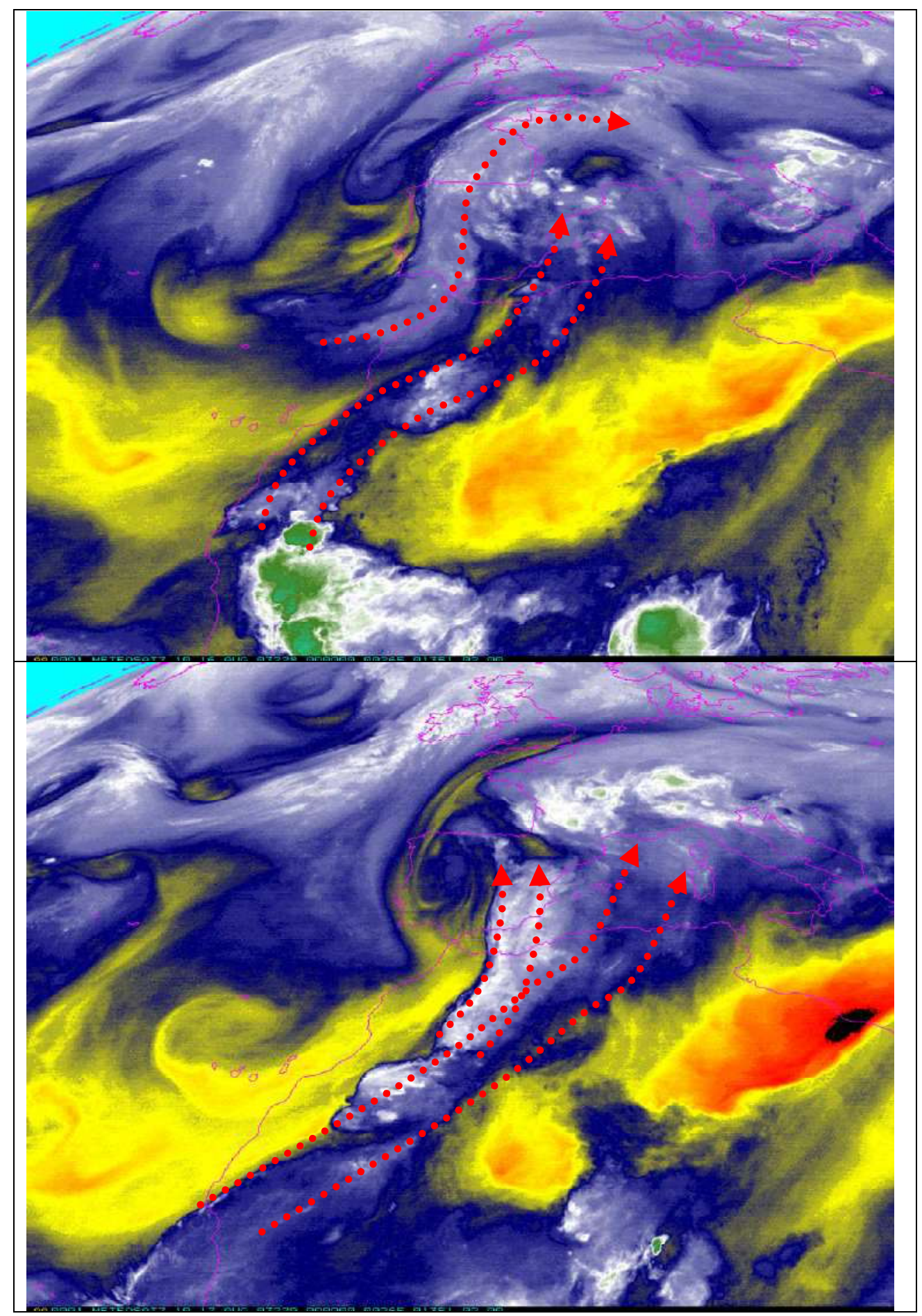

Figura IV.4.5: Imágenes del canal WV del Meteosat de las 00 UTC de los días 16 y 17 de agosto de 2003. El día 16 (arriba) se observan dos cintas transportadoras húmedas (conveyors húmedos), una de ellas proveniente de la ZCIT (Ilamarada de la zona de convergencia intertropical). El día 17 (abajo) se distingue una llamarada proveniente del Atlas, a la que contribuyen los restos de la convección del día anterior.

\section{Índices meteorológicos}

En la Figura IV.4.6 podemos ver los valores para las 06 UTC de los mismos índices utilizados para situaciones de invierno y de verano. Se aprecia que los mayores valores de cizalladura son menores que en las situaciones Atlánticas. El LI7 negativo marca la inestabilidad de todo el litoral Mediterráneo al norte de Alicante. El LI identifica las zonas con mayor inestabilidad, destacando la zona del Delta del Ebro, lugar en el que se observa el overshooting a las 06:30 UTC.

EI CAPE durante este episodio fue muy grande, alcanzándose valores superiores a $2000 \mathrm{~J} / \mathrm{kg}$ entre Baleares y Cataluña y de hasta 1100 de CAPE3 en la costa de Castellón (Figura IV.4.6). 

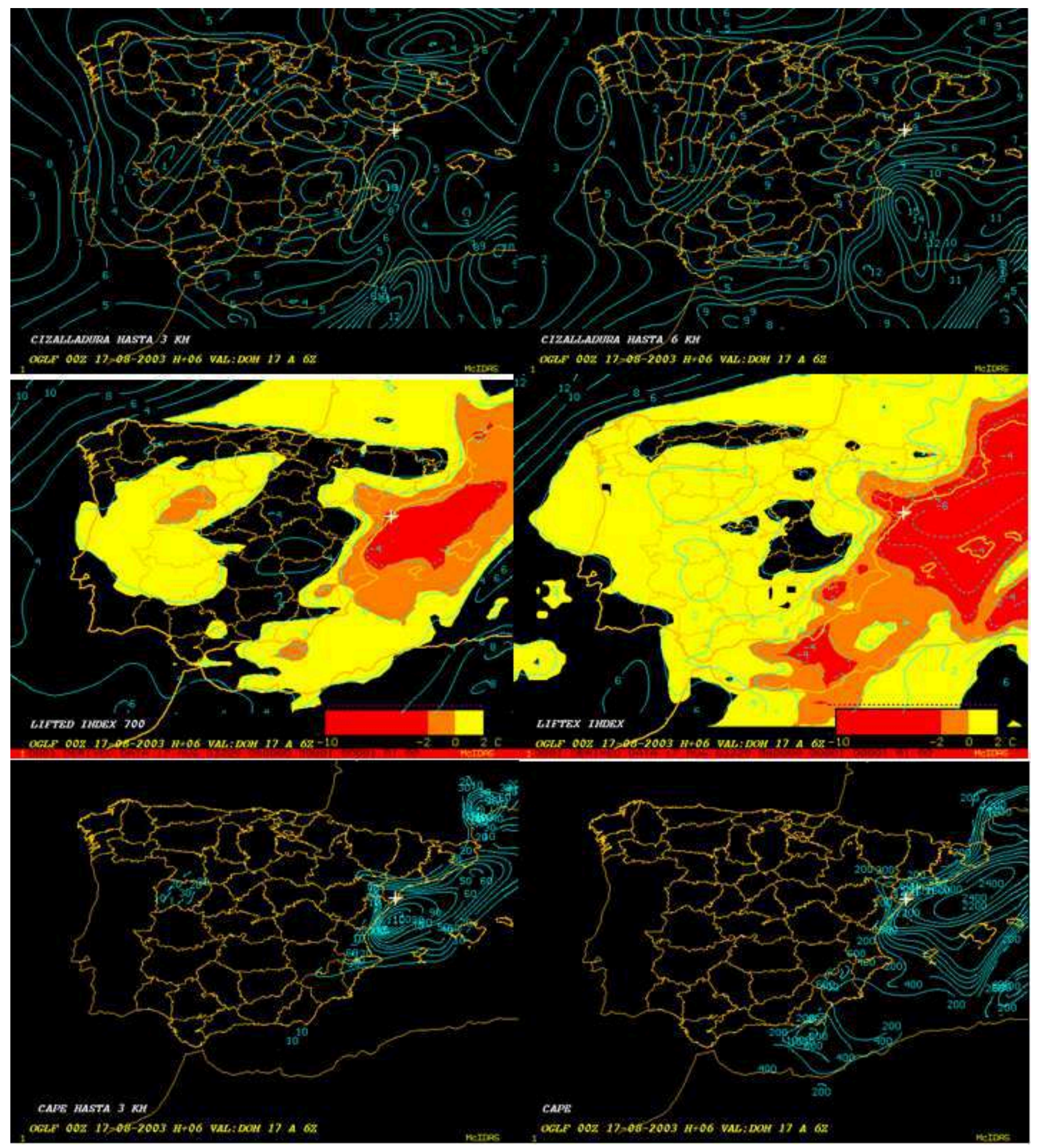

Figura IV.4.6: Valores de algunos índices y parámetros, el 17 de agosto de 2003 a 6 UTC. De izquierda a derecha y de arriba a abajo son los siguientes: a) CIZ3, b) CIZ6, c) LI7, d) LI, e) CAPE3, f) CAPE. 


\section{Sondeos observados y datos de radar}

En el sondeo realizado por un avión en las inmediaciones del Aeropuerto de Alicante a las 21:29 UTC, se aprecian las diferentes evoluciones partiendo desde tierra con los valores de temperatura y punto de rocío observados. Los valores de CAPE eran muy diferentes dependiendo de la masa de aire desde la que se evolucionara. Resultaban muy grandes para lugares con puntos de rocío elevados (Alicante) y casi nulos desde aquellos lugares con valores de punto de rocío pequeños (Albacete). Las condiciones del Aeropuerto de Alicante se repiten a las 5:27 UTC en el aeropuerto de Barcelona, observándose al amanecer unas condiciones de gran inestabilidad, con CAPE del orden de $2000 \mathrm{~J} / \mathrm{kg}$ y LI inferior a - $5^{\circ} \mathrm{C}$.
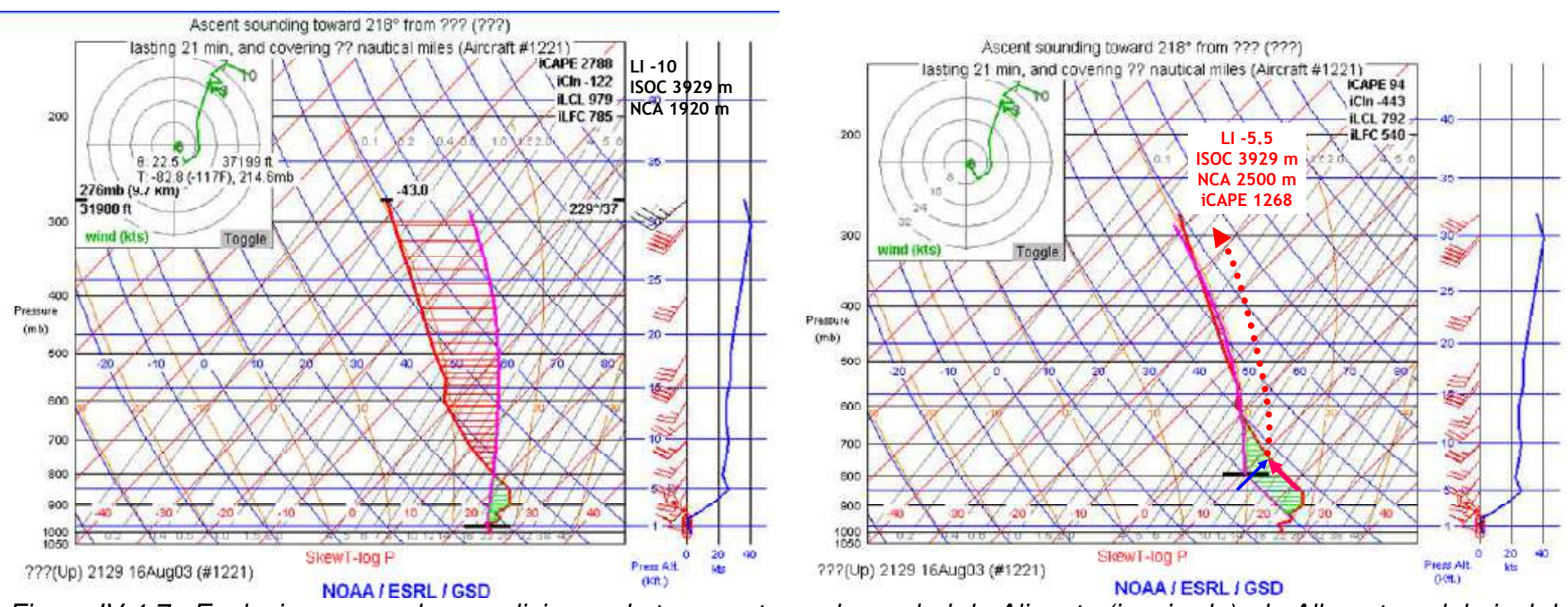

Figura IV.4.7: Evoluciones para las condiciones de temperatura y humedad de Alicante (izquierda), de Albacete y del nivel de $850 \mathrm{hPa}$ (derecha), para un sondeo observado en el Aeropuerto de Alicante a las 21:29 TUC del día 16 de agosto de 2003.

El primer desarrollo importante se observa entre 3 y 4 UTC sobre el norte la provincia de Murcia, pasando el número de descargas eléctricas de 34 entre 2:30 a 3:00, a 183 en la siguiente media hora y a 550, de ellos 229 positivos, de 3:30 a 4:00. Lo más probable es que este desarrollo se produjera por efectos orográficos, ya que la evolución desde unos 1500 metros con puntos de rocío como los que detectan los análisis de $850 \mathrm{hPa}$ en la zona, unos $12^{\circ} \mathrm{C}$, provocaría un CAPE del orden de $1300 \mathrm{~J} / \mathrm{kg}$, más cercano al que correspondería a evoluciones desde el nivel del mar (como Alicante) que desde la masa de aire seca (Albacete) (Figura IV.4.7). Posteriormente los desarrollos se propagaron hacia zonas llanas formando una estructura en línea en la dirección del flujo en capas medias y altas que puede sugerir la acción de ondas gravitatorias (Polvorinos y Sánchez-Laulhé, 1999) o circulaciones de brisa sobre la frontera entre las masas de aire Mediterránea y Peninsular. 

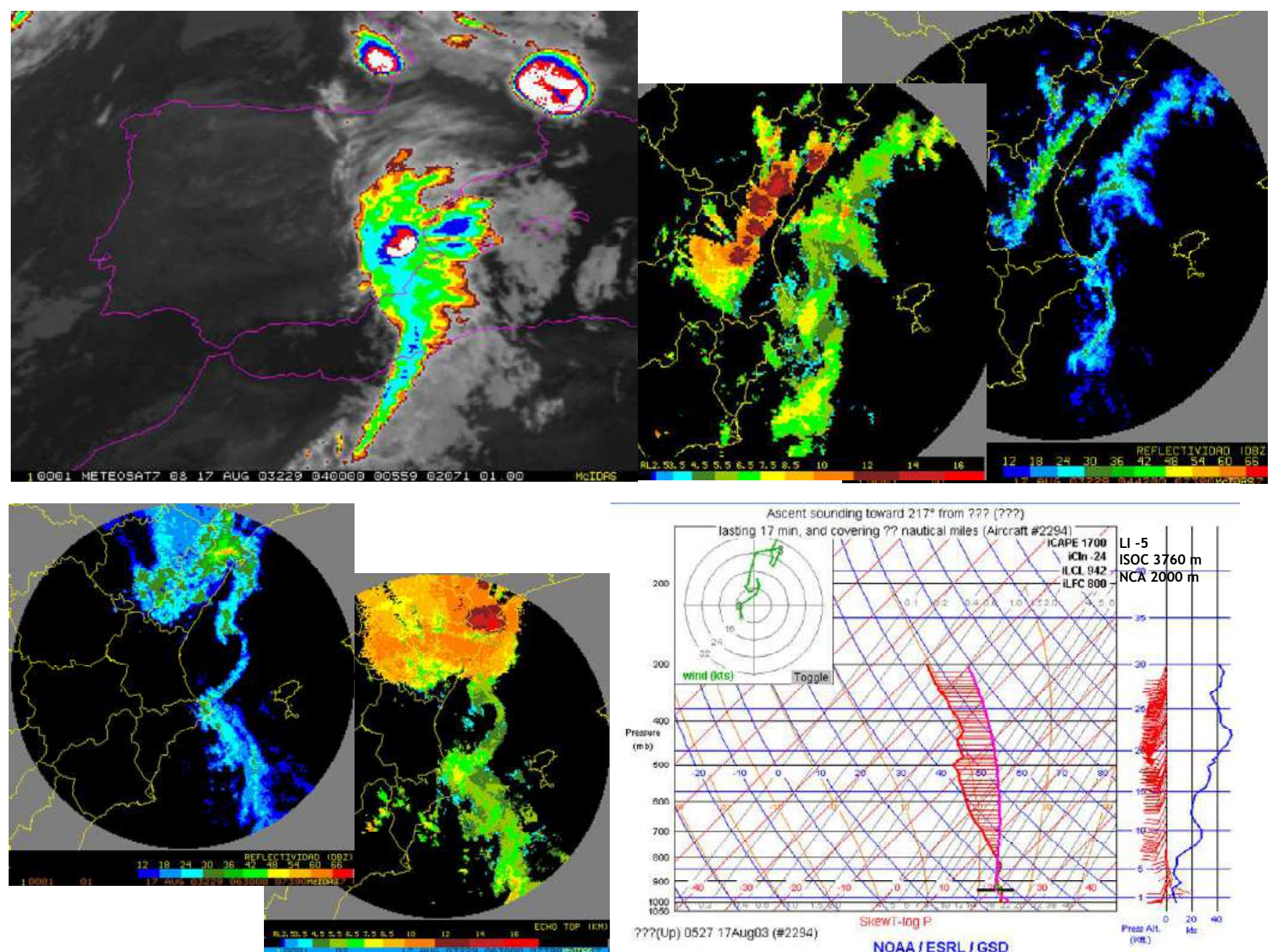

Figura IV.4.8: Imagen del canal IR del Meteosat de las 04 UTC del 17 de agosto de 2003. Imágenes de las 4:40 y 6:30 UTC del PPI y ECHOTOP del radar de Valencia. Evolución y sondeo observado en Barcelona a las 05:27 UTC del día 17.

Hacia el amanecer, en la frontera de las provincias de Castellón y Tarragona, se aprecia un aumento de los echotops $(16 \mathrm{~km})$ y se pierde la estructura lineal paralela a la costa mediterránea. Se formó un sistema convectivo cuasilineal de eje transversal a la dirección del flujo en capas medias, que en su movimiento hacia Francia se movió atrapado por la costa catalana provocando tornados y destrozos por rachas muy fuertes de vientos convectivos lineales.
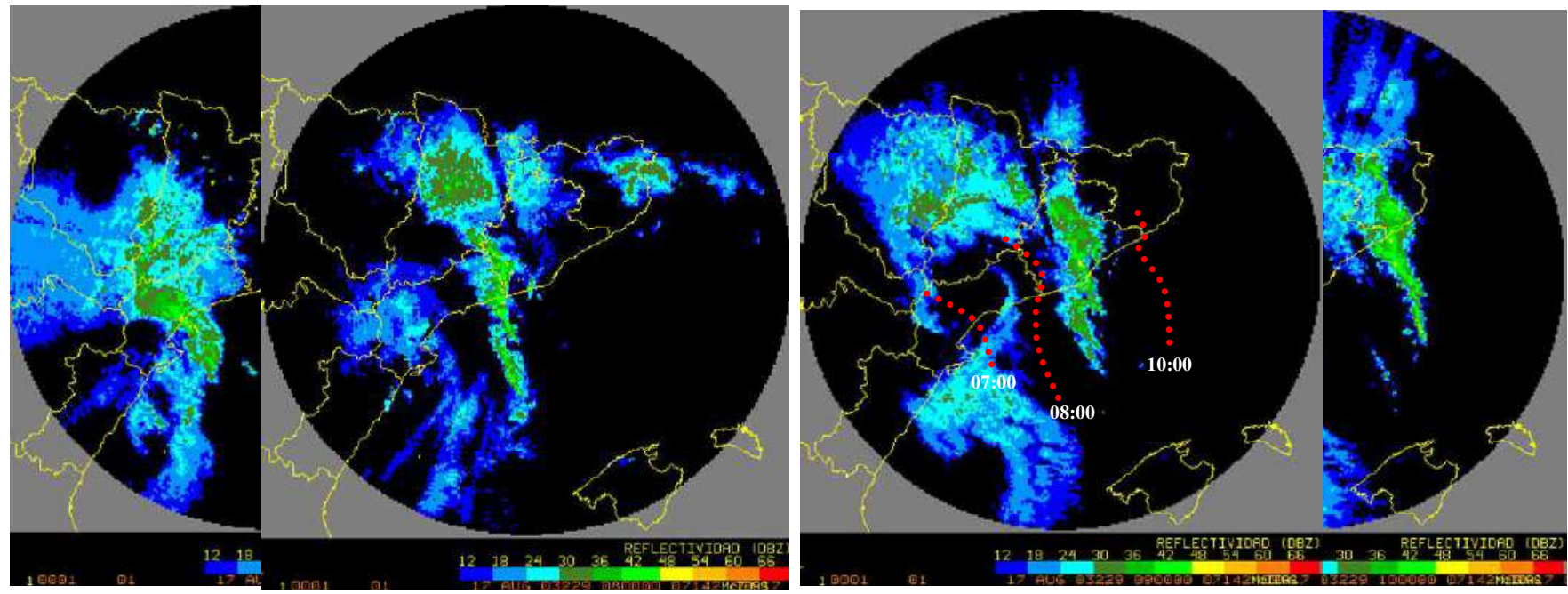

Figura IV.4.9. Imágenes PPI del radar de Barcelona de las 7, 8, 9 y 10 del día 17 de agosto de 2003. Sobre la imagen de las 09 UTC situaciones del eje mayor del sistema tormentoso a las 7, 8 y 10 UTC. 


\section{V.- CONCLUSIONES}

A lo largo de este capítulo se pondrán de manifiesto, de manera breve, las principales conclusiones a las que se ha llegado en este trabajo sobre climatología de tornados en la España Peninsular y Baleares.

La muestra de datos que se ha empleado para la elaboración de la climatología de tornados en la zona de estudio es una colección de $\mathbf{2 2 4}$ tornados (entre tornados terrestres y trombas marinas) registrados entre 20032012. Aunque son sólo 10 años y la muestra pueda parecer insuficiente en tamaño, se ha optado por disponer de una cantidad de años donde claramente se ha incrementado el número de reportes fiables de tornados respecto a épocas anteriores. Con ello trataríamos de disponer de una base de datos con información de "cierta homogeneidad".

Las fuentes de información principales para la generación de la base de datos han sido las observaciones de aficionados (internet), medios de comunicación, los estudios e informes realizados por AEMET y documentación facilitada por el Consorcio de Compensación de Seguros.

\section{V.1.- Climatología básica de tornados}

De los 224 tornados hubo 138 que fueron terrestres (62\%), mientras que 86 fueron trombas marinas (38\%).

En cuanto a la distribución mensual, en general la máxima actividad de tornados en sentido amplio, ocurre a finales de verano y otoño, algo también típico en otros países Mediterráneos del sur de Europa.

Los tornados terrestres tienen un máximo relativo a finales de verano y otoño, y otro de menor intensidad en primavera (abril). En cambio las trombas marinas presentan un máximo notabilísimo a finales de verano y principios del otoño.

Durante el día, las horas más favorables para la ocurrencia de tornados y trombas marinas se sitúa durante la tarde (entre 12 y 18 UTC), debido fundamentalmente al importante papel que juega el calentamiento diurno en el disparo convectivo. En el caso de las trombas marinas hay que hacer la salvedad de que en la muestra existe una destacada frecuencia durante el día debido sobre todo a la dificultad de avistamiento de aquéllas durante la noche.

Todos los tornados (terrestres y marinos) fueron de intensidad EF2 o inferior (figura II.1.5), con un predominio claro de la categoría EF0 (70\%), seguida de la EF1 (23\%), y por último la EF2 (7\%). Mención especial merecen las trombas marinas, cuya intensidad fue EF0 en un $97 \%$ de los casos, mientras que el $3 \%$ restante fue EF1.

En cuanto a la distribución espacial conjunta de tornados y trombas marinas cabe destacar un máximo en la costa Mediterránea. Las trombas marinas presentan una mayor incidencia en el mar Mediterráneo, especialmente en las costas de Baleares y este Peninsular, con un máximo secundario en Gibraltar, noroeste de la Península y Golfo de Vizcaya. Mientras que en cuanto a los tornados terrestres, la franja Mediterránea y el Golfo de Cádiz se erigen en las áreas de mayor actividad en este sentido.

El patrón espacial de frecuencia de tornados está condicionado por varios factores, entre ellos la presencia de varios tipos de configuraciones atmosféricas favorables (en general algunas asociadas a precipitaciones intensas en el área Mediterránea o al paso de frentes Atlánticos con convección embebida en la parte oeste de la península, o a situaciones de tormentas fuertes especialmente en primavera-verano en zonas interiores de centro y norte peninsular). Por ello la mayor parte de tornados y trombas marinas a finales de verano y otoño ocurren en el área Mediterránea, tendiendo luego durante el invierno y primavera a desplazarse el máximo hacia zonas situadas más al oeste.

Hay que tener en cuenta que en la base de datos disponible para este trabajo (2003-2012) aparecen 17 casos de tornados significativos (categoría EF2 ó superior). Sin embargo históricamente se han producido tornados de categoría EF3 o incluso mayor, aunque probablemente con muy baja frecuencia. En la recta final del siglo XX merecen especial mención los tornados de Sevilla en 1978, Ciutadella-Ferreries (Baleares) en 1992, y Navaleno-San Leonardo de Yagüe (Soria) en 1999, pudiendo haber sido todos ellos de categoría EF3. Si nos remontamos a épocas más antiguas, hay información de dos tornados muy intensos: uno el de Madrid de 1886 que causó 47 muertes y que pudo haber sido de categoría EF3, y otro el de Cádiz de 1671 que pudo ser un EF3 y ocasionó más de 60 víctimas mortales. 


\section{V.2.- Climatología básica de descargas eléctricas.}

Se ha realizado una climatología básica de las descargas nube-tierra en la zona de latitud comprendida entre $35^{\circ} \mathrm{N}$ a $44^{\circ} \mathrm{N}$ y longitud desde $10^{\circ} \mathrm{W}$ a $5^{\circ} \mathrm{E}$.

Existe una importante variabilidad interanual, mientras que la media mensual marca un máximo entre los meses de mayo y septiembre, algo que tiene relación entre otros factores, con el ciclo anual de la temperatura del aire en superficie. En cuanto a la distribución horaria, aparece un máximo hacia las 16 UTC y un mínimo a las 9 UTC, respondiendo al ciclo diurno de insolación. meses fríos.

El porcentaje de descargas positivas respecto a las totales es del $9 \%$, concentrándose su máximo en los

La densidad media anual de descargas sugiere que el factor orográfico es uno de los más influyentes en la distribución espacial. Las áreas de mayor actividad eléctrica son los Pirineos, el Sistema lbérico, los Sistemas Costeros y Precosteros Catalanes y zonas de la Cordillera Cantábrica. En concreto el valor máximo puntual de densidad anual de descargas sobre tierra toma un valor en el entorno de 6 descargas $/ \mathrm{km}^{2}$ y se encuentra en el Maestrazgo turolense y castellonense. También aparecen máximos secundarios en la costa Mediterránea de Cataluña y Comunidad Valenciana, y en menor medida, Baleares. En toda esa zona se genera importante actividad convectiva, especialmente en otoño, debido al aporte de calor y humedad que transfiere el mar a la masa de aire principalmente en esa época, lo que genera importante inestabilidad. El mínimo de densidad de rayos se observa en la zona sur peninsular. Un hecho llamativo es que no se aprecia un máximo destacable en las montañas del Sistema Penibético.

Mientras que en grandes áreas del interior peninsular la actividad eléctrica comienza con la primavera con un máximo prácticamente a finales de ésta o durante el verano, en el otoño las zonas de mayor número de descargas se desplaza hacia el este debido a la influencia de mar Mediterráneo.

Aunque los tornados tienen un carácter predominantemente convectivo, para que estos se produzcan debe existir un entorno meteorológico en el que estén presentes unos determinados ingredientes. Además la observación de tornados depende mucho de la densidad de población de la zona desde donde se reporta la información, mientras que la detección de rayos es un hecho objetivo. En cualquier caso es un hecho indudable que la densidad de tornados presenta unos patrones espaciales diferentes a los de densidad de descargas eléctricas.

\section{V.3.- Parámetros meteorológicos clave}

Los sondeos meteorológicos próximos al lugar y hora de ocurrencia de los tornados muestran mayoritariamente valores significativamente anómalos de algunos parámetros, en comparación con toda la muestra de sondeos de un periodo largo.

En concreto, en general se han encontrado destacables valores de índices de inestabilidad clásicos (TT, $\mathrm{K}, \mathrm{LI}, \mathrm{LI}, \mathrm{SI})$, con un elevado valor del índice de Helicidad-Energía (EHI), con baja altitud del nivel de condensación convectivo y con entornos de bajas presiones en niveles bajos (relativamente pequeños valores del geopotencial en $925 \mathrm{mb}, \mathrm{Z925}$ ).

Si sólo tuviéramos en cuenta los tornados EF2 de la muestra, aparte de la anomalía encontrada para los parámetros anteriormente citados para todos los tipos de tornados de la muestra, destacarían también otros valores anómalos como una mayor proporción de casos de convección profunda, elevados valores de cantidad de agua precipitable y proporción de mezcla en niveles bajos, así como entornos ricos en cizalladura vertical y helicidad relativa a la tormenta en los primeros tres kilómetros. 


\section{V.4.- Densidad de tornados}

En la generación del mapa mejorado de tornados (figura III.3.1) se han realizado una serie de ajustes del mapa de tornados observados, a partir de un sistema de información geográfica, de modo que se reduzcan las limitaciones presentes en aquél.

Para los ajustes se han utilizado una serie de variables geográficas (altitud, distancia al mar, etc.) y parámetros meteorológicos determinantes en situaciones de tornados, que proporcionan altos valores del índice de correlación con la densidad de tornados observados. Estos parámetros meteorológicos son la cizalladura del viento en los primeros 3000 metros (ClZ_0_3000) y la helicidad relativa a la tormenta en la capa de los primeros 3000 metros (SRH_0_3000).

En ningún caso el mapa puede interpretarse de forma estrictamente cuantitativa, pues la fuente inicial de datos de tornados observados (muestra disponible en AEMET para el periodo 2003-2012) es incompleta y aproximada como ya se ha comentado ampliamente a lo largo del trabajo, debido a las características inherentes a la dificultosa disponibilidad de datos procedentes del avistamiento y detección de tornados.

Por otra parte el mapa evidencia la gran variabilidad que presenta la frecuencia de tornados entre unas zonas y otras, aunque prácticamente todas las Comunidades Autónomas han sufrido algún tornado durante el periodo de estudio (2003-2012). Asimismo se aprecian ciertas limitaciones en cuanto a la posible sobrevaloración de la densidad de tornados en zonas altamente pobladas, y por el contrario una infravaloración en áreas deshabitadas, todo ello debido a la mayor y menor cantidad de fuentes de información disponible de reportes de tornados. En cualquier caso, y a pesar de algunas carencias, el mapa debe responder en gran medida a la existencia de una conjunción de valores adecuados de inestabilidad, cizalladura y helicidad, junto con una orografía apropiada que maximice los valores de dichas variables. Los valores máximos de densidad anual de tornados en una rejilla de $0.5^{\circ}$ de lado, se sitúa en la costa de Barcelona (entre 4 y 5 tornados/año). Le siguen áreas de la Comunidad Valenciana, Baleares, Málaga y Cádiz (entre 2,5 y 4 tornados/año). En cambio los valores mínimos se encuentran en amplias zonas del interior peninsular.

\section{V.5.- Caracterización meteorológica de las situaciones de tornado}

Los tornados en la Península y Baleares son mayoritariamente de categorías EF0 y EF1 según la escala Fujita Realzada, siendo por tanto no significativos según la terminología norteamericana. Una importante parte de los tornados son realmente trombas marinas ("waterspouts") que tienen su ciclo de vida sobre el mar aunque en algunos casos pueden afectar al litoral. Y estas trombas marinas son casi todas de categoría EF0.

Todos los tornados tienen en común que se desarrollan en un entorno meteorológico de al menos cierta inestabilidad y rico en helicidad y cizalladura del viento. No obstante hay distintas formas de generación de tornados. También es importante comentar que se excluyen explícitamente a los vórtices de racha ("gustnados") de la categoría de tornados.

En cuanto a su genealogía, nos encontramos en España, básicamente con dos tipos de tornados:

- Tornados no mesociclónicos. Parecen los más frecuentes e incluyen tanto a los tornados no supercelulares como aquellos supercelulares no mesociclónicos.

- Tornados mesociclónicos. Se producen en la fase de colapso del mesociclón de la supercélula (o minisupercélula).

Respecto a su distribución espacial y estacional, los tornados se pueden encuadrar mayoritariamente en alguno de estos tipos:

- Invernales (vertiente Atlántica y Mar de Alborán),

- De primavera-verano (interior de la Península) y

- De otoño o finales de verano (Mar Mediterráneo y Mar de Alborán). 
Finalmente se ha intentado una clasificación de los tipos de situaciones generadoras de tornados, a partir del marco meteorológico sinóptico y mesoescalar de un número suficientemente significativo de casos disponibles, llegándose a la conclusión de que se pueden resumir en tres tipos

\section{a.- Tornados de la vertiente Atlántica (en situaciones preferentemente de invierno y otoño)}

En España son relativamente frecuentes los tornados invernales, particularmente en la vertiente Atlántica, y sobre todo cerca de los litorales del Golfo de Cádiz y, en menor medida, de Galicia. En otras zonas del mundo con características climáticas similares, como California o el sur de Australia, se da la misma circunstancia.

Las situaciones sinópticas en que se producen tornados suelen estar asociadas a profundas borrascas Atlánticas que pueden tener reflejo a todos los niveles de la troposfera. Estas estructuras sinópticas proporcionan condiciones favorables para la ocurrencia de tornados: fuerte cizalladura en capas bajas, ligera inestabilidad y perfil húmedo con niveles de condensación bajos. Suelen producirse mayoritariamente en la estación fría, en la que la masa de aire se superpone a un mar relativamente cálido, destacando por su frecuencia áreas de Galicia, Extremadura y Andalucía (sobre todo en el litoral y Valle del Guadalquivir).

Dentro de esta tipología de tornados, se distinguen a su vez dos categorías:

- Borrascas centradas al sur del paralelo $45^{\circ} \mathrm{N}$ y fuerte flujo del suroeste

- Otras situaciones Atlánticas

\section{b.- Tornados de primavera-verano (fundamentalmente en el interior Peninsular)}

En las zonas interiores, los tornados son menos frecuentes, pero en ocasiones resultan más intensos. Se presentan al final de la primavera y sobre todo en verano, en situaciones de fuerte inestabilidad térmica e importante cizalladura.

Estas situaciones se caracterizan por la presencia de una depresión térmica en superficie y paso de un embolsamiento frío en altura, o la rama delantera de una vaguada, o un vórtice mesoescalar o la existencia de una línea de deformación en las proximidades. Las tormentas se producen por una combinación de forzamiento térmico, orográfico y dinámico.

A finales de primavera y en verano, en el interior de la Península lbérica, el calentamiento diurno de una capa atmosférica baja muy seca, en combinación con la presencia de aire relativamente frío en niveles medios, es capaz de desarrollar perfiles con altos valores de CAPE.

Con estas situaciones, la convergencia generada por la baja térmica peninsular es capaz de disparar con cierta facilidad convección profunda, sobre todo en zonas altas del interior nordeste de la Península. En ocasiones, la inestabilidad y la convergencia en niveles bajos van acompañadas de cizalladura vertical del viento, lo que contribuye a la organización de las tormentas y a la ocurrencia con relativa frecuencia de episodios severos. La severidad se manifiesta con frecuencia en forma de granizo grande o rachas fuertes de viento, junto a una actividad eléctrica muy importante.

No es frecuente, sin embargo, que se produzcan tornados, probablemente a causa de la escasa humedad en bajos niveles. La mesoescala es decisiva para realzar la convergencia en determinadas zonas o generar un plus de vorticidad horizontal sobre fronteras baroclinas que favorezcan la propagación de la rotación hacia la superficie a pesar de la baja humedad ambiente, haciendo posible así la aparición del tornado.

\section{c.- Tornados de la vertiente Mediterránea (frecuentemente a finales de verano y durante el otoño)}

Tienen lugar en la vertiente Mediterránea, en cuya franja litoral y prelitoral el máximo de actividad convectiva se produce a finales de verano y durante el otoño. Los tornados suelen ocurrir en episodios de acusada inestabilidad en el Mediterráneo Occidental y en el Mar de Alborán, normalmente en situaciones de precipitaciones intensas ligadas a la presencia de una perturbación en capas medias-altas y a un flujo inestable de origen marítimo en los niveles inferiores.

Van asociados a vaguadas en altura, o a depresiones aisladas o a transiciones de unas a otras. Son situaciones sinópticas con chorro de cierta amplitud (meandros) y con flujo de levante en capas bajas, que provocan gran inestabilidad en el Mediterráneo Occidental y Mar de Alborán. 
La combinación de una advección de aire cálido con flujo del sur o del este en capas bajas y de vientos del suroeste en $500 \mathrm{hPa}$, provoca cizalladura vertical de viento con una hodógrafa con giro en el sentido del movimiento de las agujas del reloj.

Es suficiente con que haya inestabilidad en capas bajas (marcado por el índice LI7), pero cuanto mayor sea la inestabilidad en niveles medios (índice LI5) más probables serán los tornados.

En numerosas ocasiones los tornados son generados por sistemas convectivos que adquieren fuertes corrientes ascendentes al alcanzar la costa y que se mueven atrapados en ella precedidos por vientos provenientes del mar y paralelos al litoral.

Si el mejor mapa meteorológico para caracterizar sinópticamente las situaciones del Atlántico es el mapa de superficie, en este caso mandan los mapas de capas medias y altas.

El espectro de situaciones es continuo. Algunas situaciones Atlánticas enlazan con episodios de verano en lo que se refiere a la inestabilidad, auque la cizalladura en capas bajas siempre es mayor. Hay situaciones de verano que también lo son de la vertiente Mediterránea, pudiéndose observar tornados simultáneamente en el interior de la Península y en el área Mediterránea. 


\section{BIBLIOGRAFÍA}

- Bluestein, H.B., 1985: The formation of a "landspout" in a "broken-line" squall line in Oklahoma. Preprints, 14th Conf. on Severe Local Storms, Indianapolis, IN, Amer. Meteor. Soc., 267-270.

- Bluestein, H. B., \& Parker, S. S. (1993). Modes of isolated, severe convective storm formation along the dryline. Monthly weather review, 121(5), 1354-1372.

- Bluestein, 2008: A Funnel Cloud in a Convective Cloud Line to the Rear of a Surface Cold Front. Mon. Wea. Rev. 136, 2786-2795.

- Brady, R. H., \& Szoke, E. J. (1989). A case study of nonmesocyclone tornado development in northeast Colorado: Similarities to waterspout formation. Monthly weather review, 117(4), 843-856.

- Brooks, H.E. and C.A. Doswell C.A., 2001: Some aspects of the international climatology of tornadoes by the international climatology of tornadoes by damage classification. Atmos. Res., 56, 191-201

- Brooks, H. E., J. W. Lee, and J. P. Craven, 2003: The spatial distribution of severe thunderstorm and tornado environments from global reanalysis data. Atmos. Res., 67-68, 73-94

- Brooks, H. E., 2004: On the relationship of tornado path length and width to intensity. Weather and Forecasting, 19, 310-319.

- Burgess, D.W., R.R. Lee, S.S. Parker, and D.L. Floyd, 1995: A study of mini supercells observed by WSR-88D radars. Preprints, 27th Conference on Radar Meteorology, Vail, CO, Amer. Meteor. Soc., 4-6.

- Capel, J. J. (1999). La presión atmosférica y los vientos del Monzón lbérico en la Península lbérica: Reflexiones sobre el Monzón Ibérico. Nimbus: Revista de climatología, meteorología y paisaje, (4), 5-60.

- Caruso, J. M., \& Davies, J. M. (2005). Tornadoes in nonmesocyclone environments with pre-existing vertical vorticity along convergence boundaries. Electron. J. Oper. Meteor, 6(4), 1-36.

- Concannon P., Brooks H.E. and Doswell C.A., 2000: Climatological risk of strong and violent tornadoes in the United States. Amer. Meteor. Soc., 212-219

- Conesa, A (2004): Triggering of convection and evolution to supercell with an F3 tornado in Bajo Aragon, northeast of Teruel province. 3rd European Conference on Severe Storms, Leon

- Cooley, J. R. (1978). Cold air funnel clouds. Monthly Weather Review, 106(9), 1368-1372.

- Craven, J. P., H. E. Brooks, and J. A. Hart, 2002: Baseline climatology of sounding derived parameters associated with deep, moist convection. Preprints, 21st Conference on Severe Local Storms, San Antonio, Texas, American Meteorological Society, 643-646.

- Craven, J.P. - Brooks, H.E, 2004: Baseline climatology of sounding derived parameters associated with deep, moist convection. Nat. Wea. Digest, 28, p. 13-24.

- Davies, J. M. (2006). Tornadoes in environments with small helicity and/or high LCL heights. Weather \& Forecasting, 21(4).

- Davies, J. M. (2006). Tornadoes with Cold Core 500-mb Lows. Weather \& Forecasting, 21(6).

- Davies, J. M. (2006, November). Hurricane and tropical cyclone tornado environments from RUC proximity soundings. In Preprints, 23rd Conf. on Severe Local Storms, St. Louis, MO, Amer. Meteor. Soc (Vol. 12).

- Davies, J., \& Guyer, J. L. (2004). A preliminary climatology of tornado events with closed cold core 500-mb lows in the central and eastern United States. In Preprints, 22d Conf. on Severe Local Storms, Hyannis, MA, Amer. Meteor. Soc., CD-ROM B (Vol. 7).

- Davies-Jones, R. (1984). Streamwise vorticity: The origin of updraft rotation in supercell storms. Journal of the atmospheric sciences, 41(20), 2991-3006.

- Doswell III, C. A., \& Burgess, D. W. (1993). Tornadoes and tornadic storms: A review of conceptual models. Geophysical Monograph Series, 79, 161-172.

- Doswell, C.A. III, and D.W. Burgess, 1998: On some issues of the United States tornado climatology. Mon. Wea. Rev., 116, 495-501.

- Elsner, J. B., Jagger, T. H., \& Elsner, I. J., 2013: A Statistical Model for Tornado Intensity. http://myweb.fsu.edu/jelsner/TornadoWindSpeeds.pdf

- Elsom D. M., 1985. "Tornadoes in Britain: Where, when and how often". The Journal of Meteorology, vol. 10, 100

- Font, I. (2000). Climatología de España y Portugal (Vol. 76). Universidad de Salamanca

- Fujita, T. T. (1981). Tornadoes and downbursts in the context of generalized planetary scales. Journal of the Atmospheric Sciences, 38(8), 1511-1534.

- Gaya M., 2011. Tornadoes and severe storms in Spain. Atmospheric Research 100. pp 334-343.

- Giaiotti, D. B., Giovannoni, M.. Pucillo, A. and Stel, F., 2007: The climatology of tornadoes and waterspouts in Italy. Atmospheric Research, Volume 83, Issue 2-4, p. 534-541

- Golden, J. H. (1974). The life cycle of Florida Keys' waterspouts. I. J. of Applied Meteorology, 13(6), 676-692.

- Grumm, R. H., \& Glazewski, M. (1996). P7. 1 Thunderstorm Types Associated With The "Broken-S" Radar Signature.

- Guyer, J. L., \& Dean, A. R. 1.5 Tornadoes Within Weak Cape Environments Across The Continental United States. database,2587, 6734.

- Hanstrum, B. N., Mills, G. A., Watson, A., Monteverdi, J. P., \& Doswell III, C. A. (2002). The cool-season tornadoes of California and southern Australia. Weather \& Forecasting, 17(4). 
- Kelly, D. L., Schaefer, J. T., McNulty, R. P., Doswell III, C. A., \& Abbey Jr, R. F. (1978). An augmented tornado climatology. Monthly Weather Review, 106(8), 1172-1183.

- Lee, B. D., \& Wilhelmson, R. B. (1997). The numerical simulation of non-supercell tornadogenesis. Part I: Initiation and evolution of pretornadic misocyclone circulations along a dry outflow boundary. Journal of the atmospheric sciences, 54(1), 32-60.

- Lee, B. D., \& Wilhelmson, R. B. (1997). The numerical simulation of nonsupercell tornadogenesis. Part II: Evolution of a family of tornadoes along a weak outflow boundary. Journal of the atmospheric sciences, 54(19), 2387-2415.

- Leitao, P., 2002: Tornadoes in Portugal. Atmospheric Research. 67-68, 381-390.

- Lemon, L. R., \& Doswell III, C. A. (1979). Severe thunderstorm evolution and mesocyclone structure as related to tornadogenesis. Monthly Weather Review,107(9), 1184-1197.

- Markowski, P. M. EN Rasmussen, JM Straka, and DC Dowell, 1998b: Observations of low-level baroclinity generated by anvil shadows. Mon. Wea. Rev, 126, 2942-2958.

- Markowski, P. M., Straka, J. M., \& Rasmussen, E. N. (2002). Direct surface thermodynamic observations within the rear-flank downdrafts of nontornadic and tornadic supercells. Monthly weather review, 130(7).

Rhea, J. 0., 1966: A study of thunderstorm formation along drylines. J. Appl. Meteor, 5, 58-63.

- McAvoy, B. P., Jones, W. A., \& Moore, P. D. (2000). Investigation of an unusual storm structure associated with weak to occasionally strong tornadoes over the eastern United States. In Preprints, 20th Conf. on Severe Local Storms, Orlando, FL, Amer. Meteor. Soc (pp. 182-185).

- McCaul Jr, E. W. (1991). Buoyancy and shear characteristics of hurricane-tornado environments. Monthly weather review, 119(8), 1954-1978.

- McCaul Jr, E. W., \& Weisman, M. L. (1996). Simulations of shallow supercell storms in landfalling hurricane environments. Monthly weather review, 124(3), 408-429.

- McCaul Jr, E. W., \& Weisman, M. L., 2001: The sensitivity of simulated supercell structure and intensity to variations in the shapes of environmental buoyancy and shear profiles. Monthly Weather Review, 129, 664687.

- Markowski, P. M., \& Straka, J. M. (2000). Some observations of rotating updrafts in a low-buoyancy, highly sheared environment. Monthly weather review, 128(2).

- Pérez Puebla F. y Zancajo. C., 2010. Regímenes tormentosos en la Península lbérica durante la década 20002009. Bol. AME, 28,28-35.

- Polvorinos F. y Sánchez-Laulhé J.M., 1999. Estudio de los fenómenos convectivos ocurridos en el Sureste Peninsular el 4 de septiembre de 1999. Comunicación del IV Simposio Nacional de Predicción.

- Przybylinski, 1995: The Bow Echo: Observations, Numerical Simulations, and Severe Weather Detection Methods. Weather and Forecasting, vol 10 203-218.

- Rasmussen, E. N., and D. O. Blanchard, 1998: A Baseline climatology of Sounding-Derived Supercell and Tornado Forecast parameters. Wea. Forecasting, 13, 1148-1164.

- Rauhala, Jenni, Harold E. Brooks, David M. Schultz, 2012: Tornado Climatology of Finland. Mon. Wea. Rev., 140, 1446-1456.

- Rivas Soriano, L., de Pablo, F., Tomas, C., 2005: Ten-year study of cloud-to-ground lightning activity in the Iberian Peninsula. J. Atmos. Solar-Terr. Phys., 67, 1632-1639.

- Romero R., Gayà M. and Doswell C.A., 2007: European climatology of severe convective storm environmental parameters: A test for significant tornado events. Atmospheric Research. Vol 83. pp 389-404

- Sánchez-Laulhé J. M., 2005: El tornado de Cádiz de 1671. Boletín Asociación Meteorológica Española AME, № 9 Julio 2005, 11-15

- Sánchez-Laulhé, J.M. 2010: Tornados en la provincia de Málaga del 1 de febrero de 2009. II Jornadas de Meteorología y Climatología en el Mediterráneo Occidental

- Silverman, B. W., 1986. Estimación de densidad para las estadísticas y el análisis de datos. New York: Chapman y Hall

- Sioukas M., Szilagyi W., and Keul A., 2013: Waterspout outbreaks over areas of Europe and North America: Environment and predictability. Atmospheric Research. 123, 167-179

- Thompson, R. L., R. Edwards and J.A. Hart, 2002: An Assessment of Supercell and Tornado Forecast Parameters with RUC-2 Model Close Proximity Soundings.

- Trapp, R. J., \& Weisman, M. L. (2003). Low-level mesovortices within squall lines and bow echoes. Part II: Their genesis and implications. Monthly weather review, 131(11).

- Trapp, R. J., Tessendorf, S. A., Godfrey, E. S., \& Brooks, H. E. (2005). Tornadoes from squall lines and bow echoes. Part I: Climatological distribution. Weather \& Forecasting, 20(1).

- Wakimoto, R. M., \& Wilson, J. W. (1989). Non-supercell tornadoes. Monthly Weather Review, 117(6), 11131140.

- Weldon, RB. and Holmes, S.J., 1991: Water vapor imagery: interpretation and applications to weather analysis and forecasting. NOAA, Technical Report NESDIS 57.

- Wicker, L.J. and L. Cantrell, 1996: The role of vertical buoyancy distributions in miniature supercells. Preprints, $18^{\text {th }}$ Conference on Severe Local Storms, San Francisco, CA, Amer. Meteor. Soc., 225-229. 


\section{GLOSARIO}

- Baja: Región de la atmósfera en donde la presión está baja con respecto a los alrededores del mismo nivel. También se pueden utilizar como equivalentes los términos de baja presión, baja o borrasca.

- Baroclina: Región en la que existe un gradiente de temperatura sobre una superficie de presión constante. Es una zona favorable para el reforzamiento o debilitamiento de sistemas meteorológicos. La cizalladura del viento es, también, característica de una zona baroclina.

- Ciclogénesis: Desarrollo o profundización de un centro de bajas presiones.

- Cizalladura: Diferencia del viento (en intensidad o dirección) entre dos puntos. Si están a distintas altitudes se hablará de cizalladura vertical; si no, de cizalladura horizontal.

- Convección: Transporte vertical de calor y humedad (ascendente o descendente) en una atmósfera inestable. El término 'convección' y 'tormenta' a menudo se usan indistintamente, aunque no siempre que hay convección se desarrollan tormentas.

- Convergencia: Contracción de un campo vectorial. La convergencia en un campo de viento horizontal indica que, en un área dada, está entrando más aire del que sale, a ese nivel. El resultado suele ser la generación de movimientos verticales hacia arriba si la convergencia se produce en niveles bajos, 0 movimientos descendentes si la convergencia aparece en niveles altos.

- Corriente en chorro: Fuerte y estrecha corriente de aire concentrada a lo largo de un eje casi horizontal en la alta troposfera o en la estratosfera, caracterizada por una fuerte cizalladura vertical y horizontal del viento.

- Descarga eléctrica: Corriente eléctrica atmosférica que se forma cuando se generan grandes concentraciones de carga eléctrica en la troposfera, en nubes del tipo cumulonimbus.

- Dorsal: Prolongación de un anticiclón que se desplaza entre dos depresiones, representada por un sistema de isobaras en forma de "U" invertida, cuya concavidad está curvada hacia las presiones más altas.

- Escala Fujita Mejorada: (Enhanced Fujita Scale, en inglés). Es una escala utilizada para catalogar la intensidad de los tornados en función de los daños provocados. Va desde EF0 hasta EF5.

- Flanking Line: Línea de cúmulos o torres de cúmulos conectados y extendiéndose hacia afuera a partir de la parte más activa de una supercélula.

- Forzamiento: Disponibilidad de fuerzas dinámicas que propician movimientos convectivos.

- Funnel Cloud: Embudo de condensación que se prolonga desde la base de torres de cúmulos o cumulonimbus, asociado a una columna rotatoria de aire que no está en contacto con el suelo.

- Geopotencial: Es la energía potencial que posee un cuerpo por encontrarse en el campo gravitatorio terrestre, referido a un nivel de referencia, que se toma correspondiendo con el nivel medio del mar. Numéricamente es igual al trabajo que habría que realizar contra la gravedad para elevar la unidad de masa desde el nivel medio del mar hasta el lugar en el que está situada la masa.

- Gustnado: Pequeño tornado que normalmente es débil y de corto ciclo de vida, que tiene lugar a lo largo del frente de racha de una tormenta. Muchas veces es visible sólo como una nube de polvo o basura cerca del suelo.

- Helicidad: Propiedad de un fluido en movimiento que indica si el entorno es favorable para que se desarrolle un flujo helicoidal (como el de un sacacorchos). La helicidad es proporcional a la fuerza del flujo, a la cizalladura vertical del viento, y a la vorticidad. La helicidad atmosférica se calcula a partir del perfil vertical del viento en la parte más baja de la troposfera (usualmente desde superficie hasta 3 ó $6 \mathrm{~km}$ ), y se mide en relación al movimiento de la tormenta (helicidad relativa a la tormenta). Valores altos de helicidad relativa a la tormenta (generalmente alrededor de $150 \mathrm{~m}^{2} / \mathrm{s}^{2}$ o más) favorecen el desarrollo de rotación en niveles medios (mesociclones).

- Hodógrafa: Gráfico que representa la distribución vertical de los vientos horizontales, usando coordenadas polares. Una hodógrafa se obtiene dibujando los puntos finales de los vectores de viento a varias altitudes, y conectando estos puntos en orden siguiendo una altura creciente. La interpretación de una hodógrafa puede ayudar en la predicción del tipo de tormenta que se puede formar en el entorno.

- Inestabilidad: Tendencia a acelerar de las parcelas de aire cuando éstas son desplazadas de su posición original. La inestabilidad es un requisito previo en tiempo tormentoso. Cuanto mayor es la inestabilidad, más grande es la probabilidad de desarrollo tormentoso. Suele medirse a partir de índices y sondeos termodinámicos.

- Kriging: Método geoestadístico o técnica de interpolación que utiliza un modelo de variograma para la obtención de datos, basado en la premisa de que la variación espacial continúa con el mismo patrón.

- Landspout: Término acuñado por Howard Bluestein para referirse a tornados no asociados a mesociclones. Es en esencia una expresión coloquial para describir tornados que se forman en una nube madre en fase de desarrollo a partir de una vorticidad generada en una zona frontera en niveles bajos.

- Mesociclón: Zona de importante vorticidad vertical (normalmente ciclónica) de alrededor de 2 a $10 \mathrm{~km}$ de diámetro, en el seno de una tormenta supercelular. Normalmente se encuentran junto a la corriente 
ascendente y junto a la corriente descendente del flanco trasero. A veces, los tornados de las supercélulas se forman en los mesociclones. El radar doppler detecta los mesociclones persistentes que tienen una extensión vertical significativa.

- Outbreak tornádico: Oleada de tornados. Situación en la que se producen varios tornados en una determinada zona.

- Overshooting: Protuberancia en forma de cúpula sobre un yunque tormentoso, que representa la región donde existe una intensa corriente ascendente.

- Punto de rocío: Medida de la humedad atmosférica. Es la temperatura a la que el aire debe ser enfriado, a presión y proporción de mezcla constantes, para alcanzar la saturación.

- Rayo: Conjunto de una o varias descargas eléctricas generado por la presencia de una determinada carga en las nubes. Puede haber rayos nube-nube, intranube y nube-tierra.

- Reflectividad (Z): En meteorología representa (en escala logarítmica, dBZ), la proporción de la potencia devuelta por las partículas de precipitación respecto a la potencia inicialmente emitida por el radar. Cuantas más partículas precipitantes haya y mayor sea su concentración, mayor será la reflectividad, y por consiguiente la intensidad de la precipitación.

- Sistema Convectivo: Estructura convectiva observada en satélite, que tendrá su equivalencia en la detección radar, aunque con diferente interpretación.

- Sondeo: Perfil atmosférico observado a partir de una cápsula que toma medidas en la vertical. Sirve para determinar la variación de variables meteorológicas (temperatura, humedad, viento, etc.) sobre la vertical de un punto. Se representan en diagramas termodinámicos.

- Supercélula: Tormenta que posee un profundo y persistente mesociclón.

- Tornado: Columna de aire que gira violentamente, estando en contacto con el suelo y colgando de una nube cumuliforme, y con frecuencia (pero no siempre) visible como una nube embudo. Para que un vórtice sea considerado como tornado, debe estar en contacto con el suelo y con la base de la nube.

- Tromba marina: Es un tornado sobre el agua. Las trombas marinas son comunes a lo largo de la costa Mediterránea en situaciones de importante inestabilidad principalmente durante el otoño e invierno. Son más pequeños y más débiles que los tornados de origen terrestre. Las trombas marinas pueden volcar los barcos, o infligirles daños de cierta consideración. Cuando tocan tierra en general rápidamente pierden fuerza y desaparecen, aunque pueden causar desperfectos en la franja litoral.

- V-notch: Patrón o muesca en forma de "V", asociada a severidad de tormentas detectadas en radar.

- Vaguada: Prolongación de una depresión, representada por un sistema de isobaras en forma aproximadamente de "V".

- Vorticidad: Variable que mide la rotación local en el flujo de un fluido. En meteorología se suele computar la componente vertical de dicha rotación.

- Wall cloud: Formación nubosa baja que se descuelga por debajo del resto de la tormenta, usualmente asociada a la presencia de un mesociclón (rotando lentamente). Cuando en el mesociclón supercelular se forman tornados, normalmente surgen de dicha nube pared.

- Waterspout: Tromba marina

Algunas de las definiciones han sido extraídas parcialmente del documento "A COMPREHENSIVE GLOSSARY OF WEATHER TERMS FOR STORM SPOTTERS" (NOAA Technical Memorandum NWS SR-145). NOAA/NWS/WFO Norman. www.srh.noaa.gov/oun/? $n=$ spotterglossary2\#Glossary Se recomienda su uso para la explicación sencilla de elementos relacionados con la convección severa. 


\section{LISTA DE ACRÓNIMOS}

- 700_500LR: gradiente térmico vertical entre 700 y $500 \mathrm{mb}$. (으 $/ \mathrm{km})$.

- AEMET: Agencia Estatal de Meteorología.

- ASCAT: Advanced Scatterometer.

- BRN: Bulk Richardson Number (Número de Richardson global, adimensional).

- CAPE: Convective Available Potential Energy (Energía potencial convectiva disponible, J/kg).

- CAPPI: Constant Altitude Plan Position Indicator (Exploración cartesiana horizontal radar, dBZ).

- $\mathbf{C b}$ : Cumulonimbus.

- CCL: Convective Condensation Level (Nivel de condensación convectivo, m).

- CIN: Convective INhibition (Energía de inhibición convectiva, $\mathrm{J} / \mathrm{Kg}$ ).

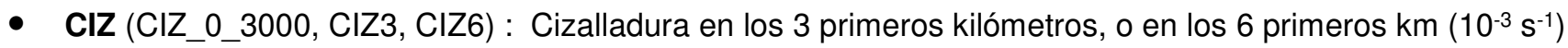

- $\mathrm{Cu}$ : Cúmulo.

- dBZ: deciBelios de Reflectividad.

- ECMWF (CEPPM): European Centre for Medium range Weather Forecasting.

- EF: Enhanced Fujita Scale (Escala Fujita realzada o mejorada).

- EHI: Energy Helicity Index (Índice de Helicidad Energía, adimensional).

- EL: Equilibrium Level (Nivel de equilibrio, m).

- hPA: hecto PAscales (milibares).

- HRVIS: High Resolution VISible.

- IR: Infra-Red (infrarrojo).

- ISOC: Isocero (m).

- K: Índice K (adimensional).

- kA: kilo Amperio.

- Kt: Knots (nudos).

- LCL: Lifting Condensation Level (Nivel de condensación por ascenso, m).

- LFC: Level of Free Convection (Nivel de convección libre, m).

- LI (LI5): Lifted Index en $500 \mathrm{mb}\left({ }^{\circ} \mathrm{C}\right)$.

- LI7: Lifted Index en $700 \mathrm{mb}(0 \mathrm{C})$.

- MAX: Máximo de reflectividad radar en la columna (dBZ).

- mb: milibares.

- MMR: Medium Mixing Rate (proporción de mezcla en capas bajas, g/kg).

- MSG: Meteosat of Second Generation.

- PPI: Plan Position Indicator (Exploración polar radar correspondiente a la elevación más baja)

- PSL: Pressure at Sea Level (presión al nivel del mar, mb)

- PW: Precipitable Water (Agua precipitable, mm)

- QuickScat: Quick Scatterometer.

- SI: Showalter Index ( $\left.{ }^{-} \mathrm{C}\right)$.

- SINOBAS: Sistema de Notificación de OBservaciones Atmosféricas Singulares. (http://sinobas.aemet.es).

- SM_DDD: Storm Movement Direction (Dirección de movimiento de la tormenta, o).

- SM_FF: Storm Movemente Force (Intensidad de movimiento de la tormenta, kt).

- SRH_0_3000: Storm Relative Helicity (Helicidad relativa a la tormenta en los tres primeros kilómetros, $\mathrm{m}^{2} / \mathrm{s}^{2}$ ).

- $\mathbf{T}$ : temperatura.

- TI: ThetaE Index (은).

- TOP: Tope, Ecotop o Echotop (máxima altitud de los ecos superiores a $12 \mathrm{dBZ}$, en km).

- TT: Total de totales (ํ $\mathrm{C})$.

- UTC: Coordinated Universal Time. Es equivalente a horas "Z".

- VIL: Vertical Integrated Liquid $\left(\mathrm{kg} / \mathrm{m}^{2}\right)$.

- VIS: VISible

- WV: Water Vapour.

- Z: altitud geopotencial (m), o reflectividad (dBZ)

- ZCIT: Zona de Convergencia Intertropical. 
ANEXO: ESCALA FUJITA REALZADA

La "Enhanced Fujita Scale" (Escala Fujita Realzada) se emplea desde 2007 (en sustitución de la original de Fujita-Pearson) para caracterizar la fuerza estimada de los tornados en función del daño que provocan. Tiene seis niveles que van del 0 al 5 representando el incremento en la violencia de los daños.

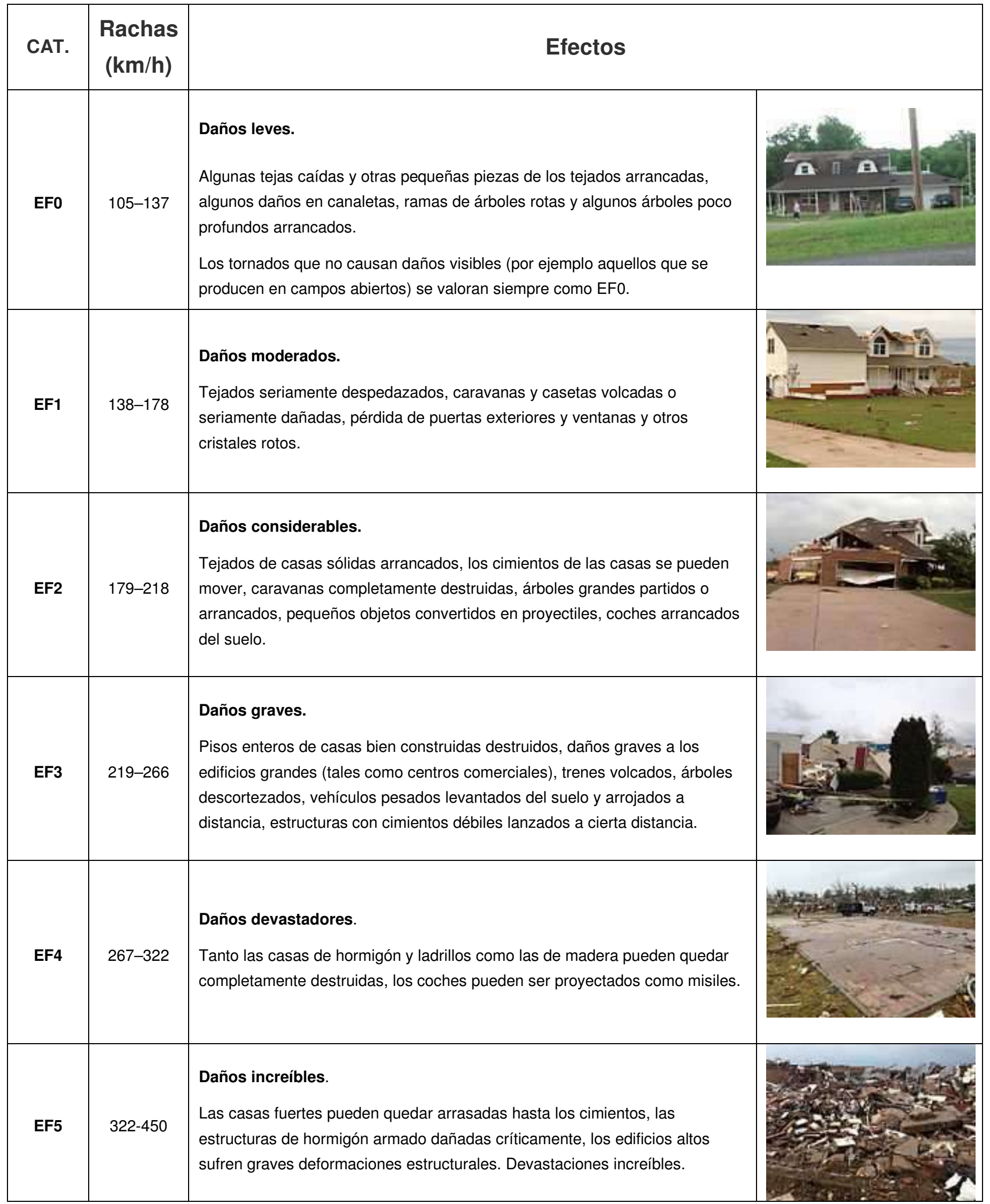

Tabla A.1: Escala Fujita mejorada o realzada. Adaptada del NWS (NOAA). 


\section{AGRADECIMIENTOS}

Queremos expresar nuestra gratitud hacia todas las personas (especialmente de AEMET) que han participado en la recopilación y estudio de tornados que han acaecido en España.

También se agradece a Antonio Mestre Barceló (Jefe de Área de Climatología y Aplicaciones Operativas de AEMET) la revisión de este trabajo. 